\title{
Improving the Seismic Performance of Existing Bridge Structures Using Self-centering Dampers
}

by

\author{
Xi Cheng \\ A thesis submitted to the Faculty of Graduate and Postdoctoral \\ Affairs in partial fulfillment of the requirements \\ for the degree of
}

Master of Applied Science

in

Civil Engineering

Carleton University

Ottawa, Ontario

○2017

Xi Cheng 
The undersigned hereby recommends to the

Faculty of Graduate and Postdoctoral Affairs

acceptance of the thesis

\title{
Improving the Seismic Performance of Existing Bridge Structures Using Self-centering Dampers
}

\author{
submitted by Xi Cheng \\ in partial fulfillment of the requirements for the degree of
}

Master of Applied Science

Professor Murat Saatcioglu, External Examiner

Professor Heng-Aik Khoo, Examiner

Professor Jeffrey Erochko, Thesis Supervisor

Professor David T. Lau, Thesis Co-supervisor

Department of Civil and Environmental Engineering

Carleton University

January, 2017 


\section{Abstract}

In this study, the potential benefits of retrofitting concrete bridges with self-centering energy-dissipation (SCED) braces are investigated. For this purpose, four concrete bridges with pre-stressed decks are selected as study cases. Three-dimensional nonlinear models of these bridges are analyzed using OpenSEES. Nonlinear time-history analyses are conducted to evaluate the seismic performance of the original and retrofitted bridge structures. These models are subjected to earthquake records at maximum credible hazard level. A design procedure for the SCED braces is proposed. The target activation force design factor $D F$ and the energy dissipation capacity $\beta$ are the two major design parameters investigated in the parametric study and the combination of design parameter is recommended based on the bridge geometry and brace configuration. The results demonstrate that the SCED brace system improves the seismic performance of all example bridges by decreasing peak drifts and eliminating residual displacements during and after the seismic events. 


\section{Acknowledgments}

I would first like to thank my thesis advisors Professor Jeffrey A. Erochko and Professor David T. Lau of the Department of Civil and Environmental Engineering at Carleton University for their invaluable guidance and support. They consistently allowed this paper to be my own work, but steered me in the right direction whenever they thought I needed it.

The author sincerely appreciate the time and feedback provided by Professor Murat Saatcioglu and Heng-Aik Khoo in the review of this work.

The author would also like to acknowledge Mr. Vishnu K. Vishnukanthan for providing the example bridge information and SAP2000 models.

The author would like to acknowledge the support of his colleagues and friends, especially Dawei Zhang, Tonghua Zhang and Xin Fan for their technical and moral support.

Finally, the author must express very profound gratitude to his family for their support during this work. Specially, he would like to thank his parents Longshan Cheng and Hongzhen Liu, and his best friend Jing Xue for providing him with continuous encouragement. 


\section{Table of Contents}

Abstract

Acknowledgments $\quad$ iv

Table of Contents $\quad$ v

List of Tables viii

List of Figures $\quad$ x

Nomenclature $\quad$ xiv

1 Introduction 1

1.1 Background and motivation $\ldots \ldots \ldots \ldots \ldots \ldots$

1.2 Objectives ..................... 6

2 Development of Self-Centering Devices $\quad 7$

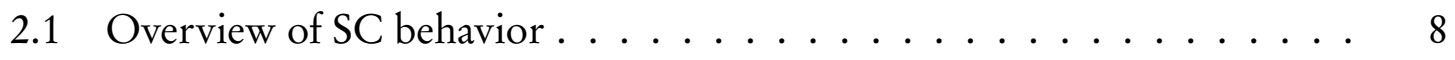

2.2 Self-centering System Examples $\ldots \ldots \ldots \ldots \ldots$

2.2.1 Shape memory alloys (SMAs) . . . . . . . . . . . . 10

2.2.2 Energy Dissipating Restraints, Ring Springs and Friction Damping Braces . . . . . . . . . . . . . . . . . 11

2.2.3 Rocking Systems . . . . . . . . . . . . . . . . . . . . . . 14 
2.3 The Self-Centering Energy-Dissipative Brace $\ldots \ldots \ldots \ldots$

2.3.1 Hysteretic Response of the SCED Brace . . . . . . . . . 18

2.3.2 SCED Braces in Retrofit . . . . . . . . . . . . . . . . 21

3 Description and Modeling of Bridges 24

3.1 Description of Bridge . . . . . . . . . . . . . . . . . . 24

3.2 Finite Element Model of Selected Bridges . . . . . . . . . . . 28

3.2.1 Bridge Model Geometry . . . . . . . . . . . . . . . . . 31

3.2.2 Modeling of Mass and Material _ . . . . . . . . . . . 34

3.2.3 Modeling of Superstructure . . . . . . . . . . . . . 38

3.2.4 Modeling of Piers . . . . . . . . . . . . . . . . 40

3.2.5 Modeling of Abutment . . . . . . . . . . . . . . . 46

3.2.6 Modeling of Self-centering Braces . . . . . . . . . . . . 49

4 Generation of Ground Motion Time Histories 53

4.1 Modal Pushover Based Scaling . . . . . . . . . . . . . . . . 55

4.2 Scaling Results . . . . . . . . . . . . . . . . . . 60

5 Retrofit Schemes and SCED Brace Design 69

5.1 Retrofit Scheme . . . . . . . . . . . . . . . . . . . . . . . . . . . 69

5.2 Design of SCED Braces . . . . . . . . . . . . . . . . . 72

5.3 Parametric Study for Desirable Design . . . . . . . . . . . . 78

6 Retrofit Performance $\quad 84$

6.1 Performance of Original Structure . . . . . . . . . . . . . . 84

6.2 Performance of Retrofitted Structures . . . . . . . . . . . . . . 90

6.2.1 Peak Displacement . . . . . . . . . . . . . . . . . . . 90

6.2.2 Peak Acceleration and Velocity _. . . . . . . . . . . 93

6.2 .3 Base Shear . . . . . . . . . . . . . . . . . . . . . . . 98 
6.2.4 Cumulative Curvature and Ductility . . . . . . . . . 103

6.3 Comparison of Different Retrofit Schemes . . . . . . . . . . . . . 108

6.4 Summary of Results . . . . . . . . . . . . . . . . . 110

7 Conclusions $\quad 126$

7.1 Summary of the Research . . . . . . . . . . . . . 126

7.2 Primary Contribution of the Thesis . . . . . . . . . . . . 128

7.3 Suggestion for Future Research . . . . . . . . . . . . . . . . . 129

List of References $\quad 131$

Appendix A Drawings of the Example Bridges 139 


\section{List of Tables}

3.1 General Geometric Properties of the Example Bridges . . . . . . . . 33

3.2 Discretization of the Example bridges . . . . . . . . . . . . 34

3.3 Properties of Reinforcing Steel in OpenSees Model . . . . . . . . . . 37

3.4 Material Properties in Models . . . . . . . . . . . . . . . . . . . . . 39

3.5 Parameters in the Parametric Study . . . . . . . . . . . . . . 44

4.1 Properties of Ground Motion Records . . . . . . . . . . . . . . . . 61

4.2 Scaling Factors of Ground Motion Records . . . . . . . . . . . 66

5.1 Base Reduction Factors for Each Model . . . . . . . . . . . . . . . 74

5.2 Properties of the SCED Brace in M1 Retrofit . . . . . . . . . . 80

5.3 Properties of the SCED Brace in M2 Retrofit . . . . . . . . . . 81

5.4 Properties of the SCED Brace in M3 Retrofit . . . . . . . . . . . 82

5.5 Properties of the SCED Brace in M4 Retrofit . . . . . . . . . . 83

6.1 Peak Rotation $\angle \gamma$ at Bent of Example Bridges without Retrofit . . . . 88

6.2 Seismic Performance (Displacement) of Example Bridges without Retrofit 116

6.3 Seismic Performance of Retrofitted M1 _ . . . . . . . . . . . . . . . 117

6.4 Seismic Performance of Retrofitted M2 _ . . . . . . . . . . . . . 118

6.5 Seismic Performance of Retrofitted M3 _ . . . . . . . . . . . . . 119

6.6 Seismic Performance of Retrofitted M4 _ . . . . . . . . . . . . . . 120

6.7 Seismic Performance (SRSS of $a_{\max }$ and $v_{\max }$ ) of Example Bridges without Retrofit . . . . . . . . . . . . . . . . . . . . . . . 121 


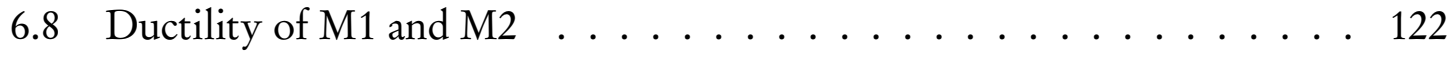

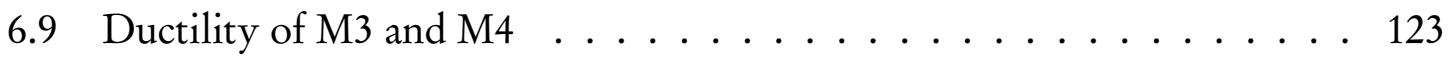

6.10 Brace Properties in Retrofit Scheme-2 for M4 . . . . . . . . . . . . 124

6.11 Response Comparison in Different Schemes for M4 . . . . . . . . . . 124 


\section{List of Figures}

2.1 Idealized Force-Displacement Relationship $\ldots \ldots \ldots \ldots$

2.2 The Energy Dissipating Restraint (EDR) (from [45]) . . . . . . . . . 12

2.3 Ring Spring (from $[13]) \ldots \ldots \ldots \ldots \ldots \ldots$

2.4 Friction Damping Brace $($ from $[48]) \ldots \ldots \ldots \ldots \ldots \ldots$

2.5 Rocking Systems (from [13]) . . . . . . . . . . . . . . . 15

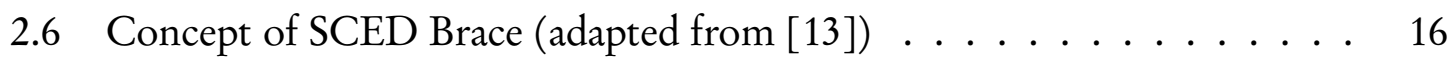

2.7 Internal Frction Damper (from [53]) $\ldots \ldots \ldots \ldots \ldots \ldots \ldots$

2.8 SCED Brace Mechanics (adapted from [13]) . . . . . . . . . . . . 19

2.9 Retrofit Bridge Bent with BRB (from [56]) . . . . . . . . . . 22

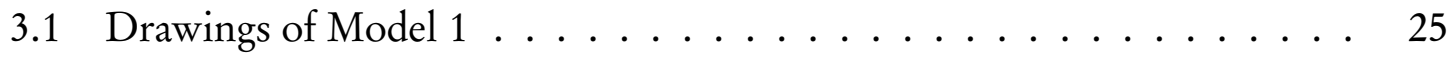

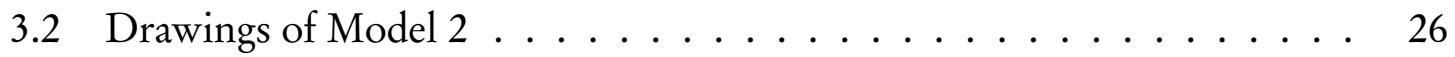

3.3 Drawings of Model $3 \ldots \ldots \ldots \ldots \ldots \ldots$

3.4 Drawings of Model $4 \ldots \ldots \ldots \ldots$

3.5 Coordinate Systems and Mass Distribution . . . . . . . . . . 32

3.6 Rotational Mass . . . . . . . . . . . . . . . . . . . . . . 35

3.7 Steel02 and ReinforcingSteel Stress-Strain Model in OpenSees . . . . . . 36

3.8 Concrete01 and Concrete02 Stress-Strain Model in OpenSees . . . . . . 38

3.9 Fiber Section Model in OpenSees _ . . . . . . . . . . . . . . . 41

3.10 Column Element Model in OpenSees . . . . . . . . . . . . . 43

3.11 Parametric Study of Concrete Pier . . . . . . . . . . . . . . . 45 
3.12 Abutment Behaviour . . . . . . . . . . . . . . . . . . . 48

3.13 Shear Key Properties $[$ from $[68]] \ldots \ldots$

3.14 SCED Brace Hysteresis . . . . . . . . . . . . . . . . . 50

3.15 Effective Initial Stiffness of SCED Brace . . . . . . . . . . . . . 51

4.1 Modal Pushover Scaling (MPS) Procedure . . . . . . . . . . . . . . 57

4.2 Fundamental Mode Shape of Models . . . . . . . . . . . . . . . . 62

4.3 Modal Pushover Curves Based on Fundamental Mode . . . . . . . . 63

4.4 Acceleration Response Spectrum of Scaled Ground Motions for M1 . . . 63

4.5 Acceleration Response Spectrum of Scaled Ground Motions for M2 . . . 64

4.6 Acceleration Response Spectrum of Scaled Ground Motions for M3 . . . 64

4.7 Acceleration Response Spectrum of Scaled Ground Motions for M4 . . . 65

4.8 Scaling Results of MPS . . . . . . . . . . . . . . . . . . . 67

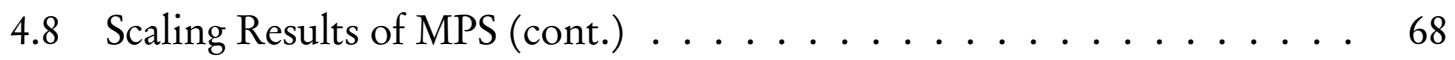

5.1 Retrofit Schemes for Bridges . . . . . . . . . . . . . . . 71

5.2 SCED Brace Cross-Section (from [15]) . . . . . . . . . . . . . 77

5.3 Parametric Study Space . . . . . . . . . . . . . . . . . . 78

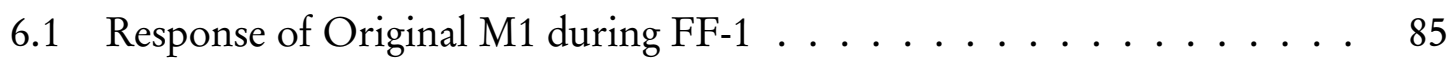

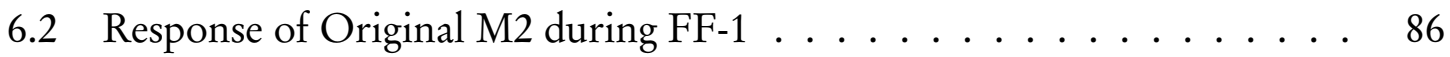

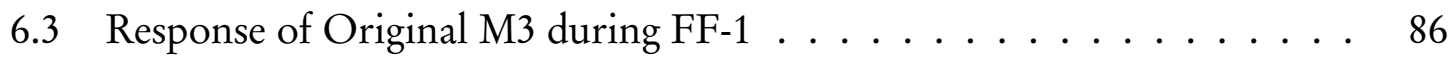

6.4 Response of Original M4 during FF-1 . . . . . . . . . . . 87

6.5 Angles in Fluextural Deforamtion Asessment . . . . . . . . . . 87

6.6 Comparison of Peak Displacement for M1 f . . . . . . . . . . . 94

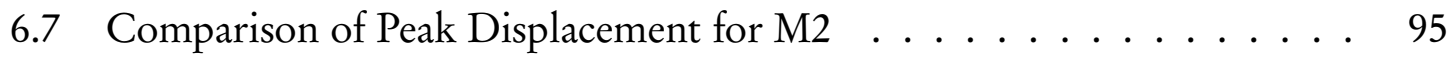

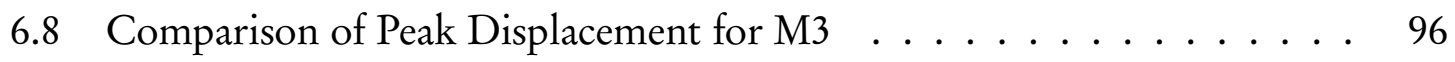

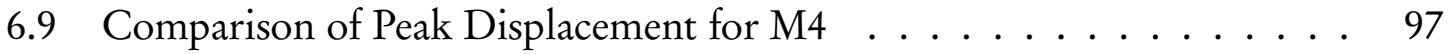

6.10 Comparison of SRSS Peak Acceleration and Velocity for M1 . . . . . . 99

6.11 Comparison of SRSS Peak Acceleration and Velocity for M2 . . . . . 100 
6.12 Comparison of SRSS Peak Acceleration and Velocity for M3 . . . . . . . 101

6.13 Comparison of SRSS Peak Acceleration and Velocity for M4 . . . . . . . 102

6.14 M4: Base Shear Time History during FF-7 in Case-1 $(\beta=0.9, D F=8) 104$

6.15 M4:Base Shear Time History during FF-1 $(\beta=0.45) \ldots$. . . . . . . 105

6.16 M4:Base Shear Time History during FF-1 $(D F=2) \ldots 106$

6.17 Comparison of Cumulative Curvature for M1 . . . . . . . . . . . . 107

6.18 Comparison of Cumulative Curvature for M2 . . . . . . . . . . 108

6.19 Comparison of Cumulative Curvature for M3 . . . . . . . . . . . . . 109

6.20 Comparison of Cumulative Curvature for M4 . . . . . . . . . . . . . 110

6.21 The illustration of yielding curvature . . . . . . . . . . . . 111

6.22 Comparison of Upper Ductility for M1 . . . . . . . . . . . . . . 112

6.23 Comparison of Upper Ductility for M2 . . . . . . . . . . . . . 113

6.24 Comparison of Upper Ductility for M3 . . . . . . . . . . . . . . . . 114

6.25 Comparison of Upper Ductility for M4 . . . . . . . . . . . . . 115

6.26 Time History Comparison of Mid-Bent Displacement . . . . . . . . . 125

A.1 Plan of M1 . . . . . . . . . . . . . . . . 140

A.2 Elevation of M1 . . . . . . . . . . . . . . . 141

A.3 Cross Section of M1 . . . . . . . . . . . . . . . . . . 142

A.4 Bearing of M1 . . . . . . . . . . . . . . . . . . . . 142

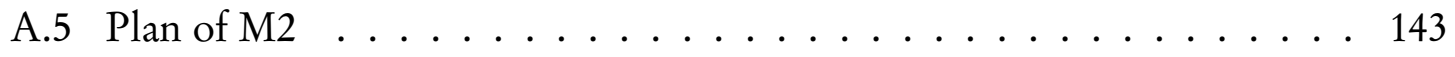

A.6 Elevation of M2 . . . . . . . . . . . . . . . . . 144

A.7 Cross Section of M2 f . . . . . . . . . . . . . . . . 145

A.8 Bearing of $\mathrm{M} 2 \ldots \ldots \ldots \ldots \ldots \ldots$

A.9 Plan of M3 . . . . . . . . . . . . . . . . . . . 146

A.10 Elevation of M3 . . . . . . . . . . . . . . . . 147

A.11 Cross Section of M3 . . . . . . . . . . . . . . . . 148

A.12 Pier Cross-section and Bearing of M3 . . . . . . . . . . . . 148 
A.13 Plan of M4 . . . . . . . . . . . . . . . . . . . . . . . . . . . 149

A.14 Elevation of M4 . . . . . . . . . . . . . . . . . 150

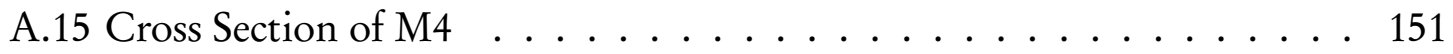




\section{Nomenclature}

$\bar{A}_{n} \quad$ target pseudo-spectral acceleration at period of $\mathrm{n} t h$ mode

$\beta \quad$ energy dissipation capacity of the SCED brace

$m \quad$ structural mass matrix

$\Delta_{1}$ and $\Delta_{\text {trans }}$ the tolerance between the target deformation and the peak deformation of SDOF idealized from longitudinal and transverse modes, respectively

$\Delta_{\text {gap }}$ gap length between the deck and the abutment

$\Delta_{\text {shrink }}$ shrinkage shortening of the deck

$\Delta_{\text {temp }}$ thermal displacement of the deck

$\Delta_{\text {ult }}$ deformation capacity of the aramid tendons

$\mu_{s} \quad$ coefficient of static friction

$\mu_{\Delta} \quad$ ductility of the pier

$\phi_{n}, \omega_{n}$ and $T_{n}$ mode shape, frequency and period of the $\mathrm{n} t h$ mode

$\rho_{s} \quad$ ratio of the volume of transverse confinement to that of the confined concrete core

$\rho_{c c} \quad$ ratio of area of longitudinal reinforcement to are of core section

$\varepsilon_{\text {slip }} \quad$ slip deformation of the SCED brace

A cross-sectional area

A total area of the steel tubes of the SCED brace

$a(t) \quad$ acceleration time history

$A_{c} \quad$ effective wall area 
$A_{p}$ and $L_{p}$ effective area and length of the tendons

$A_{s} \quad$ total area of tension reinforcement

$A_{s p} \quad$ area of spiral

AI Arias intensity

$d_{s} \quad$ diameter of spiral

$d_{w} \quad$ width of the deck

$D_{t g t} \quad$ target peak deformation in modal-pushover-based scaling method

$E_{c} \quad$ effective secant modulus of elasticity of concrete

$E_{p}$ and $E_{s}$ effective Young's Modulus of the tendon and the steel

$E_{s h} \quad$ initial stiffness in strain hardening of the steel

$F \quad$ slip force of the friction damper of the SCED brace

$f_{l}^{\prime} \quad$ effective lateral stress

$F_{N} \quad$ total normal force provided by the bolts in the friction damper of the SCED brace

$F_{b s, L}$ and $F_{b s, N L}$ the maximum total base shear of the equivalent and nonlinear bridge models, respectively

$f_{c c}^{\prime}$ and $\varepsilon_{c c}^{\prime}$ compressive strength and corresponding strain for unconfined concrete

$f_{y e} \quad$ expected yield strength of the steel

$f_{y h} \quad$ yielding strength of transverse reinforcement

$h$ depth of the pier

I total moment inertia of the steel tubes of the SCED brace

$I_{z z}$ and $I_{y y}$ second moment of area about the horizontal axes

$J \quad$ torsional moment of inertia

$K \quad$ effective length factor given by AISC manual

$k_{1}^{+} \quad$ the initial stiffness of the SCED brace in tension

$k_{2} \quad$ post-activation stiffness of the SCED brace

$k_{2}^{-} \quad$ post-activation stiffness of the SCED brace in compression 
$k_{e} \quad$ confinement effectiveness coefficient

$K_{i} \quad$ initial embankment fill stiffness, taken as $14.35 \mathrm{kN} \mathrm{mm}^{-1}$

$k_{i} \quad$ stiffness of the inner steel tube

$k_{o} \quad$ stiffness of the outer steel tube

$k_{p} \quad$ stiffness of the tendons

$K_{a b u t}$ initial stiffness of abutment

$L \quad$ distance from critical section to the point of contra-flexure

$L_{\text {trib }}$ tributary length

$M_{n}^{*}$ and $\Gamma_{n}$ effective mass and modal participation factor of $\mathrm{n} t h$ mode

$M_{Z Z}$ rotational mass of the deck about longitudinal direction

Mass $_{\text {nodal }}$ nodal translational mass

$P \quad$ the external force added to the SCED brace

$P_{a} \quad$ activation force of the SCED brace

$P_{o} \quad$ nominal axial load capacity according to ACI

$P_{a, T o t a l}$ total activation force of the braces in the transverse or longitudinal direction

$P_{b w} \quad$ capacity of the abutment

$P_{P r e}$ the pretensioning force of the SCED brace

$P_{u l t} \quad$ ultimate load of the SCED brace

$R \quad$ reduction factor defined by the ratio of $F_{b s, L}$ to $F_{b s, N L}$

$R_{y} \quad$ yield-strength reduction factor

$R_{\text {pier }}$ radius of the pier

$R P_{i}$ and $R P_{E Q, j}$ response of the bent-i and the response of the $j t h$ ground motion $R P_{n m l}$ normalized response of the structure

$R P_{O r}$ and $R P_{R r}$ responses of the original and retrofitted structure

$s \quad$ spiral spacing

$s_{1}^{*} \quad$ force distribution matrix used in modal pushover analysis 
$s$, clearance between spiral bars

$t_{r} \quad$ total duration of the accelerogram

$V_{b 1}-u_{r 1}$ first-mode modal pushover curve

$w \quad$ width of the backwall 


\section{Chapter 1: Introduction}

\subsection{Background and motivation}

Recent major earthquakes (e.g. 2010 Chile; 1995 Kobe, Japan; 1994 Northridge, California) have demonstrated that many existing old bridges constructed before the adoption of more stringent seismic design standards are vulnerable to earthquake damage. In the past several decades, experiences and research have shown that older existing bridges in regions of high seismicity designed and constructed using now obsolete old design standards will likely suffer damage due to high seismic load demands that exceed original design demands [1-3]. Vulnerable bridges include newer bridges designed in accordance with a ductile design philosophy that relies on the plastic hinging of bridge columns or piers to dissipate seismic energy. Consequently, many bridges, old and new, are found after earthquakes to suffer moderate to severe permanent residual displacement damage. The impact and significance of this damage ranges from service interruption impeding emergency response immediately after earthquakes, to requiring complete demolition. It is also costly and time-consuming to repair residual displacement damage. As such, there is an urgent need to develop effective seismic retrofit techniques to improve the post-earthquake performance and resilience of these structurally deficient bridges, particularly by reducing or eliminating residual displacements.

Structures designed in accordance with the modern seismic design philosophy are

expected to experience inelastic response during an earthquake $[4,5]$. As recognized by 
Filiatrault et al. [5], there are two main drawbacks of these designs:

(i) The lateral resisting elements will be in need of repair or suffer damage that is beyond repair in moderate and strong earthquakes, respectively.

(ii) The earthquake effect can be mitigated by providing effective energy dissipation capacity to the structure. To achieve this goal, a properly designed structure should have the capacity to undergo wide hysteresis during earthquakes. However, typical ductile structural design often results in residual deformations after earthquakes. Significant permanent deformations, together with $P-\Delta$ effects during strong ground shaking, can threaten the stability of the structure.

In a resilient community, critical public infrastructures are expected to be able to withstand earthquakes, to continue to provide full service minimizing disturbance to the public immediately after minor and moderate events, to maintain crucial service to aid in emergency response and recovery efforts, and to minimize economic losses in the case of major disaster events. The downtime caused by small, moderate to strong earthquakes should be minimized. One of the common causes of bridge damage and downtime is permanent residual displacement after earthquakes, resulting in discontinuity in alignment or elevation, which affects the serviceability and function of the bridge.

Compared with buildings, bridge structures typically have much less or no redundancy. This means that progressive failure initiated from one structural member or component can lead to collapse or severe damage to the entire structure. Conventionally designed bridges take advantage of inelastic deformation in the plastic hinges of piers to dissipate seismic energy. However, significant residual deformation at piers can lead to discontinuity at expansion joints of the bridges resulting in the removal of the bridges from service. Permanent residual displacement and the resulting damage are expensive and time-consuming to repair. Bridges with severe damage or significant residual deformation may even require demolition. For instance, studies have documented the cases 
where bridges were demolished due to the failure of the concrete piers. The resulting misalignment caused by bridge pier failures makes it difficult to realign the superstructures to their original positions after earthquakes [6].

As noted by Priestley et al. [2], highway systems in many countries had been built before seismic behavior and earthquake load effect of bridges were well understood. In addition, many existing bridges constructed prior to the development of the modern seismic codes have also been exposed to overuse and exacerbated seismic risk due to higher traffic volume from increased urbanization and economic growth, which induces their accelerated deterioration. Canada has over 70000 bridges [7] and more than $40 \%$ of currently used bridges were built over 50 years ago using obsolete design standards [8]. According to Statistics Canada, bridges in Canada had a mean service life of 43.3 years and the average age of them is 24.5 years in 2007. Comparing the average age with the mean service life of the bridges, it indicates that $57 \%$ of their estimated useful life has been consumed [9]. In general, it is known that these old bridges do not have the strength, ductility, and resilience to resist expected seismic loads or to satisfy displacement demand. In today's public financing environment, public funds are not available for replacement of these deficient existing structures [8]. Thus, developing methods for assessing and retrofitting existing bridges can arguably be considered as more significant than improving code and standard specifications for new design [2].

Observations of bridge damage and performance in past earthquakes and in experimental research have identified common deficiencies in existing bridges. These observations and identified deficiencies have motivated research into developing effective retrofit strategies for deficient bridges. The observed common causes of damage and collapse of bridge structures during the 1971 San Fernando earthquake in California include loss of support of bridge superstructure, brittle failure of bridge piers, and foundation and embankment failures. The lessons learned from this earthquake not only accelerated the development of seismic design codes for bridges, but also led to implementation of an 
early bridge retrofit program [10]. In the retrofit program, restrainers were installed to prevent the loss of support failure of bridge superstructures. The restrainers, typically consisting of cables or bars, limit the relative hinge displacements to prevent the unseating at the support. After the 1986 Palm Springs earthquake in California, shear keys were added to limit the transverse movements of bridge superstructures during earthquakes. These retrofit measures of shear keys together with new restrainers helped bridges to perform better in the 1992 Joshua Tree earthquake. During the 1989 Loma Prieta earthquake and 1991 Talamanca earthquake, unseating at support remained a major concern in performance of some bridges. Failure of bridge piers and abutments still caused major damage and collapse of several bridges. Although the need for retrofit of bridges has been recognized since the 1971 San Fernando earthquake, accelerated efforts to retrofit the entire inventories of bridges were made by highway departments (USA, Japan, New Zealand) after the 1989 Loma Prieta earthquake $[2,11]$.

It is recognized that the goals of retrofitting techniques should not only focus on improving life safety and preventing collapse but also avoiding damage when it is possible. Seismic retrofit methods for bridges can be commonly categorized as either a strengthening retrofit, or as a retrofit that isolates the superstructure from the piers and substructures $[11,12]$. In the first category, the typical retrofitting practice is to strengthen pier members in bridge structures. To prevent shear failure at the piers, several retrofit solutions have been proposed. The most extensively used method to enhance the flexural ductility, shear strength or lap-splice performance of bridge columns is the use of steel jacketing [2]. The steel jackets can help both circular and noncircular sections. Similarly, composite materials such as carbon fiber reinforced polymer have been used as an alternative to the steel jacketing method have been used to enhance confinement performance of bridge columns. For retrofit of cap beams of bridge piers, the method of adding a concrete jacket with reinforcement surrounding the cap beam is usually used to enhance the flexural and shear strength of the cap beam. In some cases, 
post-tensioned dowels are installed in the jackets as well. The second category, the isolation retrofit approach, has found more limited application due to the cost, the extensive requirements for modification at the piers and abutments, and the durability and postearthquake properties of isolators $[5,11]$.

In the past decade, interest in the use of self-centering (SC) systems as a retrofit method has considerably increased. An SC system is typically characterized by a flagshaped hysteretic loop and by two fundamental behavior: recentering and energy dissipation [13]. The first behavior is driven by the restoring force, either generated by the massive self-weight or pretensioned cables or tendons. The energy dissipation behavior can be achieved from viscous or friction dampers, mechanism or fluid springs or shape memory alloys.

Self-centering moment resisting systems using post-tensioning concepts were first developed for prestressed concrete buildings [14]. Inspired by this, several researchers supplemented steel and concrete building structures with the flag-shaped hysteretic systems [5,15-17]. Efforts have been extended to bridge structures as well (e.g. [4,18-21]). For bridge structures, recent research efforts in SC systems have focused mainly on posttensioned rocking pier mechanism; however, such SC systems are difficult or impractical for use in retrofitting existing bridges.

To address the need and limitations of existing retrofit techniques for bridges, a recently-developed self-centering axial member called the Self-Centering EnergyDissipative brace (SCED) [15] is adapted for the retrofit of bridges in this study. Previous studies on retrofitting structures using SCED braces have focused on building applications. Investigation on the use of SCED braces for bridge retrofit has been lacking. SCED braces may be particularly appropriate for bridge retrofit since one of the most common bridge performance issues after an earthquake is a horizontal or vertical misalignment between bridge superstructures and the approaching access roadways due to excessive permanent deformations from inelastic responses of the bridges. Because of 
the self-centering hysteretic characteristics of SCED braces, the use of SCED braces is investigated in this research as a new retrofit technique for existing bridges may solve this problem by eliminating residual displacements. This retrofit method is particularly attractive for retrofitting lifeline and major-route bridges because of their critical function of providing uninterrupted service in aid of emergency response and recovery effort immediately after an earthquake.

\subsection{Objectives}

The research develops a new mitigation solution for the retrofit of deficient bridges to improve their performance and to enhance their resilience to earthquakes. The proposed new bridge retrofit method deploys SCED braces at the bridge abutments or bridge bents to reduce peak displacement responses of the bridge and to inherently reduce or eliminate residual deformations of the bridge after severe earthquakes.

Four existing concrete bridges in Ottawa, which were designed in accordance with now obsolete design standards, are selected as study cases to evaluate the effectiveness of the proposed bridge retrofit strategy using SCED braces. The example bridges are modeled in OpenSees [22]. Nonlinear time history analysis of the bridges are conducted. This research can be divided into two phases:

(i) Assessment of the performance of example bridges under maximum credible earthquakes.

(ii) Retrofit these original example bridges using SCED braces which are designed according to the proposed procedure. This includes a parametric analysis of the design parameters for the SCED braces. 


\section{Chapter 2: Development of Self- Centering Devices}

Most structural systems are not designed to resist rare events such as strong earthquakes elastically. They are designed with strength capacity lower than the elastic demand from the earthquake so that they are expected to experience some structural damage due to inelastic response during strong earthquakes. An inelastic response in the structural system typically leads to permanent residual deformations of the structure after the earthquakes. Large residual deformations would require removal of the structure from service for an extended period. Repairing such structural damage can be expensive and time-consuming due to the distributed nature of the damage throughout the structure. For those structures with severe or significant residual deformations, demolition may be required due to the high cost and difficulty in repairing them.

In resilient and sustainable communities, the development of high performance structures that are able to withstand strong earthquakes is an important step towards achieving a safe and secured society. To meet this goal, various types of self-centering systems for improving resilience of structures have been developed to reduce or eliminate residual deformations.

As discussed by Christopoulos et al. [23], the main structural elements of an ideal seismic resistant system should remain undamaged and return to its original position after an earthquake. Figure 2.1 shows a comparison of the force-displacement hysteretic 
behavior of conventional structures and structures with SC systems. Despite the fact that an SC system typically has less energy dissipation ability and more frequent stiffness changes per cycle than a conventionally designed ductile structural system, the most attractive feature of an SC system is that the zero-force and zero-displacement self-centering behavior of the SC hysteresis at each cycle leads to much less cumulative deformation of the structure during and after the earthquake. A previous study has shown that even though they have less energy dissipation per cycle, SC systems exhibit similar displacement performance as similarly sized elastoplastic systems [24].

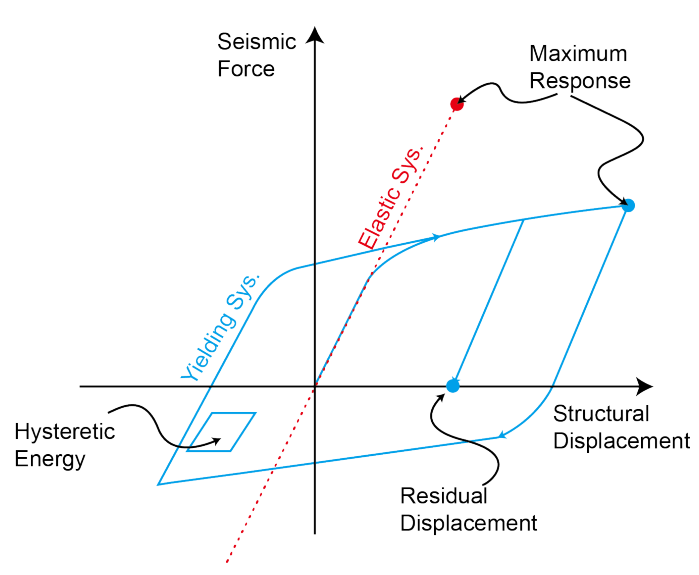

(a) Conventional Elastoplastic Hysteresis

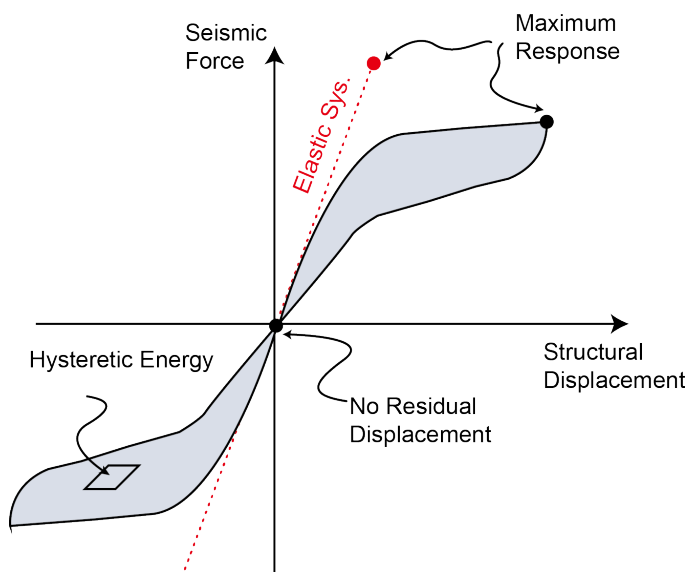

(b) SC System Hysteresis

Figure 2.1: Idealized Force-Displacement Relationship

\subsection{Overview of SC behavior}

In general, the flag-shaped hysteresis which has multiple stiffness changes is achieved by a gap opening mechanism, whether at the base of a wall, at a beam-column interface, or with the body of specially designed SCED brace. At the formation of a gap, the stiffness of the system changes, creating the bilinear backbone for the flag-shape. The fundamental behavior of an SC system typically includes both a re-centering mechanism and supplemental energy dissipation. The former can be provided by restoring force 
behavior of conventional structures and structures with SC systems. Despite the fact that an SC system typically has less energy dissipation ability and more frequent stiffness changes per cycle than a conventionally designed ductile structural system, the most attractive feature of an SC system is that the zero-force and zero-displacement self-centering behavior of the SC hysteresis at each cycle leads to much less cumulative deformation of the structure during and after the earthquake. A previous study has shown that even though they have less energy dissipation per cycle, SC systems exhibit similar displacement performance as similarly sized elastoplastic systems [24].

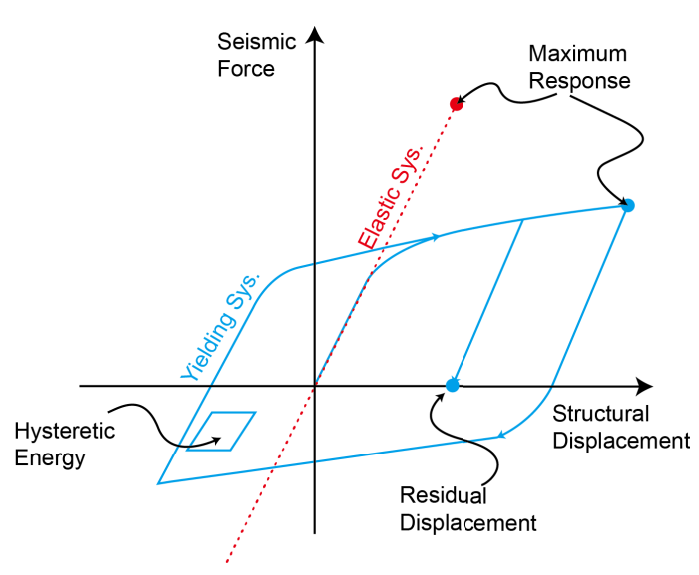

(a) Conventional Elastoplastic Hysteresis

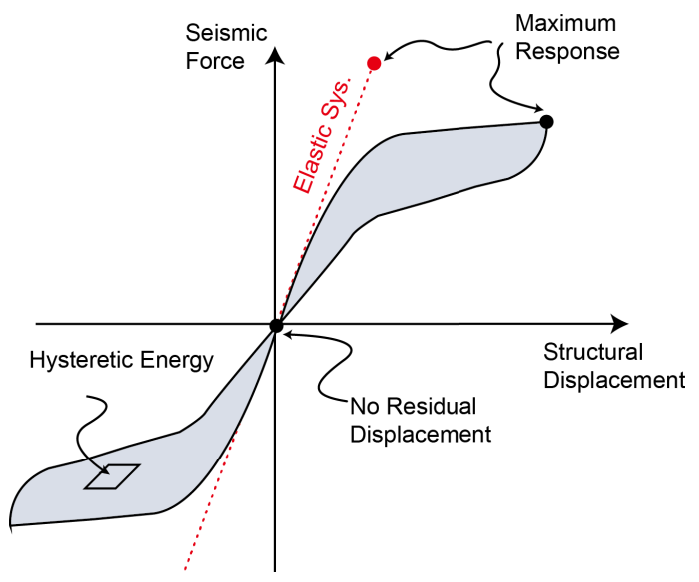

(b) SC System Hysteresis

Figure 2.1: Idealized Force-Displacement Relationship

\subsection{Overview of SC behavior}

In general, the flag-shaped hysteresis which has multiple stiffness changes is achieved by a gap opening mechanism, whether at the base of a wall, at a beam-column interface, or with the body of specially designed SCED brace. At the formation of a gap, the stiffness of the system changes, creating the bilinear backbone for the flag-shape. The fundamental behavior of an SC system typically includes both a re-centering mechanism and supplemental energy dissipation. The former can be provided by restoring force 
elements (e.g. a tendon) and the latter can be provided by various energy dissipating elements.

The stiffness changes of the self-centering system is caused by gaps forming between surfaces which are connected together [25]. The interface between the two surfaces initially has a compression force provided by tendons or gravity force. This provides a high initial stiffness to the interface. When a tension force is applied to the interface, a gap will form only when the initial compression force is overcome. Once the gap is formed, only the lateral stiffness caused by that remaining tendon force or gravity force remains, producing the bilinear stiffness effect. Depending on the location of the gaps, the SC system can be classified into three categories. The first category, which includes rocking walls [26] and rocking columns/piers [4, 12,27], develops gaps between the rocking element and the foundation. The unbonded post-tensioned strands, together with the self-weight, close the gaps and realign a structure back to a vertical condition after the seismic events. In the second category, gaps occur within beam-column joints [28-31] in a building. Post-tensioned elements that are usually located along the beams close the gaps when the ground motion dies down. In the third category, instead of occurring in structure itself, the gaps form within specially designed self-centering devices. For instance, the gaps open between the end plates of the SCED brace and the axial tubes; these gaps are closed by axial post-tensioned tendons once the external force is removed (e.g., $[13,15])$.

The significant structural configuration changes that often associated with rocking systems prevent them from being practically used in retrofit applications. To retrofit deficient bridges, adding self-centering braces to the original structure is expected to be a practical and feasible approach to mitigate seismic damage due to excessive displacement and residual deformations.

The second fundamental behavior of an SC system is the inclusion of supplemental energy dissipaters in the system. According to Chancellor et al. [25], these dissipaters can 
be divided into hysteretic damping elements, viscous damping elements, and frictional damping elements. The hysteretic energy dissipation behavior may involve axial yielding or a combination of shear and flexural yielding of inelastic materials in making the devices. The systems based on frictional damping elements involve multiple plates sliding against each other. However, there are several issues needed to be addressed, such as unstable friction coefficient, loss of normal force, and wear of the friction surfaces, that can affect the performance of frictional damping elements. For the structure whose drift is greatly reduced by the SC system, the hysteretic and frictional damping elements can hardly become engaged under such small drift. The viscous damping elements relying on the velocity are applied under this circumstance [32].

\subsection{Self-centering System Examples}

To date, a large variety of self-centering systems have been developed. This section will provide a review of the most notable previously-developed SC systems.

\subsubsection{Shape memory alloys (SMAs)}

Since the first observation of the shape memory effect [33], shape memory alloys have been extensively studied for their characteristics and practical applications [17]. The SMAs are used in seismic design and retrofit applications due to their energy dissipation capability, large elastic strain capacity, hysteretic damping and negligible residual strain.

These unique properties of SMA materials have resulted in great impact on development of devices using SMAs and their applications [34-36]. Studies investigating the use of SMA devices in buildings have been conducted by several researchers (e.g., [37-39]). These studies demonstrate that the implementation of SMA devices could significantly improve the damping and self-centering capacity to reduce dynamic

Xi Cheng, Department of Civil and Environmental Engineering, Carleton University 
response of buildings. For instance, a study by Ocel et al. [40] on beam-column connections with SMA rods indicates that the SMA bracing elements retain self-centering capability even after experiencing $5 \%$ strain and provide hysteretic damping for strains greater than $1 \%$. After being heated to the transformation temperature, the rods recover around $75 \%$ of their undeformed shape and perform with less than $5 \%$ difference in the following tests. The SMA devices have been implemented in the seismic rehabilitation of several historical buildings, such as San Giorgio bell tower in Italy [41] and the Basilica di San Francesco in Assisi [42].

SMAs have also been implemented in bridge structures. Wilde et al. [43] has presented a laminated rubber bearing isolation system with an SMA bar damper. This type of bearing isolation system is installed between the superstructure and the top of a pier and can work in both tension and compression. On retrofit of expansion joints, restrainers have been used to prevent excessive relative displacement at the movement joint between adjacent bridge members to prevent loss of support failure. DesRoches et al. [44] have developed shape memory alloy (SMA) restrainers which have self-centering hysteretic characteristics and can dissipate more seismic energy than conventional restrainers. DesRoches et al. [44] install the SMA restrainers between the bridge superstructure and the abutment or between the bridge superstructure and the pier top. The results show that SMA restrainers have stable energy dissipation capacity and have negligible residual deformations after the earthquakes. SMA restrainers are proved to be effective in reducing the response of the bridge decks subjected to near-field ground motions.

\subsubsection{Energy Dissipating Restraints, Ring Springs and Friction Damping Braces}

As noted by Erochko [13], three notable self-centering braces have been developed before the SCED braces. However, none of these braces are practical for scaling up to a 
magnitude that would be required for a full-scale building or bridge application.

The energy dissipating restraint (EDR) is a self-centering bracing element originally developed for supporting pipe systems in nuclear plants [23]. As shown in Figure 2.2, this passive friction device consists of internal springs, compression wedges, stops and a cylinder. When the brace is compressed and the external force exceeds the slip force of the friction wedges, the device is activated. With increasing compressive load, the rod and the friction wedges move together toward the left stops. After the rod strikes the stop, the external force rises due to the compression in the spring. When in tension, the rod and the wedges move toward the right end of the cylinder. The mechanics of the EDR is explained by Nims et al. [45].

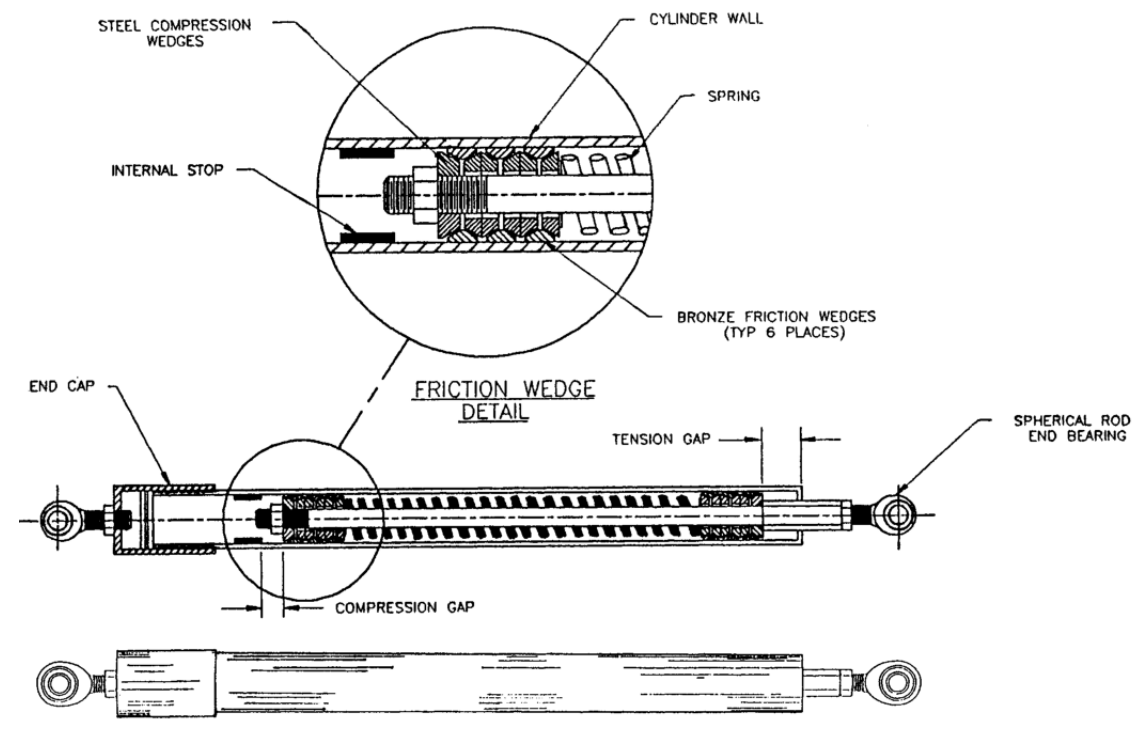

Figure 2.2: The Energy Dissipating Restraint (EDR) (from [45])

Similarly, the SHAPIA damper using a ring spring, also known as friction spring, has been developed by Spectrum Engineering in Canada [46]. As shwon in Figure 2.3, the main components of the ring spring are the inner and outer rings. When the brace is under compressive load, the axial displacement is accompanied by the sliding of rings on the conical friction surfaces [47]. Filiatrault et al. [47] has conducted performance evaluation tests of the ring spring damping system. The flag-shaped hysteresis loops 
of such damper are found to be stable, repeatable and identical in both tension and compression. It is also found that the amount of energy dissipated by the friction ring damper is in the range that would be sufficient to protect structure from severe inelastic deformation.
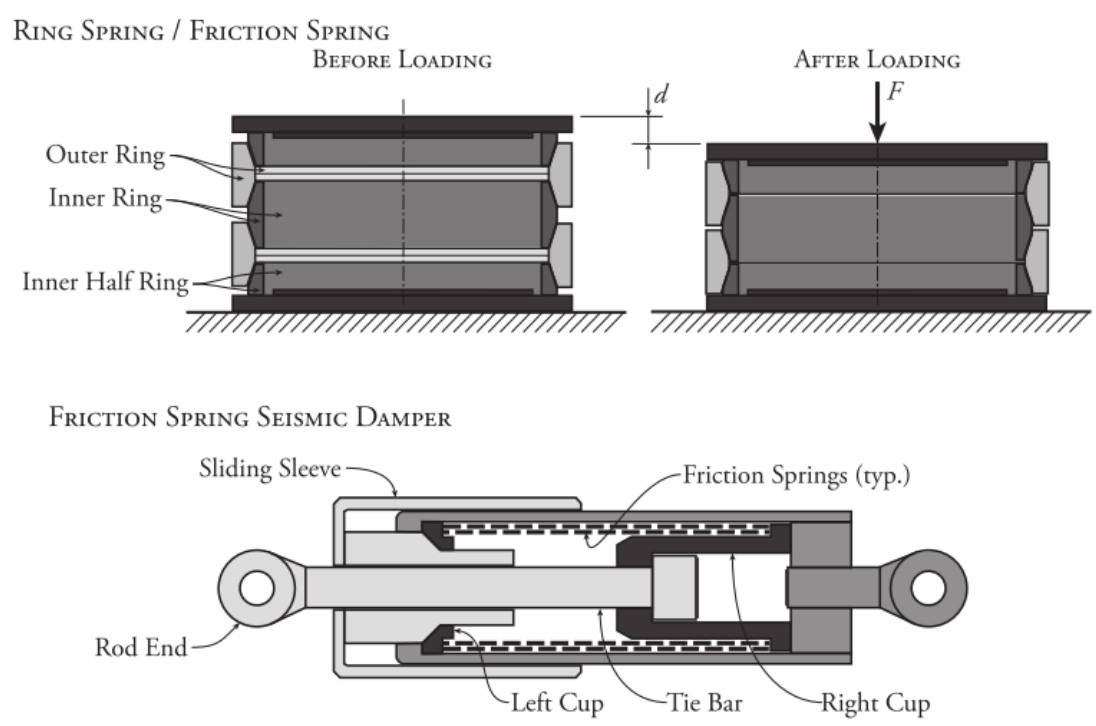

Figure 2.3: Ring Spring (from [13])

The third notable self-centering bracing system termed friction damping brace is developed and tested by Zhu et al. [48]. As illustrated in Figure 2.4, the brace mainly consists of two steel parts (Block A and Block B) and Nitinol wire strands. The steel parts are connected together by the strands and the bolts. The strands are made of SMA and inherently possess self-centering behavior. The bolts aim to provide different amount of normal force on the friction interface such that the energy dissipation capacity can be adjusted. Once the steel parts move relatively to each other, the strands will elongate and the friction interface will dissipate energy. 

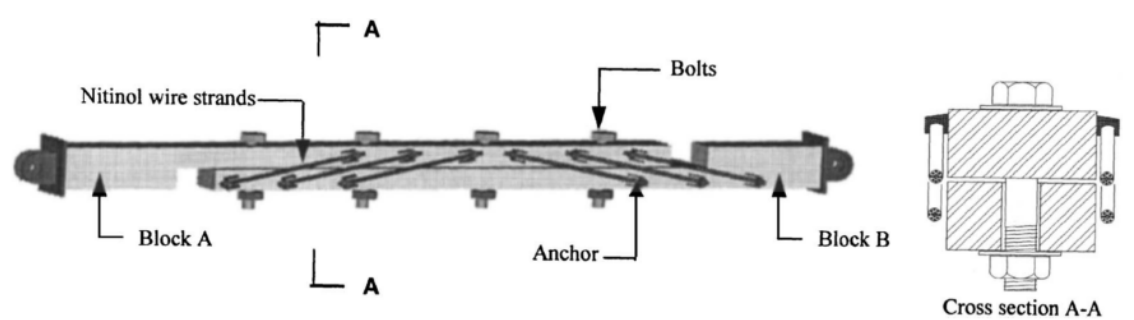

Figure 2.4: Friction Damping Brace (from [48])

\subsubsection{Rocking Systems}

As inspired by the PRESSS (Precast Seismic Structural Systems program), the precast concrete elements are assembled through post tensioned techniques at the interface [27]. This rocking mechanism prevents or minimizes damage in the structural system. As previously mentioned, the rocking systems develop gaps between individual elements when they have relative movements. Typical examples of such system are rocking walls and rocking moment frames as shown in Figure 2.5. 


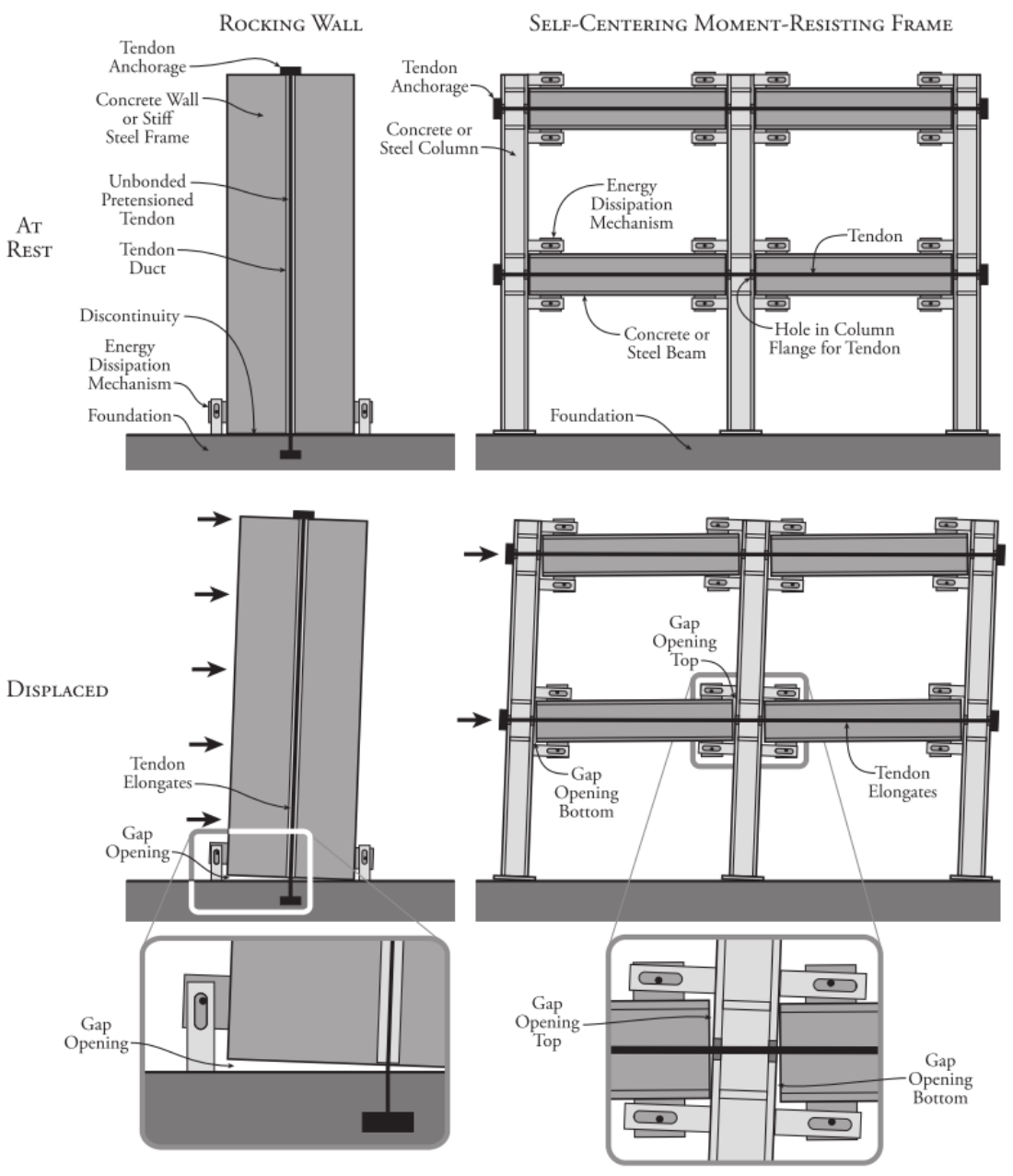

Figure 2.5: Rocking Systems (from [13])

Precast rocking systems based on similar principles have been previously adapted for application to bridge piers. These systems have attracted increasing interest for new construction of bridges due to their advantages of less traffic disruption, faster construction speed, reduced lifetime cost and reduced environmental impact [49]. Researchers (e.g., $[49,50])$ have found that segmental precast unbonded post-tensioned piers can effectively resist lateral cyclic forces, but experience large displacements without significant or sudden loss of strength [4]. Cyclic load test results show that segmental rocking bridge 
piers have smaller residual deformations, less damage, and higher energy dissipation compared with monolithic reinforced concrete piers [51]. To increase energy dissipation capacity, a further study conducted by Chou and Chen [52] has used reduced steel plate as an energy dissipating device to increase the energy dissipation and moment resistance capacities. The results showed that these dissipaters increase the energy dissipation by about $50 \%$ at $4 \%$ drift. Another similar study is presented by Guo [21], which shows that a self-centering bridge pier connected by unbonded post-tensioned tendons and mild steel reduces the residual deformation and has stable energy dissipating capacity.

\subsection{The Self-Centering Energy-Dissipative Brace}

The original SCED brace is first explained by Christopoulos et al. [15] and extended by Erochko [13]. As mentioned in the previous section, earlier self-centering braces are difficult to be scaled up to the order of magnitude that would be required for practical implementation in a full-scale structure. To solve this problem, instead of restoring the position by a set of springs, the SCED brace uses prestressed cables or tendons which have a higher stiffness and capacity to provide the restoring force.

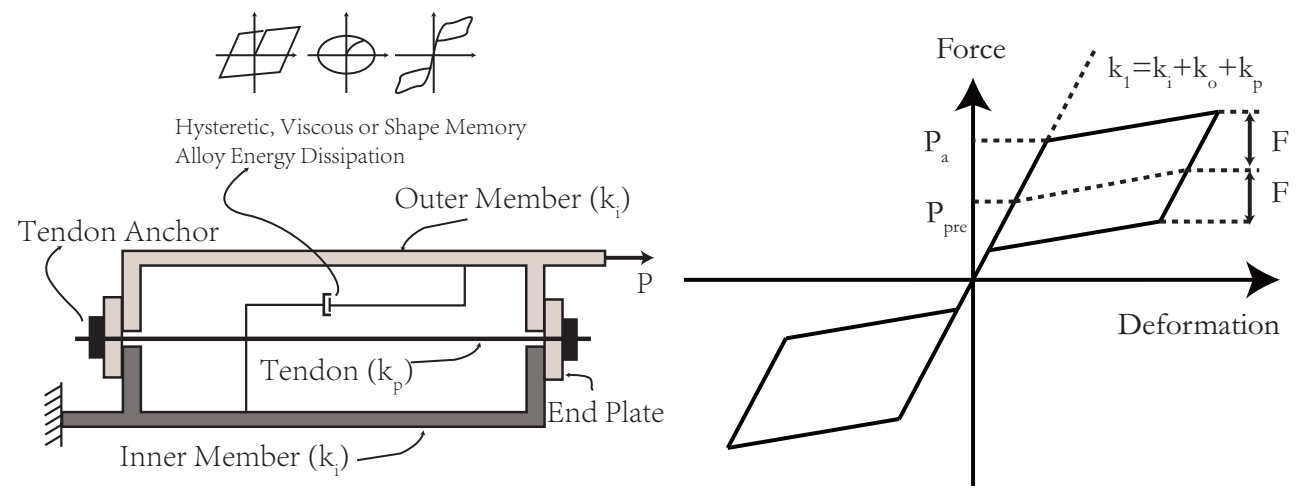

Figure 2.6: Concept of SCED Brace (adapted from [13]) 


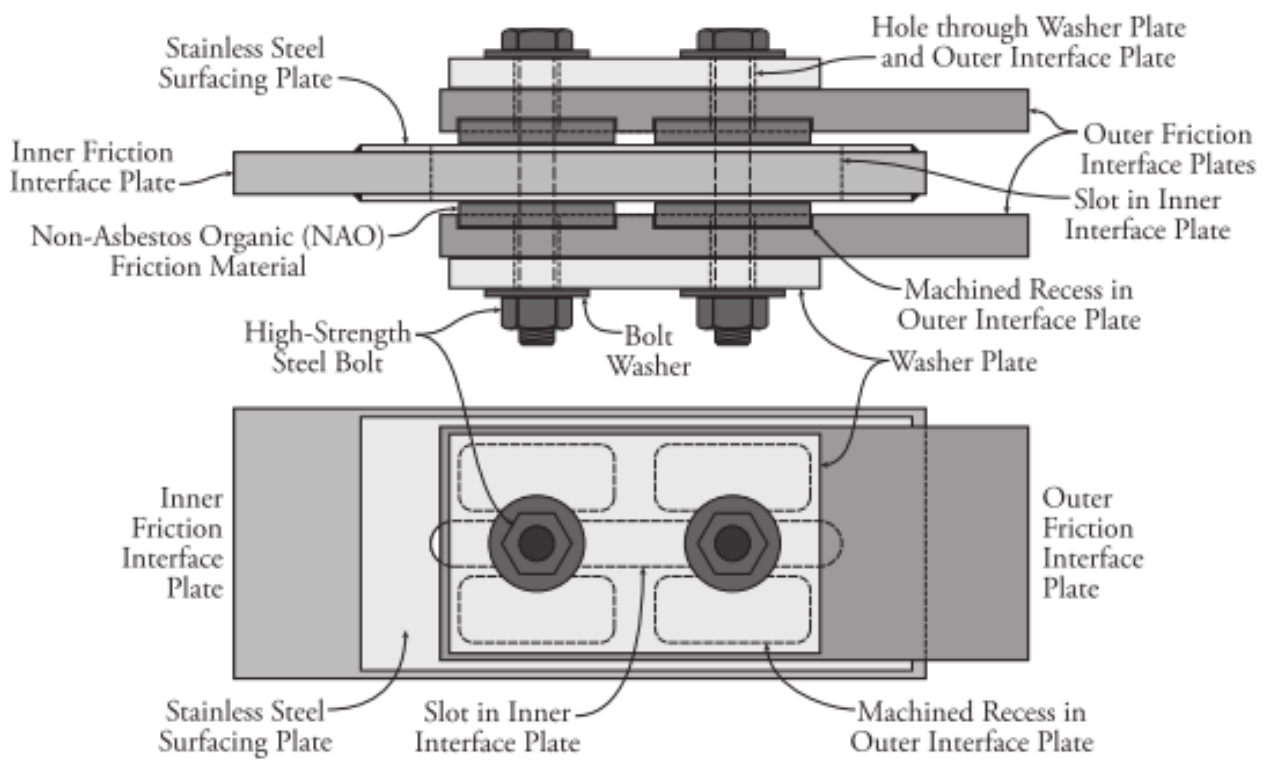

Figure 2.7: Internal Frction Damper (from [53])

As shown in Figure 2.6, the brace mechanism of a SCED system has four main components: (1) an inner steel member, (2) an outer steel member, (3) energy dissipating device and (4) a tensioning system. The inner steel member can be an I-section beam or a steel tube. The tensioning system usually consists of pretensioned tendons which are installed between the end plates. Once the relative movement between the inner and outer members is induced, the energy dissipating device is activated, accompanied by stiffness change. Energy dissipaters which may potentially be used with SCED braces include hysteretic yielding devices, friction slip devices, viscous dampers, or shape memory alloys. In this research, seismic energy is assumed to be dissipated by a friction slip device. The friction damper as shown in Figure 2.7 is developed by Kim [53]. It consists of inner and outer interface plates, friction material pads, stainless steel surfacing plates welded to inner interface plate, high strength steel bots and washer plates. The inner plate has a slot to allow the bolt movement. The bolts connect friction damper through the holes in the outer plates and the slots in the inner plate. The coulomb friction behavior is assumed in the interfaces and the slip force $F$ of the internal friction damper is 
calibrated according to Equation 2.1:

$$
F=\mu_{s} F_{N}
$$

where $F$ is the slip force of the damper, $\mu_{s}$ is the coefficient of static friction and $F_{N}$ is the total normal force provided by the bolts. Proper torquing of the steel bolt is required such that the friction pads subjected to considerable shear stress and axial stress will not deteriorate. The design procedure proposed in this research does not explicitly consider the internal friction damper design by assuming that all the components in the damper are able to provide stable and sufficient friction force.

At one end, the brace is mounted to the main structure with the inner member, and at the other end, it is mounted to the main structure with the outer member. The total area of the tendons, the modulus of elasticity, and the initial pretensioning force are selected to achieve a desired strength, post-activation stiffness of the SCED brace.

\subsubsection{Hysteretic Response of the SCED Brace}

The simplified and full step-wise hysteretic responses of the SCED brace are presented by Erochko [13]. The difference between these two types of model is whether the end plates separate from the inner or outer members simultaneously. Considering the purposes of the research, the simplified model will be considered to be sufficiently close to the true shape. The only modification that is made to this simplified model is that an effective initial stiffness of $60 \%$ of the theoretical combined stiffness value is used to account for construction tolerance effects as suggested by Erochko et al [13]. 

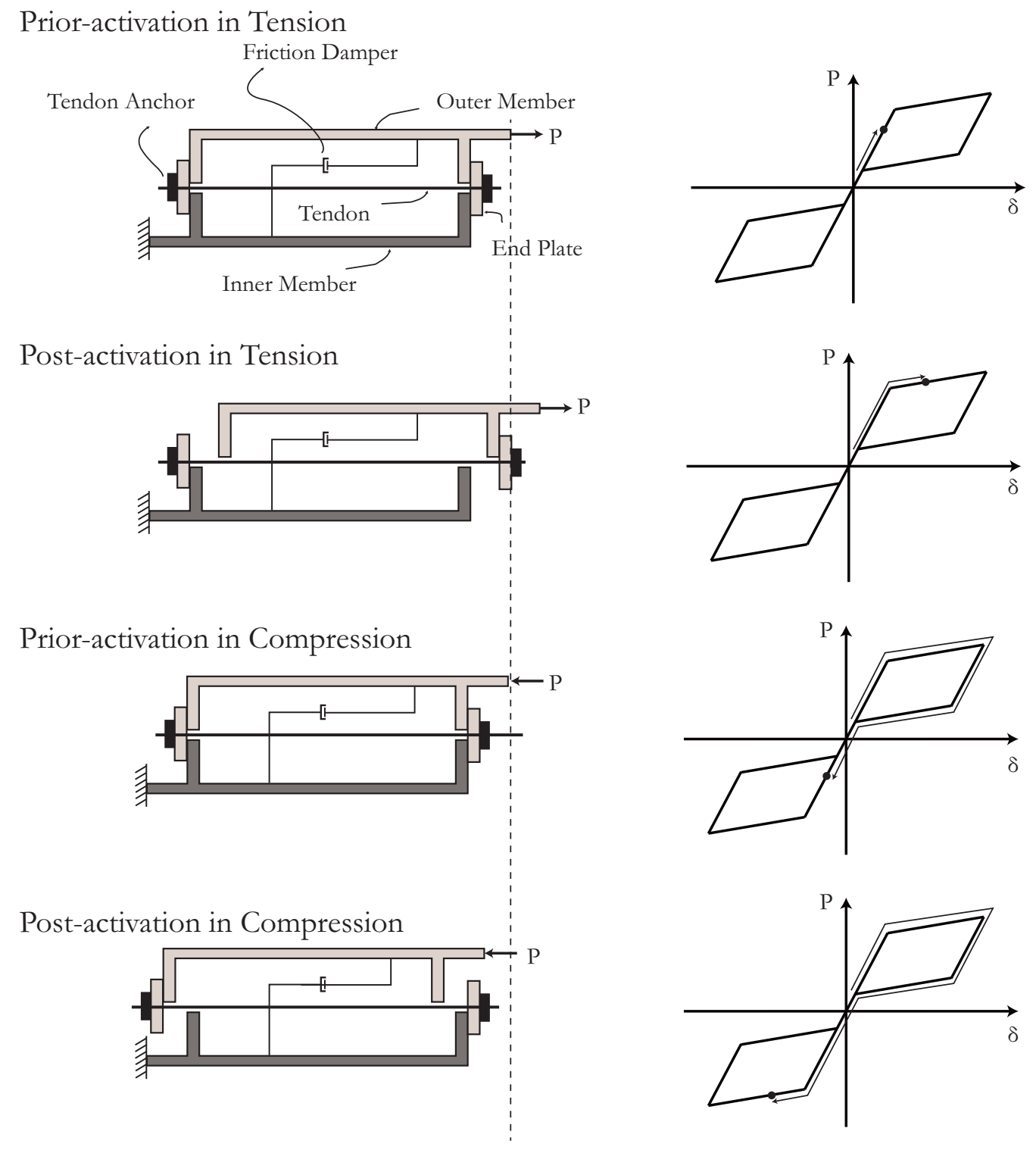

Figure 2.8: SCED Brace Mechanics (adapted from [13])

To illustrate the behavior of a SCED brace equipped with friction slip mechanism, Figure 2.8 adapted from Erochko [13] is provided. Since the tendons are pretensioned during assembly, there is a compression force in the inner and outer members and a tension force in the tendons when the brace is at rest. As an external force $P$ is added to the brace, the pretensioning force $P_{p r e}$ is reduced proportionally to the external force $P$ 
until $P_{p r e}$ is overcome. Prior to that point, the SCED brace exhibits high initial stiffness $k_{1}^{+}\left(\right.$or $\left.k_{1}\right)$ which is the sum of the stiffness of the axial elements: inner and outer tubes and the tendons, as shown in Equation 2.2:

$$
k_{1}^{+}=k_{i}+k_{o}+k_{p}
$$

If $P$ keeps increasing, the brace will be 'activated' when $P$ surpasses the sum of $P_{p r e}$ and friction force $F$ (the incremental force induced by the elongation of the tendons prior to activation is small and therefore ignored in this explanation). Thus, the activation force $P_{a}$ is defined as Equation 2.3:

$$
P_{a} \approx P_{p r e}+F
$$

After the activation on the tension side, the gap opens between the inner and outer members. The stiffness of the SCED brace is now provided solely by the tendons. Therefore, the load capacity of the tendons generally limits the ultimate load capacity $P_{u}$ of the SCED brace. When $P$ is decreased from the peak, the pretensioning force in the tendons tends to pull the steel members back to their original position. However, since the friction mechanism is locked, all three axial elements work in unison as one unit and the stiffness changes back to $k_{1}$ (Equation 2.2). The inner and outer members are able to move relative to each other once $P$ decreases by $2 F$, which is the vertical width of the flag hysteresis. This width is exact $2 F$ because the friction mechanism unloads and reloads in the opposite directions before the relative movement occurs. The width of the flag hysteresis is generally expressed in terms of $P_{a}$ as shown in Equation 2.4:

$$
2 F=\beta P_{a}
$$

Once the friction device is slipping again in that opposite direction, the stiffness of the 
brace reverts to the stiffness of the tendons alone until the gaps are closed. After the gaps are closed on the tension side, all the axial elements will deform simultaneously again, which means the stiffness of the brace is $k_{1}$.

Before the activation on the compression side, the activation load and stiffness are the same as they are on the tension side. The post-activation stiffness in the compression direction is slightly different but can be simplified as the stiffness of tendons since $k_{p}$ is much smaller than $k_{i}$ and $k_{o}$, as shown in Equation 2.5. As such, the hysteresis of the SCED brace is approximately symmetric.

$$
k_{2}^{-}=\frac{1}{\frac{1}{k_{i}}+\frac{1}{k_{o}}+\frac{1}{k_{p}}}
$$

However, the theoretical properties of the SCED braces may not be achieved due to the imperfection of members and fabrication. For instance, the effective initial stiffness is much lower than $k_{1}[13]$.

\subsubsection{SCED Braces in Retrofit}

Two pioneering building modeling projects related to SCED braces have been performed by Tremblay et al. [24] and Choi et al. [54]. Both studies compare the performance of buildings retrofitted with SCED braces and buckling restrained braces (BRB). Tremblay et al. [24] investigates five steel frame buildings with different heights and implemented two types of bracing members. The buildings equipped with SCED braces generally have better performance regarding peak story drifts and residual lateral deformation. Because of the sharp stiffness transitions assumed in the SCED brace numerical model, it is expected that the building frame could experience large floor acceleration. The tests conducted by Erochko et al. [13] have experimentally shown that the high stiffness transitions induce higher floor accelerations; however, it is found that the SCED 
brace numerical model exaggerates this effects

Another SCED frame study is conducted by Choi et al. [54]. Besides comparing SCED and BRB braced frames, special moment-resisting frames are investigated as well. Although it is found SCED braced frames experience similar peak story drifts, the much smaller residual drift response is found to be a desirable advantage. Similarly, this study shows higher floor acceleration in SCED braced frame compared with the other two systems.

A full-scale SCED brace and telescoping (T-SCED) brace have been tested by Erochko $[13,55]$ in a full-scale steel test frame. The results show that the SCED brace achieves full self-centering capability while accommodating a 3.8\% drift in the test frame. Shake table tests of a one-third scaled SCED braced frame are also carried out in the research conducted by Erochko et al. $[13,55]$. The companion OpenSees model and SAP2000 model of the test frames are able to predict the results of the tests. A six-story frame braced with SCED braces is modeled to compare the effects of theoretical initial stiffness and lower effective stiffness of the braces on the frame response. The case study shows that a lower effective initial stiffness does not significantly affect the dynamic response of the frame even though it modifies the building fundamental period.

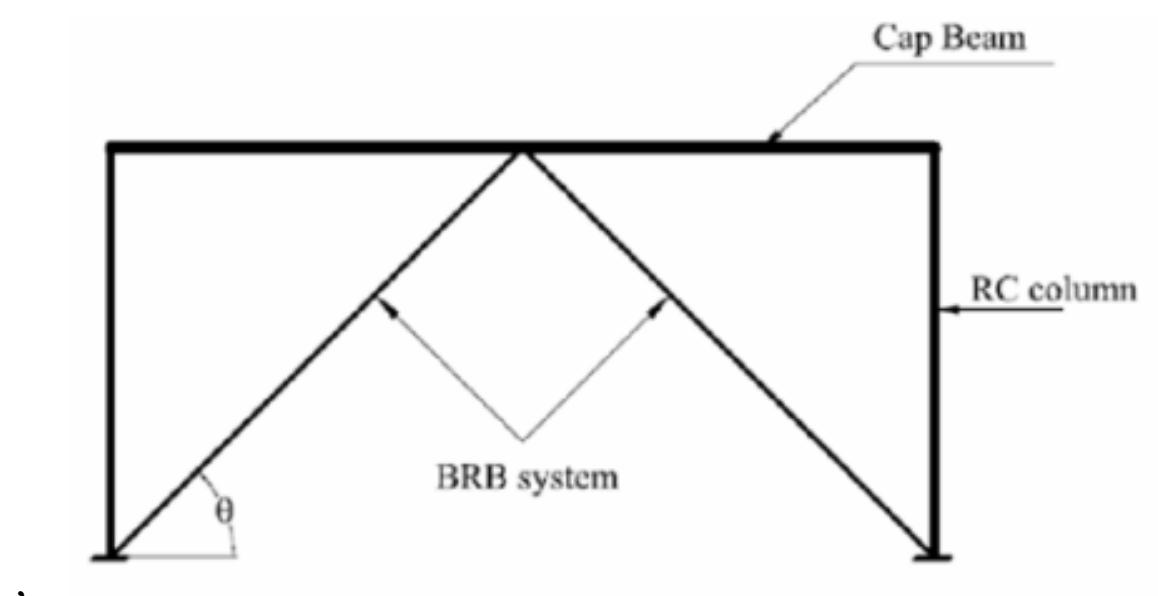

Figure 2.9: Retrofit Bridge Bent with BRB (from [56]) 
To the knowledge of the author, the SCED brace has not been implemented in the retrofit of bridges either in analytical model or laboratory experiment. The application of the buckling restrained brace $(\mathrm{BRB})$ in previous bridge retrofit studies implies the potential of the SCED braces. El-Bahey et al. [56] introduce the concept of structural fuses in design and retrofit of bridges. As shown in Figure 2.9, buckling restrained braces (BRB) have been proposed for used in retrofit of reinforced concrete bridge bents [56]. A similar retrofit technique has been proposed by Celik et al. [57] where the BRBs placed at the bridge end diaphragms to resist bidirectional earthquake effects in straight bridge superstructures. Similar to these previous BRB studies, SCED braces can be installed close to the abutments or between the piers in a bent. 


\section{Chapter 3: Description and Modeling of Bridges}

\subsection{Description of Bridge}

The bridges selected for this study have prestressed concrete slab decks supported by circular concrete piers. The example bridges with different geometric layouts consist of bridges constructed between the 1960s and 1970s in the City of Ottawa, Ontario. The number of piers of each bent and the number of spans vary among these bridges.

The first example bridge as shown in Figure 3.1, named Model 1 (M1), is a continuous two-span concrete bridge with a prestressed concrete hollow core deck. The superstructure is supported by a single two-pier bent. The fixed bearing, as shown in Figure 3.1(a), installed between the pier top and the deck is a Rota Bearing which consists of piston plate, confined rubber and cylinder plate. An example of this type of rubber pot bearing is those manufactured by the Andre Rubber Company Ltd [58] which allows rotation about a horizontal axis (which can be modeled as a pinned or universal joint connection) [59]. At the two ends of the bridge, the decks are supported on abutments. The cross section of the pier and the deck are shown in Figure 3.1(b). The pier, 762 $\mathrm{mm}$ (2.5 ft.) in diameter, is reinforced with 20-\#11 longitudinal, Grade 40 bars and \#5 spirals at space of $102 \mathrm{~mm}$ (4 in.) The pier reinforcement is covered by $51 \mathrm{~mm}(2 \mathrm{in}$.) of concrete cover. 


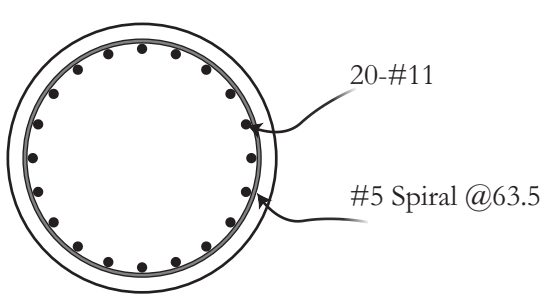

Section A-A

Unit: $\mathrm{mm}$

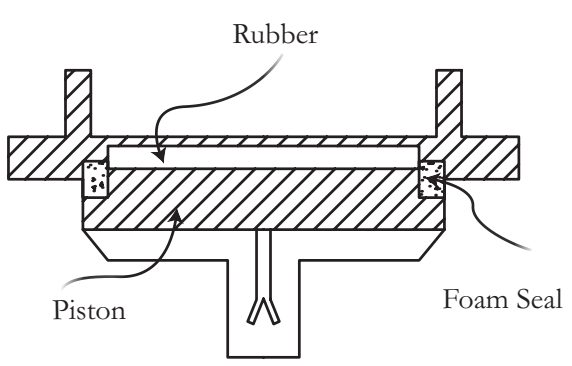

Fixed Bearing Schematic Drawing

(a) Bearings and Column Cross Section

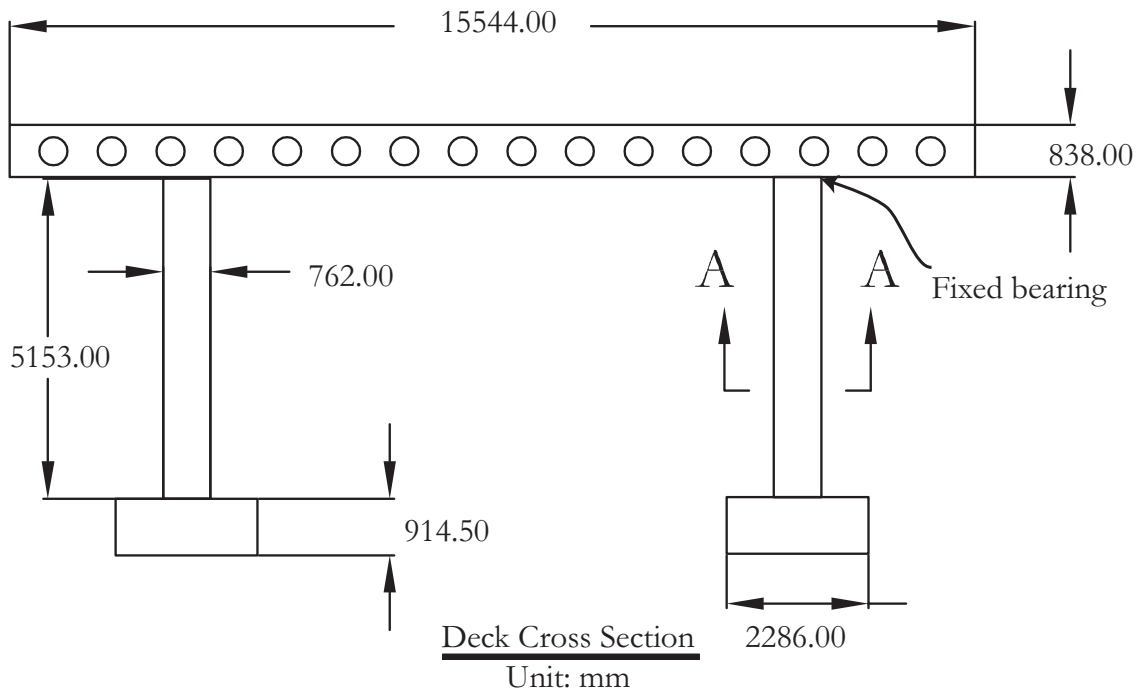

(b) Cross Section of Deck

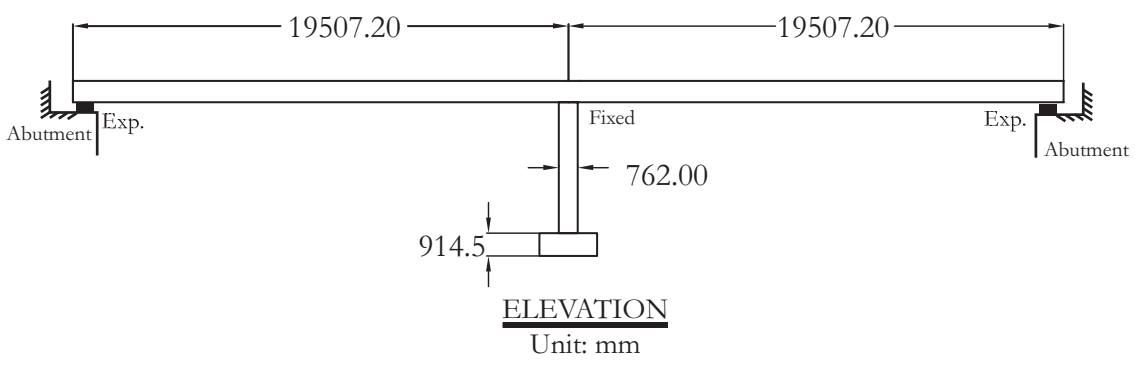

(c) Bridge Profile

Figure 3.1: Drawings of Model 1

The example bridges, shown in Figure 3.2 to Figure 3.4, are referred as Model 2 (M2), Model 3 (M3) and Model 4 (M4), respectively. The concrete decks of these 
bridges are supported on fixed bearings at the bents and on expansion bearings at both abutments. The bridges of Model 2 and Model 3 are continuous three-span bridges and supported by two-pier bents and three-pier bents, respectively. The dimensions of main structure members and the reinforcement configurations of M2, M3 and M4 are shown in Figure 3.2 to Figure 3.4.

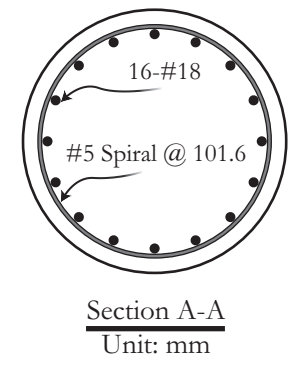

(a) Bearings and Column Cross Section

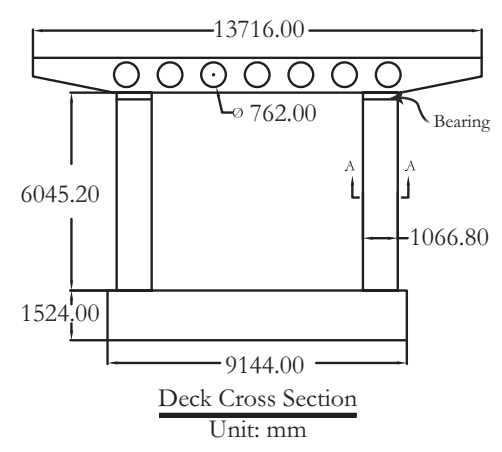

(b) Cross Section of Deck

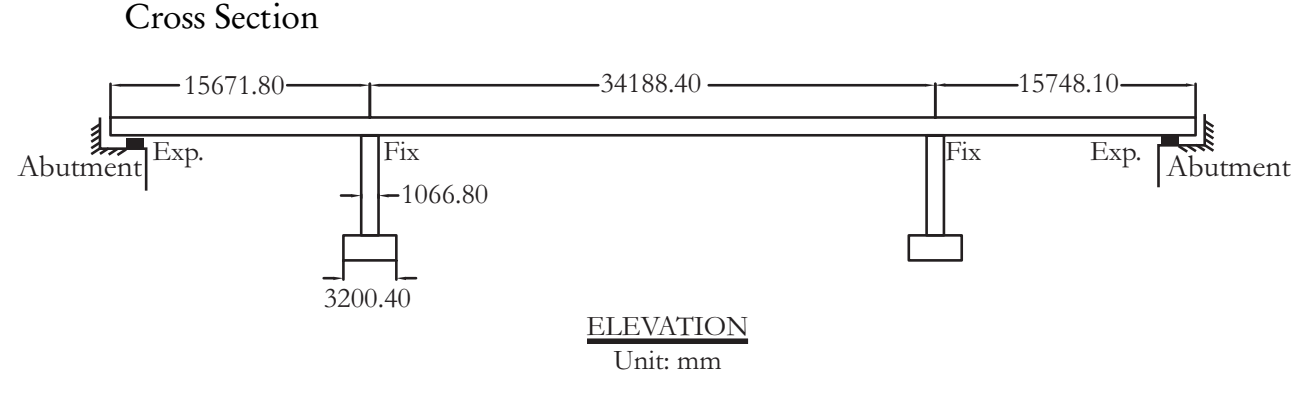

(c) Bridge Profile

Figure 3.2: Drawings of Model 2 


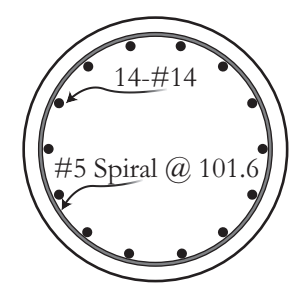

$\frac{\text { Section A-A }}{\text { Unit: } \mathrm{mm}}$

(a) Bearings and Column Cross Section

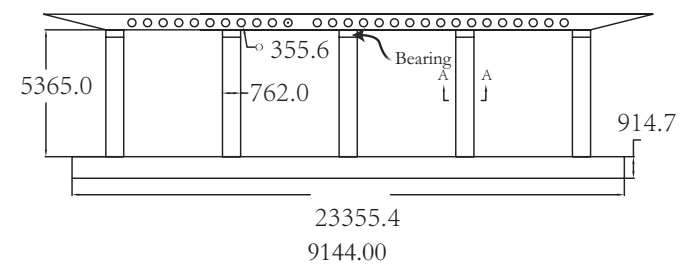

$\underline{\text { Deck Cross Section }}$

(b) Cross Section of Deck

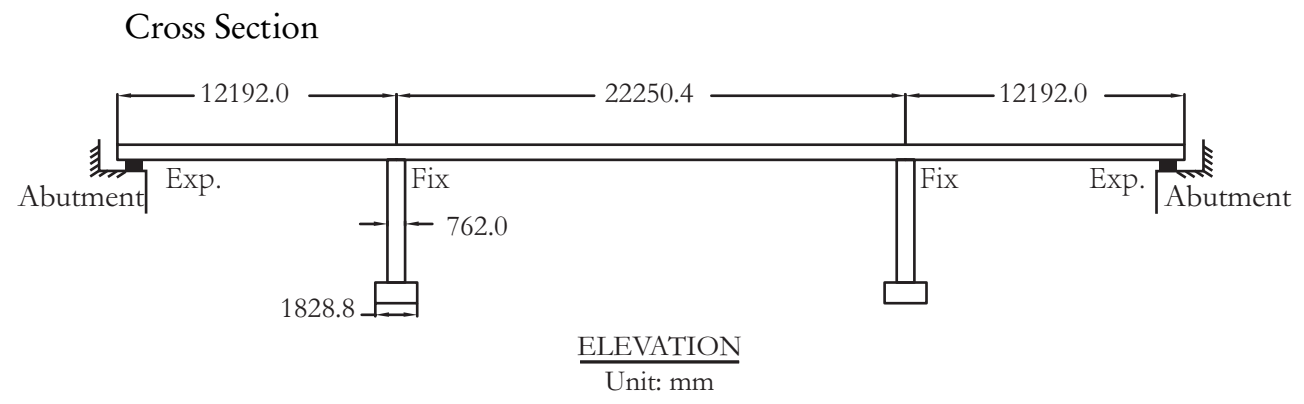

(c) Bridge Profile

Figure 3.3: Drawings of Model 3 


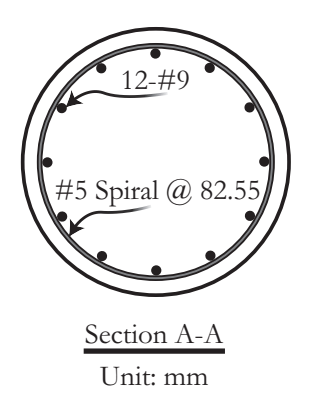

(a) Bearings and Column Cross Section

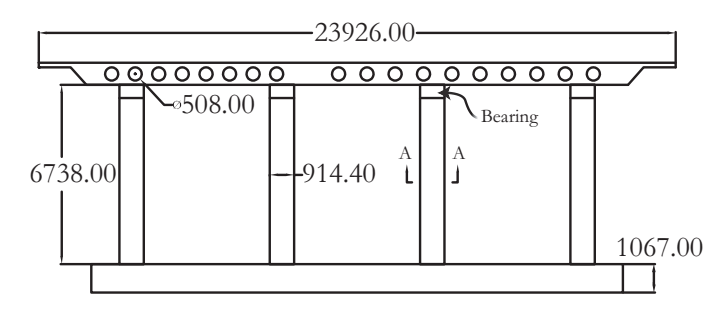

$\frac{\text { Deck Cross Section }}{\text { Unit: } \mathrm{mm}}$

(b) Cross Section of Deck

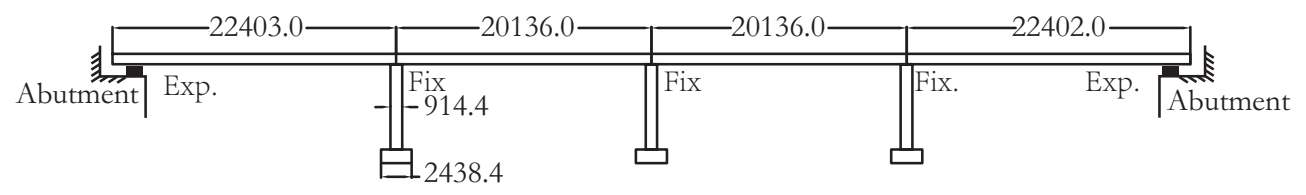

$$
\frac{\text { ELEVATION }}{\text { Unit: } \mathrm{mm}}
$$

(c) Bridge Profile

Figure 3.4: Drawings of Model 4

\subsection{Finite Element Model of Selected Bridges}

The seismic modeling and analysis of bridge structures have evolved over recent years due to rapid advances and development in earthquake engineering and capabilities in computer modeling of complex structures, including development of advanced computer tools for analyzing dynamic behavior of structures. It is now possible to use readily available computer tools to analyze dynamic time-history response of bridge structures subject to bi-directional ground motions in both longitudinal and transverse directions 
simultaneously, and considering the nonlinearity of material and geometry in the response behavior.

In structural analysis using modern computer tools, the structure is discretized into mathematical elements and their connections and interactions. Based on the levels of details in the discretization, the structural models can be characterized into Lumpedparameter Models (LPMs), Structural Component Models (SCMs) and Finite Element Models (FEMs). The LPMs are simple in mathematical formulation, but significant knowledge and experience are required to estimate the force-deformation relationships of the idealized elements. A Structural Component Model has idealized structural subsystems which are connected to represent the general geometry of the bridge. The FEMs discretize the actual geometry of the bridge with large number of connected separate components. Obviously, the geometric discretization efforts increase from LPMs to SCMs. On the other hand, a higher level of knowledge in the behavior of the modeled structure in terms of engineering judgment is required in modeling of structures by the SCM and LPM approaches.

The random nature of seismic events, uncertainties in material properties and uncertain boundary conditions in the field make the modeling and analysis of structures subject to earthquake loading more difficult than for other load effects, such as dead and live load effects. The availability of advanced models and analysis tools, to the contrary, does not automatically mean that seismic response characteristics of structures can be accurately predicted. It still requires considerable in-depth understanding of the problem, especially in the following areas [2]:

- Soil structure interaction at abutments and piers

- Movement joint characterization

- Hysteresis load-deformation characteristics and damping

- Shear and bending deformation with increasing ductilities 
- Deformation in joints and connections

- Dynamic interaction of bridge section with different response characteristics

For the study here, the following assumptions are made in the structural models of the example bridges:

- The effects of the small skew angle are ignored;

- The bridge decks are assumed to be elastic during seismic attack, and the piers are connected with rigid link elements;

- The boundary conditions at the bottom of the piers are fixed in all directions;

- A spring model is adopted to represent the behavior of the bridge abutment; and the bearing stiffness is ignored due to the limited contribution to the overall response and failure modes of the structure;

The example bridges selected in the present study have been modeled in a previous study by Vishunukanthan [1] in SAP2000 using three-dimensional spine models. In the present study, the example bridges are modeled at a similar level of detail.

This section discusses the analytical modeling of four reinforced concrete bridged using OpenSees version 2.5 [22]. OpenSees (Open System for Earthquake Engineering Simulation) is a general nonlinear time-history structural analysis software that is widely used in earthquake engineering applications. The models are constructed according to the guidelines presented by Aviram et al. [60]. The bridge piers are modeled using fiber sections with concrete and steel properties assigned via pre-defined material models in OpenSees. Gap elements are used to model the gap between the abutment and the deck. The bottom of the piers are fixed in all directions. The damping behavior of the bridges are summed to be proportional to the mass and stiffness properties of the bridges. The inherent damping in the structure is modeled using 5\% Rayleigh damping in modes 1 
and 12. In the following sections, the modeling of nonlinear column elements, superstructure, and abutment are described in further detail.

\subsubsection{Bridge Model Geometry}

\subsubsection{Coordinate System}

The coordinate system used in this research is shown in Figure 3.5(a). The global $\mathrm{X}$-axis is in the direction of the expansion gap center line, denoted as the transverse direction; the global Y-axis indicates the vertical direction of the bridge; while the Zaxis is the chord connecting the abutments and mid-bents, referred to as longitudinal direction.

It is recommended by Aviram [60] that the coordinate system be setup so that the orientation of all frame elements in a bridge structure coincides with the positive direction of the global axis for structure without skew. As shown in Figure 3.5(a), each element is defined in the direction from node $i$ to node $j$, pointing to the positive direction of the global axes. For these elements, the local degrees-of-freedom are defined as shown in Figure 3.5(b). 


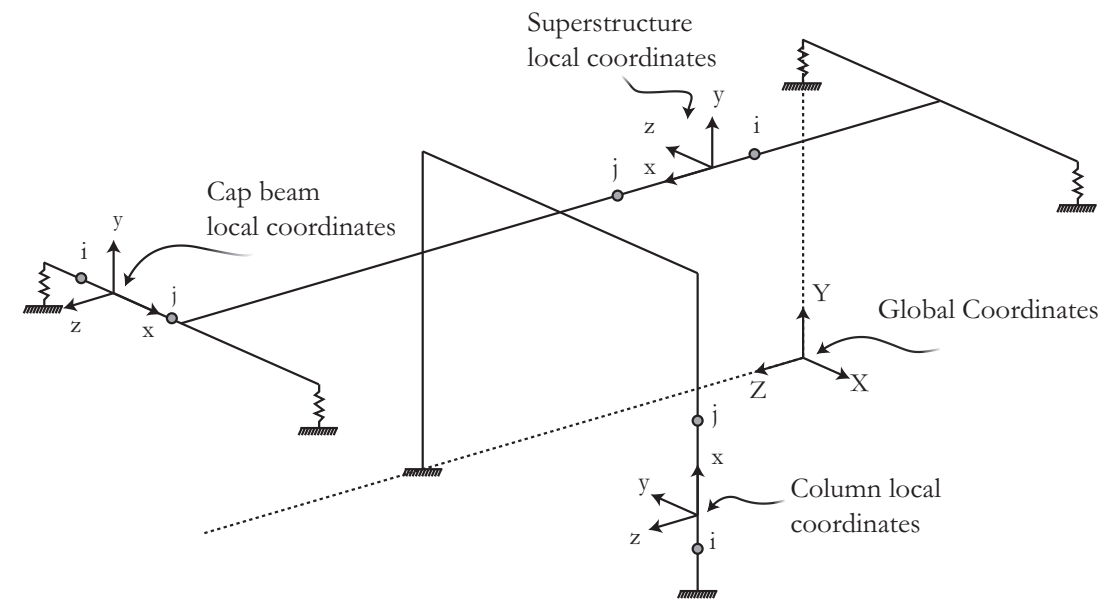

(a) Coordinate System

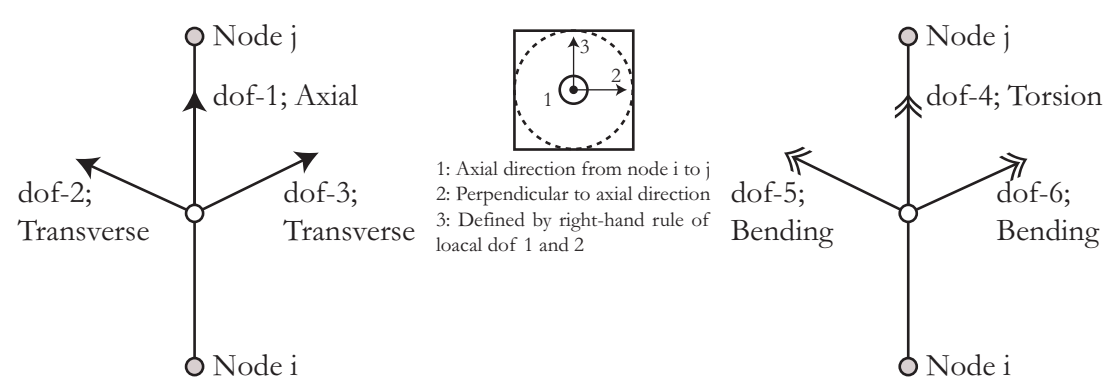

Translation Degree of Freedom

Translation Degree of Freedom

(b) Degree of Freedom in OpenSees

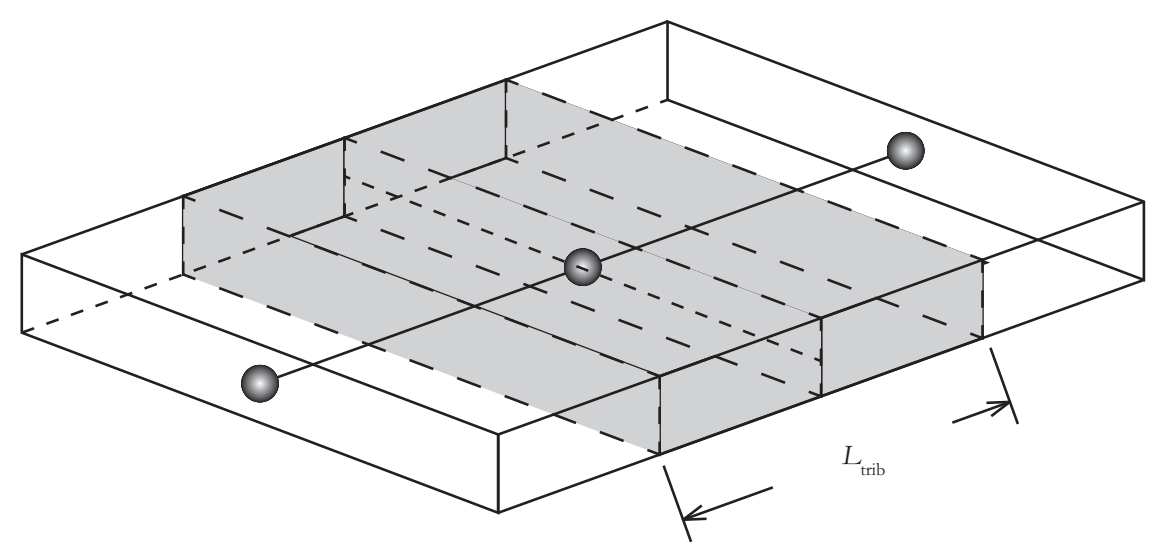

(c) Tributary Mass

Figure 3.5: Coordinate Systems and Mass Distribution 
The basic structural geometry properties of the example bridges are presented in Table 3.1.

Table 3.1: General Geometric Properties of the Example Bridges

\begin{tabular}{lcccc}
\hline Parameters & Model 1 & Model 2 & Model 3 & Model 4 \\
\hline Span length (m) & $19.5+19.5$ & $15.7+34.2+15.7$ & $12.2+22.3+12.2$ & $22.4+20.1+20.1+22.4$ \\
Deck width (m) & 15.5 & 13.7 & 25.8 & 23.9 \\
Deck depth (m) & 0.84 & 1.07 & 0.66 & 0.83 \\
Piers per bent & 2 & 2 & 5 & 4 \\
Pier height (m) & 5.2 & 6.0 & 5.4 & 6.7 \\
Pier diameter (m) & 0.76 & 1.07 & 0.76 & 0.91 \\
\hline
\end{tabular}

\subsubsection{Node and Element}

In three-dimensional spine model of the bridge deck, the equivalent line model of the bridge deck is located at the centroid of the cross section of the bridge deck. The beam-column element responses are expressed in the form of resultant force and moment, such as axial, shear, torsion and bending actions at specific location in the model. Mesh refinement has been considered for each bridge model in order to ascertain that numerical models with sufficient accuracy are used in the analysis of the example bridges and that converged numerical results are obtained. A relatively coarse model used in the dynamic analysis has at least four elements per span for the superstructure and three elements per column [61]; similarly, it is recommended by Aviram et al. [60] that the superstructure, cap beam, and column bents should be discretized into a minimum of five elements with equal length. These refinements help approximate the distributed mass of the bridge components with lumped mass at the nodes and maintain a reasonable mass 
distribution during the numerical solution process $[60,62]$. The translational and rotational mass corresponding to the tributary mass associated with each node are assigned according to Section 3.2.2. The tributary length $L_{t r i b}$ used in calculating translational and rotational mass is defined in Figure 3.5(c).

The numbers of segment in the superstructure and piers are summarized in $\mathrm{Ta}$ ble 3.2. Sensitivity studies determining the appropriate modelling refinements have been conducted and shown in the following sections.

Table 3.2: Discretization of the Example bridges

\begin{tabular}{ccccc}
\hline Number of elements & Model 1 & Model 2 & Model 3 & Model 4 \\
\hline Deck(per span) & 10 & 10 & 10 & 10 \\
Pier & 5 & 5 & 7 & 5 \\
\hline
\end{tabular}

\subsubsection{Modeling of Mass and Material}

\subsubsection{Translational Mass}

The unit mass of the normal concrete as defined by CalTrans [63] of $2286 \mathrm{~kg} / \mathrm{m}^{3}$ is used in the bridge models. To account for other components on the superstructure, the unit weight of the deck, as recommended by Vishunukanthan [1], is taken as 24.5 $\mathrm{kN} / \mathrm{m}^{3}$. Similarly, the unit weight of the columns and foundations are both assumed as $24.0 \mathrm{kN} / \mathrm{m}^{3}$ in this study.

The nodal translational mass of the model is assigned to mid nodes according to Equation 3.1 and the translational mass of the end node is half of Mass nodal $_{\text {. }}$

$$
\text { Mass }_{\text {nodal }}=\frac{\mathrm{m}}{L_{\text {trib }}}
$$




\subsubsection{Rotational Mass}

Rotational mass is considered in modeling the superstructure by a spine model in order to properly account for the torsional behavior of the bridge deck. The accurate modeling of the superstructure rotational mass increases the accuracy of the analysis results in capturing the dynamic response and fundamental modes in the transverse direction of the bridge. The rotational mass is estimated using Equation 3.2 [60]:

$$
M_{Z Z}=\frac{M d_{w}^{2}}{12}=\frac{(m / L) L_{\text {trib }} d_{w}^{2}}{12}
$$

For bridges with significant torsional mode, the rotational mass is also modeled for the piers according to the following Equation 3.3:

$$
M_{Y Y}=\frac{1}{2} M R_{\text {pier }}^{2}
$$

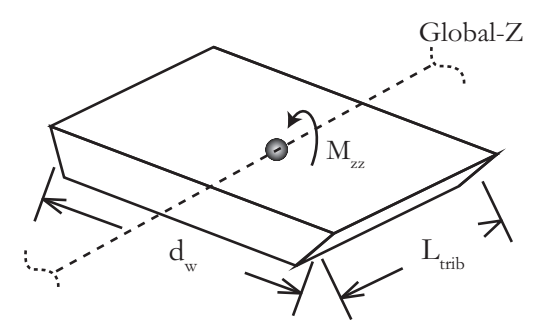

(a) Rotational Mass of Deck

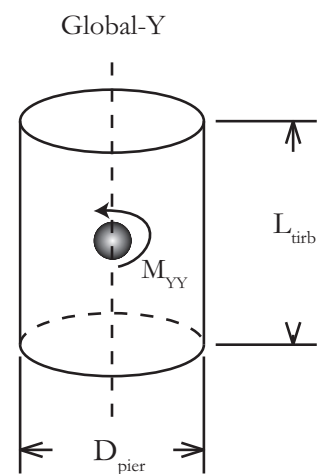

(b) Rotational Mass of Column

Figure 3.6: Rotational Mass 


\subsubsection{Material Properties}

The material model used for modeling reinforcing steel has an initial linear elastic part, a yield plateau, strain hardening and softening stages. For the bridge models of the example bridges, two different uniaxial material models in OpenSees material library are considered. The uniaxial material named Steel02 and ReinforcingSteel are shown in Figure 3.7(a) and Figure 3.7(b), respectively. In ReinforcingSteel model, the yield point is defined by the expected yield strength of the steel, $f_{y e}$. The length of the yield plateau is a function of the steel strength and bar size. The strain-hardening curve in ReinforcingSteel is a parabola with an initial stiffness defined as $E_{s h}$ and terminating at ultimate tensile strain $\varepsilon_{s u}$. The parameters provided by CalTrans [63] can be found in Table 3.3.

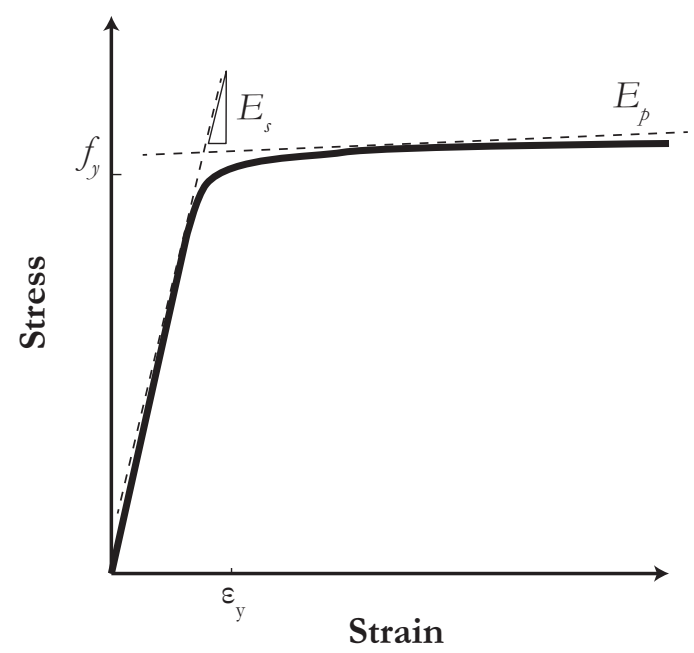

(a) Steel02

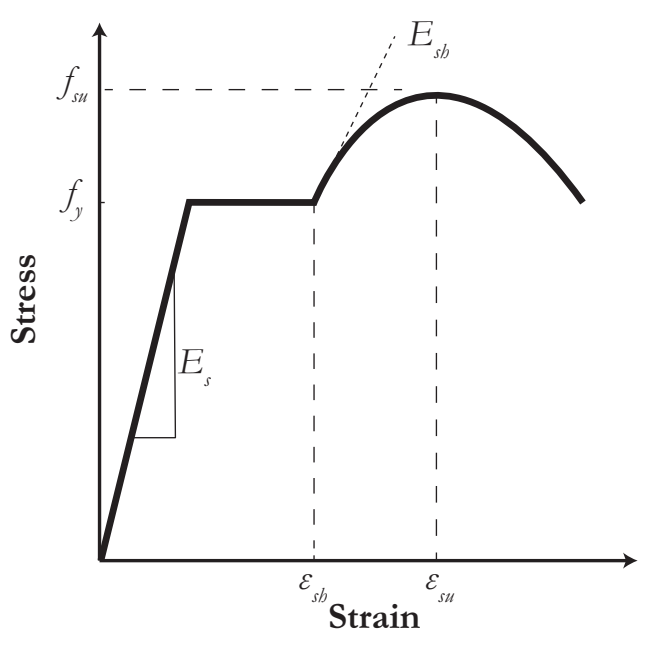

(b) ReinforcingSteel

Figure 3.7: Steel02 and ReinforcingSteel Stress-Strain Model in OpenSees

The Steel02 model is based on a Giuffre-Menegotto-Pinto Model. This model is characterized by the initial stiffness and post-yield stiffness which is a proportion of the initial stiffness. The model includes the Baushinger effect considering the stiffness degradation under cyclic load and the isotropic hardening option for tension and compression. 
Table 3.3: Properties of Reinforcing Steel in OpenSees Model

\begin{tabular}{|l|c|l|c|}
\hline Modulus of Elasticity & $E_{s}=200000 \mathrm{MPa}$ & Expected Yield Strength & $f_{y}=420 \mathrm{MPa}$ \\
\hline Expected Tensile Strength & $f_{u e}=655 \mathrm{MPa}$ & Expected Yield Strain & $\varepsilon_{y e}=0.0023$ \\
\hline Onset of Strain Hardening & $\varepsilon_{s h}= \begin{cases}0.0125 & \# 9 \\
0.0115 & \# 11 \\
0.0075 & \# 14 \\
0.0050 & \# 18\end{cases}$ & Ultimate tensile strain & $\varepsilon_{s u}= \begin{cases}0.120 \leq \# 10 \\
0.090 & \geq \# 11 \\
\hline\end{cases}$
\end{tabular}

As noted by Jeong [12], it can predict the basic material response accurately but ignores the initial yielding plateau or the degradation of the steel strength.

The uniaxial stress-strain behavior for confined and unconfined concrete in the bridge piers are represented by Mander's model [64]. As specified by CalTrans [63], the effective secant modulus of elasticity $E_{c}$ is taken as equal to:

$$
E_{c}= \begin{cases}w_{c}^{1.5}(0.043) \sqrt{f_{c}^{\prime}} & \mathrm{MPa} \\ w_{c}^{1.5}(33) \sqrt{f_{c}^{\prime}} & \mathrm{psi}\end{cases}
$$

The concrete is commonly modeled by Concrete01 and Concrete02, as shown in Figure 3.8(a) and Figure 3.8(b). The Concrete01 constructs a Kent-Scott-Park concrete material with degraded linear unloading stiffness. This model does not consider the tensile strength of the concrete. Concrete02, on the contrary, accounts for the tension strength. Thus, this concrete model is capable of modeling the initial cracking of the cover concrete. However, a more accurate model requires more parameters to define its constitutive model.

Increase in strength and corresponding increase in strain are considered in Mander's concrete model [64] to account for the effect of confinement to concrete material properties in the modeling of the bridge pier response.

A sensitivity study presented in a later section provides details on study carried 


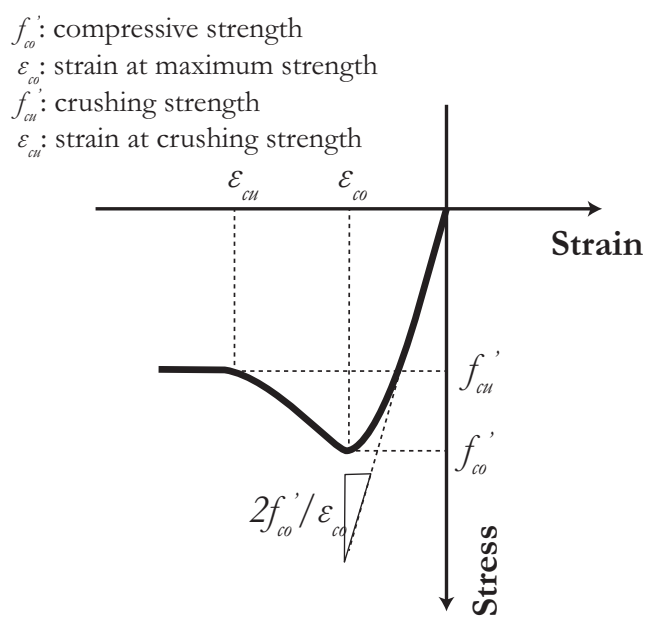

(a) Concrete01

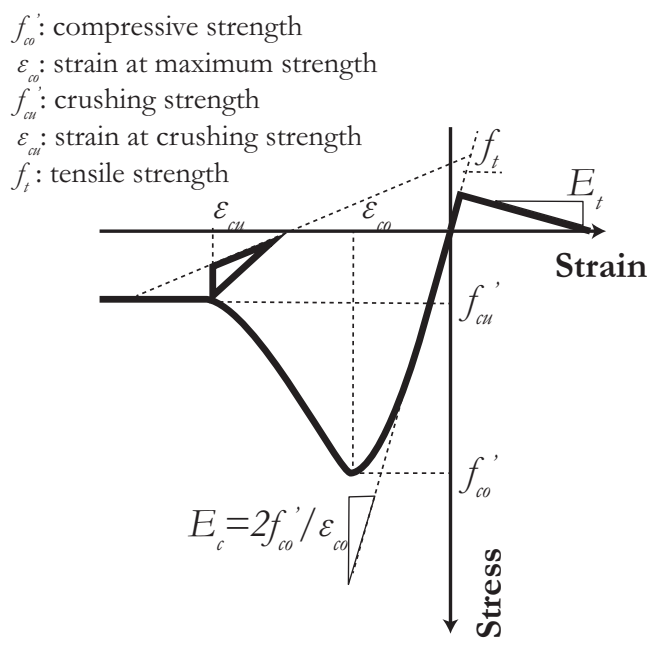

(b) Concrete02

Figure 3.8: Concrete 01 and Concrete 02 Stress-Strain Model in OpenSees

out to determine which material models are proper for the current research. The recommended material properties for the example bridges can be determined from the sensitivity study and they are shown in Table 3.4.

\subsubsection{Modeling of Superstructure}

The superstructure consists of the bridge deck and a support system for the deck spanning piers or bents. The bridge superstructure is expected to remain essentially elastic during earthquakes due to it being protected by the capacity design $[2,60]$. Thus, nonlinear modeling considerations are concentrated on the joints and connections to the supporting bents where plastic hinges are likely to occur. In this study, the superstructure is modeled as a spine with beam elements located at the centroid of the cross section along the length of the bridge.

The decks of the example bridges in this study are prestressed concrete slabs. The

cross-sectional area $A$, the torsional moment of inertia $J$, and the second moment of area about the horizontal axes $I_{z z}$ and $I_{y y}$ are calculated automatically using Section Designer 
Table 3.4: Material Properties in Models

\begin{tabular}{|c|c|c|c|c|}
\hline Parameter & M1 & M2 & M3 & M4 \\
\hline \multicolumn{5}{|l|}{ Piers } \\
\hline Concrete Model & Concrete 01 & Concrete01 & Concrete 01 & Concrete 01 \\
\hline Cover & 34.5 & 31.0 & 27.6 & 27.6 \\
\hline Confined & 55.2 & 38.6 & 39.9 & 41.0 \\
\hline Cover & 2.0E-03 & 2.0E-03 & $2.0 \mathrm{E}-03$ & $2.0 \mathrm{E}-03$ \\
\hline Confined & $8.3 \mathrm{E}-03$ & $4.5 \mathrm{E}-03$ & $6.1 \mathrm{E}-03$ & 7.1E-03 \\
\hline Cover & 0.0 & 0.0 & 0.0 & 0.0 \\
\hline Confined & 33.1 & 31.6 & 23.9 & 37.9 \\
\hline Cover & $5.0 \mathrm{E}-03$ & $5.0 \mathrm{E}-03$ & $5.0 \mathrm{E}-03$ & $5.0 \mathrm{E}-03$ \\
\hline Confined & $2.3 \mathrm{E}-02$ & $1.2 \mathrm{E}-02$ & $1.9 \mathrm{E}-02$ & $1.5 \mathrm{E}-02$ \\
\hline \multirow{2}{*}{$\begin{array}{l}\text { Steel Model } \\
\qquad F_{y}^{\dagger}\end{array}$} & Steel02 & Steel02 & Steel02 & Steel02 \\
\hline & 455.1 & 455.1 & 455.1 & 386.1 \\
\hline $\mathrm{b}$ & 0.01 & 0.01 & 0.01 & 0.01 \\
\hline \multicolumn{5}{|l|}{ Deck } \\
\hline Concrete Model & Concrete 01 & Concrete01 & Concrete01 & Concrete 01 \\
\hline$f_{c}^{\prime \dagger}$ & 34.5 & 34.5 & 34.5 & 34.5 \\
\hline
\end{tabular}

in SAP2000. As discussed by Priestley et al. [2], the pre-stressed decks are modeled with gross section properties.

In multi-pier bent bridges, the piers are connected using rigid elements at the top in the transverse direction. These rigid elements are connected to nodes at the top of the column and extended to the center of the beam-column joint using link elements. The maximum bending moment at the top of the column is examined as a critical response quantity for the understanding of the dynamic response and performance of the bridge. The connections between the piers and the superstructure are considered to be rigid. 


\subsubsection{Modeling of Piers}

During severe earthquakes, the conventionally designed piers can achieve large inelastic deformations with significant residual deformations. To capture the nonlinear behavior of the piers, they are modeled using nonlinear elements with fiber sections. The basic modeling approach followed in this study uses force-based fiber-section elements with distributed plastic hinges to model the bridge piers. The effect of local stiffness degradation is captured with sectional moment curvature analysis based on layered member cross section. The cross section is represented by an assemblage of longitudinally oriented, unidirectional steel and concrete fibers [12]. For modeling the columns, the effect of bar pullout from base is not considered.

\subsubsection{Material and Fibers in Cross Section}

The concrete piers are modelled using fiber sections. The fiber section comprises of reinforcing steel fibers and concrete fibers. The concrete fibers inside and outside of the confined region are modeled with different properties for confined and unconfined concrete. The confined concrete parameters are calculated according to Mander's model. The stress-strain of Mander's confined concrete model is presented by Equation 3.5 [64].

$$
\begin{gathered}
f_{c c}^{\prime}=f_{c o}^{\prime}\left(-1.254+2.254 \sqrt{1+\frac{7.94 f_{l}^{\prime}}{f_{c o}^{\prime}}}-2 \frac{f_{l}^{\prime}}{f_{c o}^{\prime}}\right) \\
\varepsilon_{c c}=\varepsilon_{c o}\left[1+5\left(\frac{f_{c c}^{\prime}}{f_{c o}^{\prime}}-1\right)\right] \\
f_{l}^{\prime}=\frac{1}{2} k_{e} \rho_{s} f_{y h} \\
k_{e}=\frac{1-\frac{s^{\prime}}{2 d_{s}}}{1-\rho_{c c}} \\
\rho_{s}=\frac{4 A_{s p}}{d_{s} S}
\end{gathered}
$$


where $f_{c o}^{\prime}$ and $\varepsilon_{c c}^{\prime}$ are compressive strength and corresponding strain for the unconfined concrete, respectively; $f_{l}^{\prime}$ is the effective lateral stress which can be calculated per Equation 3.7; $k_{e}$, shown in Equation 3.8, is the confinement effectiveness coefficient; $s$ is the the clearance between spiral bars; $d_{s}$ is the the diameter of spiral; $\rho_{c c}$ is the ratio of area of longitudinal reinforcement to area of core section; $\rho_{s}$ is the ratio of the volume of transverse confinement to that of the confined concrete core; $A_{s p}$ is the area of spiral; $s$ is the spiral spacing; $f_{y h}$ is the yielding strength of transverse reinforcement.

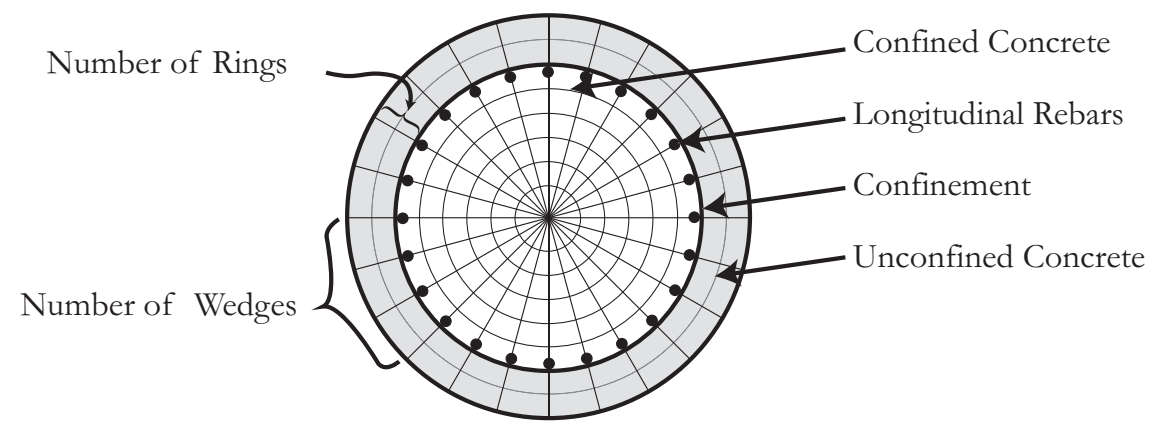

Figure 3.9: Fiber Section Model in OpenSees

As shown in Figure 3.9, the cross-section of the pier can be divided into three parts: confined concrete area, unconfined concrete area and longitudinal bar area. The concrete region is discretized into smaller rings and wedges. The proper amount of rings and wedges is chosen based on the sensitivity study discussed in Section 3.2.4.3.

\subsubsection{Element Configuration}

Two modeling strategies are mainly used for modeling nonlinear concrete columns. One method distributes plastic hinges along the whole element, and the other method concentrates plasticity within a region where nonlinear deformation occurs.

The columns using these two strategies are idealized according to bridge geometry and SDC (Seismic Design Criteria) [63]. The column bottom and top ends are connected to the centroid of the foundation and superstructure centroid with rigid offsets, 
respectively.

Distributed plasticity elements may be modeled using the forceBeam Column element in OpenSees. The moment-curvature response, as well as axial load and deformation, at each integration point along the member is determined from the fiber section assigned to the element. The number of integration points is a critical parameter of this type of element. On the other hand, instead of distributing plasticity throughout the element, beam WithHinges element limits nonlinear constitutive behavior within the user-defined regions at the ends of the element. The remainder of the element behaves elastically using the element's effective stiffness. This element only has integration points within the hinge regions and two points per hinge are able to predict the curvature distribution accurately. The controlled parameters of this element are plastic hinge lengths and effective stiffness of the elastic part of the column. In the sensitivity analysis, the plastic hinge length is calculated by Equation 3.10 according to Bae et al. [65].

$$
\frac{l_{p}}{h}=\left[0.3\left(\frac{P}{P_{o}}\right)+3\left(\frac{A_{s}}{A_{g}}\right)-0.1\right]\left(\frac{L}{h}\right)+0.25>0.25
$$

where $h$ is the depth of the pier; $P_{o}=0.85 f_{c}\left(A_{g}-A_{s}\right)+f_{y} A_{s}$ is the nominal axial load capacity according to ACI; $A_{s}$ is the total area of tension reinforcement; $L$ is the distance from critical section to the point of the contra-flexure.

The schematic drawings for both of these two modeling strategies are shown in Figure 3.10. 


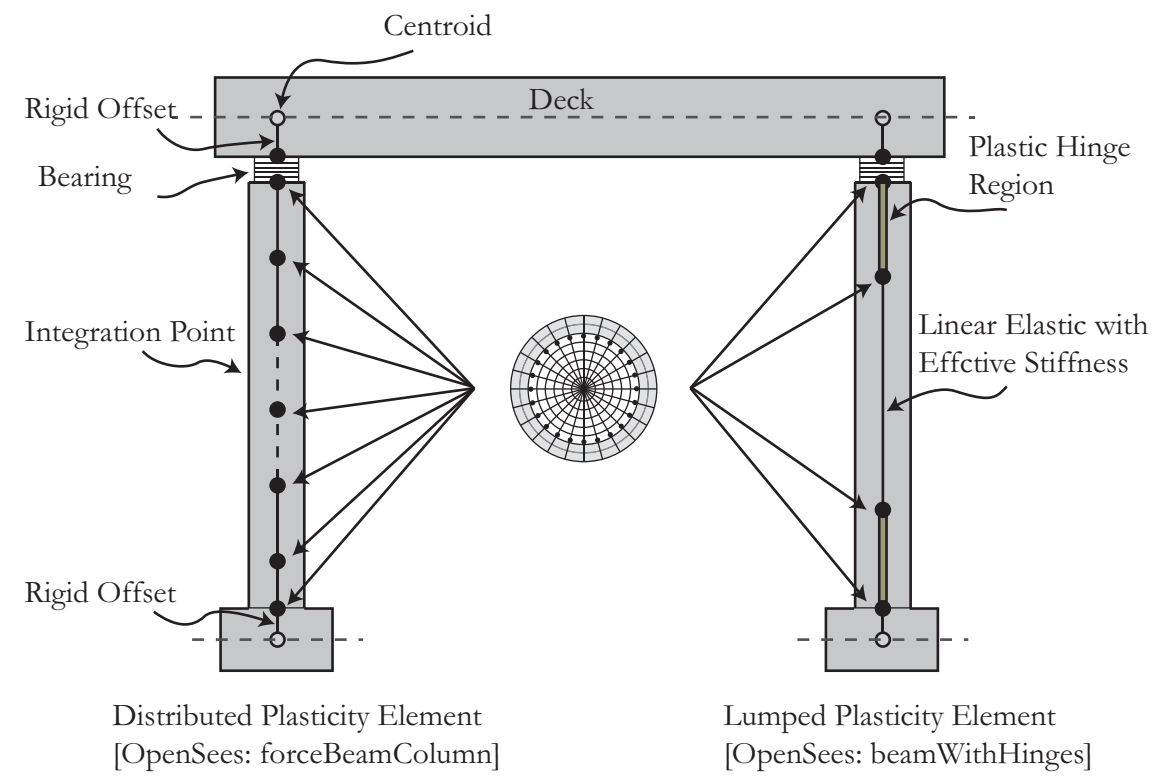

Figure 3.10: Column Element Model in OpenSees

\subsubsection{Sensitivity Study}

The selection of material constitution and plasticity distribution should avoid the convergence problem under either pushover or dynamics analysis. Thus, a sensitivity study is conducted to determine the best bridge pier modeling strategies. The piers in M1 is selected as the specimen in the sensitivity study. The parameters involved in the parametric experiment include the number of fibers in the cross-section, the number of elements in the pier, concrete and reinforcing steel material types. The concentrated plasticity model may cause convergence problem under some analyses as shown by Zadeh et al. [66]. Therefore, distributed plasticity model is used for the bridge column in this study.

The Phase- 1 in the parametric study aims to specify a minimum number of rings and wedges required to represent the confined and unconfined concrete properly. Comparison is made using moment-curvature relationship for all parameter combinations. 
Table 3.5: Parameters in the Parametric Study

\begin{tabular}{|c|c|c|c|c|c|c|c|c|c|c|c|c|c|}
\hline \multirow{2}{*}{ Phase } & \multirow{2}{*}{ Test } & \multirow{2}{*}{ No. } & \multicolumn{2}{|c|}{ Parameters } & \multirow{2}{*}{ Phase } & \multirow{2}{*}{ Test } & \multirow[t]{2}{*}{ No. } & \multirow{2}{*}{$\begin{array}{l}\text { Parameters } \\
\text { Element \# }\end{array}$} & \multirow{2}{*}{ Phase } & \multirow{2}{*}{ Test } & \multirow{2}{*}{ No. } & \multicolumn{2}{|c|}{ Parameter } \\
\hline & & & Rings & Wedges & & & & & & & & Concrete & Steel \\
\hline \multirow{5}{*}{1} & \multirow{5}{*}{ Fiber \# } & $1-1$ & 1 & 4 & \multirow{5}{*}{2} & \multirow{5}{*}{ Element \# } & $2-1$ & 1 & \multirow{5}{*}{3} & \multirow{5}{*}{ Material } & 3-1 & C1 & S1 \\
\hline & & $1-2$ & 2 & 8 & & & $2-2$ & 3 & & & $3-2$ & $C 1$ & S2 \\
\hline & & $1-3$ & 4 & 16 & & & $2-3$ & 5 & & & 3-3 & $C 2$ & S1 \\
\hline & & $1-4$ & 8 & 32 & & & $2-4$ & 7 & & & $3-4$ & $C 2$ & S2 \\
\hline & & $1-5$ & 10 & 10 & & & $2-5$ & 9 & & & & & \\
\hline
\end{tabular}

Figure 3.11(a) shows that the section stiffness and strength from Test 1-1 to Test 1-4 increase when increasing the total number of the fibers. The computing time also increases following the increase in the number of section fibers in the model. In the study, it is determined the optimal number of rings and wedges is selected as 10, which give accurate converged results without excessive computing time. 


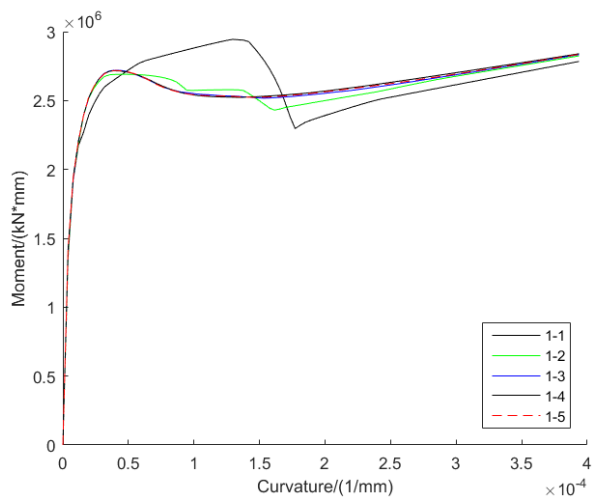

(a) Phase-1 Results

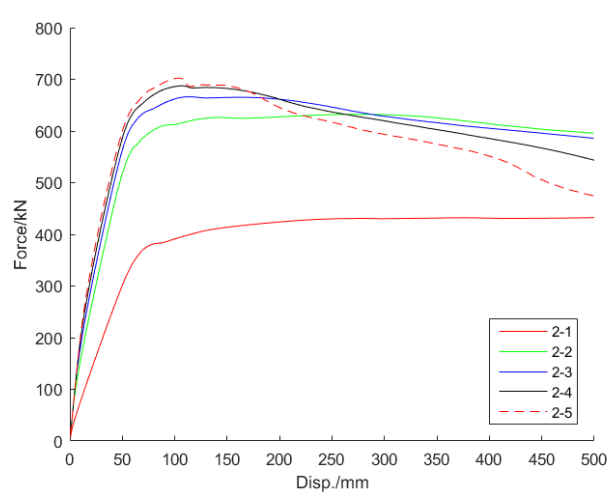

(b) Phase-2 Results

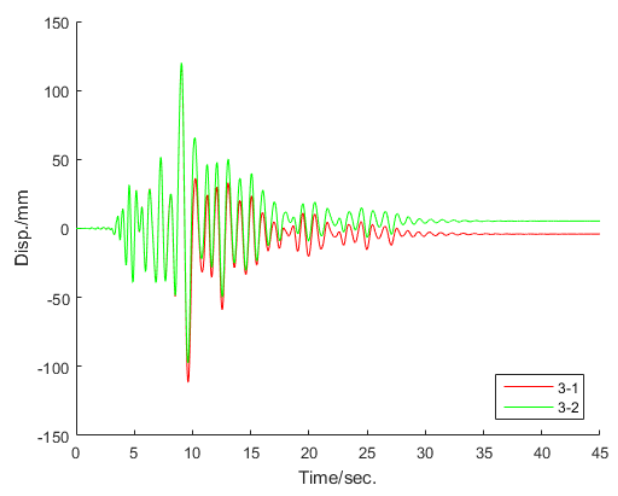

(c) Phase-3 Results

Figure 3.11: Parametric Study of Concrete Pier

Once the optimum configuration of cross-section is determined, pushover analysis is carried out in Phase-2 to determine the most suitable element type and configuration for modeling the bridges. As mentioned previously, the concentrated plasticity element raises convergence issues. Therefore, the preferred element type is the element with distributed plasticity. For the distributed plasticity element, both the stiffness and strength of the cantilever pier are found to converge when the number of elements used in the model is over five. As shown in Figure 3.11(b), the piers in Test 2-3 and Test 2-4 have very close pushover curves. Considering common modeling suggestions and the results of the sensitivity study, the bridge piers are discretized into at least five elements. 
With the proper fiber and element configuration, the effect of different material types is investigated in Phase-3 of the parametric sensitivity study. Under moderate dynamic loads, the cantilever piers in Test 3-1 and 3-2 exhibit almost identical responses. When exposed to a more intensive excitation, the cantilever piers with Concrete01 but different steel materials have same peak displacement $(119 \mathrm{~mm})$ and close residual deformations at the top. However, it is obvious that the residual deformations in Test 3-1 and Test 3-2 are in opposite direction as shown in Figure 3.11(c). From this perspective, either Steel02 or ReinforcingSteel is suitable for modeling the piers. It is noticed that the computing time for Test 3-1 is half of that for Test 3-2. Some convergence problems are encountered in Test 3-3 and Test 3-4. Thus, Concrete01 and Steel02 are recommended material in this study.

\subsubsection{Modeling of Abutment}

Abutments are earth-retaining systems giving traffic access to and from the bridge. An abutment system usually consists of back walls, wing walls, shear keys, bearing pads, and piles supporting the seats. Abutments are massive structures mobilizing and interacting with massive soils. The higher stiffness of abutments, due to their larger size and geometry compared with bridge bents, attracts higher seismic forces. The gap between the abutment and superstructure are necessary to allow temperature, creep and shrinkage movements. Under longitudinal seismic response, after the gap has been closed, high stiffness and resistance are provided by the abutment to resist bridge deck movement. Consequently, properly designed abutments can be economical means for inertial resistance [60].

Including the abutment behavior, soil-structure interaction, and embankment flexibility, the prediction of the entire bridge system seismic response can be complicated. Modeling assumptions and the choice of abutment models could have a significant effect 
on the response of the bridge. There are three commonly adopted models for abutments, such as the roller abutment model, simplified abutment model and spring abutment model. Usually, abutment capacity and stiffness characteristics are predicted based on empirical relations. Vishunuthan [1] adopts a roller abutment model to estimate the lower bound of longitudinal and transverse resistance of the bridges. Kaviani et al. [67] model the abutment with five nonlinear springs with gap elements.

The abutments of the example bridges are seat-type abutments with exterior shear keys. Thus, the spring abutment model is adopted to model the longitudinal response of the backfill and the expansion joint, and the transverse response of the exterior shear keys. The effects of the bearing pads, pile groups and wingwalls are ignored due to their limited contributions to the overall response and failure modes of the structure [67]. The longitudinal behavior of abutment is represented by nonlinear springs with gap elements as shown in Figure 3.12(a). The initial stiffness $K_{a b u t}$ and capacity $P_{b w}$ of the abutment in the longitudinal direction are determined based on CalTrans' [63] recommendations:

$$
\begin{gathered}
K_{a b u t}=K_{i} \times w \times \frac{h_{b w}}{1.7}(\mathrm{~m}, \mathrm{kN}) \\
P_{b w}=A_{e} \times 239 \mathrm{kPa} \times \frac{h_{b w}}{1.7}(\mathrm{~m}, \mathrm{kN})
\end{gathered}
$$

where $K_{i}$ is the initial embankment fill stiffness; $w$ is the width of the backwall; $h_{b w}$ is the height of the backwall; $A_{e}$ is effective wall area. According to CalTrans [63], $K_{i}$ is taken as $14.35 \mathrm{kN} \mathrm{mm}^{-1}$

The expansion joints accommodate movements induced by concrete shrinkage and creep, shortening produced by pretensioning, thermal variations, seismic loads and so on [61]. The seismic movements are usually not explicitly considered in their design due to the uncertainties in prediction of the seismic displacement demand, and the increasing costs concerning large displacements. As recognized by [61], the shrinkage shortening 
and thermal displacements can be determined by Equation 3.15 if the skew of the structure is ignored.

$$
\begin{gathered}
\Delta_{\text {shrink }}=\beta \mu L_{\text {trib }}(1000 \mathrm{~mm} / \mathrm{m}) \\
\Delta_{\text {temp }}=\alpha L_{\text {trib }} \delta T(1000 \mathrm{~mm} / \mathrm{m}) \\
\Delta_{\text {gap }}=0.6 \times \frac{\Delta_{\text {shrink }}+\Delta_{\text {temp }}}{0.45}
\end{gathered}
$$

where $L_{t r i b}$ is the length of structure subjected to shrinkage or thermal variation; $\beta$, ultimate shrinkage strain, is estimated as $0.0002 ; \mu$, accounting for restraining effect imposed by structural elements, is estimated as 0.5 for prestressed concrete slab; $\alpha$ is the coefficient of thermal expansion; $\delta T$ is the temperature variation.

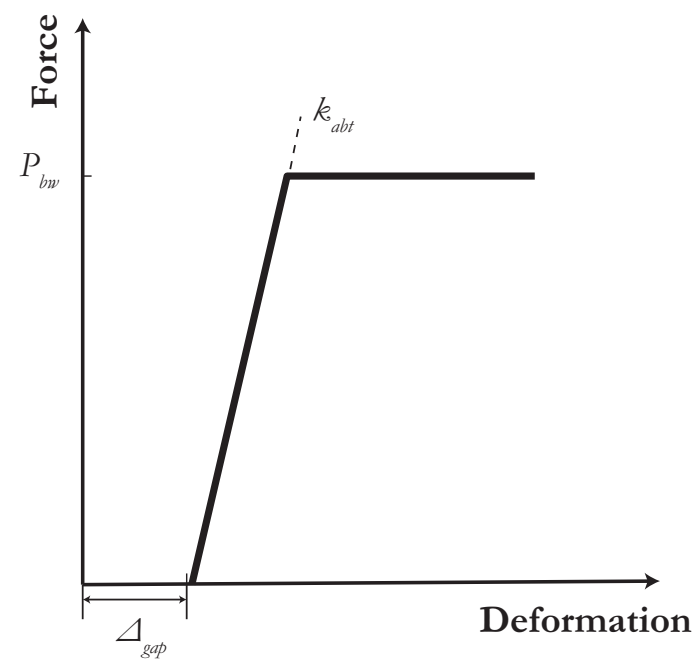

(a) Longitudinal response of abutment

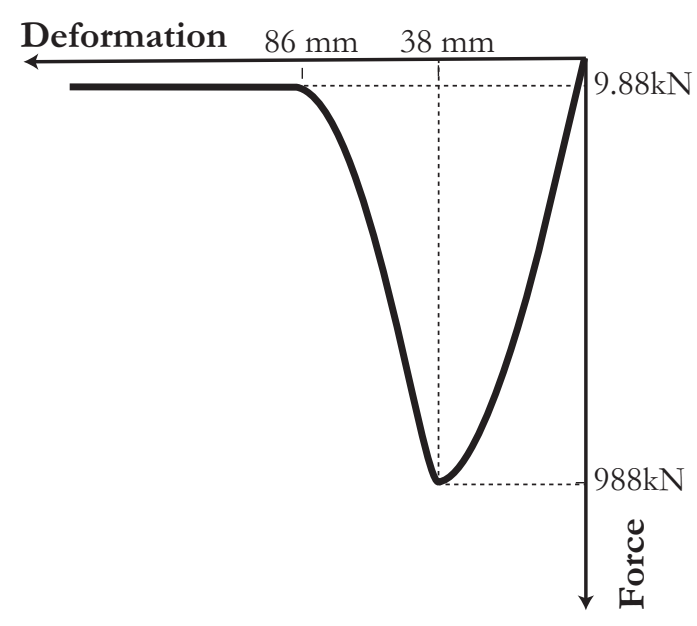

(b) Transverse response of abutment

Figure 3.12: Abutment Behaviour

According to SDC [63], the shear key design in seismic zones has two different assumptions: (1) shear keys remain intact; (2) shear keys fail completely. The shear keys are supposed to fail since the bridges are subjected to MCE level ground motions. Megally et al. [68] has conducted laboratory experiments on exterior shear keys to obtain 
comparison information on the difference between the actual strengths and the design values. The shear key's dimensions and force-displacement relationship from the test are shown in Figure 3.13. This shear key performs as a structural fuse and prevent further damage in the abutment during the tests. The failure mechanism follows the strut-andtie analogous model where the lateral load is transferred to the footing by a diagonal compressive strut [68]. Due to lack of details available of the example bridges, the shear keys capacity and corresponding deformation are assumed according to the experiment data presented by Megally et al. [68] considering their similar dimensions. The constitutive behavior of the exterior shear key is represented by the no tensile strength concrete (Concrete01) model, as shown in Figure 3.12(b), considering it can only take compressive load.

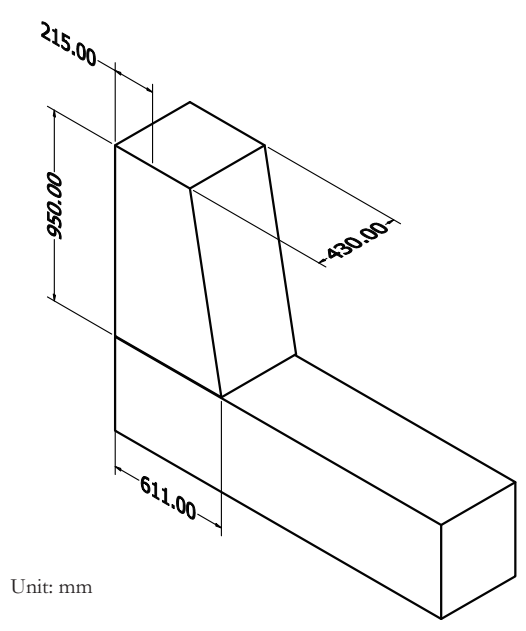

(a) Schematic Drawing of Shear Key

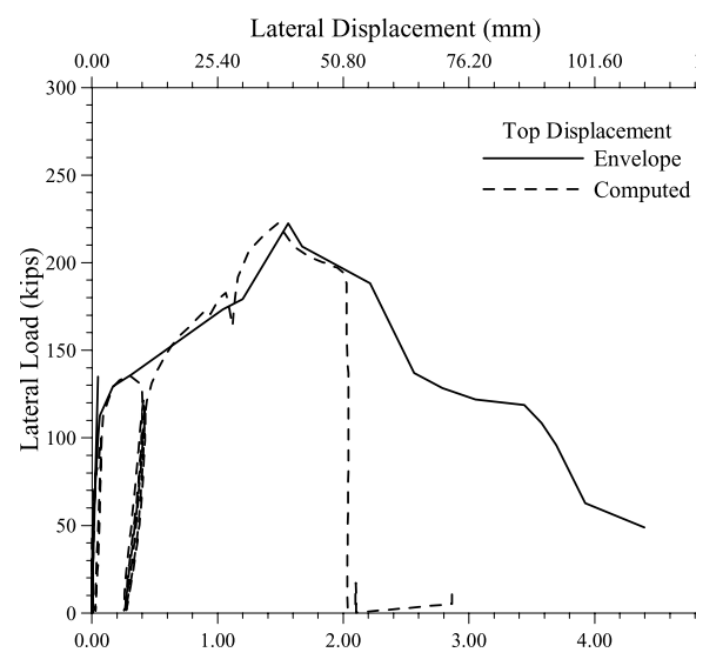

(b) Load-Deformation Response of Shear Key

Figure 3.13: Shear Key Properties [from [68]]

\subsubsection{Modeling of Self-centering Braces}

Erochko et al. [13] has developed a self-centering hysteresis model as a uniaxial material for OpenSEES [22]. This material is capable of modeling the external fuse and 
the bearing effect due to the limited deformation capacity. The constitutive behavior of the self-centering material model is shown in Figure 3.14. Its behavior is characterized by the following parameters:

- Activation force, $P_{a}$;

- Energy dissipation capacity parameter, $\beta$;

- Initial stiffness, $k_{1}$ and post-activation stiffness $k_{2}$;

- Slip deformation, $\varepsilon_{s l i p}$

- Total deformation that cause the external fuse to bear;

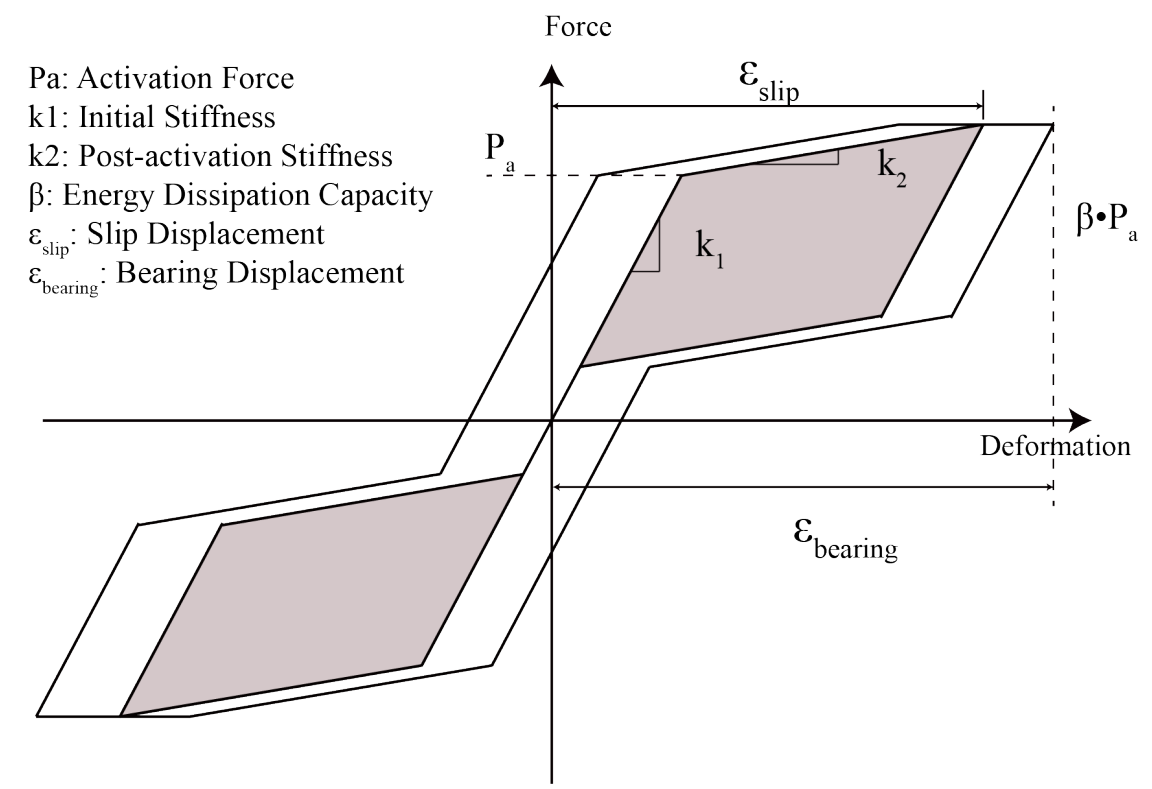

Figure 3.14: SCED Brace Hysteresis

In this research, no external fuse is considered for simplicity, therefore, the hysteretic response of the SCED brace is only affected by the parameters $k_{1}, k_{2}, P_{a}$ and $\beta$. The initial stiffness is controlled by the steel members and the tendons. As previously discussed, several different devices can be implemented in a SCED to dissipate energy. 
The friction mechanism is attractive given that it is easy to control the slip force and remains undamaged under cyclic loads. The parameter $\beta$ indicates the internal friction force magnitude, which is controlled by the friction pad and high strength steel bolts providing normal force.

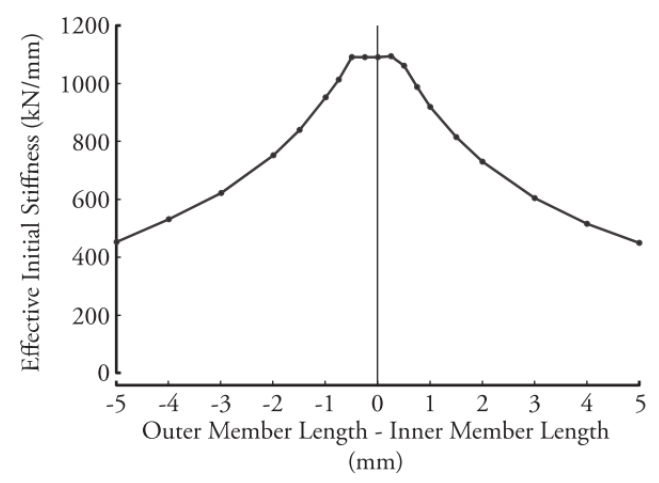

(a) Effect of Member Length Difference on Effective Initial Stiffness (from [13])

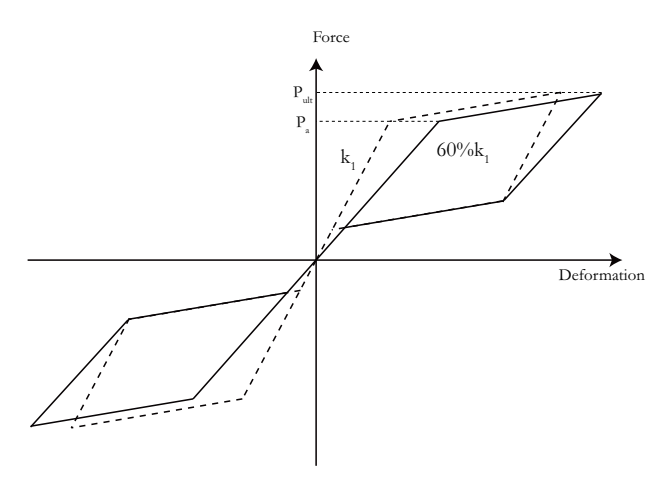

(b) Initial Stiffness Reduction

Figure 3.15: Effective Initial Stiffness of SCED Brace

As noted by Erochko et al. [13], the realistic $k_{1}$ is lower than the theoretical calculated value by Equation 2.2 even with identical length members and perfect fabrication. For a force-based design which relies on the structure period estimation, it is important the designer uses a realistic value of the initial stiffness instead of the value obtained using theoretical model [13]. As such, effective initial stiffness should be used in modeling of the SCED brace. The reduction of the initial stiffness should consider the effects of length differences and fabrication conditions. The increasing axial member difference reduces the effective initial stiffness rapidly as it is shown in Figure 3.15(a). For instance, a $5 \mathrm{~mm}$ difference in length decreases the initial stiffness by approximate $60 \%$ from the highest possible value. Figure 3.15(a) reveals that the length difference less than $0.5 \mathrm{~mm}$ does not decrease initial stiffness. The effective initial stiffness of the SCED brace is suggested to be reduced by $40 \%$ from the theoretical value while $P_{a}, k_{2}$ and $\beta$ remain the 
same as shown in Figure 3.15(b). 


\section{Chapter 4: Generation of Ground Mo- tion Time Histories}

For earthquake design and evaluation of structures, analysis of the response behavior and performance of structures can be carried out by two approaches: 1) time history analysis using recorded or simulated ground motions as direct input to the analyzed structures; or 2) response spectrum method of which the input excitation is represented by the response spectrum of acceleration or displacement of the design ground motion. Since the response spectrum method is based on linear elastic analysis of structures, it is primarily suitable for force-based design of structures for earthquake resistance which relies on the use of modification factors, such as the force modification factor or ductility factor to approximately account for the nonlinear behavior of structures during strong earthquakes. Because of this limitation, the response spectrum method is not appropriate for analysis of structures which undergo severe inelastic cyclic responses during strong shaking of major earthquakes due to possible deterioration of strength and stiffness resulting from accumulated damage, or structures that are irregular, or have higher mode effect, etc [69]. As a result, the nonlinear response history analysis (RHA), which requires a suitable set of acceleration time history records as seismic excitation, is employed in this study.

In the present study, appropriate selected acceleration records from previous earthquakes are scaled to the same level of design spectrum considered for the example bridge. 
As noted by Boomer and Acevedo [69], there are three basic methods to obtain acceleration records for nonlinear response history analysis. The first one is using software, such as SIMQKE [70], to generate artificial accelerations that are compatible with the design spectrum that represents the seismicity at the location of the design structure. As a result, the generated artificial earthquake records can be expected to closely match the original design spectrum and there is no need to scale them. Another attraction of this method is that it can generate records for sites which do not experience many earthquakes of different intensities, only having limited actual earthquake record data suitable for use at the sites; however, applying these records, especially for nonlinear RHA, can be problematic since these strong motions may typically possess unreasonably high energy content because the design spectrum is not equivalent to the input from a single earthquake, but rather the envelope upper bound function of the energy content from multiple earthquakes that affect the design structure. The second method is directly generating synthetic acceleration records based on seismological source models. In this approach, assumptions are made on path and site effects and source model. The parameters required to characterize the earthquake source have high uncertainty and sensitivity. This method is typically used for sites located in regions where there are well known and identified earthquake faults or sources with ample information from observations of previous or continuing seismic activities or theoretical seismological source models. The third method is using earthquake records from past earthquakes. Several databases have been established by researchers [71-73]. For instance, COSMOS and PEER are two earthquake record databases of strong-motion data from worldwide locations.

In FEMA P695 [74], the ground motion records are obtained from PEER NGA Database. These records are categorized into Far-Field (FF) and Near-Field (NF) sets which will be scaled to the target spectrum using modal-pushover-based scaling (MPS) method proposed by Kalkan et al. [75]. The selection criteria are explained in FEMA P695 [74]. 
In this study, a subset of the FEMA Far-Field and Near-Field records are used as input excitations for the example bridges. For each type of ground motion, records recorded during ten different earthquakes are selected to assemble the subset. These earthquakes occurred at different locations and have different magnitudes. Each record has two horizontal components. The component with larger PGA is denoted as C1 and the other component is denoted as $\mathrm{C} 2$. By assigning one component into the longitudinal direction and the other into the transverse direction, 20 records can be produced for each subset. The properties of the selected ground motions are shown in Table 4.1. The magnitudes of records in Far-Field Set vary between M6.5 and M7.6 with M7.0 in average. The average site-source distance is $16.4 \mathrm{~km}$. The Set-NF consists of 20 records with pulse characteristics in the motion records. The pulse-like records have magnitudes from M6.5 to M7.9 with M7.0 in average. The average site-source distance is $4.2 \mathrm{~km}$. The duration of each ground motion record is determined based on the Arias intensity [76]. The Arias intensity is defined as:

$$
A I=\frac{\pi}{2 g} \int_{0}^{t_{r}} a^{2}(t) d t
$$

where $a(t)$ is the acceleration time-history, $t_{r}$ is the total duration of the accelerogram and $g$ it the gravity acceleration. Over the duration, the Arias intensity accumulates from $5 \%$ to $95 \%$ of the total integral.

\subsection{Modal Pushover Based Scaling}

As noted by Kalkan et al. [75], the intensity scaling method of ground motions is more appropriate than spectral matching techniques in performance-based design and evaluation methodologies. Records scaled by intensity-based scaling methods can facilitate accurate and efficient RHA. However, the intensity scaling methods, such as peak 
ground acceleration, Arias intensity and effective peak ground velocity, do not generally consider the structural properties. This drawback may raise problems for structures experiencing large nonlinearity or responding significantly in higher vibration modes [75].

Improved intensity based scaling methods have been proposed by considering the elastic response of the structure in the scaling procedure. These improved scaling methods provide better results, but they still do not take into consideration the inelastic response of structures. This is important because most structures are expected to experience inelastic actions as means to dissipate seismic energy during strong shaking of earthquakes. Furthermore, these preceding intensity scaling methods are not suitable for scaling near-fault ground motion records because of the high energy pulse characteristics of these records which can induce much higher inelastic deformation than typical farfield records. To achieve a better results on the estimate of median engineering demand parameters (EDP) and their dispersion, several researchers (e.g. [77,78]) have proposed new scaling methods based on inelastic deformation spectrum. 


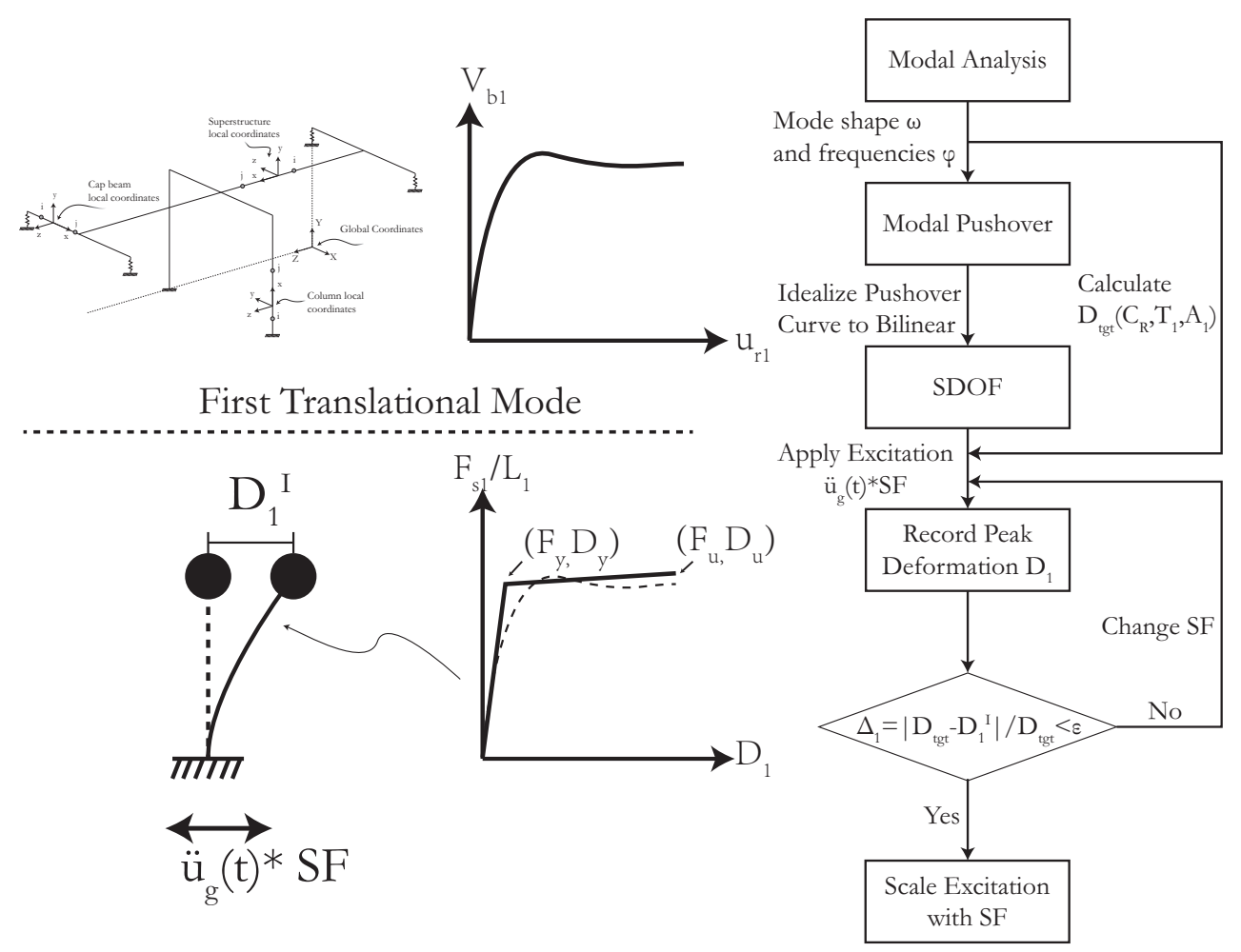

Figure 4.1: Modal Pushover Scaling (MPS) Procedure

This research employs a new convenient scaling method, the model-pushover-based scaling method (MPS), which explicitly considers the structure strength for evaluating existing structures and designing new structures. The full scaling procedure, as shown in Figure 4.1, is explained in detail by Kalkan et al. [75]. The scaling procedure is briefly summarized as follows:

1. Determine the target pseudo-acceleration response spectrum. In this study, the spectrum at the seismic hazard level of $2 \%$ in 50 years for Victoria, BC provided by NBCC 2015 [79] is selected as the target spectrum.

2. Conduct modal analysis of the original structure to get frequencies $\omega_{1}$ (or periods $T_{1}$ ) and mode shapes $\phi_{1}$ of the first mode. Since the scaling steps for different modes are similar, the first-mode-based scaling is illustrated here for clarity and simplicity. Besides, the longitudinal displacement of any node along the deck can 
be the roof considering the great rigidity of the deck.

3. Conduct modal pushover analysis of the original structure and develop pushover curve $V_{b 1}-u_{r 1}$. The force distribution used in the modal pushover analysis is defined as:

$$
s_{1}^{*}=\boldsymbol{m} \phi_{1}
$$

where $\boldsymbol{m}$ is the structural mass matrix and $\phi_{1}$ is the fundamental mode shape.

4. Convert the pushover curve $V_{b 1}-u_{r 1}$ to the force-deformation $F_{s 1} / L_{1}-D_{1}$ relation of the first-mode SDOF system. The conversion can be achieved by utilizing the following equations:

$$
\begin{gathered}
F_{s 1} / L_{1}=\frac{V_{b 1}}{M_{1}^{*}} \\
D_{1}=\frac{u_{r 1}}{\Gamma_{1} \phi_{r 1}}
\end{gathered}
$$

where $M_{1}^{*}$ and $\Gamma_{1}$ are the effective mass and modal participation factor of the first mode, respectively. $\phi_{r 1}$ is the value of $\phi_{1}$ at the roof.

5. Idealize the pushover curve $F_{s 1} / L_{1}-D_{1}$ using a bilinear curve characterized by $D_{y}, F_{y}, D_{u}$ and $F_{u}$ as shown in Figure 4.1. The period of the SDOF $T_{1}$ can be determined as:

$$
T_{1}=\sqrt{\frac{F_{y}}{D_{y}}}
$$

The yield-strength reduction factor can be determined as:

$$
R_{y}=\frac{M_{1}^{*} \bar{A}_{1}}{V_{b 1 y}}=\frac{\bar{A}_{1}}{F_{y}}
$$

6. Determine the target value of deformation $\bar{D}_{1}^{I}$ for the first-mode inelastic SDOF 
system. The target deformation $\bar{D}_{1}$ can be calculated as the following equations:

$$
\begin{aligned}
& D_{t g t}=C_{R} \bar{D}_{1} \\
& \bar{D}_{1}=\bar{A}_{1} \frac{T_{1}{ }^{2}}{2 \pi}
\end{aligned}
$$

where $\bar{A}_{1}$ is the target spectral acceleration at $T_{1}$ and $C_{R}$ is the empirical equation concerning $R_{y}$ explained in [80].

7. Subject the SDOF system to the ground motion scaled by $S F$ and record the peak deformation $D_{1}^{I}=\max \left|D_{1}(t)\right|$. Change $S F$ in the iterations until the normalized difference $\Delta_{1}$ shown in Equation 4.9 is within the tolerance $\varepsilon$. The tolerance in this research is taken as $5 \%$.

$$
\Delta_{1}=\frac{\left|D_{t g t}-D_{1}^{I}\right|}{D_{t g t}}<\varepsilon
$$

8. Repeat Step-7 for all the selected ground motions.

It is acknowledged that the original structure does not only respond dominantly in the longitudinal mode (first-mode) but also in the transverse mode (higher-mode). Ideally, the SDOF system idealized from the transverse-mode pushover curve is recommended to be exposed to the scaled ground motions based on the first-mode to compute the difference normalized by $D_{t g t}$ for the transverse response, denoted as $\Delta_{\text {trans. }}$. The scaled ground motions could then be ranked based on the descending $\Delta_{\text {trans }}$. By removing the scaled ground motions yielding large $\Delta_{\text {trans }}$, a subset of the scaled ground motions is suitable for the time history analysis. However, since this is a comparative response study, refining of the first-mode scaled ground motions is not necessary. As long as the original and retrofitted structures are subjected to the same ground motions, it is reasonable and feasible to compare the effectiveness of retrofitting bridges with and without SCED braces in different configurations. 
In this study the first branch of the pushover curve is idealized by using the elastic stiffness of the actual curve. The second branch of the bilinear curve is idealized using the same slope as the plateau in the actual curve. This method is found to mitigate the difference between peak deformations of the SDOF and MDOF systems subjected to the scaled ground motions. In other word, this idealizing method yield better scaling results.

\subsection{Scaling Results}

The ground motion records selected in this research are scaled to the seismic hazard level of 2\% in 50 years for Victoria, BC in Canada according to NBCC 2015 [79]. The SDOF system of each bridge is modified by the first translational mode pushover curve. The first-modes of the models are shown in Figure 4.2. Figure 4.3 presents the modal pushover curve based on the first translational mode of each model. Because the example bridges are weaker in the longitudinal direction, the stronger horizontal component of each record is applied in the longitudinal direction. As mentioned in the previous section, records provided by FEMA are employed in this research and denoted as Set-FF and Set-NF. To overcome the bias in this methodology, the two components of each record are switched and scaled based on the component in the longitudinal direction. Thus, each set of excitations has twenty earthquake tests. The selected ground motion records' resulting scaling factors are shown in Table 4.2. The scaled spectrum for all the models are shown in Figure 4.4 to Figure 4.7.

The longitudinal drift ratio at the mid-span of the MDOF model of the example

Xi Cheng, Department of Civil and Environmental Engineering, Carleton University 
Table 4.1: Properties of Ground Motion Records

\begin{tabular}{|c|c|c|c|c|c|c|c|}
\hline Set & No. & Name & Year & M & Recording Station & Duration(s) & PGA $(g)$ \\
\hline \multirow{10}{*}{ FF } & $1(11)$ & Northridge & 1994 & 6.7 & Canyon Country-WLC & 5.55 & 0.40 \\
\hline & $2(12)$ & Duzce, Turkey & 1999 & 7.1 & Bolu & 9.34 & 0.52 \\
\hline & $3(13)$ & Imperial Valley & 1979 & 6.5 & Delta & 50.32 & 0.46 \\
\hline & $4(14)$ & Kobe, Japan & 1995 & 6.9 & Nishi-Akashi & 9.71 & 0.52 \\
\hline & $5(15)$ & Kocaeli, Turkey & 1999 & 7.5 & Arcelik & 11.01 & 0.30 \\
\hline & $6(16)$ & Landers & 1992 & 7.3 & Coolwater & 8.22 & 0.48 \\
\hline & $7(17)$ & Loma Prieta & 1989 & 6.9 & Capitola & 11.91 & 0.58 \\
\hline & $8(18)$ & Superstition Hills & 1987 & 6.5 & Poe Road & 13.82 & 0.52 \\
\hline & $9(19)$ & Chi-Chi, Taiwan & 1999 & 7.6 & TCU045 & 10.81 & 0.49 \\
\hline & $10(20)$ & San Fernando & 1971 & 6.6 & La-Hollywood Stor & 10.64 & 0.44 \\
\hline \multirow{10}{*}{ NF } & $1(11)$ & Imperial Valley-06 & 1979 & 6.5 & El Centro Array \#7 & 4.79 & 0.44 \\
\hline & $2(12)$ & Irpinia, Italy-01 & 1980 & 6.9 & Sturno & 15.22 & 0.61 \\
\hline & $3(13)$ & Superstition Hills-02 & 1987 & 6.5 & Parachute Test Site & 10.32 & 0.47 \\
\hline & $4(14)$ & Loma Prieta & 1989 & 6.9 & Saratoga-Aloha & 9.36 & 0.84 \\
\hline & $5(15)$ & Cape Mendocino & 1992 & 7 & Petrolia & 16.03 & 0.72 \\
\hline & $6(16)$ & Landers & 1992 & 7.3 & Lucerne & 13.86 & 0.61 \\
\hline & $7(17)$ & Northridge-01 & 1994 & 6.7 & Sylmar-Olive View & 5.31 & 0.67 \\
\hline & $8(18)$ & Kocaeli,Turkey & 1999 & 7.5 & Izmit & 13.24 & 0.61 \\
\hline & $9(19)$ & Chi-Chi, Taiwan & 1999 & 7.6 & TCU065 & 28.57 & 0.60 \\
\hline & $10(20)$ & Duzce, Turkey & 1999 & 7.1 & Duzce & 10.78 & 0.58 \\
\hline
\end{tabular}




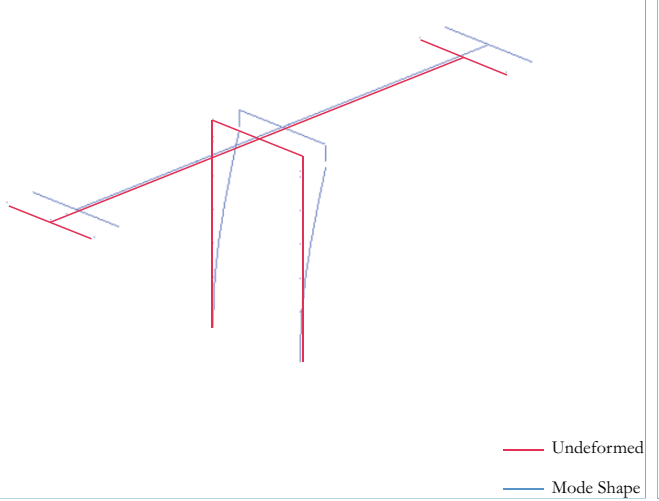

(a) $\mathrm{M} 1(T=1.38 \mathrm{~s})$

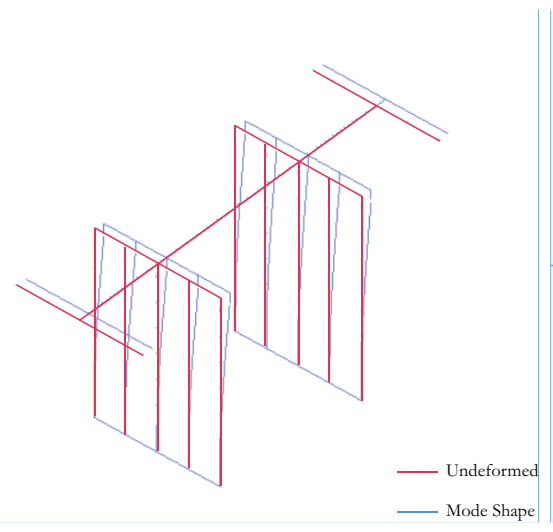

(c) $\mathrm{M} 3(T=1.05 \mathrm{~s})$

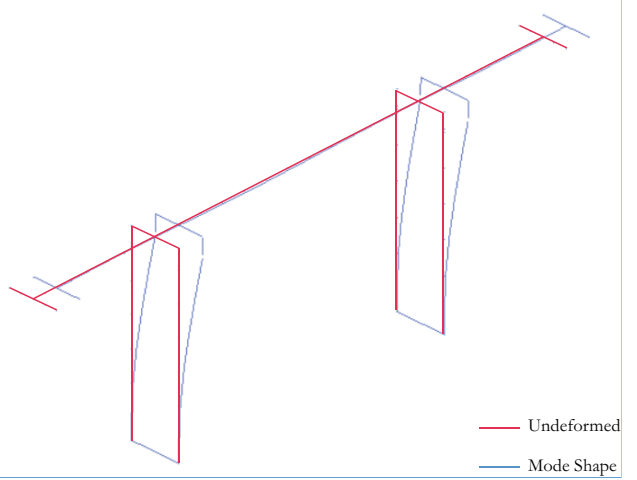

(b) $\mathrm{M} 2(T=0.76 \mathrm{~s})$

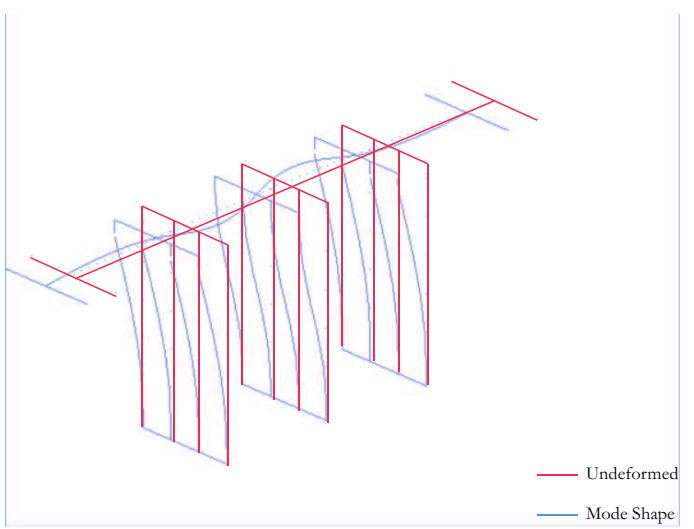

(d) $\mathrm{M} 4(T=0.91 \mathrm{~s})$

Figure 4.2: Fundamental Mode Shape of Models

bridge subject to each ground motion record is compared with the target drift ratio in Figure 4.8. The results show that the median drift ratio is generally close to the target and the dispersion of the drift ratio is confined. In comparison, the transverse drift ratio of the MDOF model has a larger dispersion. The reason is that the records are only scaled based on the component in the longitudinal direction. 


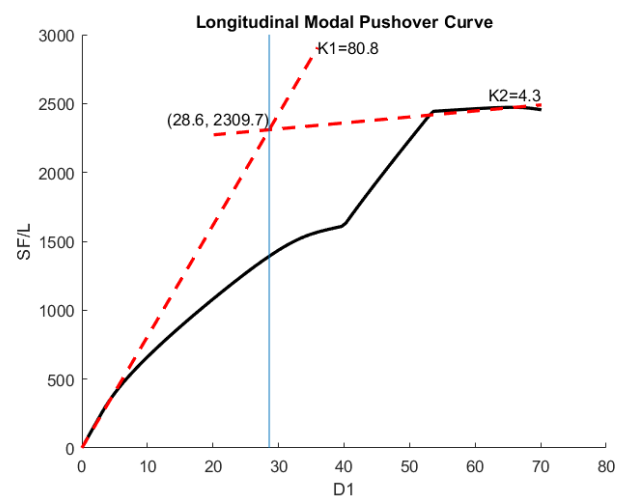

(a) M1

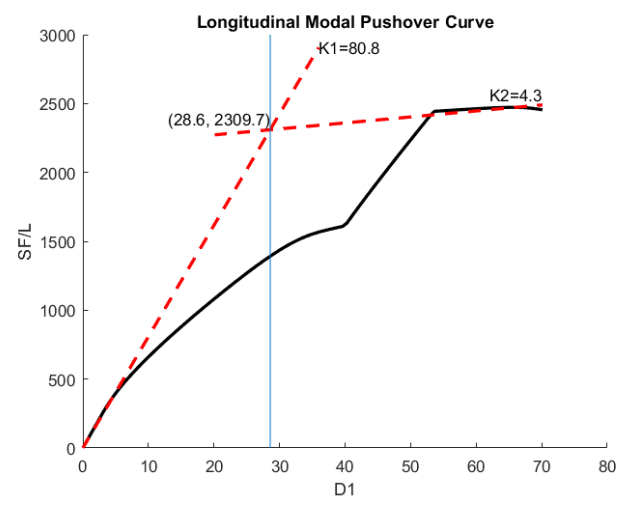

(c) M3

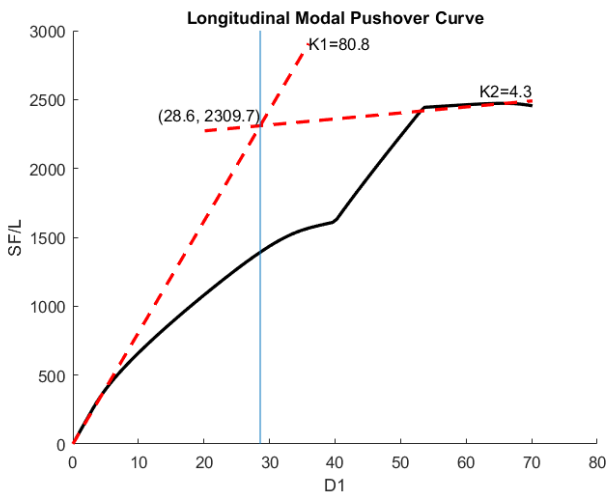

(b) M2

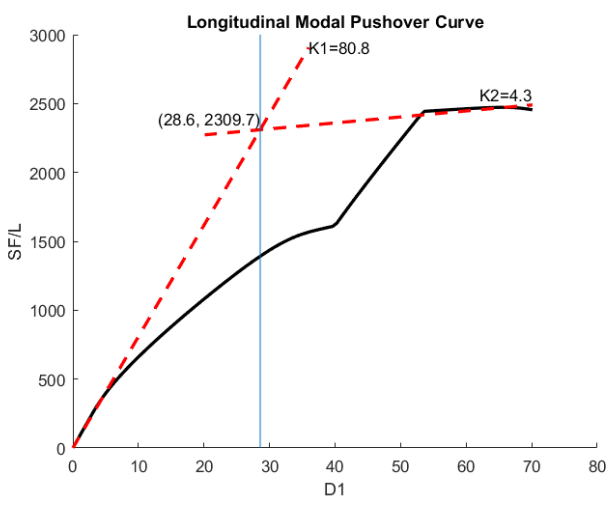

(d) M4

Figure 4.3: Modal Pushover Curves Based on Fundamental Mode

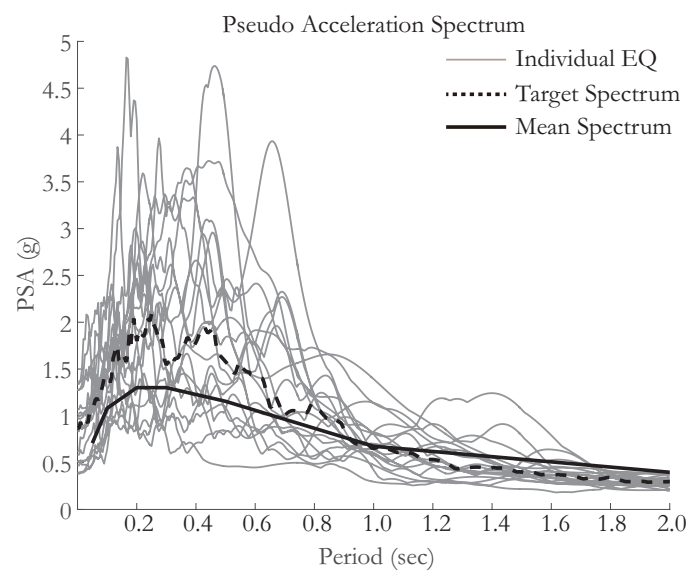

(a) FF

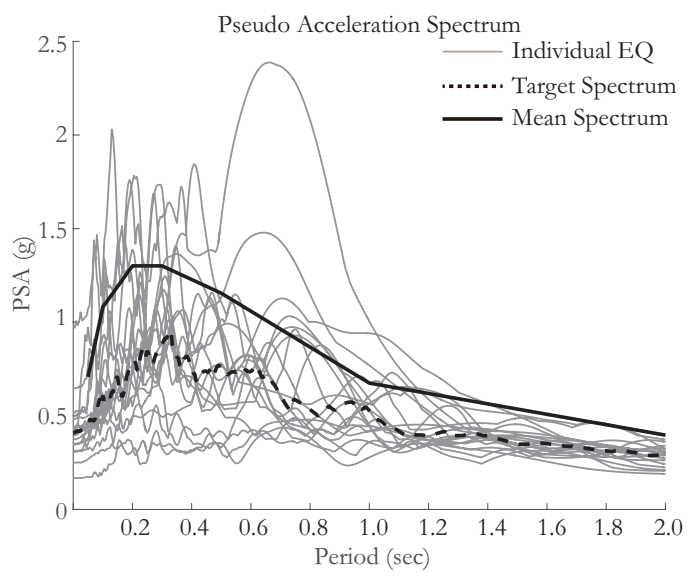

(b) NF

Figure 4.4: Acceleration Response Spectrum of Scaled Ground Motions for M1 


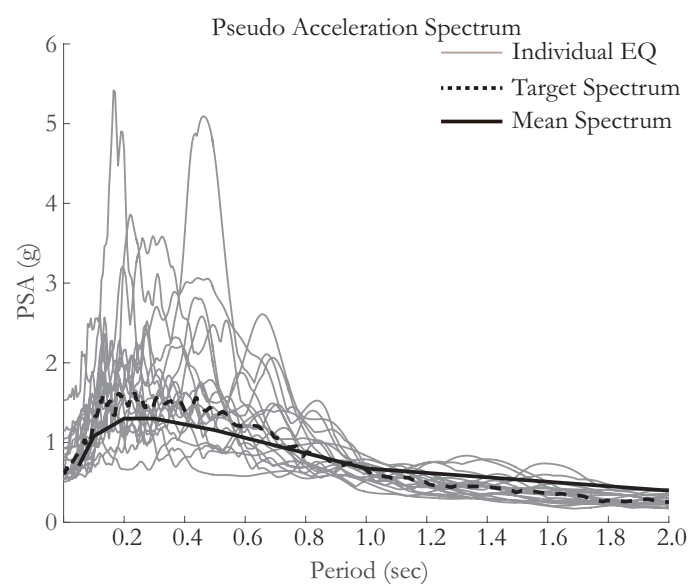

(a) $\mathrm{FF}$

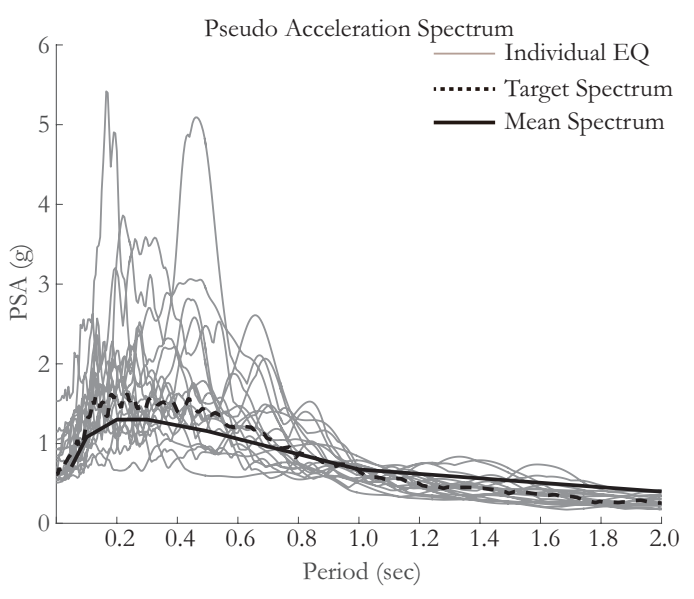

(b) $\mathrm{NF}$

Figure 4.5: Acceleration Response Spectrum of Scaled Ground Motions for M2

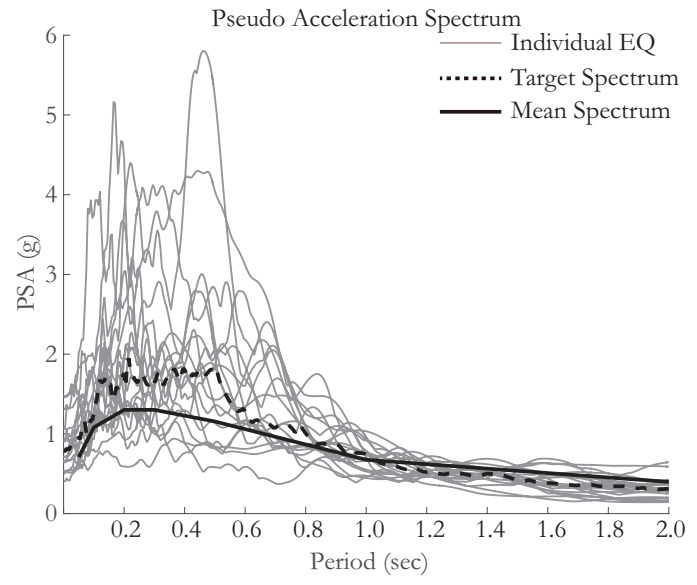

(a) FF

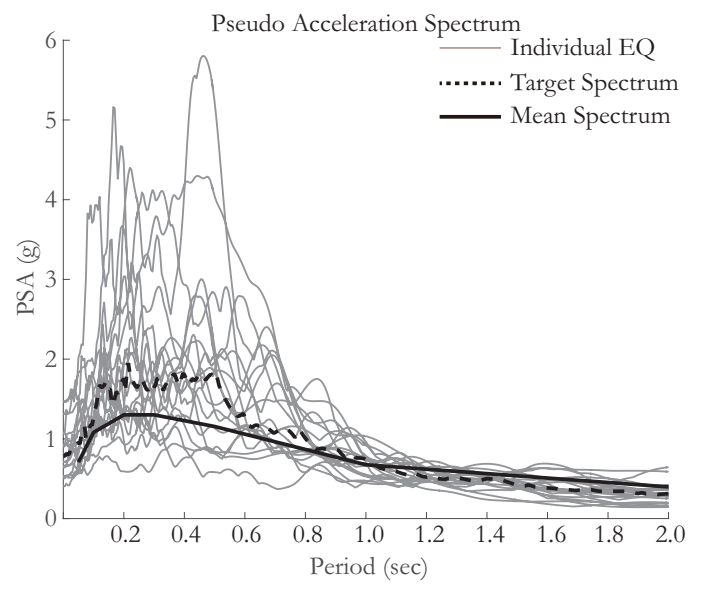

(b) NF

Figure 4.6: Acceleration Response Spectrum of Scaled Ground Motions for M3 


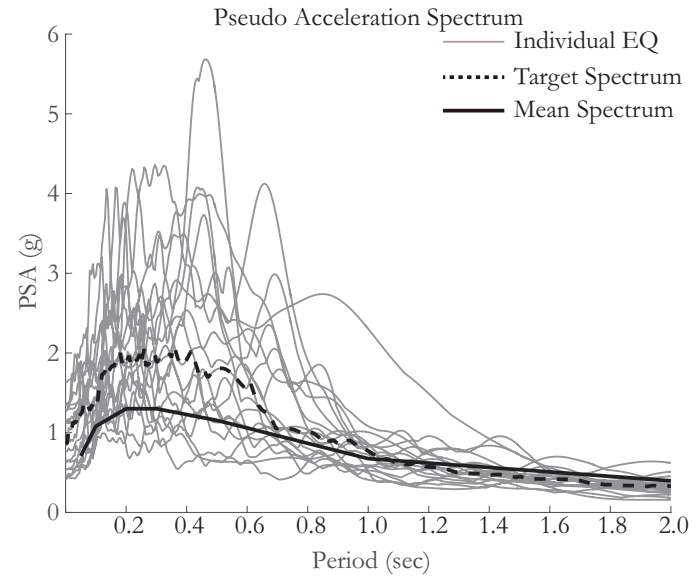

(a) $\mathrm{FF}$

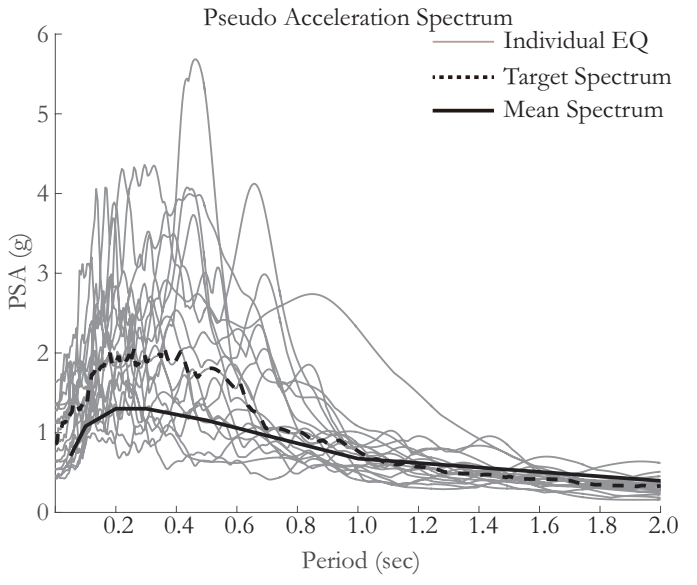

(b) NF

Figure 4.7: Acceleration Response Spectrum of Scaled Ground Motions for M4 
Table 4.2: Scaling Factors of Ground Motion Records

\begin{tabular}{|c|c|c|c|c|c|c|c|c|c|}
\hline \multirow[t]{2}{*}{ Set } & \multirow{2}{*}{$\frac{\text { No. }}{1(11)}$} & \multicolumn{2}{|c|}{ M1 } & \multicolumn{2}{|c|}{ M2 } & \multicolumn{2}{|c|}{ M3 } & \multicolumn{2}{|c|}{ M4 } \\
\hline & & 2.13 & (1.49) & 1.36 & $(1.56)$ & 1.93 & $(2.33)$ & 2.13 & (1.49) \\
\hline \multirow{9}{*}{$\mathrm{FF}$} & $2(12)$ & 1.88 & (1.79) & 1.13 & $(1.31)$ & 1.00 & (1.99) & 1.88 & (1.79) \\
\hline & $3(13)$ & 1.00 & $(1.20)$ & 1.15 & (1.91) & 1.08 & $(2.03)$ & 1.00 & $(1.20)$ \\
\hline & $4(14)$ & 2.00 & (1.94) & 2.15 & $(1.76)$ & 2.45 & $(1.75)$ & 2.00 & (1.94) \\
\hline & $5(15)$ & 4.50 & $(1.90)$ & 5.05 & $(2.45)$ & 4.81 & $(3.44)$ & 4.50 & $(1.90)$ \\
\hline & $6(16)$ & 1.60 & (2.62) & 1.45 & $(2.80)$ & 1.16 & $(3.21)$ & 1.60 & $(2.62)$ \\
\hline & $7(17)$ & 1.65 & $(2.60)$ & 1.05 & $(1.73)$ & 0.91 & $(1.44)$ & 1.65 & $(2.60)$ \\
\hline & $8(18)$ & 1.68 & (1.43) & 1.46 & $(1.73)$ & 1.70 & $(1.85)$ & 1.68 & (1.43) \\
\hline & $9(19)$ & 2.67 & (2.75) & 1.63 & $(2.26)$ & 1.30 & (3.17) & 2.67 & $(2.75)$ \\
\hline & $10(20)$ & 1.30 & (1.68) & 1.38 & (1.89) & 0.90 & $(2.90)$ & 1.30 & (1.68) \\
\hline \multirow{10}{*}{ NF } & $1(11)$ & 0.69 & (1.46) & 0.95 & $(0.93)$ & 0.90 & $(1.20)$ & 0.69 & $(0.90)$ \\
\hline & $2(12)$ & 0.63 & $(0.70)$ & 0.80 & $(1.00)$ & 0.88 & $(1.05)$ & 0.63 & $(0.88)$ \\
\hline & $3(13)$ & 0.35 & (1.08) & 0.71 & (1.51) & 0.46 & $(0.96)$ & 0.35 & $(0.46)$ \\
\hline & $4(14)$ & 0.76 & $(0.93)$ & 0.88 & $(1.23)$ & 0.70 & $(1.15)$ & 0.76 & $(0.70)$ \\
\hline & $5(15)$ & 0.71 & $(1.50)$ & 0.60 & $(1.00)$ & 0.86 & $(1.50)$ & 0.71 & $(0.86)$ \\
\hline & $6(16)$ & 4.04 & $(0.75)$ & 2.95 & $(1.40)$ & 2.80 & $(1.23)$ & 4.04 & $(2.80)$ \\
\hline & $7(17)$ & 0.60 & $(0.90)$ & 0.94 & $(0.81)$ & 0.79 & $(1.42)$ & 0.60 & $(0.79)$ \\
\hline & $8(18)$ & 0.56 & $(0.81)$ & 1.23 & $(0.86)$ & 0.95 & $(1.04)$ & 0.56 & $(0.95)$ \\
\hline & $9(19)$ & 0.61 & $(0.55)$ & 0.65 & $(0.82)$ & 0.91 & $(0.90)$ & 0.61 & $(0.91)$ \\
\hline & $10(20)$ & 0.71 & $(0.90)$ & 0.73 & $(1.49)$ & 0.94 & $(1.44)$ & 0.71 & $(0.94)$ \\
\hline
\end{tabular}

Note1: The factors without brackets are for C1 (component with larger PGA); the factors with brackets are for C2(component with smaller PGA). 


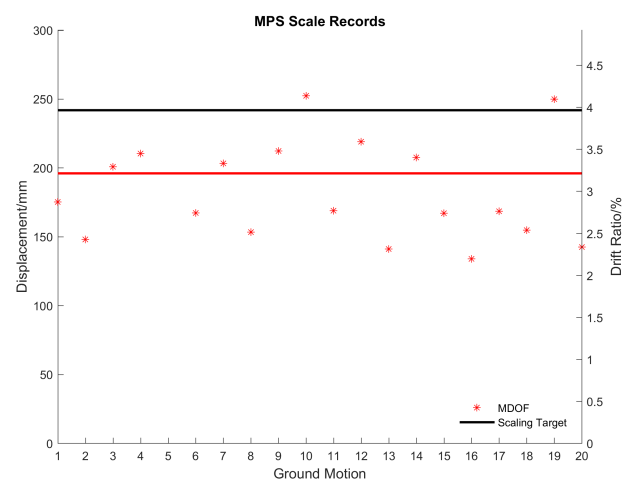

(a) M1 under Set-FF

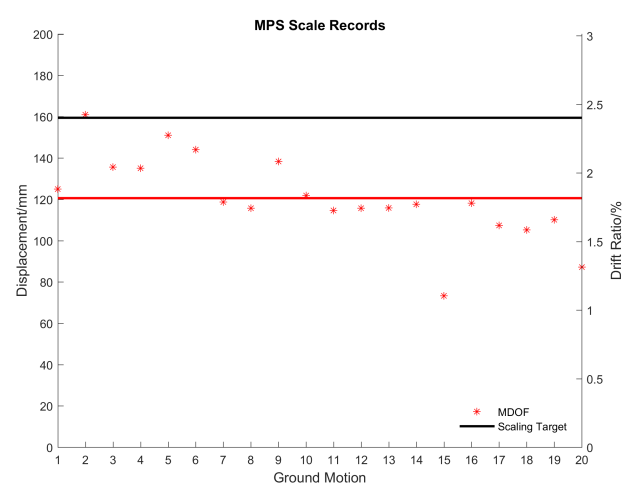

(c) M2 under Set-FF

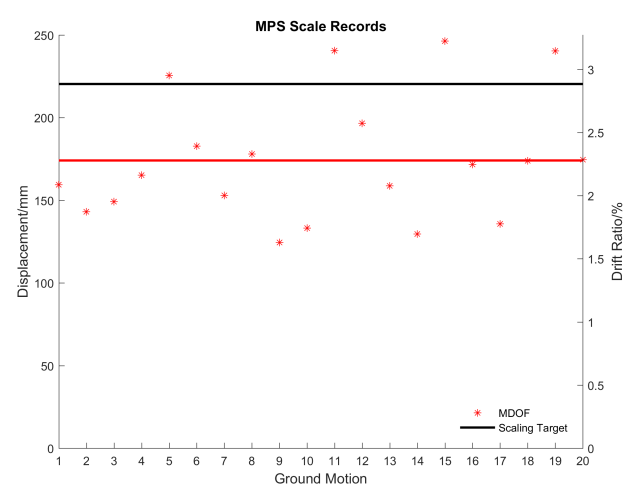

(e) M3 under Set-FF

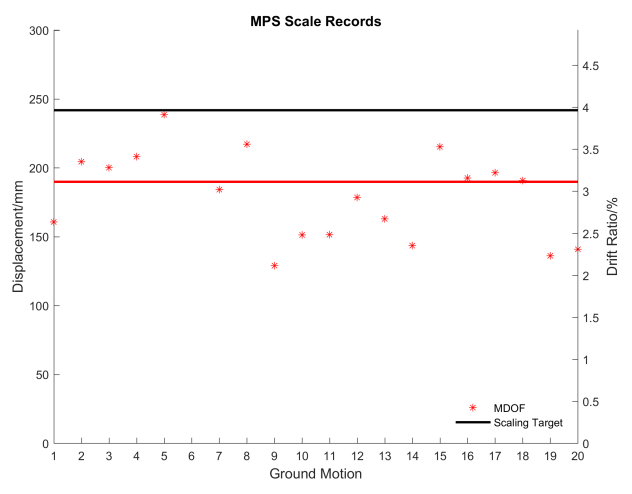

(b) M1 under Set-NF

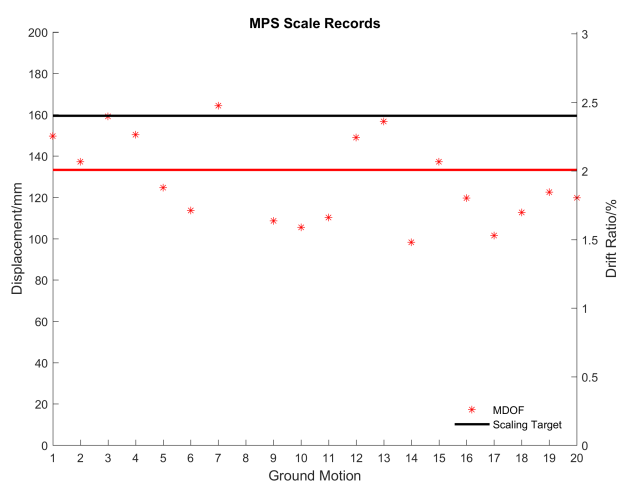

(d) M2 under Set-NF

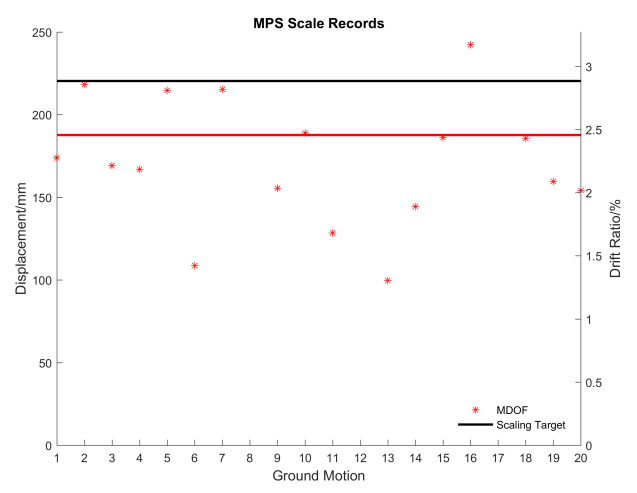

(f) M3 under Set-NF

Figure 4.8: Scaling Results of MPS 


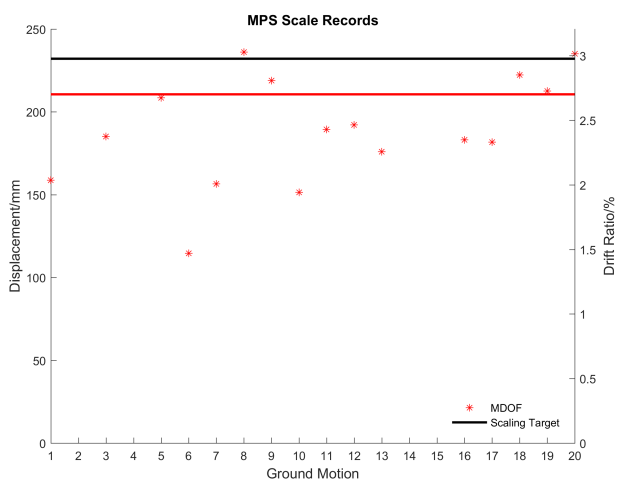

(g) M4 under Set-FF

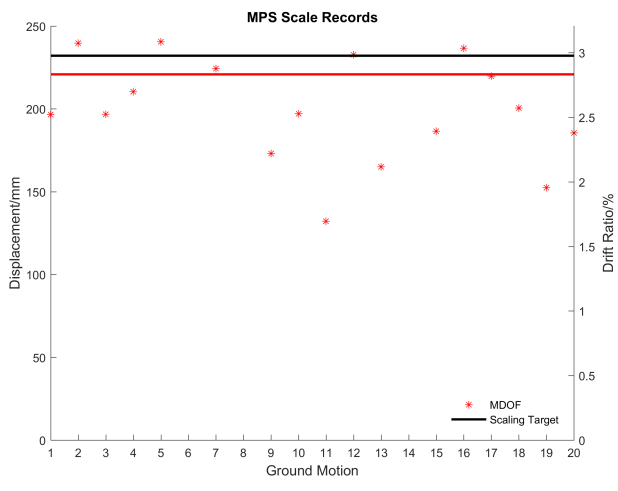

(h) M4 under Set-NF

Figure 4.8: Scaling Results of MPS (cont.) 


\section{Chapter 5: Retrofit Schemes and SCED Brace Design}

\subsection{Retrofit Scheme}

In the present study, the SCED braces are implemented in transverse and longitudinal directions of the bridge. The braces are designed separately in the longitudinal and transverse directions such that the responses in these two orthogonal directions can be controlled independently. An efficient arrangement is to place separate SCED braces in the transverse and longitudinal directions of the bridge. In engineering practice, the SCED braces can be placed by connecting the bridge abutment to the bridge deck at an angle and distance from the abutment. In this angle arrangement, the contributions of the SCED brace can be resolved into transverse and longitudinal components in its design.

Generally, the principal modes of deformation of a bridge can be categorized into transverse and longitudinal translation modes, global torsion modes, and flexural deformation modes of the superstructure. For bridges dominated by translational movements during seismic events, restraining the movement at the ends of the deck is effective and sufficient to limit the displacement at all bents. However, the significant flexural deformation of the superstructure would potentially require extra elements to reduce the response at mid-bents. Considering these possible scenarios, two retrofit schemes are 
proposed:

- Retrofit Scheme-1 (Figure 5.1(a)): Longitudinal and transverse SCED braces are installed at each end of the deck in a configuration that aligns with the transverse and longitudinal directions of the bridge. A longitudinal SCED brace is added which connects the abutment to the bottom of the bridge deck. Two transverse braces are added on each side of the abutment. This configuration can minimize the interruption to traffic during construction, but does not directly control the displacement of the bridge at mid-span.

- Retrofit Scheme-2 (Figure 5.1(b)): In addition to installing SCED braces at the two ends of the bridge as in Scheme-1, additional SCED braces can be placed at mid-bents of the bridge. In this arrangement of the SCED braces, the controlling devices of SCED braces are more evenly distributed along its length to control the displacement of the bridge. However, the installation of SCED braces in this scheme may cause interruption to traffic passing through and over the bridge during construction.

In the design of the connection mechanism of longitudinal SCED braces, it is important to consider the effect of thermal expansion of the superstructure resulting in any preloading condition of the SCED brace may have an effect on the performance of the braces during earthquakes. This is especially important for bridges in Canada as they are exposed to large diurnal and seasonal temperature gradients. Thus, lock-up devices working in series with longitudinal braces can be introduced in the retrofit. Ideally, the lock-up device is activated as a rigid connection when a transient event occurs; but only output low force resistance to deformation at low translational speed [81]. These lock-up devices are not considered in the models.

In the present study, all the example bridges are retrofitted with Retrofit Scheme-1. To assess the effectiveness of adding SCED braces at mid-bents, an alternative Retrofit 
Scheme-2 is also considered for retrofitting example bridge M4.
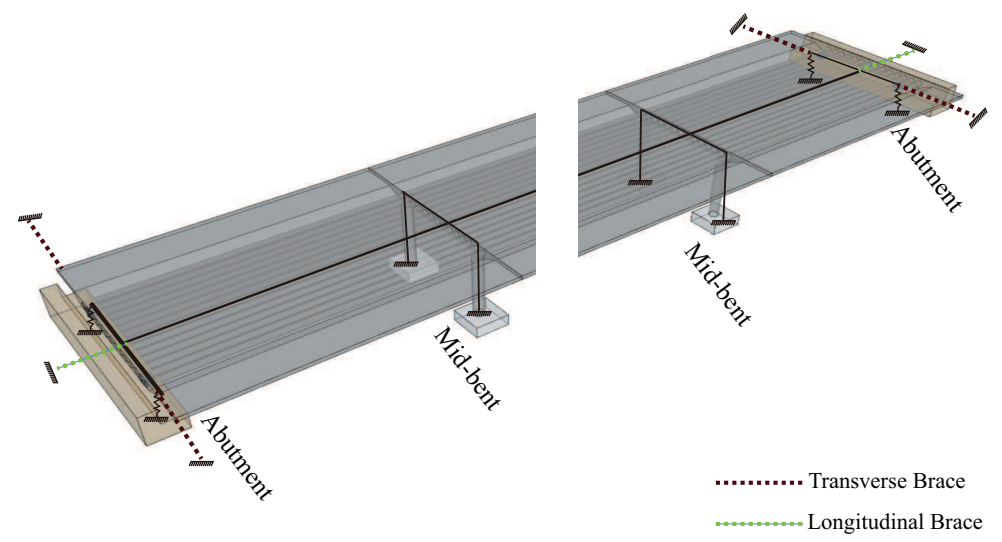

(a) Retrofit Scheme-1

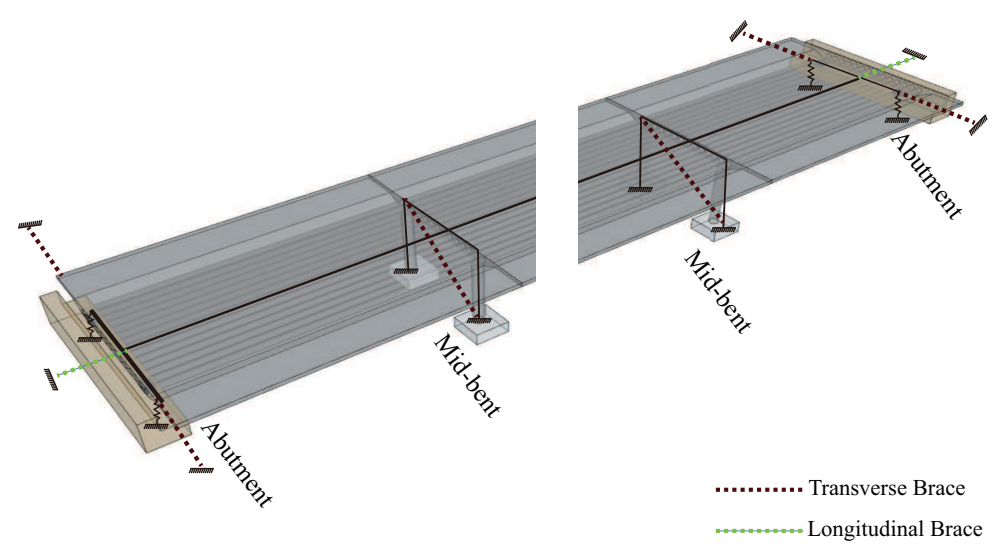

(b) Retrofit Scheme-2

Figure 5.1: Retrofit Schemes for Bridges 


\subsection{Design of SCED Braces}

The use of SCED braces for retrofitting buildings have been studied by several researchers $[13,15,24]$. In the design of the SCED braces of those earlier studies, the SCED brace demand loads can be determined through either modal response spectrum or dynamic time history analysis [13]. Once the demand loads are determined, the activation load can be set greater than the demand load [54] or the load of the SCED brace at a target drift can be set greater than the demand load [24]. As suggested by Erochko [13], the activation load design method is easier since it provides a the target activation load for design without requiring the selection of a post-activation stiffness first. When retrofitting a building, the SCED brace demand load can be determined using a design code. For instance, the target SCED force may be related to story shear in a building which is calculated using the Equivalent Lateral Force Procedure from the National Building Code of Canada [13,79].

Since SCED braces have not previously been used in the design or retrofit of bridge structures, a simple method for their design is proposed here. It is commonly accepted that the capability of the structure to deform inelastically without significant strength loss can help it survive under significant seismic events. In general, force-based design methods for seismic design of structures determine the design strength structure based on the elastic demand modified by force-reduction factors. Similarly, the SCED brace demand may be determined from the total base shear of the equivalent elastic response by selecting and applying an appropriate reduction factor $R$ defined in Equation 5.1.

$$
R=\frac{F_{b s, L}}{F_{b s, N L}}
$$

where $F_{b s, L}$ and $F_{b s, N L}$ are the total base shears of the linear and nonlinear bridge model.

To obtain the total base shear of the equivalent elastic response for the original 
structures, the original models of the example bridges are modified. The nonlinear springs representing the abutment and shear key behavior are replaced with rollers which allow the movements of the bridge superstructure in the longitudinal and transverse directions. As such, the bridge lateral load resistance is concentrated at the bridge piers only. In these modified original models, the material properties of the pier are reduced to account for cracking. The elastic total base shear for these models, $F_{b s, L}$, is determined from the time history analysis. $F_{b s, L}$ is the mean of the median total base shears in a certain direciton for each set of ground motions. Similarly, the total base shear in a certain direction of the inelastic model, $F_{b s, N L}$, is also obtained through the same procedure. Alternatively, instead of using time history analysis, $F_{b s, L}$ can be also obtained using spectrum method since the equivalent elastic structure respond with the effective initial stiffness. The ratio between $F_{b s, L}$ and $F_{b s, N L}$ is defined as base reduction factor $R_{0}$. For each bridge model, $R_{0}$ is listed in Table 5.1.

To select the activation force for the SCED braces for each retrofit, the activation force is chosen relative to the elastic total base shear $F_{b s, L}$. A parametric study is conducted to find the desirable target activation force design factor $D F$. The total brace activation force in each direction is calculated as:

$$
P_{a, T o t a l}=\frac{F_{b s, L}}{D F}
$$

Since the total base shear is calculated separately in the longitudinal and transverse directions, the $P_{a, t o t a l}$ represents the total activation force for the braces in the same direction. The variations of the design factor considered are 2, 4, 6 and 8.

For the design of the SCED braces, several assumptions are made:

- A simplified step-wise hysteretic response is assumed for the behavior of SCED brace in design. This implies the difference between the inner and outer member 
Table 5.1: Base Reduction Factors for Each Model

\begin{tabular}{cccccccc}
\hline \multirow{2}{*}{ Model } & \multirow{2}{*}{ Set } & \multicolumn{2}{c}{$F_{b s, L}(\mathrm{kN})$} & \multicolumn{2}{c}{$F_{b s, N L}(\mathrm{kN})$} & \multicolumn{2}{c}{$R_{o}$} \\
& & Trans. & Long. & Trans. & Long. & Trans. & Long. \\
\hline \multirow{4}{*}{ M1 } & FF & 3775 & 4412 & 2652 & 1589 & 1.4 & 2.8 \\
& NF & 4048 & 4071 & 2580 & 1598 & 1.6 & 2.5 \\
& Mean & 3912 & 4241 & 2616 & 1594 & 1.5 & 2.7 \\
\hline \multirow{4}{*}{ M2 } & FF & 12390 & 12279 & 5155 & 5976 & 2.4 & 2.1 \\
& NF & 16559 & 11584 & 5206 & 5833 & 3.2 & 2.0 \\
& Mean & 14474 & 11932 & 5180 & 5905 & 2.8 & 2.0 \\
\hline \multirow{4}{*}{ M3 } & FF & 7970 & 8453 & 4011 & 4842 & 2.0 & 1.7 \\
& NF & 8205 & 8377 & 3967 & 4966 & 2.1 & 1.7 \\
& Mean & 8087 & 8415 & 3989 & 4904 & 2.0 & 1.7 \\
\hline \multirow{3}{*}{ M4 } & FF & 19899 & 20243 & 5278 & 5781 & 3.8 & 3.5 \\
& NF & 19148 & 17666 & 4765 & 5821 & 4.0 & 3.0 \\
& Mean & 19524 & 18955 & 5021 & 5801 & 3.9 & 3.3 \\
\hline
\end{tabular}

stiffness, and the locations and slip forces of the friction mechanism are ignored (except that the difference between the inner and outer member stiffness is effectively considered through the use of an effective initial stiffness)

- The braces attract great amount of base shear during the earthquake. The brace connections to the deck and foundation and the brace's foundation are the critical issues to be considered in the real design. The brace connections and foundations are assumed to be rigid in this thesis.

- The length of all SCED braces $L$ is taken as $4 \mathrm{~m}$.

- The pretensioned tendon length is assumed to be the same as that of the brace and the brace deformation capacity is determined by the tendon's strain capacity. Since 
the SCED brace requires a large elongation capacity, the aramid tendon is attractive for its listed elongation capacity of 4.6\% [13]. To account for the initial setting and straightening behaviour of straight fibre tendons, the tendon strain capacity is assumed to be 1.8\% [13]. As shown in Equation 5.3, the ultimate load of the SCED brace $\left(P_{u l t}\right)$ is calculated as the total load in the SCED when the tendons reach their deformation capacity $\left(\Delta_{u l t}\right)$. Any potential loss of the pretension force is not considered.

$$
\begin{gathered}
P_{u l t}=P_{a}+\Delta_{u l t} k_{2} \\
k_{2}=\frac{E_{p} A_{p}}{L_{p}}
\end{gathered}
$$

where $A_{p}$ and $L_{p}$ are the effective area and length of the tendons.

- The energy dissipation mechanism in the SCED braces is assumed to be a friction slip damper device. No external friction fuse is included in the design of the braces and the internal friction damper is assumed to be able to provide the required friction force.

- The brace cross-section consists of two steel tubes. These tubes are designed to be large enough to resist buckling at the ultimate force in the brace. Thus, the section properties should meet the requirements:

$$
\begin{gathered}
I \geqslant \frac{P_{u l t}(K L)^{2}}{\pi^{2} E_{s}} \\
A \geqslant \frac{P_{u l t}}{f_{y}}
\end{gathered}
$$

where $K$ is the effective length factor given by AISC manual; $I$ is the total moment of inertia of the cross-section; $f_{y}$ is the yield stress of the steel.

- The effective cyclic Young's Modulus of the tendon $E_{p}$ and the steel $E_{s}$ are taken 
as $102 \mathrm{GPa}$ and $200 \mathrm{GPa}$ [13].

Once the SCED brace target activation load is determined, the brace can be designed iteratively. A recommended design procedure has been proposed by Ercohko [13] in order to reduce the amount of design iterations. The design procedure adapted from [13] is summarized below:

1. Determine the SCED brace demand load using $F_{b s, L}$ and $R$ mentioned previously.

2. Determine the activation load of the SCED brace by equating it to the demand load.

3. Select proper energy dissipation capacity parameter $\beta$. The typically value of $\beta$ ranges from 0.85 to 0.95 . In this study, three different levels of $\beta$ are evaluated to investigate its influence on retrofit performance. The base value of $\beta$ is taken as $0.9 .100 \%, 50 \%$ and $0 \%$ of this base $\beta$ are considered in the parametric study.

4. Determine the target internal slip friction force $F$ and target total tendon pretension force $P_{\text {pre }}$ using Equation 2.4 and Equation 2.3, respectively.

5. The tendon length is assumed to be same as the brace. Each tendon is pretensioned between $25 \%$ to $40 \%$ of its nominal strength. Determine the diameter and the amount of tendons required to achieve the target pretension force $P_{\text {pre }}$. An even number of the tendons is preferred to ensure symmetric distribution of the tendon force, as shown in Figure 5.2. Minimum of four tendons should be installed in order to balance the load at the end plates.

6. The detailed internal friction damper design is not considered as mentioned in the assumption above.

7. Design the brace cross-section. Beside satisfying the calculated requirements according to Equation 5.5 and Equation 5.6, the cross-section should be able to 
accommodate the tendons with sufficient clearance space. This requirement is satisfied by trial and error in an iterative design process by selecting different crosssection arrangements depending on the designer experience.

8. Use the SCED Mechanics Simulator [13] to predict the hysteresis of the SCED brace. The hysteresis of the SCED brace is characterized by $k_{i}, \alpha$ and $\beta$. As mentioned in Section3.2.6, $k_{i}$ is the effective initial stiffness. These parameters are used to model the SCED braces.

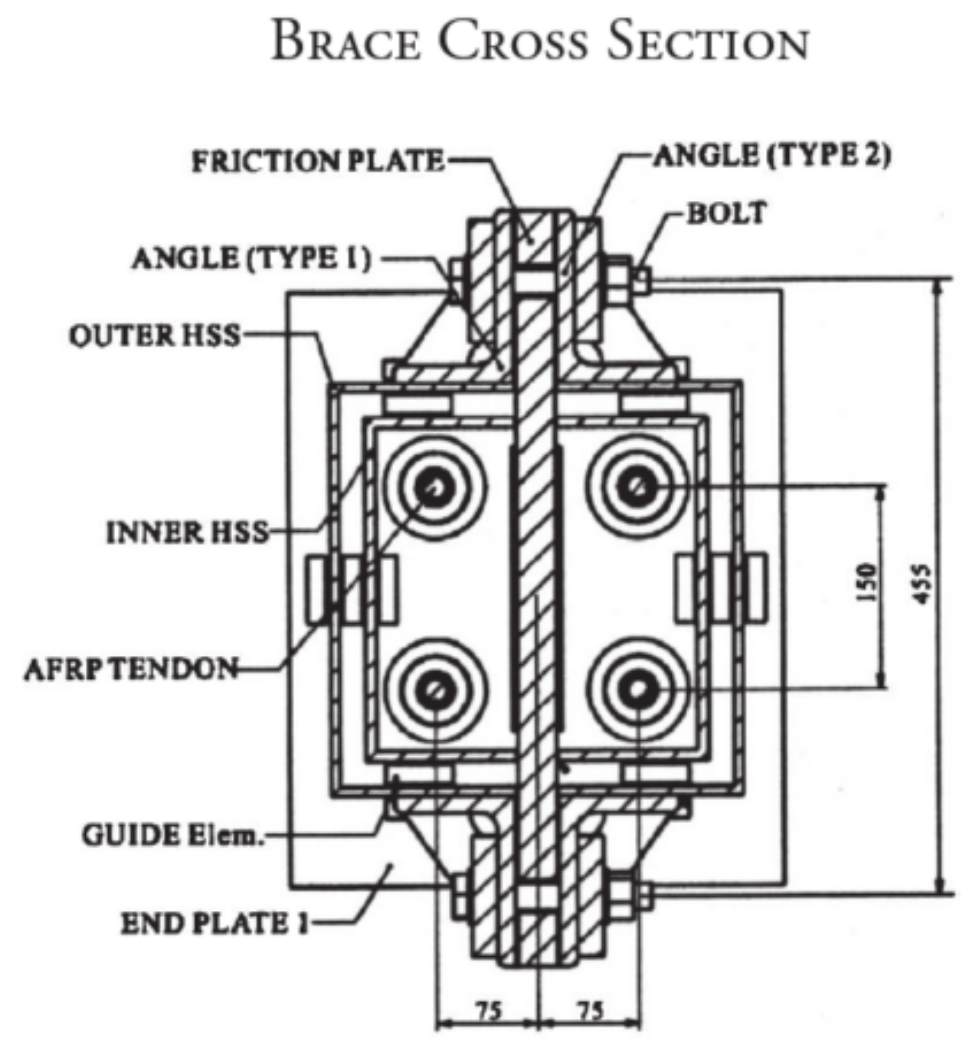

Figure 5.2: SCED Brace Cross-Section (from [15]) 


\subsection{Parametric Study for Desirable Design}

In Retrofit Scheme-1, the braces are located at both ends of the bridge. The total base shear demand in each horizontal direction is distributed into four braces in the transverse direction and two braces in the longitudinal direction. A parametric study is carried out to obtain insight on the effect of SCED braces on bridge response under seismic loads. The parametric study is conducted by varying the mechanical properties of the SCED, including $P_{a}$ and $\beta$. The parametric study space is summarized in Figure 5.3. The properties of the SCED braces designed for each case are shown in Table 5.2 to Table 5.5. The results obtained from the parametric study are discussed in the following chapter to propose a reliable design procedure for retrofitting bridges with SCED braces.

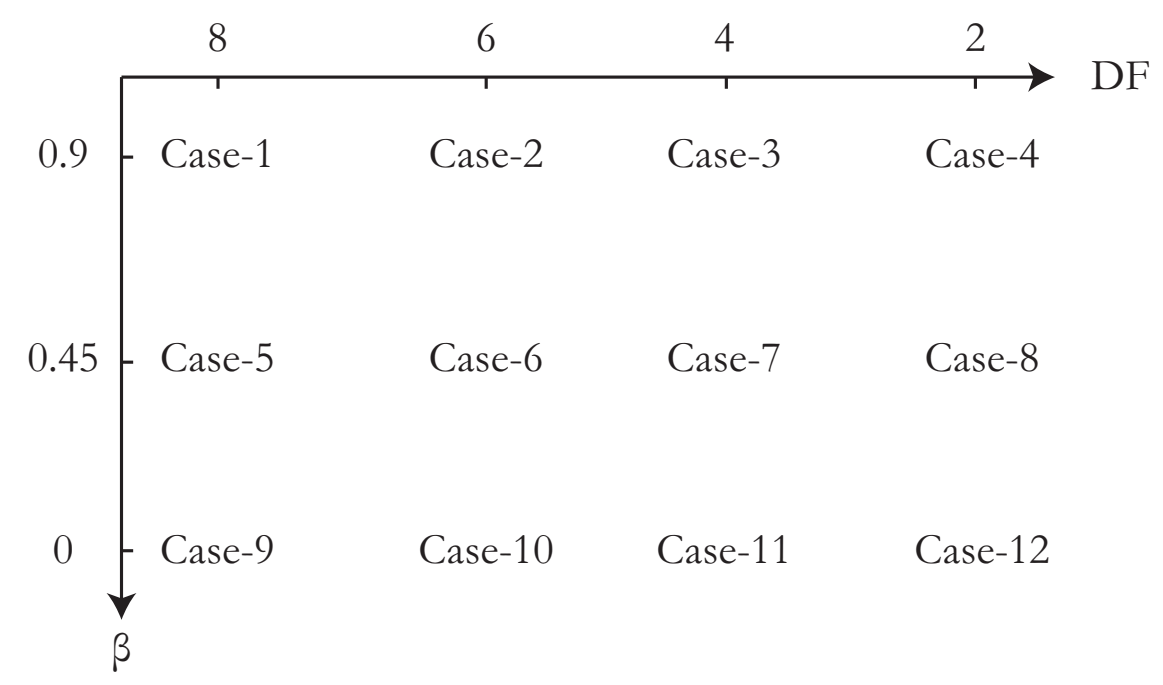

Figure 5.3: Parametric Study Space

Ideally, only one parameter should be changed in each case of the parametric study. As shown in Figure 5.3, $\beta$ is supposed to be the only variable in the control experiment consisting of Case 1,5 and 9. However, the changing of one parameter inevitably alters the influences from the other parameters considered as they are interrelated. Combining 
Equation 2.3 and Equation 2.4 gives Equation 5.7:

$$
P_{\text {pre }}=P_{a}\left(1-\frac{\beta}{2}\right)
$$

Equation 5.7 indicates that $P_{\text {pre }}$ will increase with decreasing $\beta$. The increasing $P_{\text {pre }}$ requires more and stronger tendons, which needs larger cross-section to geometrically accommodate all the tendons. As a result, an SCED brace with smaller $\beta$ becomes stiffer. Take the longitudinal braces in M3 retrofit as an example. In Case 1, 5 and 9, $\beta$ decreases from 0.9 to 0 , the effective initial stiffness $k_{1}$ increases from $167 \mathrm{kN} \mathrm{mm}^{-1}$ to $315 \mathrm{kN} \mathrm{mm}^{-1}$. Due to this effect, the retrofit performance of M3 improves when $\beta$ is reduced. This seems counter-intuitive if at the same time the influences of the change in other design parameters of the SCED brace are ignored. 


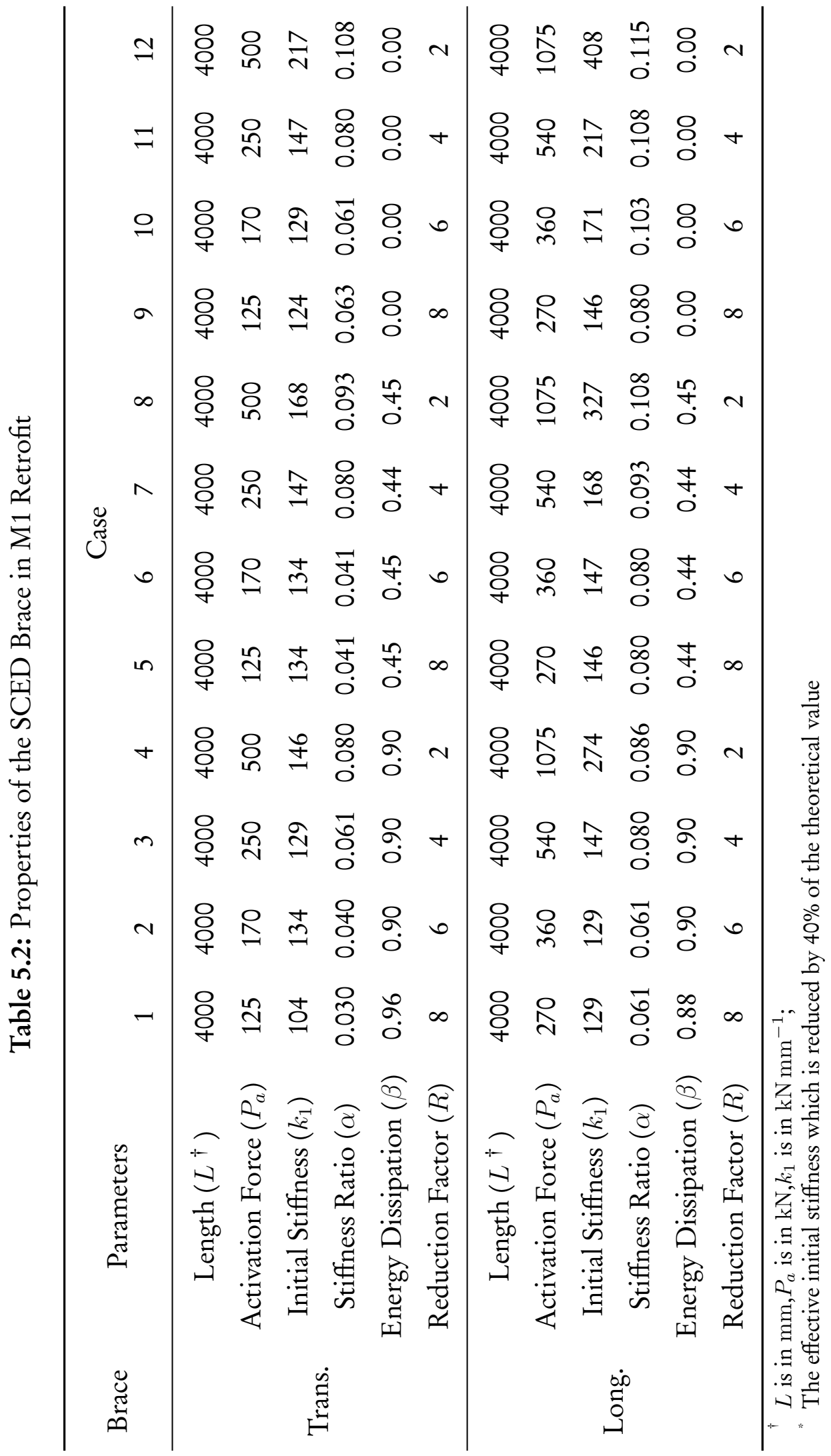




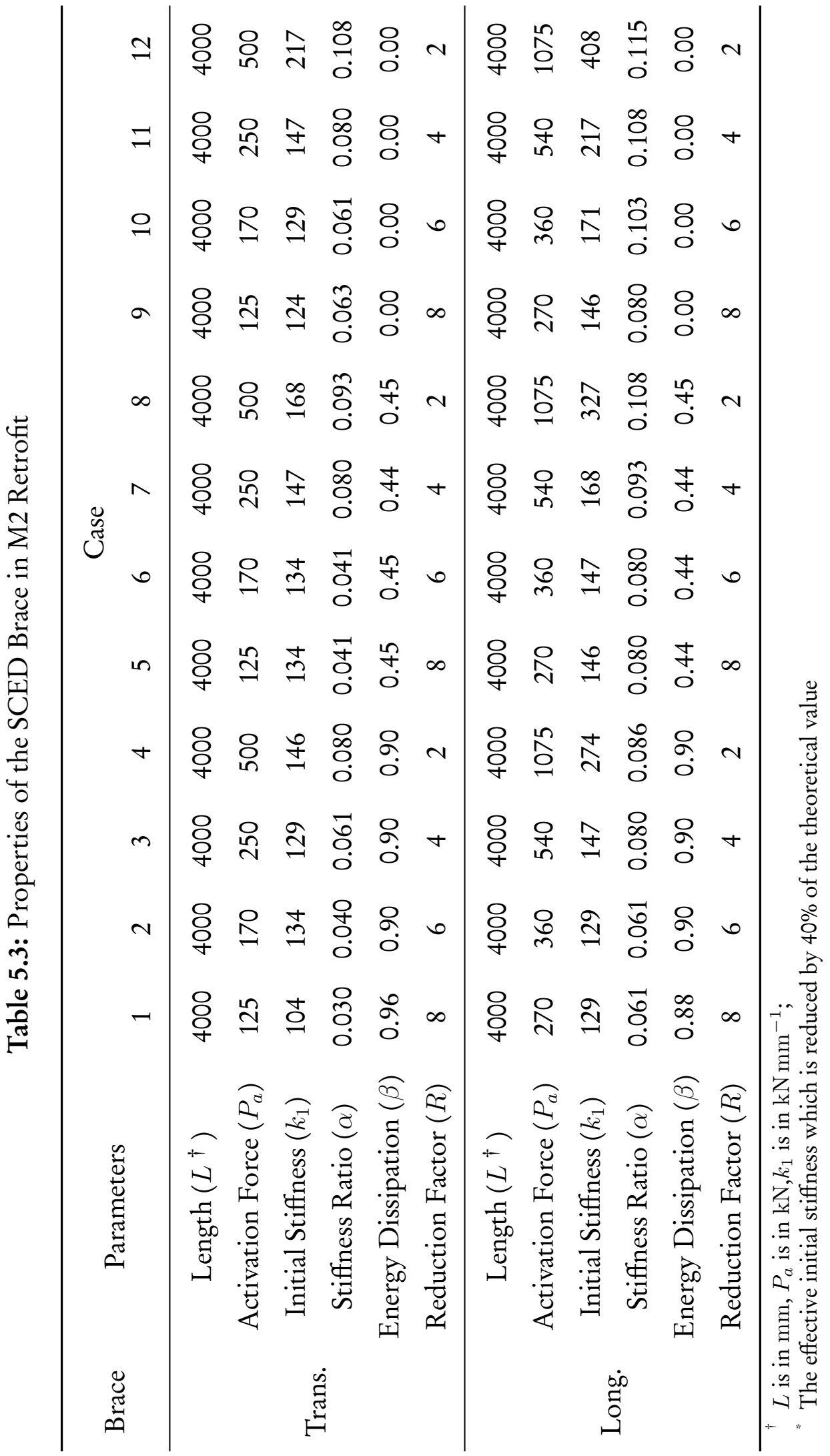




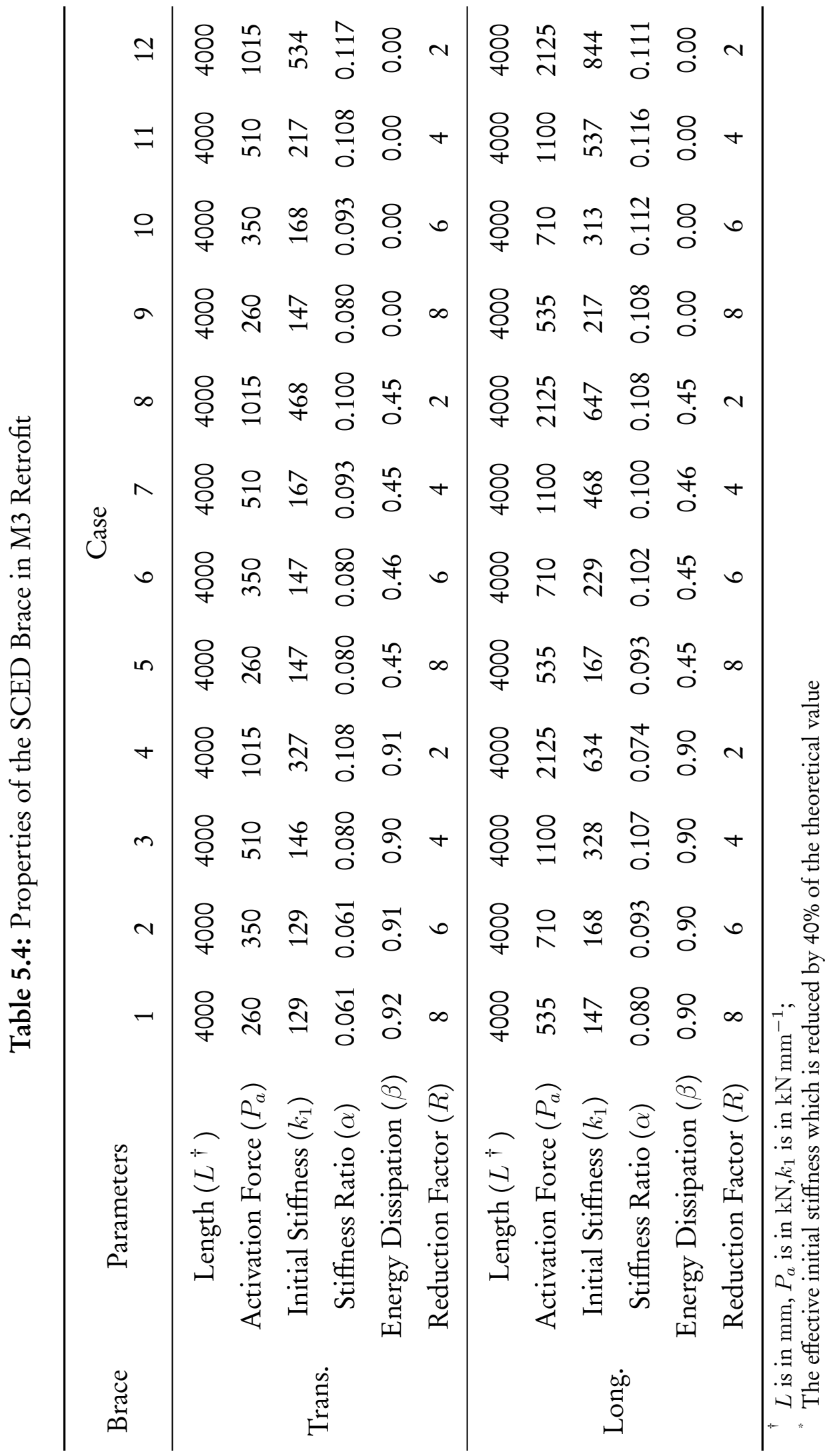




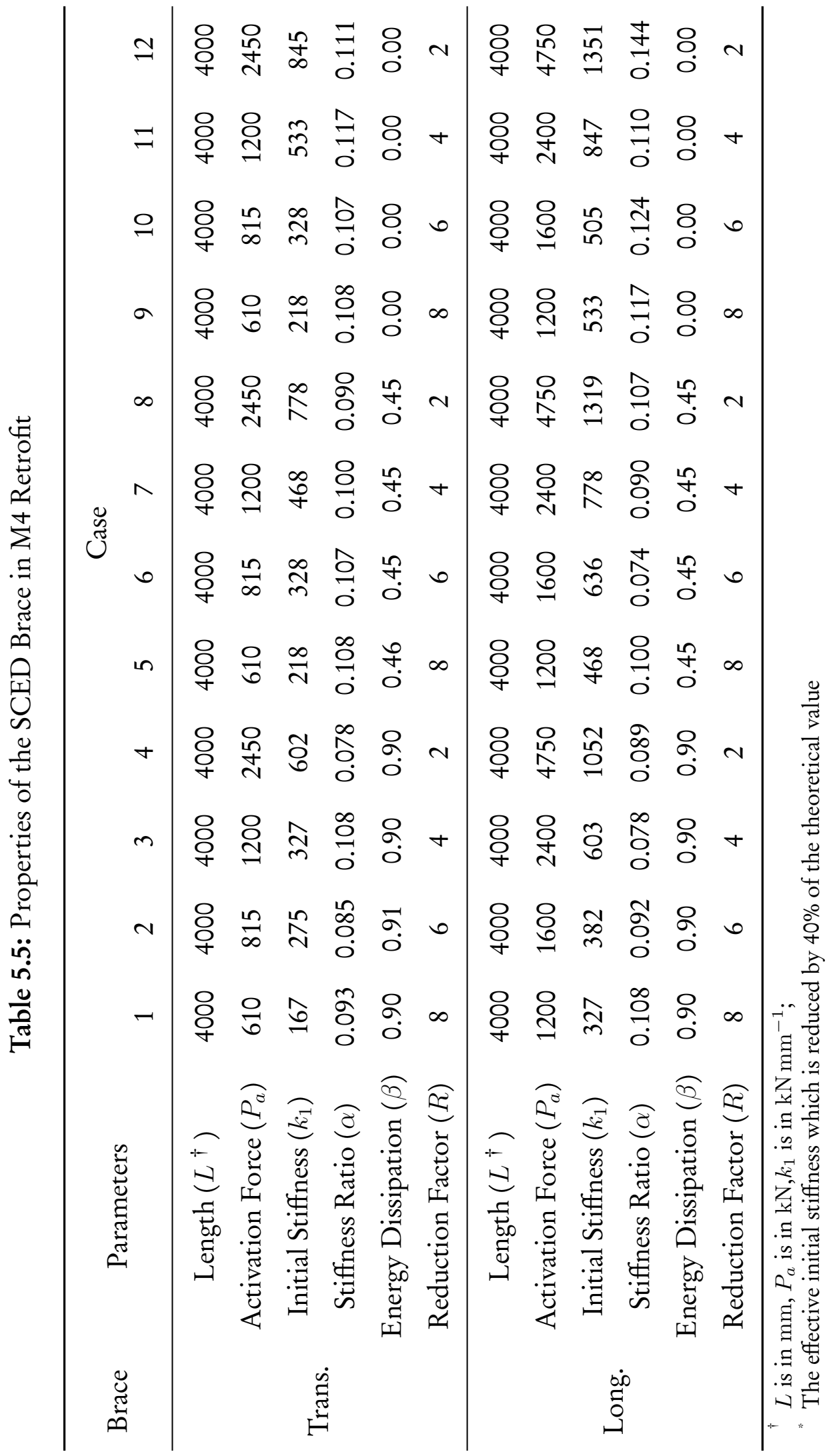




\section{Chapter 6: Retrofit Performance}

Previous studies $[13,54]$ have shown that SCED offers significant benefit for reducing residual displacements in retrofit of buildings. The effects of this new and replaceable retrofit device on bridges have not been studied to date. Two series of dynamic analysis are conducted. One focuses on the response of the original structures; the other focuses on the response of the retrofitted structures supplemented with the SCED braces. Both are subjected to the same scaled ground motions discussed in Chapter 4. By assessing the performance of the original structures, it is found that the flexural deformation mode is not significantly involved due to the large in-plane rigidity of the deck. Implementing the SCED braces at both ends of the deck can not only reduce the responses of different bents simultaneously but also prevent the global torsion mode after the failure of the shear key. Therefore, Retrofit Scheme-1 is adopted in the parametric study. This chapter mainly discusses the effects of different parameters of the SCED brace on the retrofit performance when the structure is retrofitted per Retrofit Scheme-1. A subset of the design cases is also selected to retrofit the longest model (M4) according to Retrofit Scheme-2. The effectiveness of these two retrofit schemes is also compared.

\subsection{Performance of Original Structure}

The time history analyses are performed using the far-field (FF) and near-field (NF) ground motions selected from FEMA P695 [74]. These ground motions are scaled to the 
MCE level with a probability of exceedance of $2 \%$ in 50 years. The scaling methods of the ground motions used in this study are presented in Section 4.1. The two sets of Far-Field and Near-Field ground motion records are used as input excitations to the original structures described in Section 4.2. The results of these analyses do not encounter convergence problem and the findings are presented below.

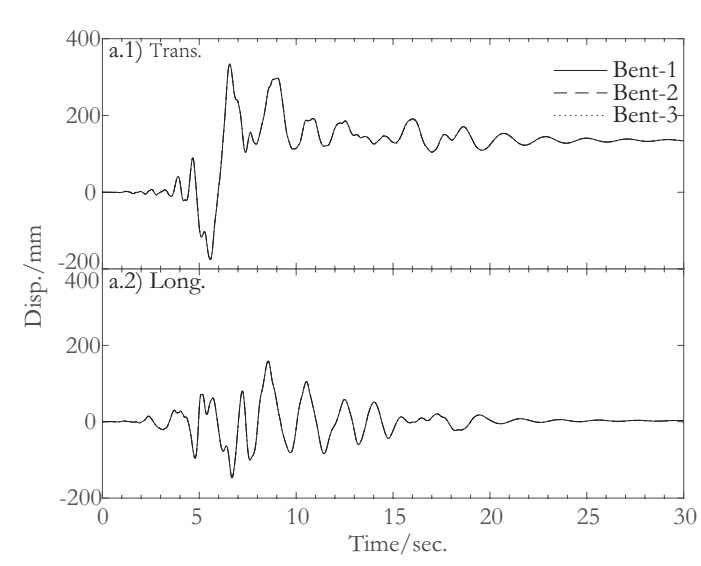

(a) Displacement Time History of Each Bent

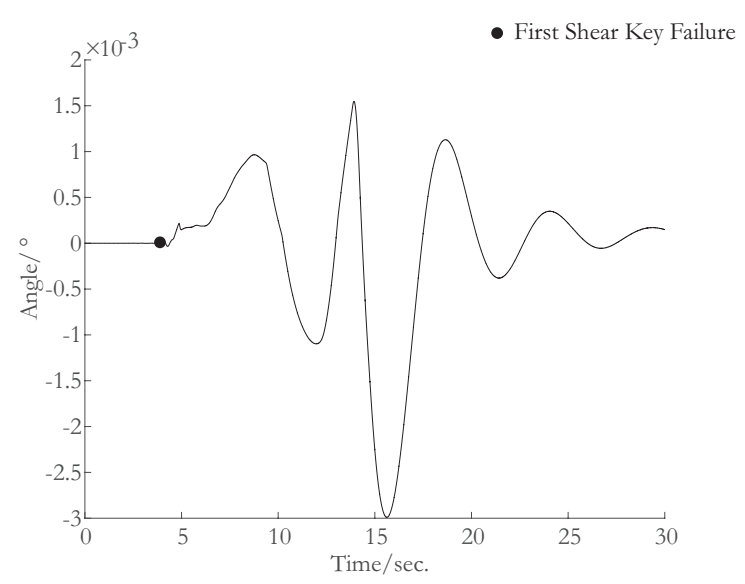

(b) Torsion of Superstructure

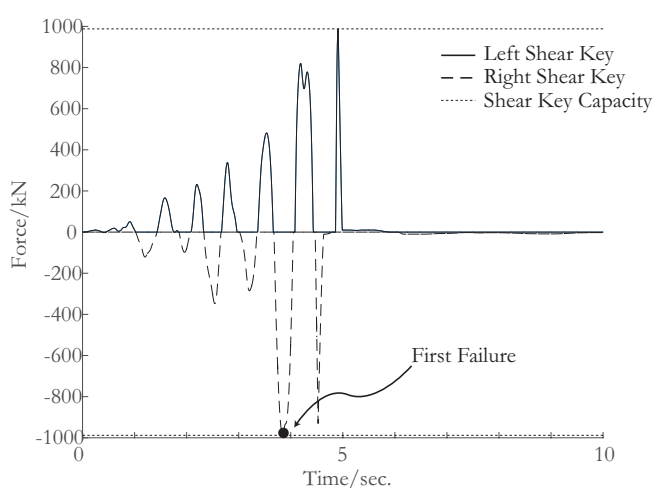

(c) Shear Key Reaction Force

Figure 6.1: Response of Original M1 during FF-1

The time history responses of all the bridge models subjected to the Canyon 


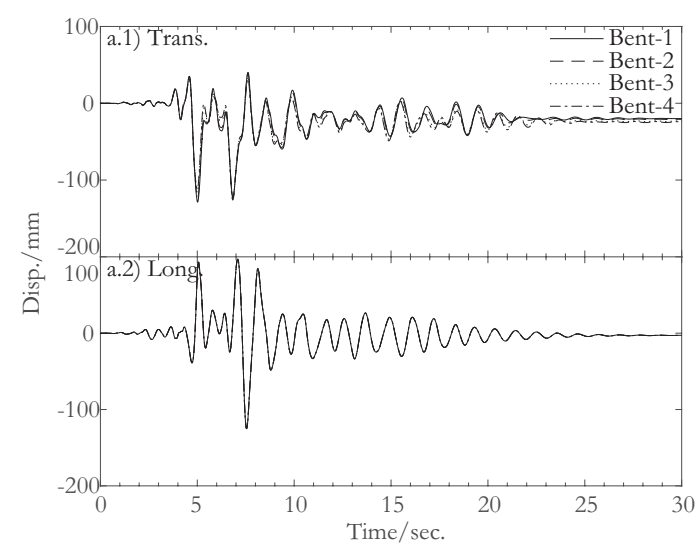

(a) Displacement Time History of Each Bent

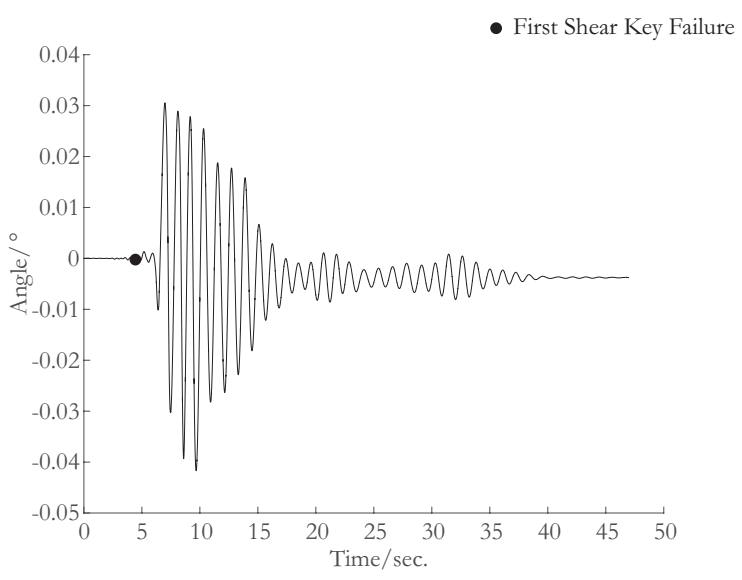

(b) Torsion of Superstructure

Figure 6.2: Response of Original M2 during FF-1

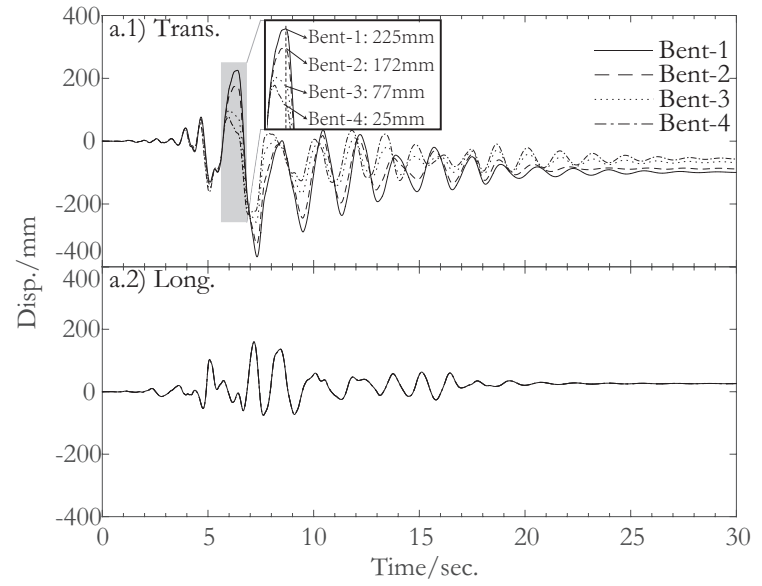

(a) Displacement Time History of Each Bent

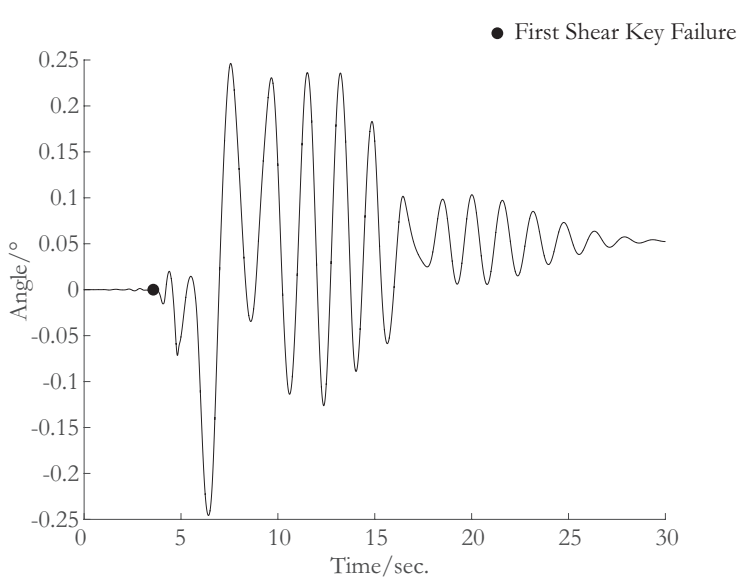

(b) Torsion of Superstructure

Figure 6.3: Response of Original M3 during FF-1

Country-WLC record obtained during the 1994 Northridge earthquake (Earthquake FF1 in Table 4.2) are presented from Figure 6.1 to Figure 6.4. These figures compare the displacement and rotation of the superstructure in each model. The displacement plots in Figure 6.1(a), Figure 6.2(a) and Figure 6.4(a) show that the superstructure of M1, M2 and M4 moves as a rigid body without significant global torsion effects. However, it can be seen from Figure 6.3(a) that M3 experiences more severe torsion than other models for this record since the decreasing displacement from one abutment to the other after 


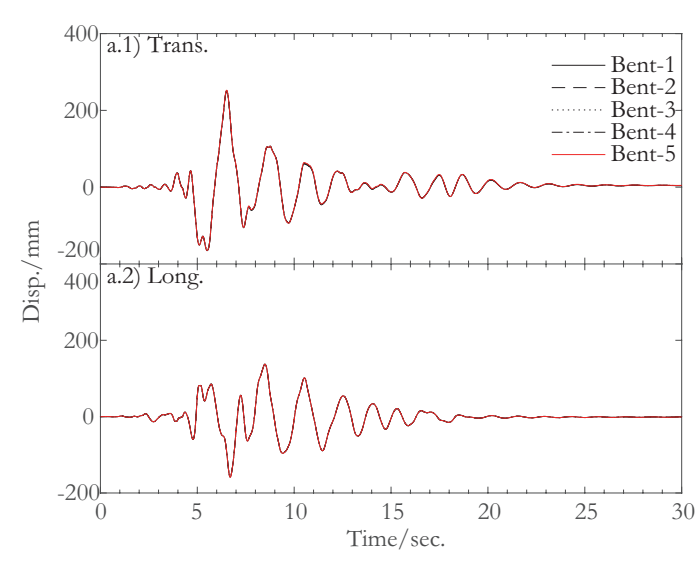

(a) Displacement Time History of Each Bent

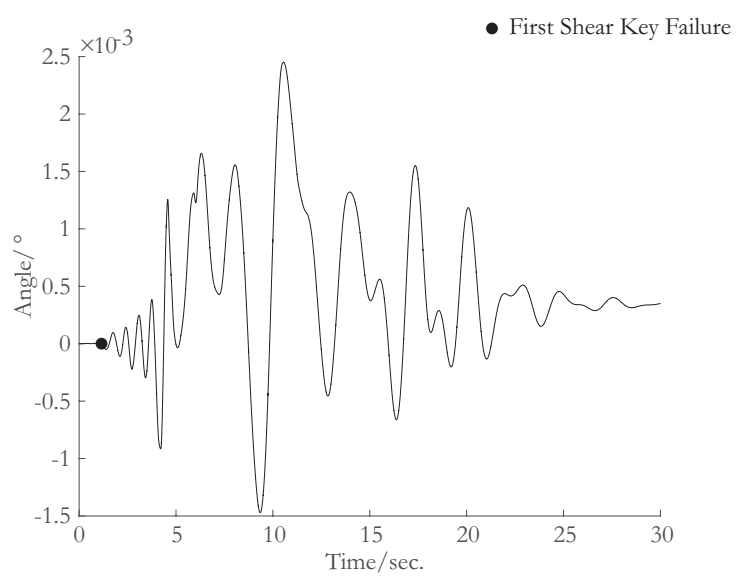

(b) Torsion of Superstructure

Figure 6.4: Response of Original M4 during FF-1

the failure of the shear key. For instance, the transverse displacements from Bent-1 (abutment) to Bent-4 (the other abutment) are $225 \mathrm{~mm}, 172 \mathrm{~mm}, 77 \mathrm{~mm}$ and $25 \mathrm{~mm}$ at $6.4 \mathrm{~s}$, respectively. During each ground motion, the longitudinal responses are almost identical at different bents.

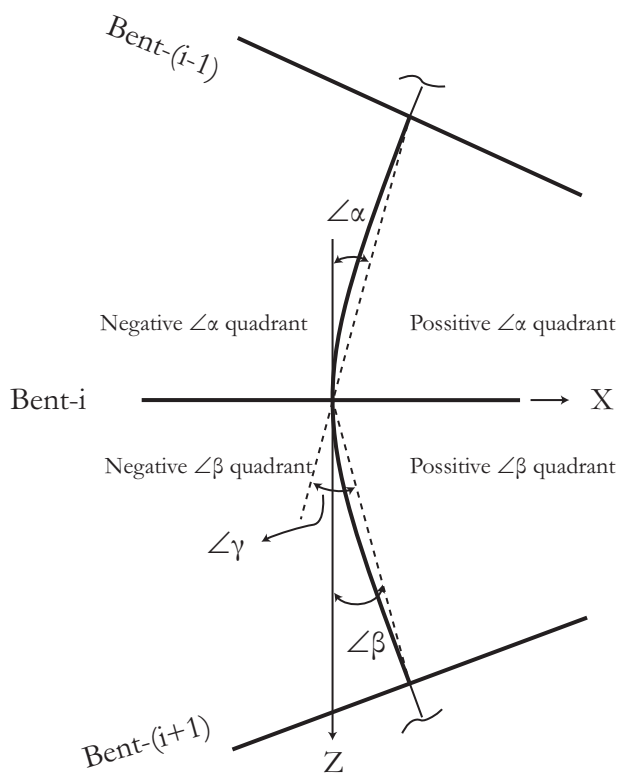

(a) Deck with Flextural Deforamtion

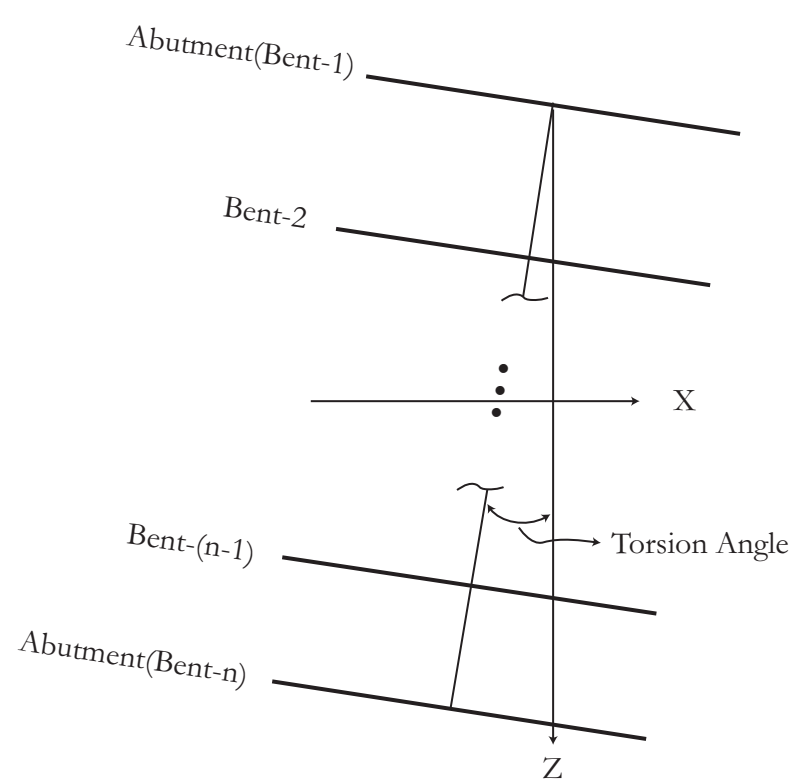

(b) Torsion Angle of Deck without Flexural Deformation

Figure 6.5: Angles in Fluextural Deforamtion Asessment 
To help assess the flexural deformation of the adjacent span, the angles $\angle \alpha, \angle \beta$ and $\angle \gamma$ are calculated from the bridge responses. As shown in Figure 6.5 (a), the superstructure moves as a rigid body when $\angle \alpha$ and $\angle \beta$ are of different signs and $\angle \gamma$ is negligible. The same positive or negative values of $\angle \alpha$ and $\angle \beta$ indicate that the deck has flexural deformation at this bent. The time histories of these three parameters show that for all the example bridges, the superstructures have negligible flexural deformation. For each model, the peak $\angle \gamma$ of each bent is used to represent the flexural deformation during each ground motion and the maximum of the peak $\angle \gamma$ stands for the flexural deformation of each set of ground motion. The peak $\angle \gamma$ of the original structures included in Table 6.1 also proves that the decks move as rigid body without flexural deformation. The global torsion of the deck can be represented by the torsion angle illustrated in Figure 6.5(b). The occurrence of torsion behavior in the bridge superstructure indicates failure of the shear key. As it is shown in Figure 6.1(b), the first failure of shear key in M1 occurred at $3.9 \mathrm{~s}$. This coincides with the time of the torsional response observed in M1.

Table 6.1: Peak Rotation $\angle \gamma$ at Bent of Example Bridges without Retrofit

\begin{tabular}{cccc}
\hline \multirow{2}{*}{ Model } & \multirow{2}{c}{ Bent } & \multicolumn{2}{c}{$\angle \gamma\left({ }^{\circ}\right)$} \\
& & FF & NF \\
\hline M1 & 2 & $1.8 \mathrm{E}-03$ & $1.7 \mathrm{E}-03$ \\
\hline \multirow{2}{*}{ M2 } & 2 & $6.1 \mathrm{E}-03$ & $6.1 \mathrm{E}-03$ \\
& 3 & $6.0 \mathrm{E}-03$ & $5.9 \mathrm{E}-03$ \\
\hline \multirow{2}{*}{ M3 } & 2 & $2.5 \mathrm{E}-04$ & $2.7 \mathrm{E}-04$ \\
& 3 & $2.5 \mathrm{E}-04$ & $2.7 \mathrm{E}-04$ \\
\hline & 2 & $7.8 \mathrm{E}-04$ & $7.6 \mathrm{E}-04$ \\
M4 & 3 & $1.2 \mathrm{E}-03$ & $1.0 \mathrm{E}-03$ \\
& 4 & $7.6 \mathrm{E}-04$ & $7.3 \mathrm{E}-04$ \\
\hline
\end{tabular}


From the discussions concerning global torsion and flexural deformation, it is concluded that the movement of the superstructure under each ground motion is the translational offset with negligible torsion or without torsion for all the original models. Thus, the response of the original structure subject to each ground motion record $\left(R P_{E Q, j}\right)$ can be represented by the mean of the response at all the bents $R P_{i}$, as shown in Equation 6.1. Since the torsion of the deck is significantly small, the maximum and mean of the response of each bent are almost identical. The performance of the structure subject to the input ground motions is presented as the mean and standard deviation of $R P_{E Q, j}$.

$$
R P_{E Q, j}=\frac{\sum_{i=1}^{n} R P_{i}}{n}
$$

where $R P_{i}$ and $R P_{E Q, j}$ are the response of bent $i$ and of the $j$ th ground motion, respectively. The $R P$ can be the peak displacement $\left(D_{\max }\right)$, the residual displacement $\left(D_{\text {res }}\right)$, the ratio of the residual to peak displacement $\left(D_{r / d}\right)$ and so on. $n$ is the total number of the bents (including abutments).

Given that the response of the bridges is sensitive to the ground motion characteristics, the mean $(\mu)$ and standard deviation $(\sigma)$ of the response recorded during ground motions in each set of excitations are calculated and presented to represent the seismic performance of the structures. The responses used to evaluate the original seismic performance are the peak displacement $\left(D_{\max }\right)$, residual displacement $\left(D_{\text {res }}\right)$ and the ratio of $D_{\text {res }}$ to $D_{\max }\left(R_{r / m}\right)$. Each of these responses is also compared in the transverse and longitudinal directions. The SRSS response is the square root of the sum of squares of the response in the transverse and longitudinal directions. The SRSS of $D_{\max }$ represents the overall maximum displacement.

The responses of the example bridges are summarized in Table 6.2. The abutment, as an economical and effective mean of inertial resistance, constrains the longitudinal movements; however, as discussed previously in this section, the shear key which aims 
to resist movements caused by service load is not capable of withstanding the severe seismic load. The failure of the shear key makes the bridges more vulnerable in the transverse direction. Therefore, the transverse peak displacement is much greater than the longitudinal peak displacement for all the bridges. The relatively greater transverse $D_{\max }$ also induces greater $D_{r e s}$ and $R_{r / m}$ in the same direction. The mean of $R_{r / m}$ can be as large as 33\% which is shown in M1. The greater $\sigma$ in the transverse direction can be attributed to the ground motion scaling method which scales each record according to the component assigned to the longitudinal direction.

\subsection{Performance of Retrofitted Structures}

\subsubsection{Peak Displacement}

The responses at all the bents of each model are similar due to negligible torsional response of the bridges or flexural deformation of the bridge deck superstructures. The response and performance of retrofitted structures are calculated and presented following the same presentation format as in the previous section. First, the effects of the brace on the retrofit performance are compared in the transverse and longitudinal direction separately. Then, the SRSS combination method is used to combine those responses to determine estimates for combined total maximum responses. The responses of the retrofitted structures are summarized in Table 6.3 to Table 6.6. The responses of the retrofitted structure are also normalized by those of the original structures to illustrate the trends of the parametric study. The normalized responses are defined in Equation 6.2:

$$
R P_{n m l}=\frac{R P_{R e}}{R P_{O r}}
$$

where $R P_{R e}$ and $R P_{O r}$ are the retrofitted and original responses, respectively.

These normalized parameters, as shown in Figure 6.6 to Figure 6.9 for each model, 
are used to evaluate the retrofit performance.

In investigating the effect of adding the SCED braces to the bridge structures, it is found the SCED braces stiffen the original structures and dissipate seismic energy during ground shaking. These two behavior obviously reduce $D_{\max }$ in the transverse and longitudinal directions. $D_{\max }$ in the longitudinal direction after retrofit, compared with that in the transverse direction, is usually smaller as shown in Table 6.3 to Table 6.6. This can be explained by the contribution of the abutments and the different numbers of braces in each direction. The contribution of the abutments has been discussed previously. By comparing brace properties in the same case (Case-1 as and example shown in Table 5.2), it is known that the total activation forces $(500 \mathrm{kN}$ and $540 \mathrm{kN})$ and the individual brace initial stiffness $\left(104 \mathrm{kN} \mathrm{mm}^{-1}\right.$ and $\left.129 \mathrm{kN} \mathrm{mm}^{-1}\right)$ in the transverse and longitudinal directions are close. It is noted that the number of braces in the transverse direction is two times of that in the longitudinal direction. Combining these two facts, the braces contribute more stiffness in the transverse direction. However, the relationship of $D_{\max }$ in the transverse and longitudinal directions is not only determined by the stiffness contributed by the braces. The original structure stiffness in different directions and the sensitivity of the structure to the different types of ground motions can also affect their behavior. The energy dissipation capacity of the braces is discussed in Section 5.3. In study of cases with the same $\beta$ value (as shown in Table 6.3 to Table 6.6), the difference between $D_{\max }$ in the transverse and longitudinal directions is mitigated with the decreasing brace design factor $(D F)$. However, this pattern is not always followed in some of the investigated cases. Generally, the mitigation of the performances in different directions can be obtained by reducing $D F$. The effects of the number of the braces in a certain direction on the stiffness and energy dissipation contributed to the structure also imply that a better retrofit performance might be achieved if the design force is distributed to more braces.

The SCED braces are effective in terms of reducing $D_{\max }$ for both FF and NF 
ground motions since the normalized $D_{\max }$ is less than 1 . By comparing the retrofit performances under far-field and near-near field ground motions, it can be concluded that the SCED braces are extremely effective at reducing $D_{\max }$ when the structure is subjected to the near-field ground motions. Previous research investigating retrofitting bridges with SMA restrainer also concludes that self-centering device is very effective for near-field ground motion [44]. From Case-1 to Case-4 ( $\beta=0.9)$ for M1, $D_{\max }$ drops about $60 \%$ (take $D F=8$ as the base) under NF ground motions but drops about $30 \%$ under FF ground motions. The same comparison is also observed in the cases with $\beta=0.45$ and $\beta=0$. It is concluded that $D_{\max }$ reduces $38 \%$ under FF ground motions but reduces $68 \%$ under NF ground motions. For other models, the reduction of $D_{\max }$ under NF ground motions is also greater than that under FF ground motions. In other word, $D F$ does not affect the retrofit performance under the far-field ground motions as significantly as it does under the near-field ground motions. By comparing Cases-1, 5 and 9 which have the same $D F(D F=8)$ but different $\beta$ ( $\beta$ is $0.9,0.45$ and 0 , respectively) (shown in Figure 6.6 to Figure 6.9), it shows that $\beta$ does not significantly affect the retrofit performance regardless of the types of ground motion.

As mentioned in Section 5.3, the decreasing $\beta$ increases the pretension force but reduces the friction force. The increasing $P_{\text {pre }}$ requires more tendons to be installed and larger dimension steel tube to geometrically contain these tendons. It increases the retrofit costs. The reduced friction force implies less seismic energy can be dissipated in each cycle. Therefore, the decreasing $\beta$ will produce stiffer braces with lower energy dissipation capability. The trade-off between the stiffness and energy dissipation capacity of the SCED braces is recognized which can affect the decision of designers in using the proposed retrofit system in actual field immplementation of bridge retrofit. Obviously, it is economical to design the braces with moderate stiffness and some energy dissipation capacity. The braces designed according to moderate $D F$ are with moderate stiffness but are more likely to deform beyond their deformation capacity. This issue can be resolved 
by implementing longer SCED braces or Telescoping (T-SCED) braces. It is recognized that longer SCED braces and T-SCED braces have larger deformation capacity which can accommodate greater response during earthquakes [55]. The structure implemented with longer SCED braces or T-SCED braces has similar performance as it is retrofitted with the SCED braces [13]. From this perspective, the combination of $D F=4$ or 6 and $\beta=0.45$ which produces braces with smaller dimensions becomes reasonable and economical. Thus, $D F=4$ or 6 and $\beta=0.45$ are the desirable design parameters.

The reduced $D_{\max }$ shows that the implemented braces protect the structural elements from significant nonlinear behavior. As a result, another substantial benefit of retrofitting bridges with the SCED braces is the appreciable drop in the residual deformation. The properly designed braces provide sufficient restoring forces to recenter the deformed structure with negligible or no residual displacement. In the parametric study for the bridge models, $D_{r e s}$ and $R_{d / r}$ are approximately zero. This benefit is attractive given that the retrofitted structures have eliminated the mis-alignment problems at the piers and the abutment approaches after earthquakes. The bridges with SCED braces would remain functional and provide the emergency access to the hospital, fire station and so on even after the MCE level earthquakes.

\subsubsection{Peak Acceleration and Velocity}

As discussed in this chapter, the performance of the bridge model subject to the selected ground motions is presented by the mean of the responses at each bent. The SRSS of the peak acceleration $\left(a_{\max }\right)$ and velocity $\left(v_{\max }\right)$ of the retrofit structures are 


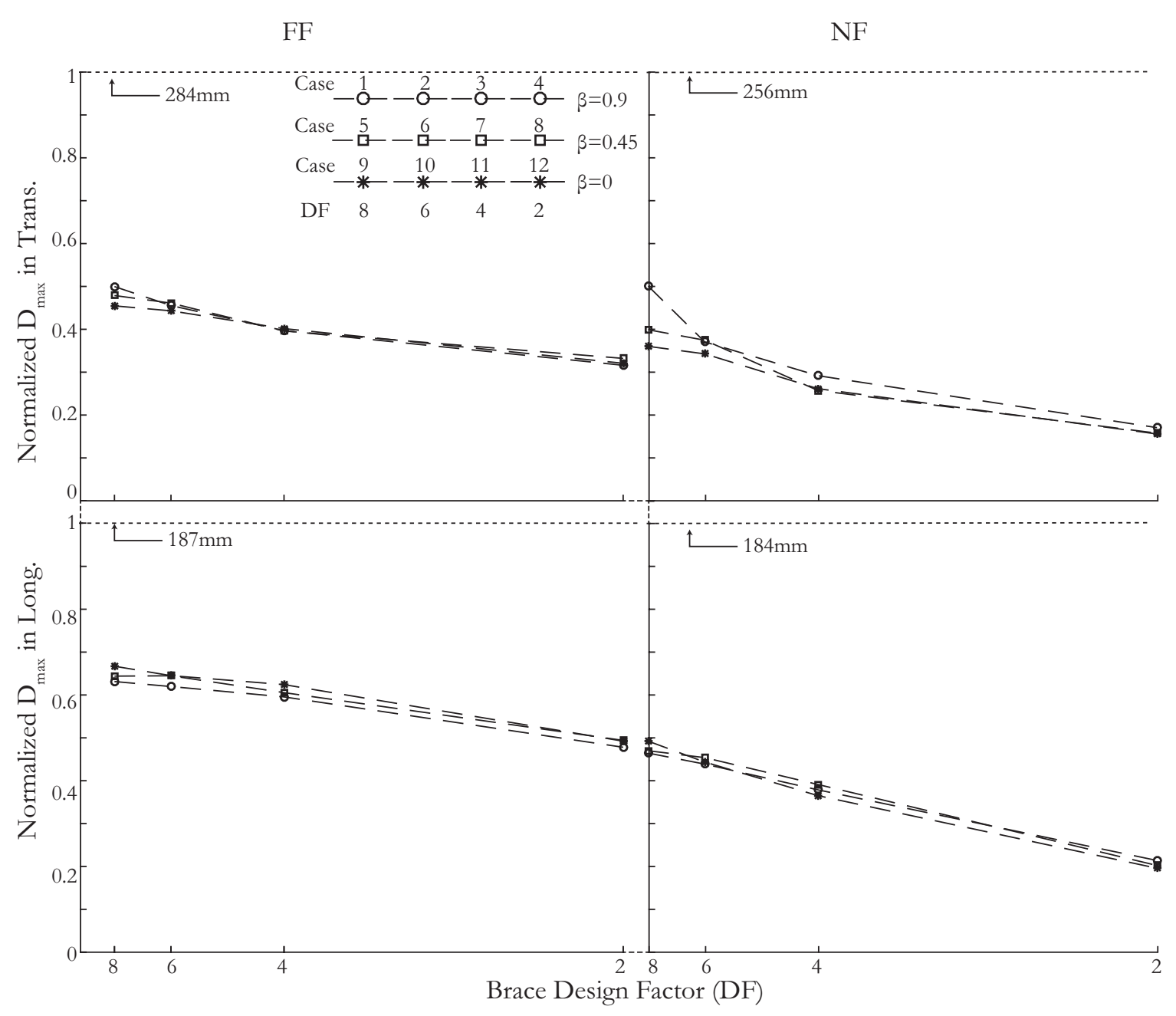

Figure 6.6: Comparison of Peak Displacement for M1

normalized with the values observed with the original structures (as shown in Table 6.7). The normalized SRSS of $a_{\max }$ and $v_{\max }$ are compared in Figure 6.10 to Figure 6.13.

It is evident that the retrofitted structures usually experience larger acceleration than the original ones. The SCED braces stiffen the structure and shift the fundamental period to a lower period. From peak acceleration response spectrum, it is known that the structure with shorter period tends to attract greater energy input from the ground motion than the longer-period ones. The parametric study reveals that the braces designed with same $\beta$ increase $a_{\max }$ when $D F$ is decreasing. For the braces with the same $D F, a_{\max }$ has negative correlation with $\beta$. The brace with smaller $\beta$ and $D F$ contributes 
FF

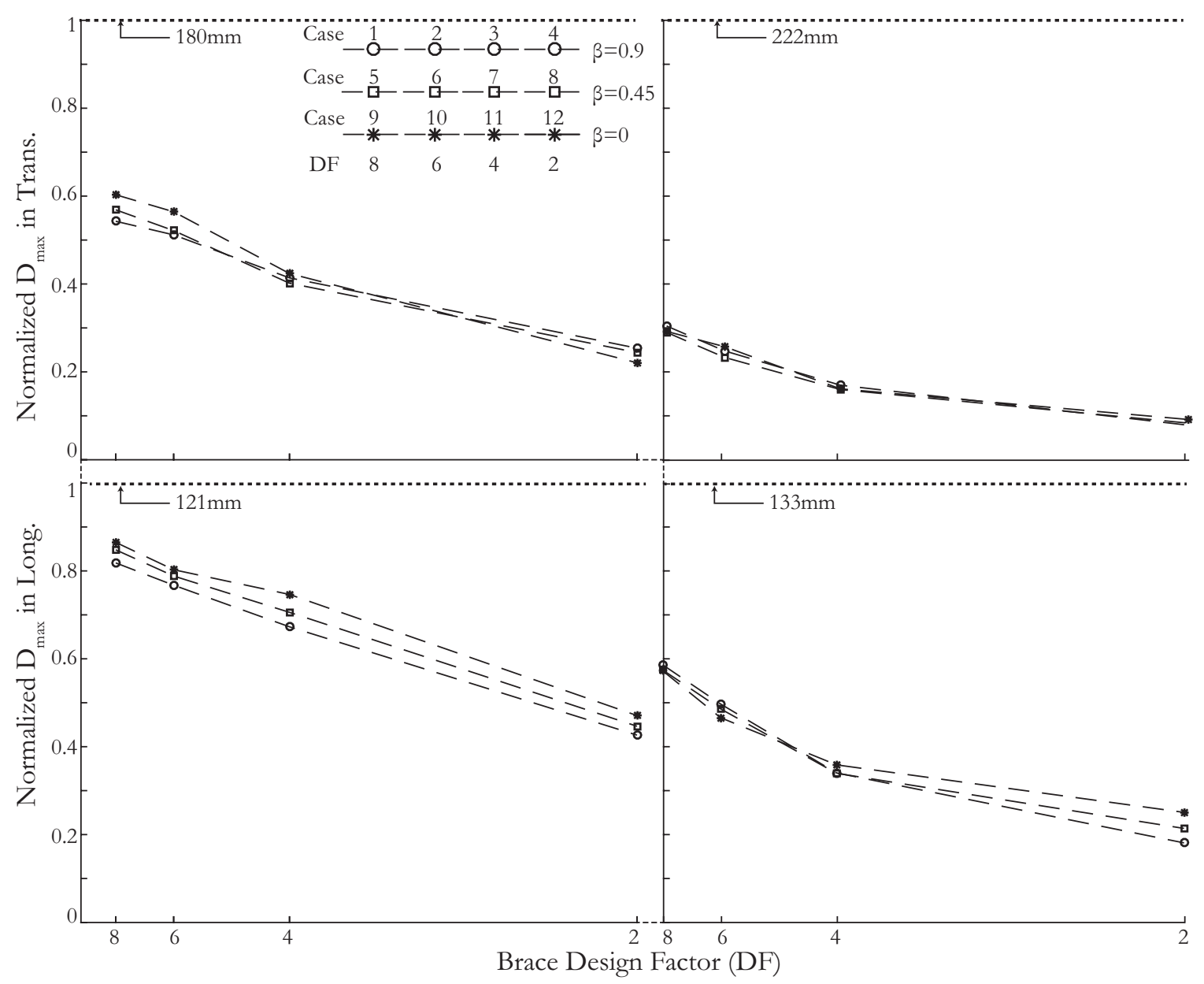

Figure 6.7: Comparison of Peak Displacement for M2

greater initial stiffness to the structure.

The SCED braces help the structures reduce $v_{\max }$ under NF ground motions but increase it slightly when the structure is subjected to the FF ground motions. In the parametric study, $D F$ does not change $v_{\max }$ in the FF ground motions but affects $v_{\max }$ in the NF ground motions. For each $D F$, the smaller $\beta$ will increase $v_{\max }$ in both ground motion types. Considering the SCED braces are extremely effective in reducing $D_{\max }$ for the structures subjected to NF ground motions, the shorter distance is traveled in the momentum. Thus, the normalized $v_{\max }$ is smaller in the NF ground motions. 
FF

$\mathrm{NF}$

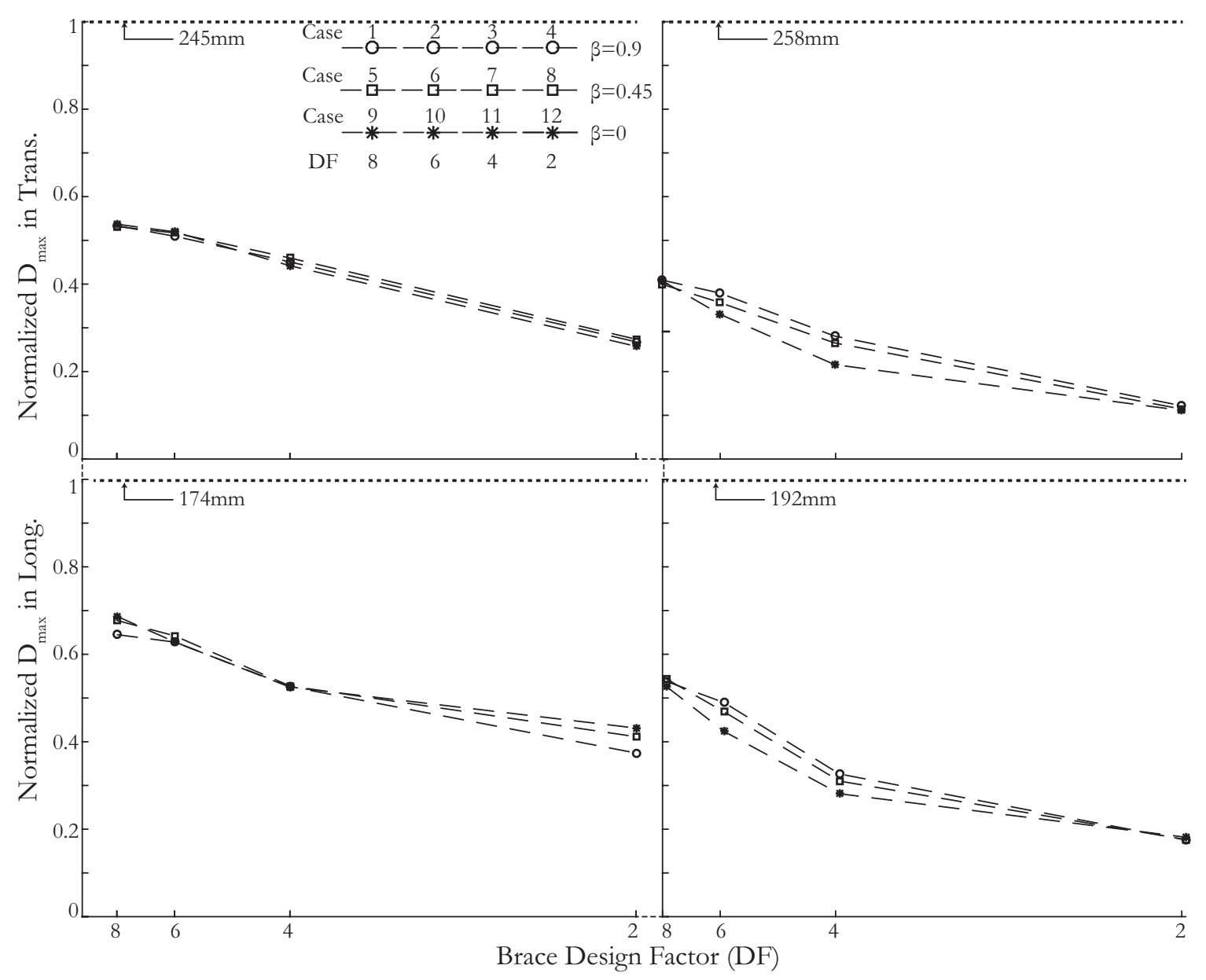

Figure 6.8: Comparison of Peak Displacement for M3

The altering of the fundamental period is not the only contribution to the increment of $a_{\max }$. The acceleration response of the SCED braced frames obtained by numerical model has been compared with shake table test by Erochko et al. [13]. It is acknowledged that the exaggerated acceleration experienced by the structure is inherent with the use of SCED braces. Figure 3.14 shows that the stiffness transitions in the model are sharp. The braces in the shake table tests provide smoother transitions in time between the low and high stiffness [13]. It is recommended a more realistic model with gradual transition could be developed and adopted in future analysis to get a better estimate of the accelerations. 
FF

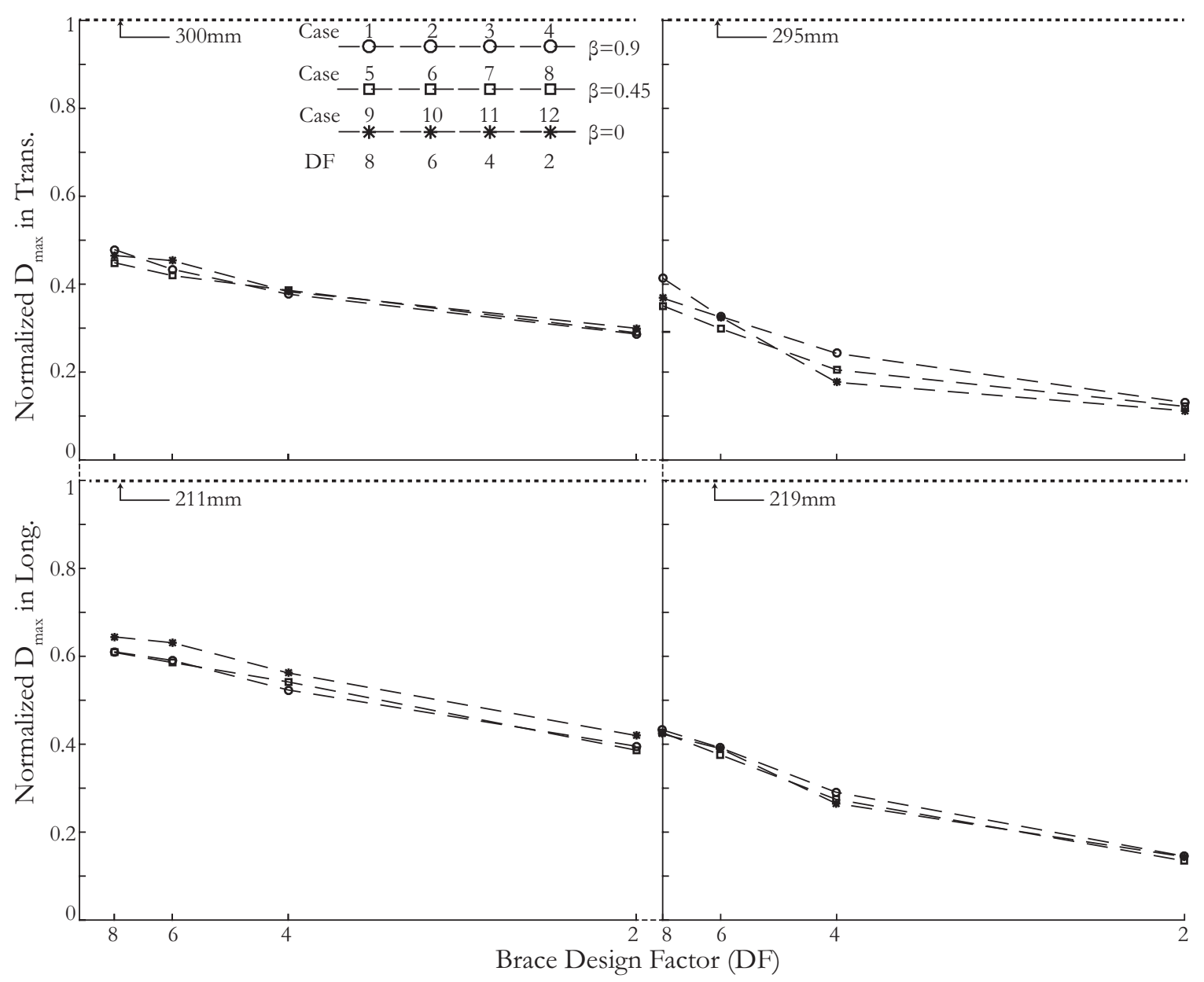

Figure 6.9: Comparison of Peak Displacement for M4

The SCED braces help the structures reduce $v_{\max }$ during NF ground motions but increase it slightly when the structure is subjected to the FF ground motions. In the parametric study, $D F$ does not change $v_{\max }$ in the FF ground motions but affects $v_{\max }$ in the NF ground motions. For each $D F$, the smaller $\beta$ will increase $v_{\max }$ in both ground motion types. Considering the SCED braces are extremely effective in reducing $D_{\max }$ for the structure subjected to NF ground motions, the structure does not have sufficient time to build up velocity in its response. Thus, the normalized $v_{\max }$ is smaller in the cases of NF ground motions compared to the cases of FF ground motions with larger $D_{\max }$. 
As recommended previously, $D F=4$ or 6 and $\beta=0.45$ is preferred in design. From the perspective of reducing $a_{\max }$ and $v_{\max }$, this combination is not preferred. The smallest $D F$ leads to the increase of normalized $a_{\max }$ by a factor of more than 2 . The larger $a_{\text {max }}$ experienced by a regular bridge may not be as significant when compared with the case of a building. The relatively small height of the bridge can reduce the $P-\Delta$ effect and limit the moment induced by the increasing inertia force. The high $a_{\max }$ in a building may lead to significantly increase in risk to the occupants' safety due to the high acceleration of non-structural components, such as suspended ceilings, overhead utility lines and falling furniture. The wide and clear space on a bridge can reduce this risk. The increase in $a_{\max }$ in the case of bridges may have a higher chance of being tolerated as long as the braces can withstand the high inertia force demand transmitted to the braces from the bridge superstructure.

\subsubsection{Base Shear}

The base shear $V$ accounts for all the lateral forces exerted on the deck and piers of the bridge. In the original structure, the base shear is resisted by the shear keys and the foundation of the piers. In the retrofitted structure, the SCED braces contribute to the resistance of the base shear. Higher base shear is observed in the retrofitted structure for all the bridge models. This is attributed to the additional stiffness provided by the braces. To compare the effects of the braces on $V$ in the individual direction, $V$ is calculated and compared in these two perpendicular directions, respectively. The time histories of $V$ in the case where $D F=8$ and $\beta=0.9$ for M4 during FF-7 are shown as an example in Figure 6.14. For each component of $V$, the values from the retrofitted and original structure are also compared.

Xi Cheng, Department of Civil and Environmental Engineering, Carleton University 


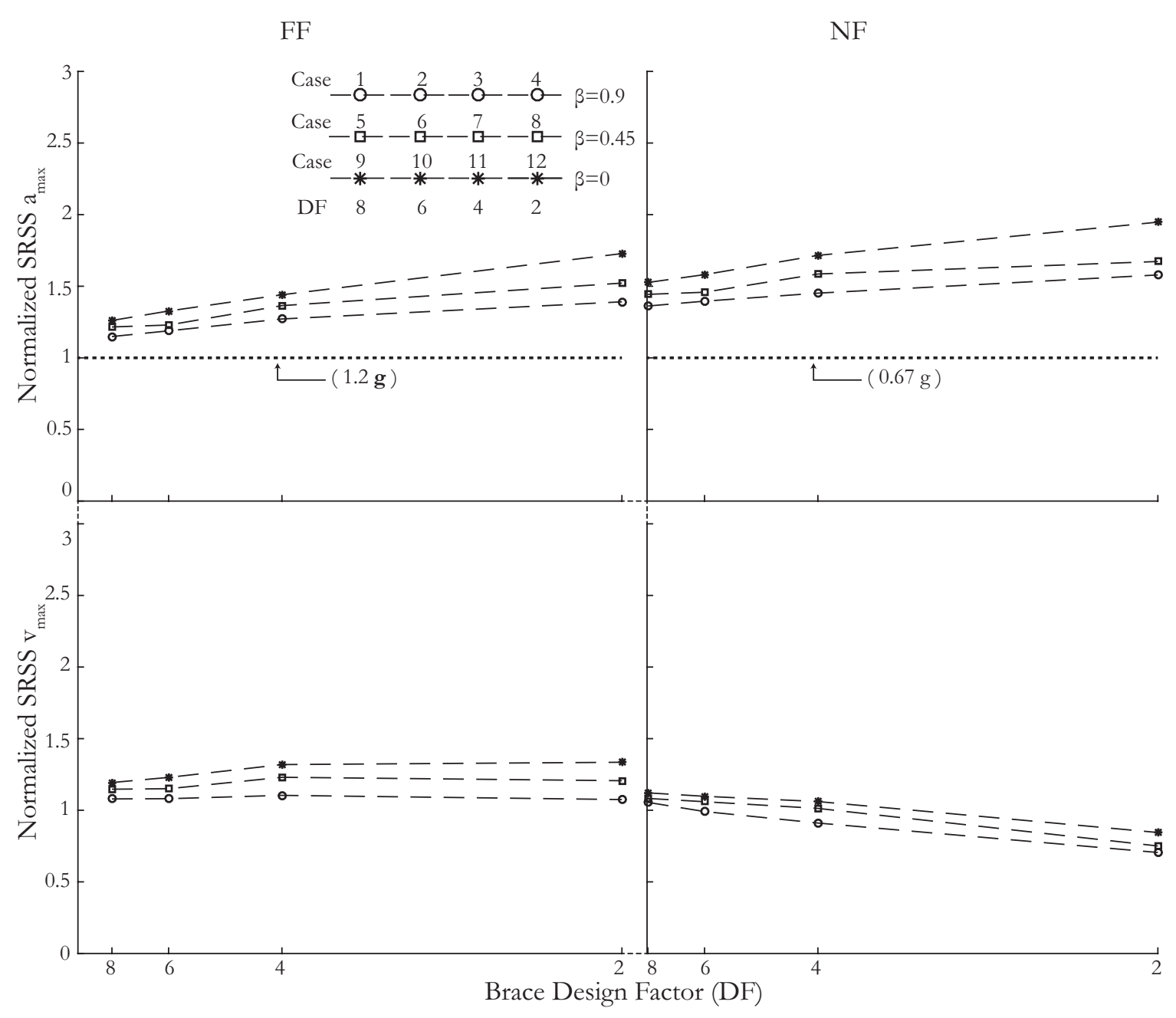

Figure 6.10: Comparison of SRSS Peak Acceleration and Velocity for M1

It is found that the total base shear $V_{\text {total }}$ increases drastically in both directions due to the braces implemented to the structure. Besides, the $V_{\text {total }}$ time history of the retrofitted structure has higher frequency content, compared with that of the original structure. These two facts can be explained by the following reason. The retrofitted structure has higher stiffness and this leads to shorter vibration periods of the bridge, thus attracting higher load.

By comparing the time histories in this case, the piers in the original structure experience greater base shear than those in the retrofitted structure. Although the total base shear is increased in the retrofitted structures, the extra base shear comes from the 


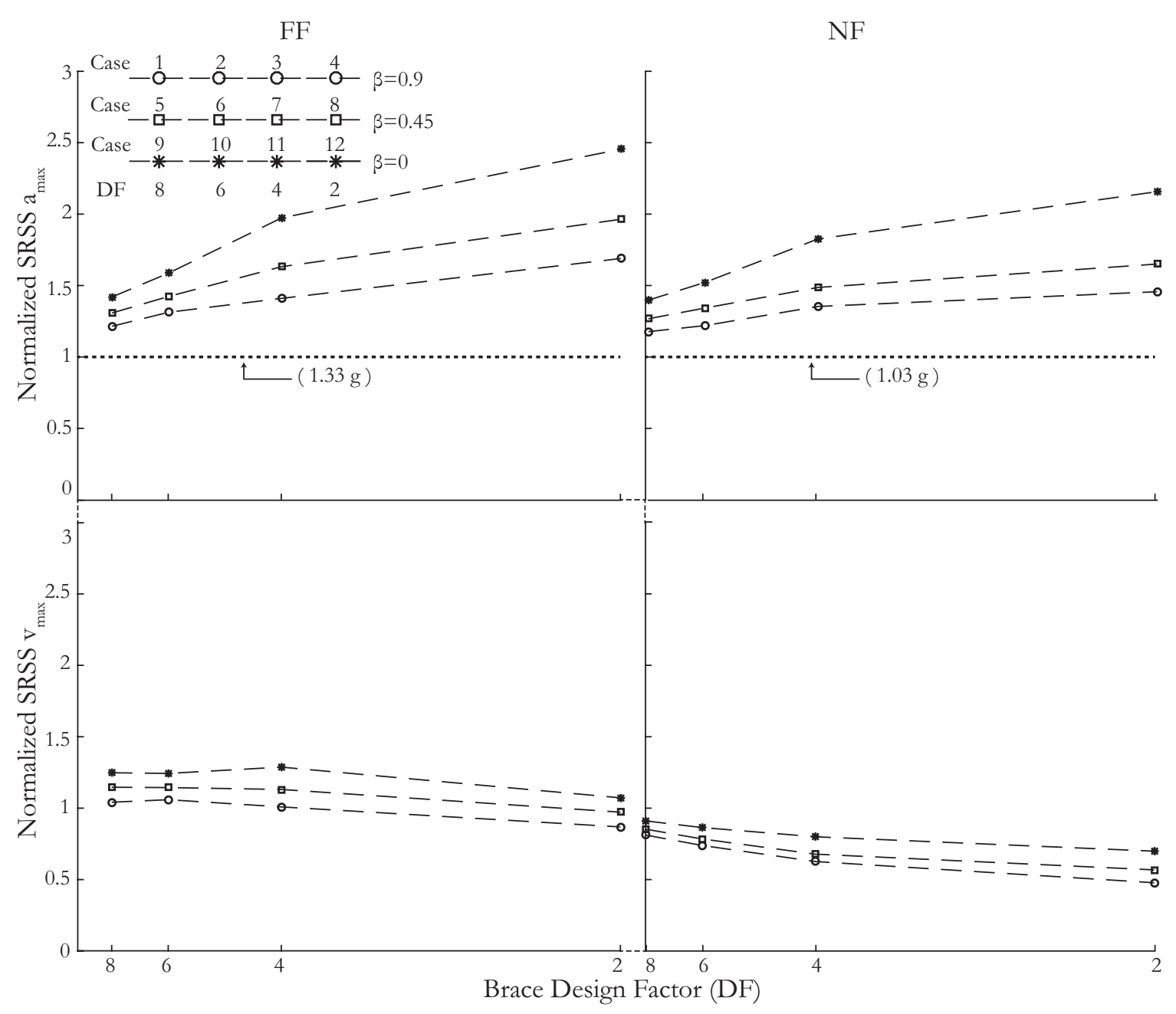

Figure 6.11: Comparison of SRSS Peak Acceleration and Velocity for M2

braces and the force experienced by the piers is reduced in both transverse and longitudinal directions. However, the piers in the retrofitted structure experience the similar peak force as they do in the original structure in some of the cases. The extended duration of the piers involved in the seismic response could increase the cumulative curvature and deteriorate the piers. It can be seen from $V_{\text {pier }}$ time histories that the piers take all the transverse base shear once the shear keys fail. The transverse braces work in series with the shear keys and take majority part of the transverse base shear. Thus, the shear keys failed later than they do in the original structure. In the longitudinal direction, the piers are effectively protected by the braces. The behavior of the base shear induced by 


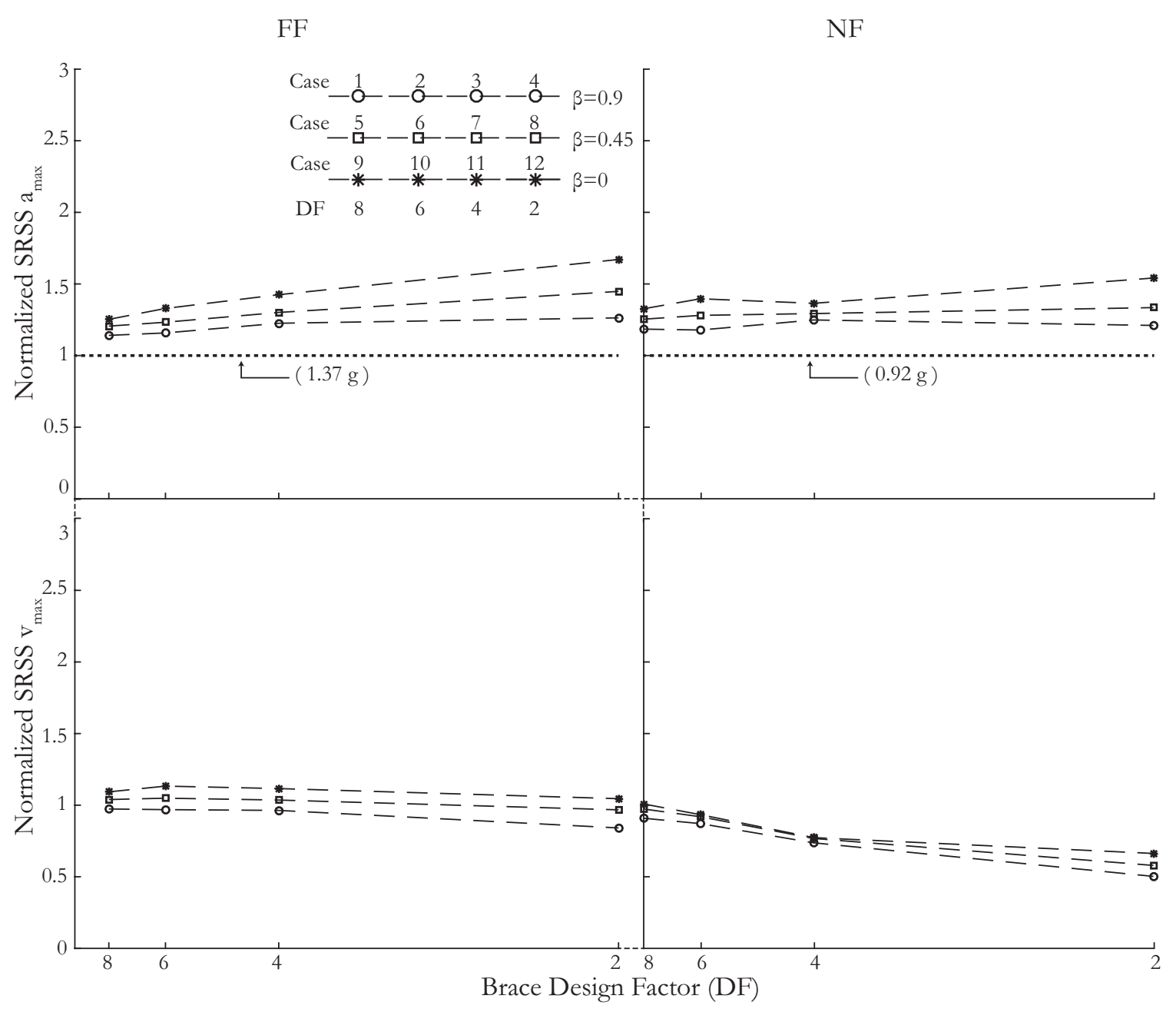

Figure 6.12: Comparison of SRSS Peak Acceleration and Velocity for M3

the gap closing at the abutments $\left(V_{a b t}\right)$ is also investigated. In some cases, $V_{a b t}$ does not arise in the retrofitted structure. This can be attributed to the case that the SCED braces protect the bridge deck superstructure limiting its displacement in the longitudinal direction preventing the gap at the expansion joints from fully close-up inducing impact force damage to the abutment.

The time histories of base shear in other cases are similar and are not presented here to avoid duplications. The results of Case-5 through Case-8 ( $\beta=0.45$ and $D F$ is 8 , 6, 4 and 2, respectively) during FF-1 for M4 are shown in Figure 6.15 to assess the effects of $D F$. For the cases with the same $\beta$ value, $D F$ does not change the waveform pattern 


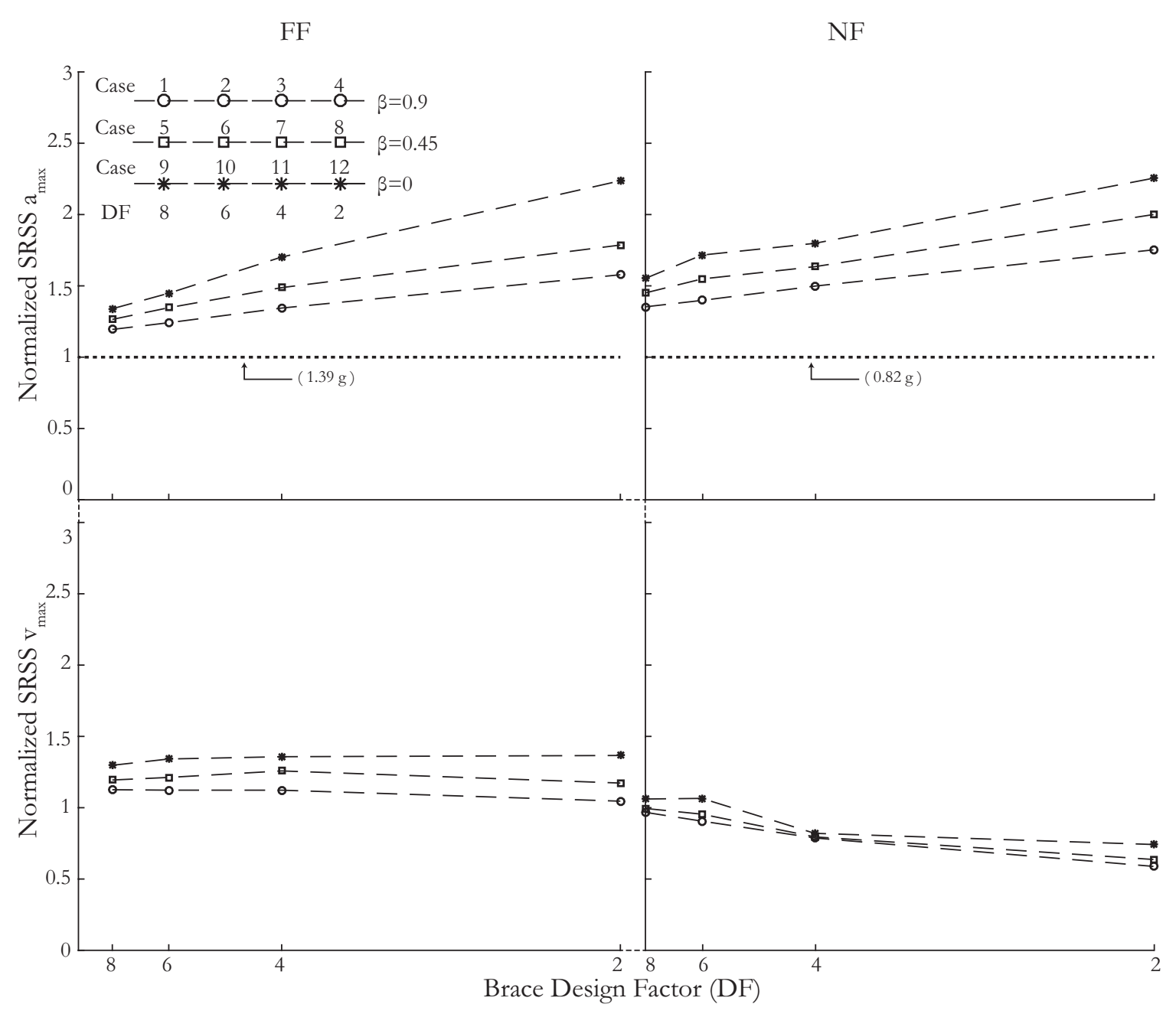

Figure 6.13: Comparison of SRSS Peak Acceleration and Velocity for M4

of the base shear time history, the change is mainly in the amplitude and it shifts in time slightly.

Figure 6.16 (Case 4, 8 and 12, which have same $D F=2$ but $\beta$ is $0.9,0.45$ and 0 , respectively) shows that the smaller $\beta$ is, the greater the peak $V_{\text {total }}$ will be. However, the variation in $\beta$ does not affect the peak $V_{\text {pier }}$. From these results, it is observed that the shear keys also fail in the retrofitted structure, but the transverse braces can effectively limit the transverse response and loads transmitted to the abutments. The decrease in $D F$ can effectively reduce the longitudinal response of the bridge and prevent the impact between the deck and the abutments. Thus, $V_{a b t}$ may disappear in some cases. The same 
qualitative conclusions can be made for the results from NF ground motions.

The great amount of the total base shear was resisted by the SCED braces. The foundation and connections of the SCED braces should be taken care of in design. The external friction fuse may be helpful in reducing the demand loads of the foundation and the connection of the braces.

\subsubsection{Cumulative Curvature and Ductility}

As it is discussed in Section 3.2 that most of the nonlinear behavior is concentrated in the bridge piers. The expansion bearing connecting the piers to the superstructure release the rotational constraint at the top of the piers while the piers are fixed at their bases. The curvature of the pier increases from the top of the pier to the point of fixity. The maximum moment of the pier is observed at the base. If the moment-curvature relationship at the fixity point is within acceptable range, the pier remains serviceable.

The cumulative curvature at the base of the pier is also compared in the parametric study. Figure 6.17 to Figure 6.20 show the normalized cumulative curvature for the design cases in the parametric study. The SCED braces effectively reduce the cumulative curvature experienced by the piers regardless of ground motion type. For the design cases with same $D F$, a greater $\beta$ yields smaller cumulative curvature. This can be attributed to the fact that the braces with higher $\beta$ contribute more damping to the retrofitted structure and thus, help the vibration die down faster. For the cases with the same $\beta$, the decreasing $D F$ results smaller cumulative curvature.

The ductility is also considered as a response index. As illustrated in Figure 6.21, the plastic hinge forms gradually and there is uncertainty in determining the exact $\phi_{y}$ 

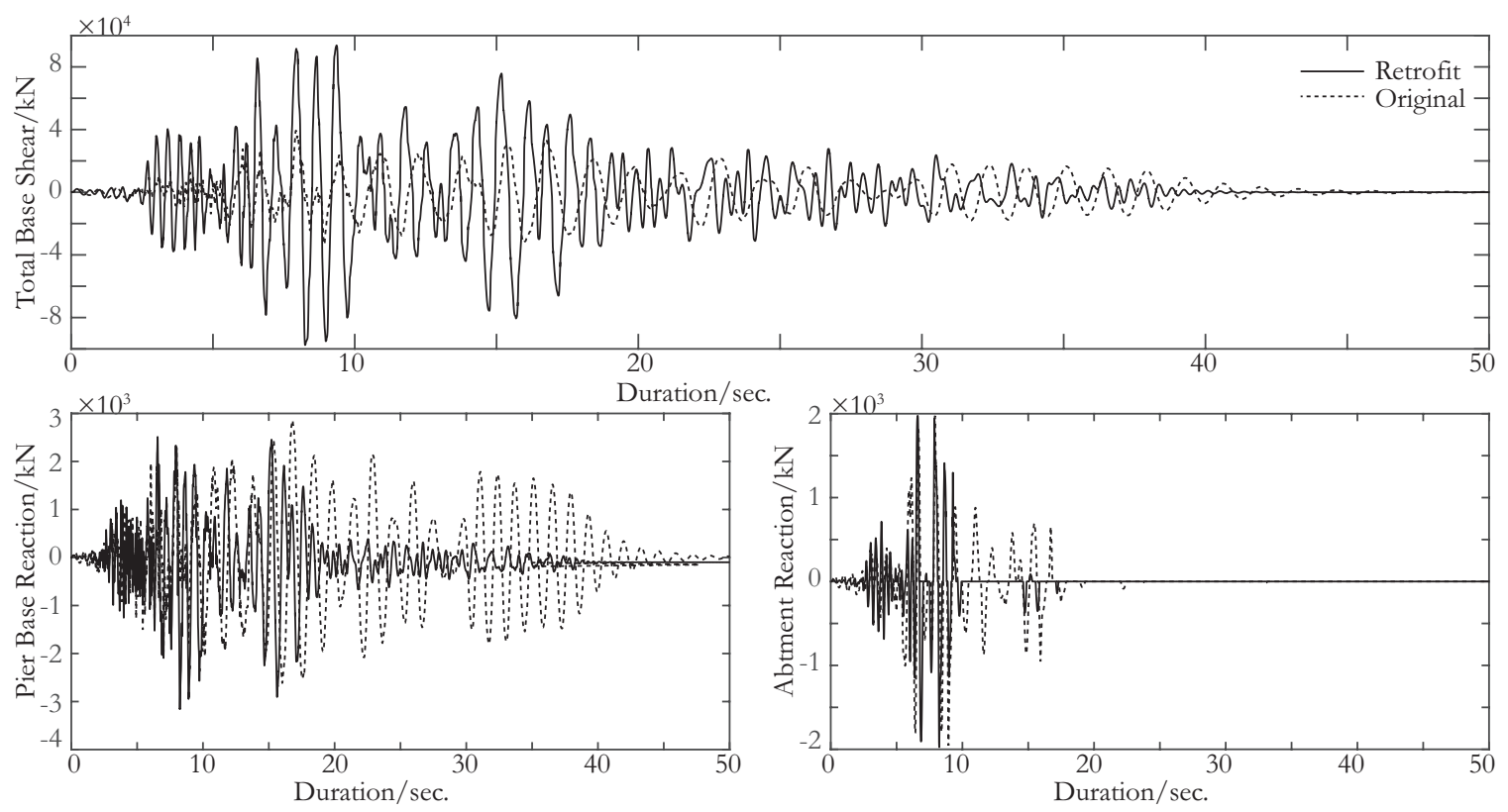

(a) Transverse Direction
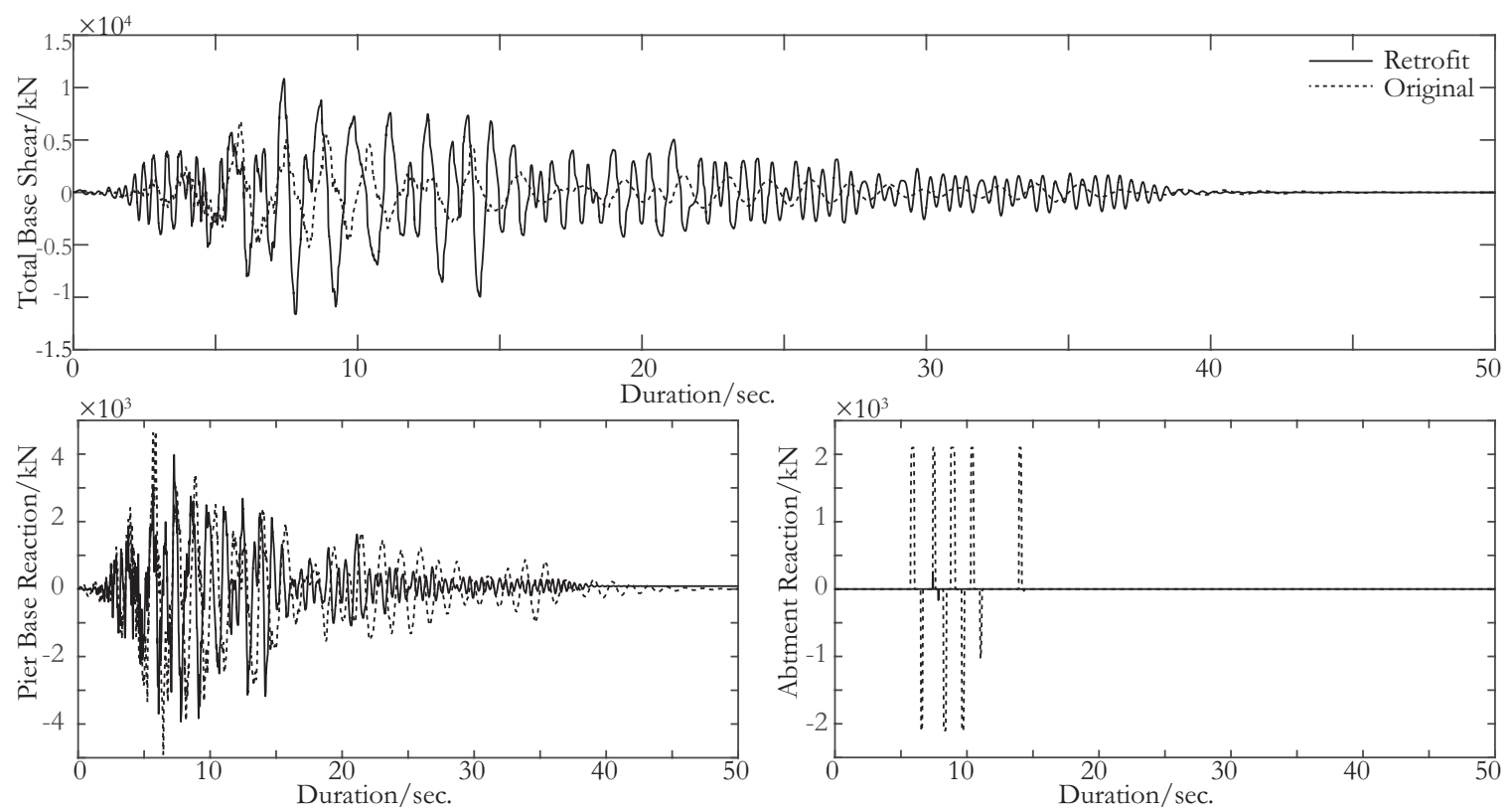

(b) Longitudinal Direction

Figure 6.14: M4: Base Shear Time History during FF-7 in Case-1 $(\beta=0.9, D F=8)$

of the pier. Therefore, the yielding curvature $\phi_{y}$ of the pier is estimated between $\phi_{y, \min }$ and $\phi_{y, \max }$. The upper and lower bound ductility of the pier, as shown in Table 6.8 to 

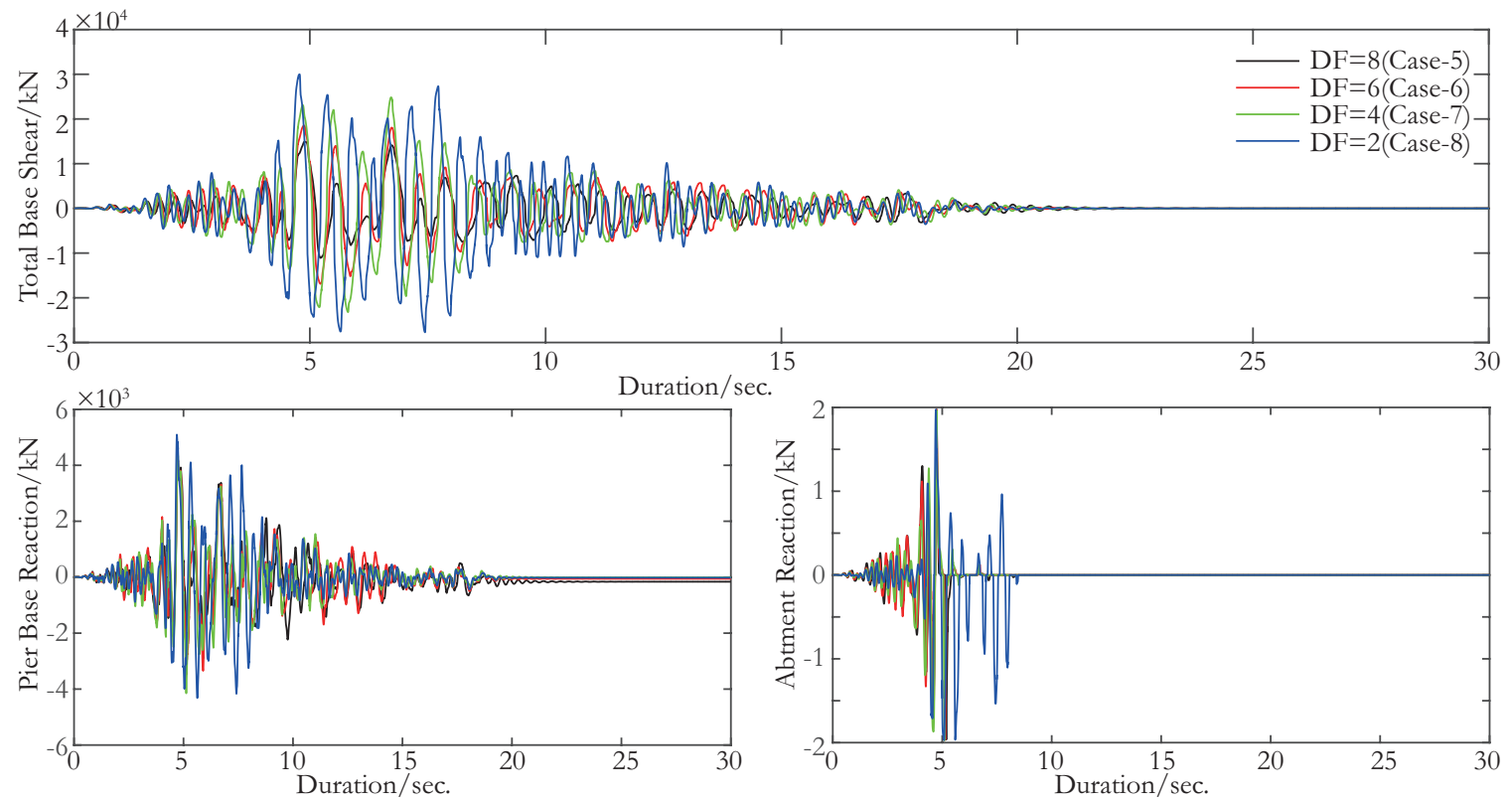

(a) Transverse Direction
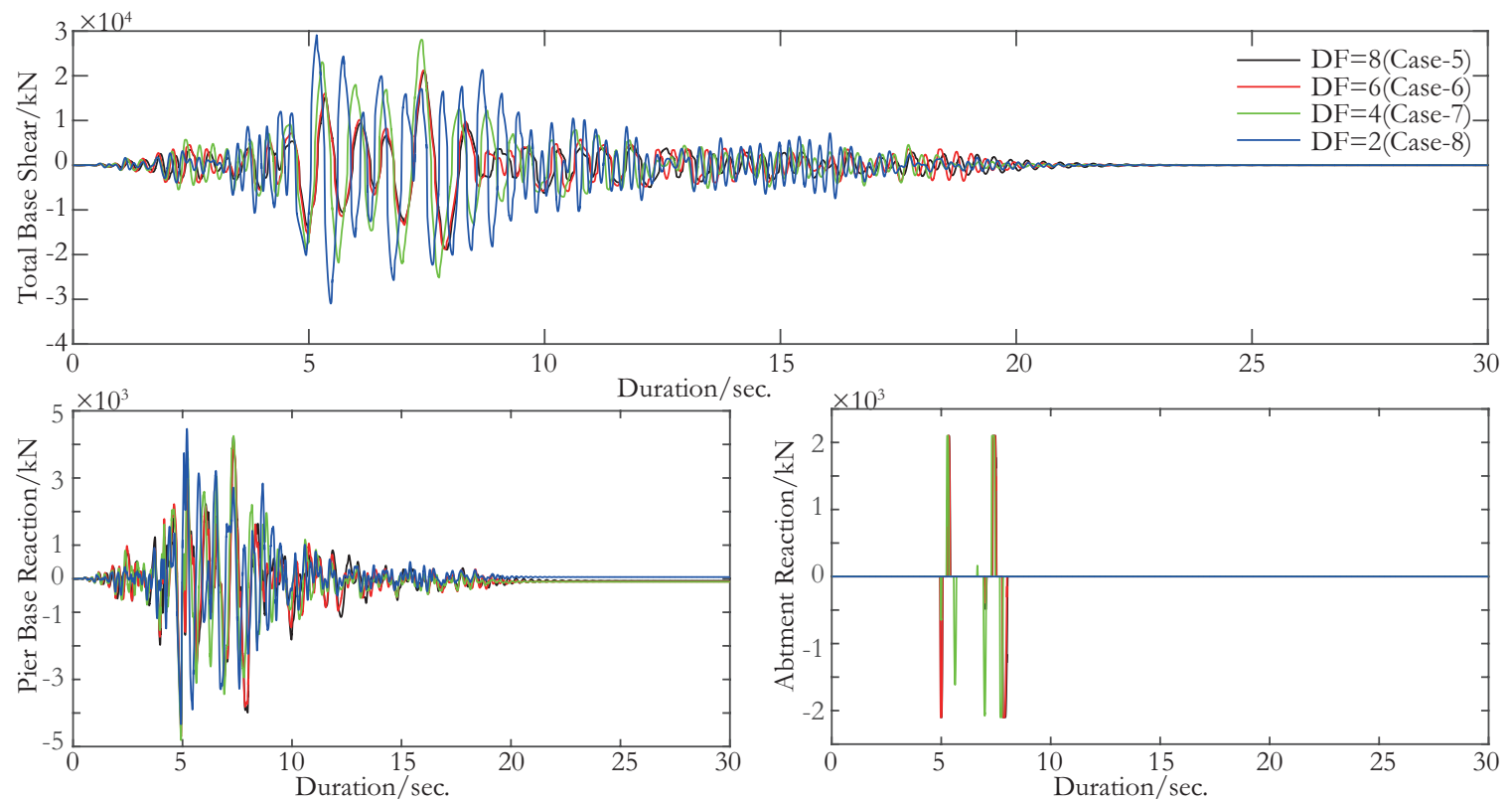

(b) Longitudinal Direction

Figure 6.15: M4:Base Shear Time History during FF-1 $(\beta=0.45)$

Table 6.9, is calculated per Equation 6.3:

$$
\mu_{\Delta}=\frac{\phi_{u}}{\phi_{y, \max }\left(\text { or } \phi_{y, \min }\right)}
$$



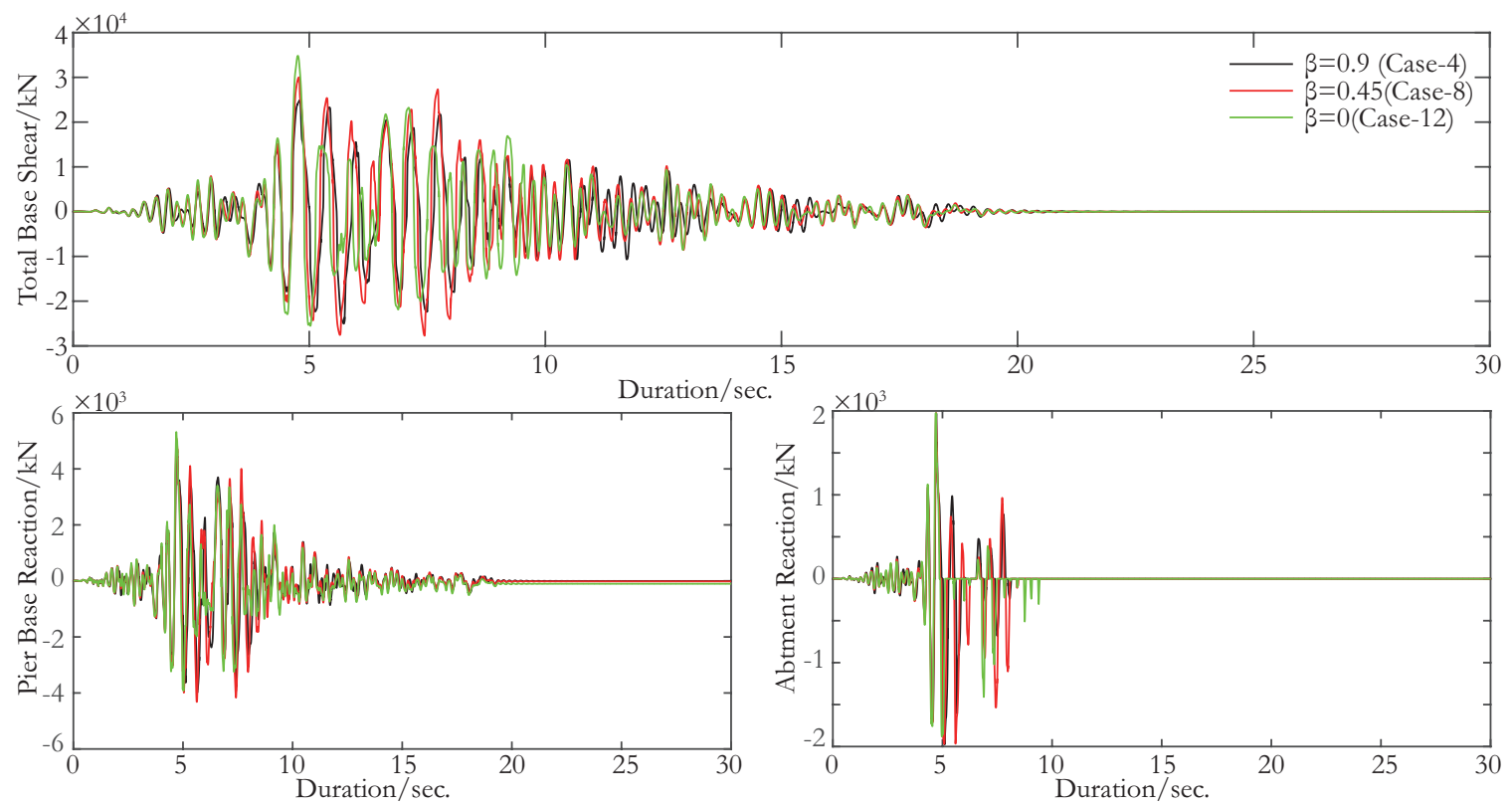

(a) Transverse Direction
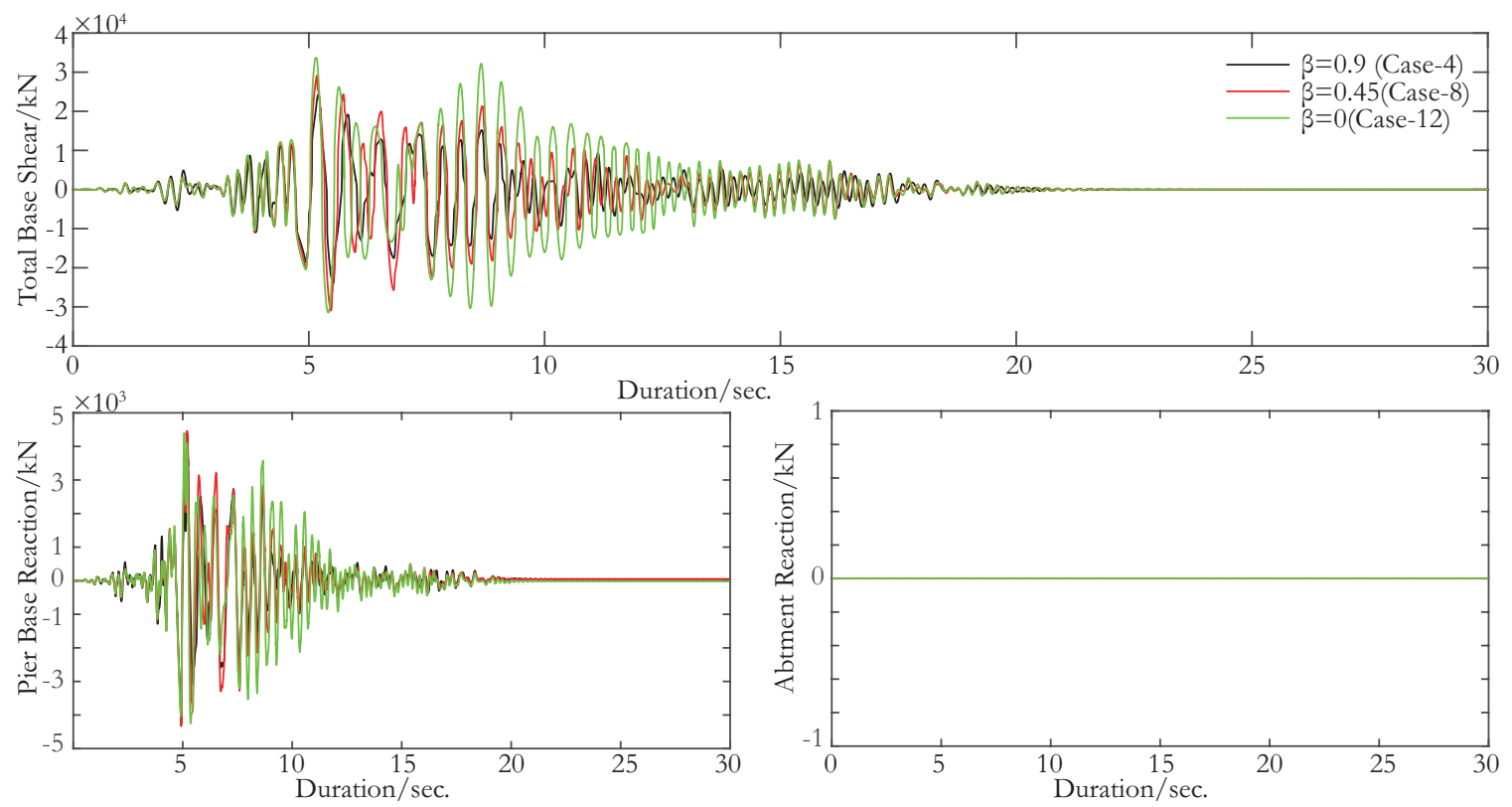

(b) Longitudinal Direction

Figure 6.16: M4:Base Shear Time History during FF-1 $(D F=2)$

Even considering the upper bound ductility in the pier response, it is no greater than 6 and in some cases the piers remain elastic. This indicates that the SCED braces 


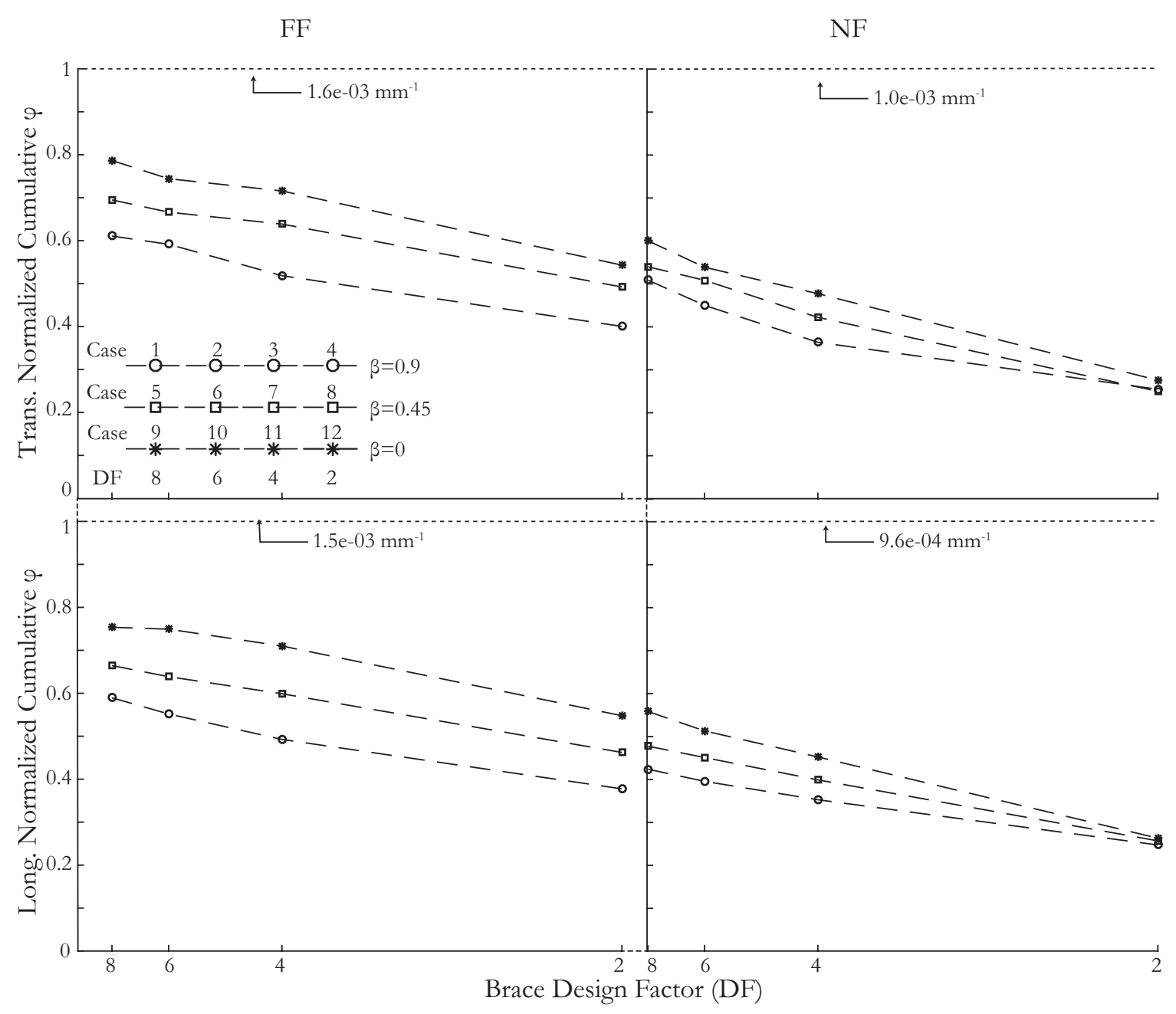

Figure 6.17: Comparison of Cumulative Curvature for M1

prevent the piers from excessive nonlinearity deformation.

The normalized upper bound $\mu_{\Delta}$ for each model is presented in Figure 6.22 to Figure 6.25. The normalized ductility is smaller than 1 in each design case. It can be concluded that $\beta$ does not change the ductility as much as $D F$ since that the trend lines with different $\beta$ are close to each other. The ductility decreases with the decreasing $D F$. 
FF

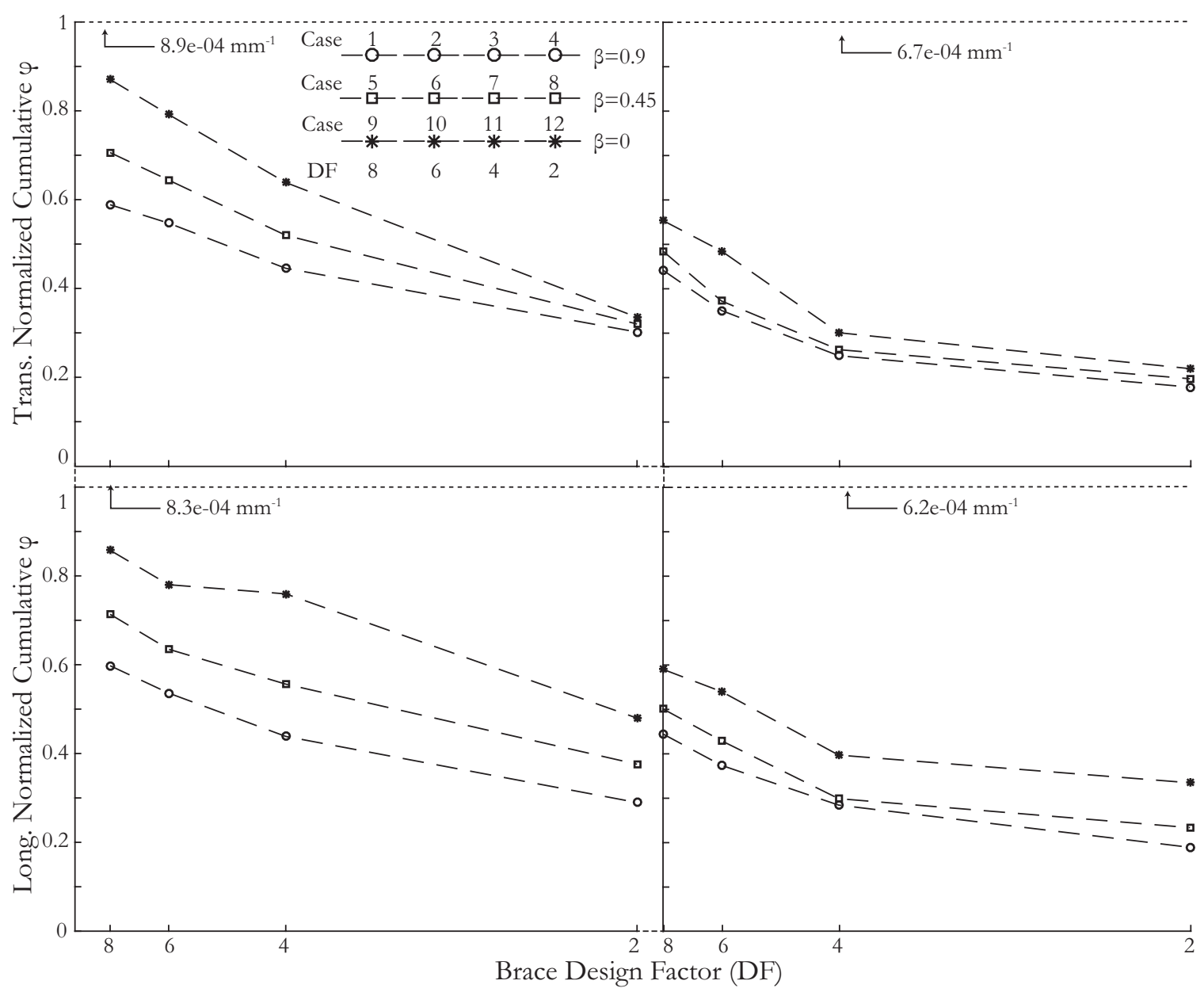

Figure 6.18: Comparison of Cumulative Curvature for M2

\subsection{Comparison of Different Retrofit Schemes}

The results compared previously in this chapter are based on Retrofit Scheme-1. It is expected that distributing the SCED braces more evenly along the length of the bridge, especially for long-span bridges, may improve the seismic performance. Thus, the effectiveness of the two retrofit schemes are compared in the case of retrofitting the bridge model M4. In Retrofit Scheme-2, mid-bent of the bridge has a SCED brace. The brace is placed at an inclined position within the bridge bent. This SCED brace does not provide resistance to the bridge response in the longitudinal direction of the bridge. The 
FF

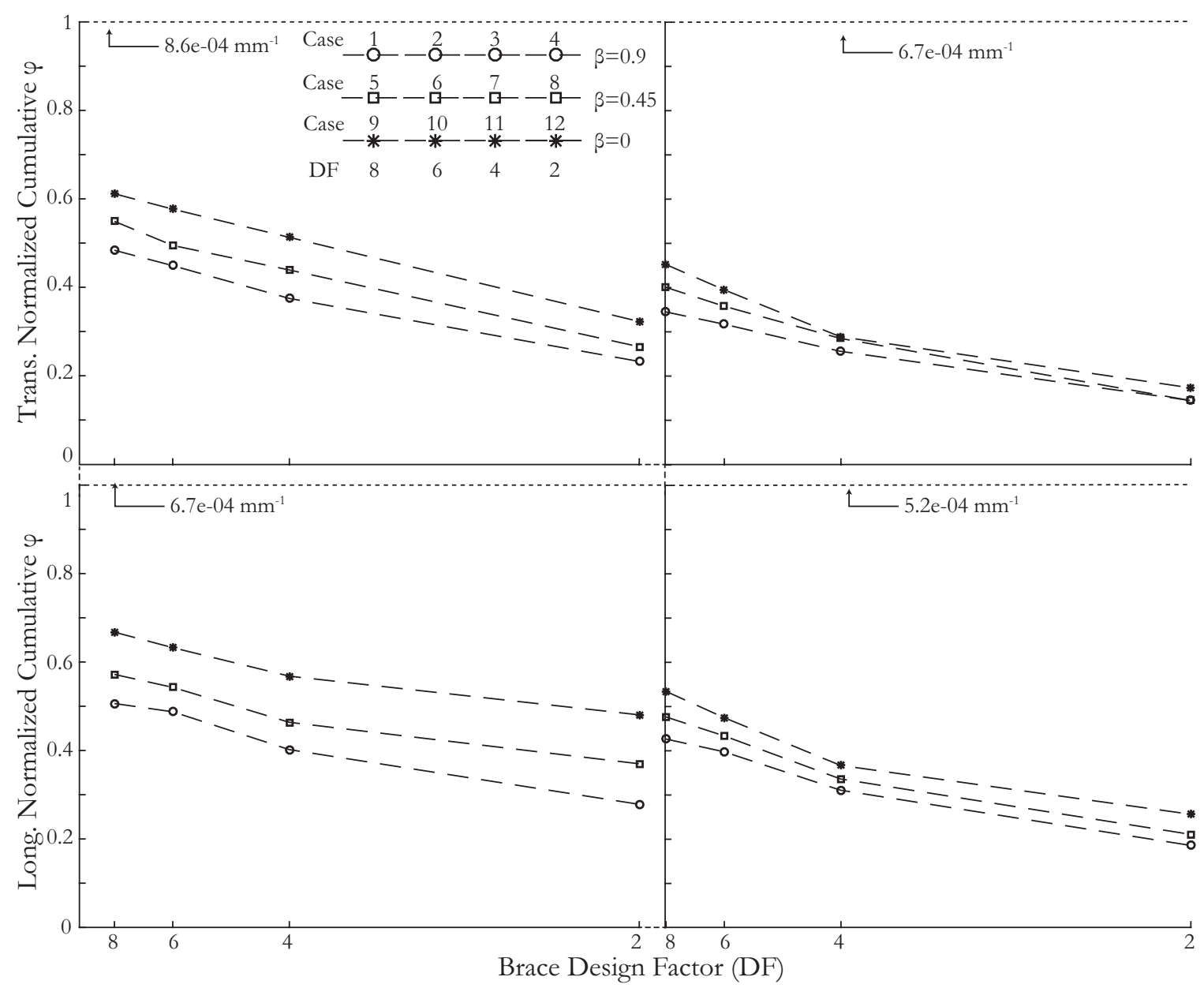

Figure 6.19: Comparison of Cumulative Curvature for M3

same SCED design is used in this retrofit scheme as before. The same design $(\beta=0.45$, $D F=2)$ as determined from parametric study is used in both retrofit schemes. The brace properties are summarized in Table 6.10.

From the summarized response results shown in Table 6.11, the differences in performance between the two schemes are small in the case of both NF and FF ground motions. The displacement time history of the mid-bent under FF-1 and NF-1 is presented in Figure 6.26. The response on the lateral plane is almost identical. Therefore, the improvement of the seismic performance due to the addition of an extra brace at midspan does not seem to be significant. This may be attributed to the fact that the 


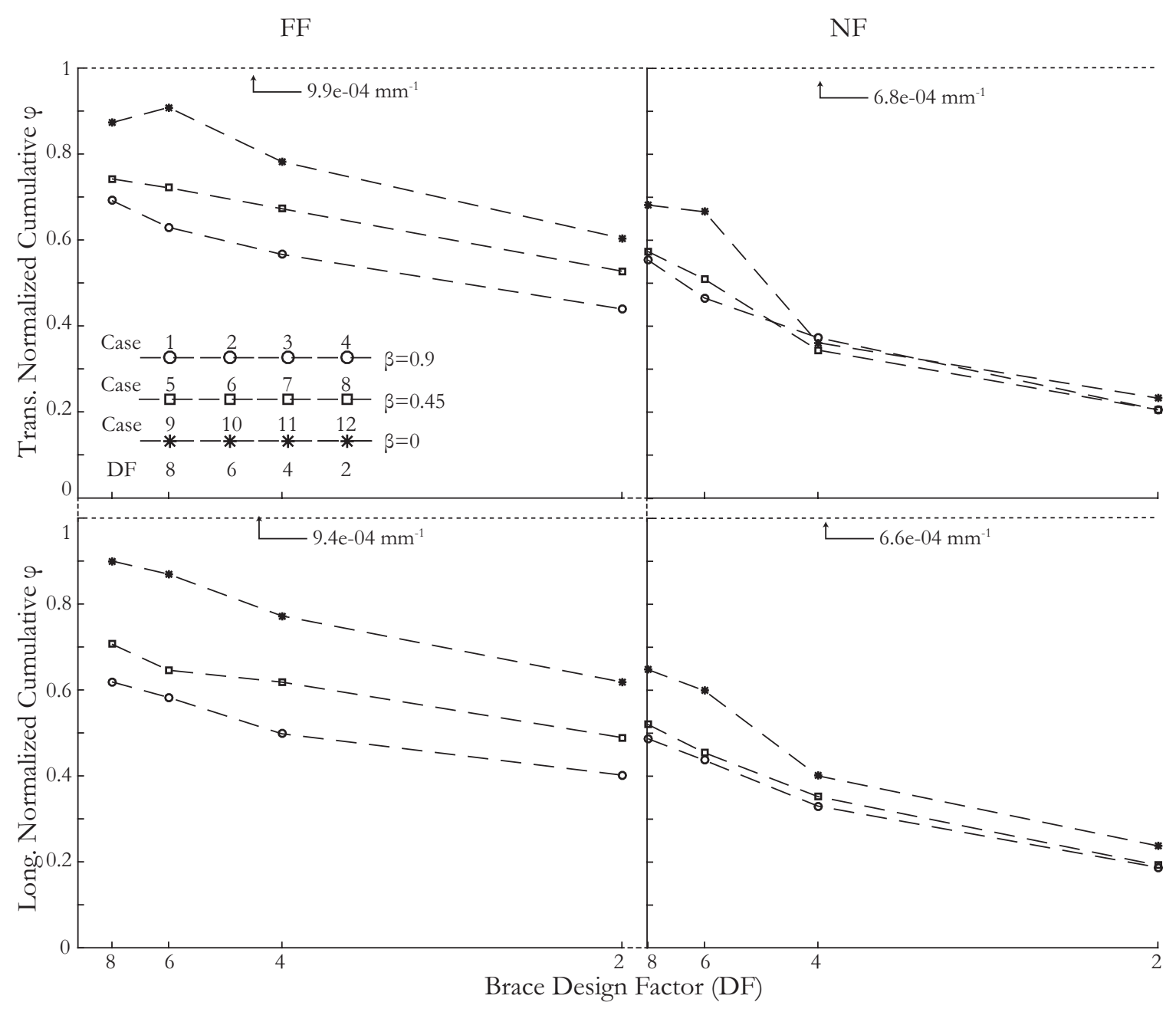

Figure 6.20: Comparison of Cumulative Curvature for M4

stiffness increased in Retrofit Scheme-2 is small enough to be negligible when compared with the stiffness of the original structure.

\subsection{Summary of Results}

The parametric study has been carried out to evaluate the effect of different ground motions and different design parameters on the retrofit performance. The results of 


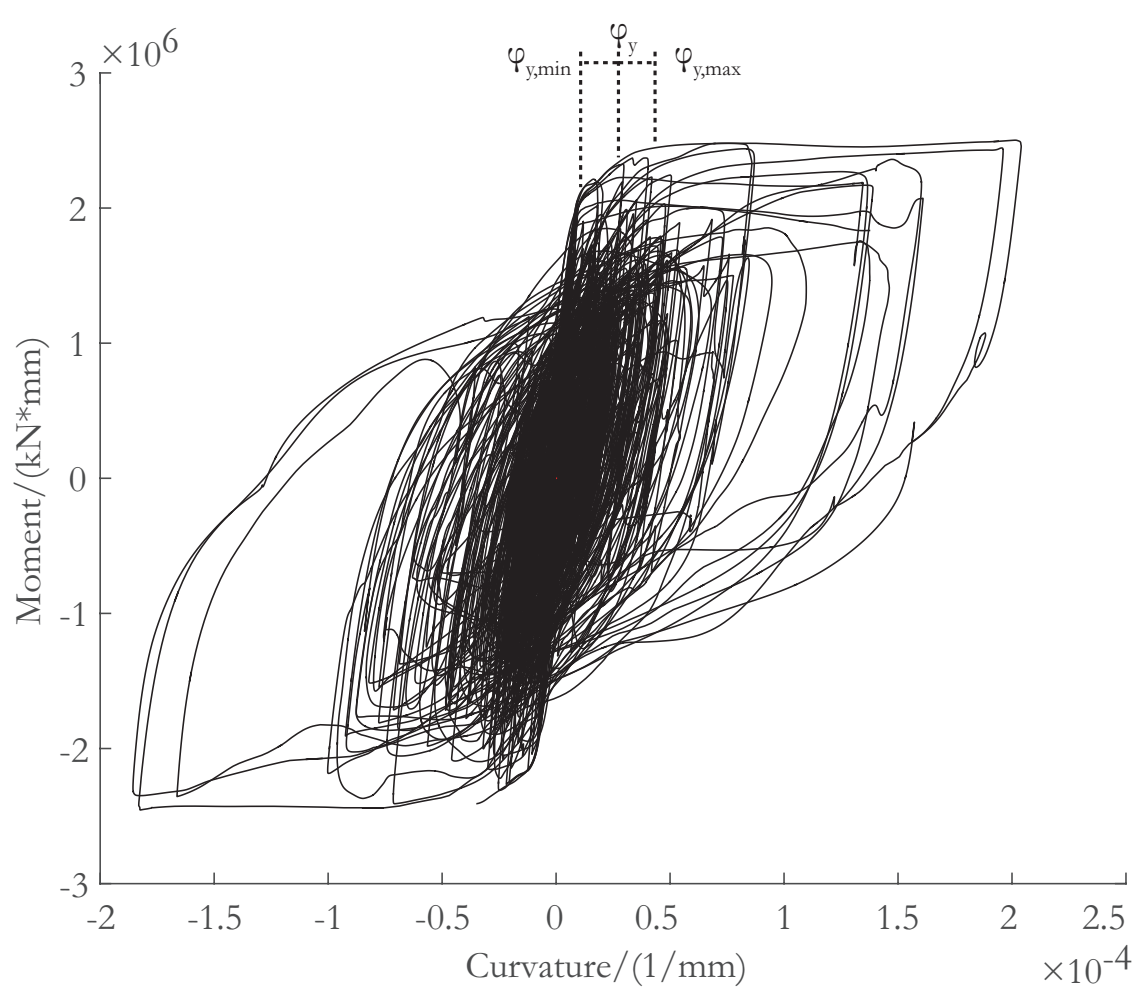

Figure 6.21: The illustration of yielding curvature

the parametric study are compared with those from the original structure. From the discussion presented in this chapter, the following conclusions are determined:

1. The residual displacements of the structure retrofitted with the SCED braces are significantly smaller than those of the original structure for both far-field and nearfield ground motions. It is also recognized that these braces are more effective when the structure is subject to near-field ground motions.

2. The parameters studied are the target activation force design factor $D F$, energy dissipation capacity $\beta$ and different retrofit schemes. The decreasing $D F$ will result in SCED designs with greater activation force $P_{a}$ and accordingly greater ultimate load $P_{u l t}$. The cross-section dimensions need to be enlarged to meet the higher design criteria. A decreasing $\beta$ implies that more force is taken by the tendons. 


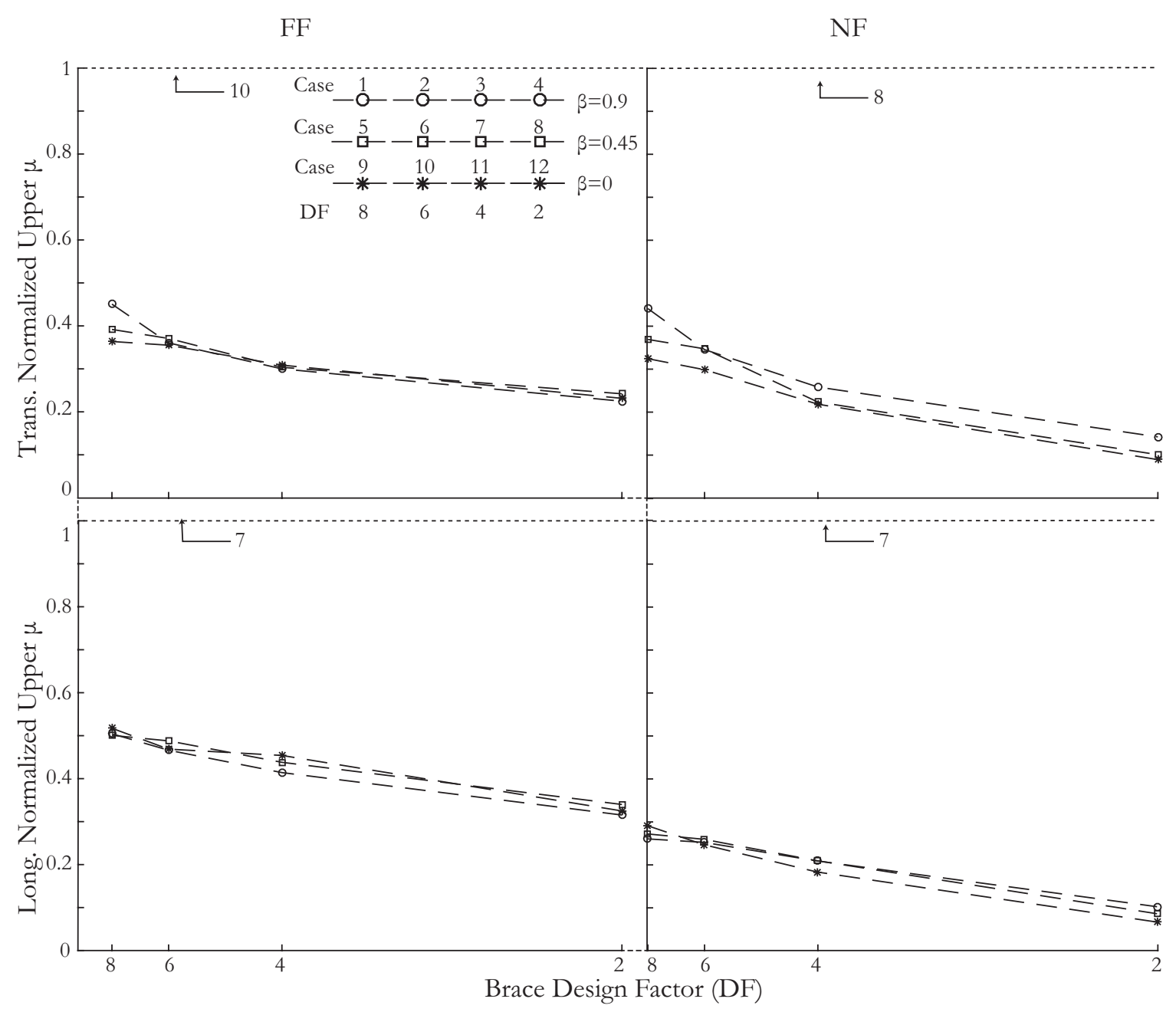

Figure 6.22: Comparison of Upper Ductility for M1

To satisfy the higher demand, the total cross-section area of the tendons must increase. The larger steel tubes are required to geometrically contain the tendons. By decreasing these two parameters, the effective initial stiffness $k_{1}$ can be increased. Therefore, a better performance can be achieved. The computational studies on SDOF structures have shown that a minimum amount of energy dissipation is required for the SC system such that it can produce similar response to that of conventional elastoplastic system. Therefore, $\beta$ should not be zero.

3. The SCED braces can effectively attract base shear and reduce the force in the 


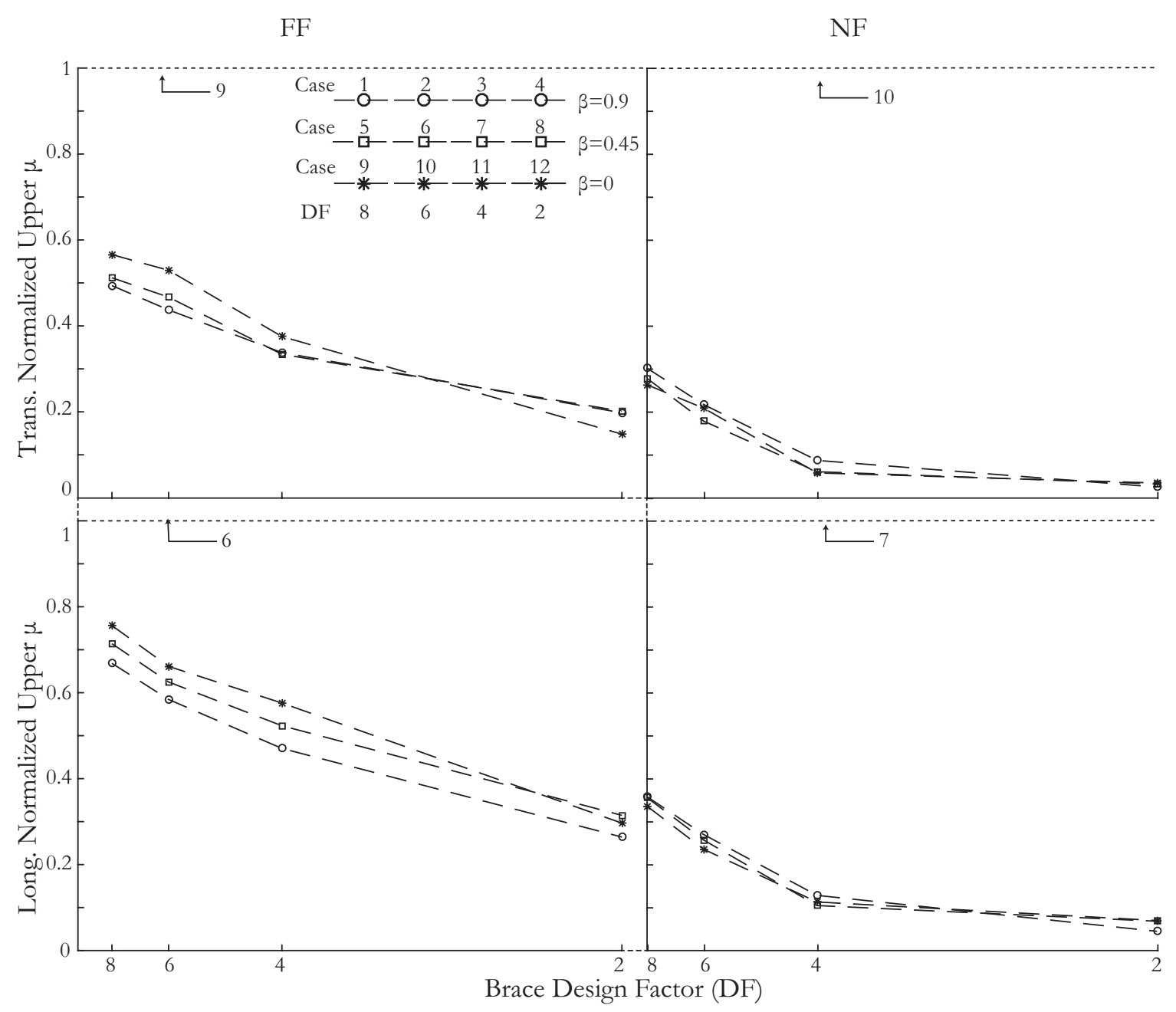

Figure 6.23: Comparison of Upper Ductility for M2

piers in some cases. The force experienced by the piers dies down faster with the help of the SCED braces in all the cases. This potential is attractive as the braces are replaceable and the bridge piers are protected from inelastic response with negligible residual deformation.

4. The parametric study conducted aims to determine the desirable design of the braces. From the results of all the models, the desirable combination of the design parameters is $\beta=0.45$ and $D F=4$ or 6 if longer braces or T-SCED braces are used to retrofit the example bridges. 


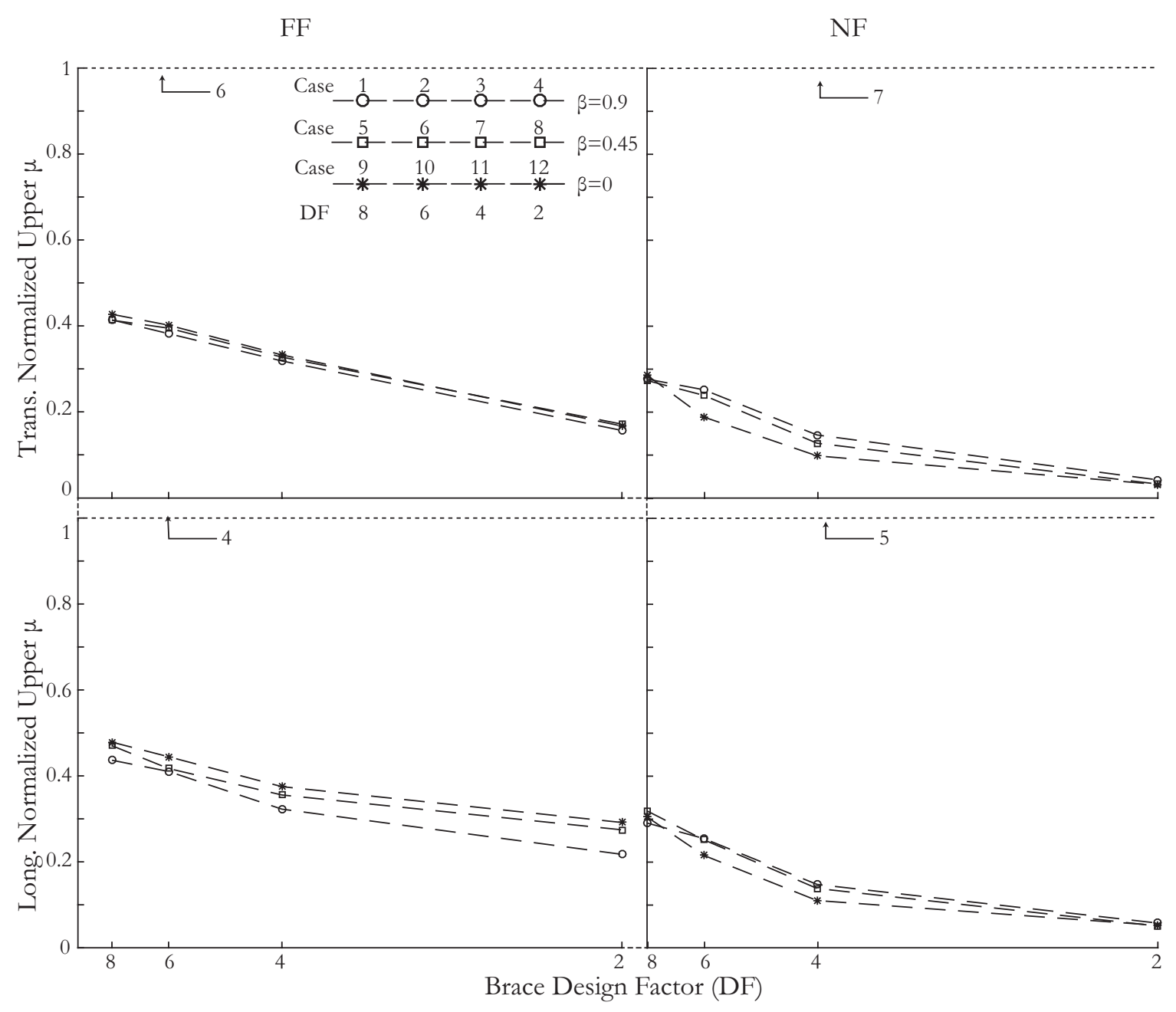

Figure 6.24: Comparison of Upper Ductility for M3

5. The desirable distribution of the SCED braces in the transverse direction is evaluated through a comparison of two different retrofit schemes for M4. In Retrofit Scheme-2, more braces are implemented in the transverse direction. However, the seismic performances of these retrofit schemes are almost identical. The extended interruption due to the installation of braces at mid-bent and higher costs of additional braces imply that the Retrofit Scheme- 2 is not preferred for the studied bridge. 


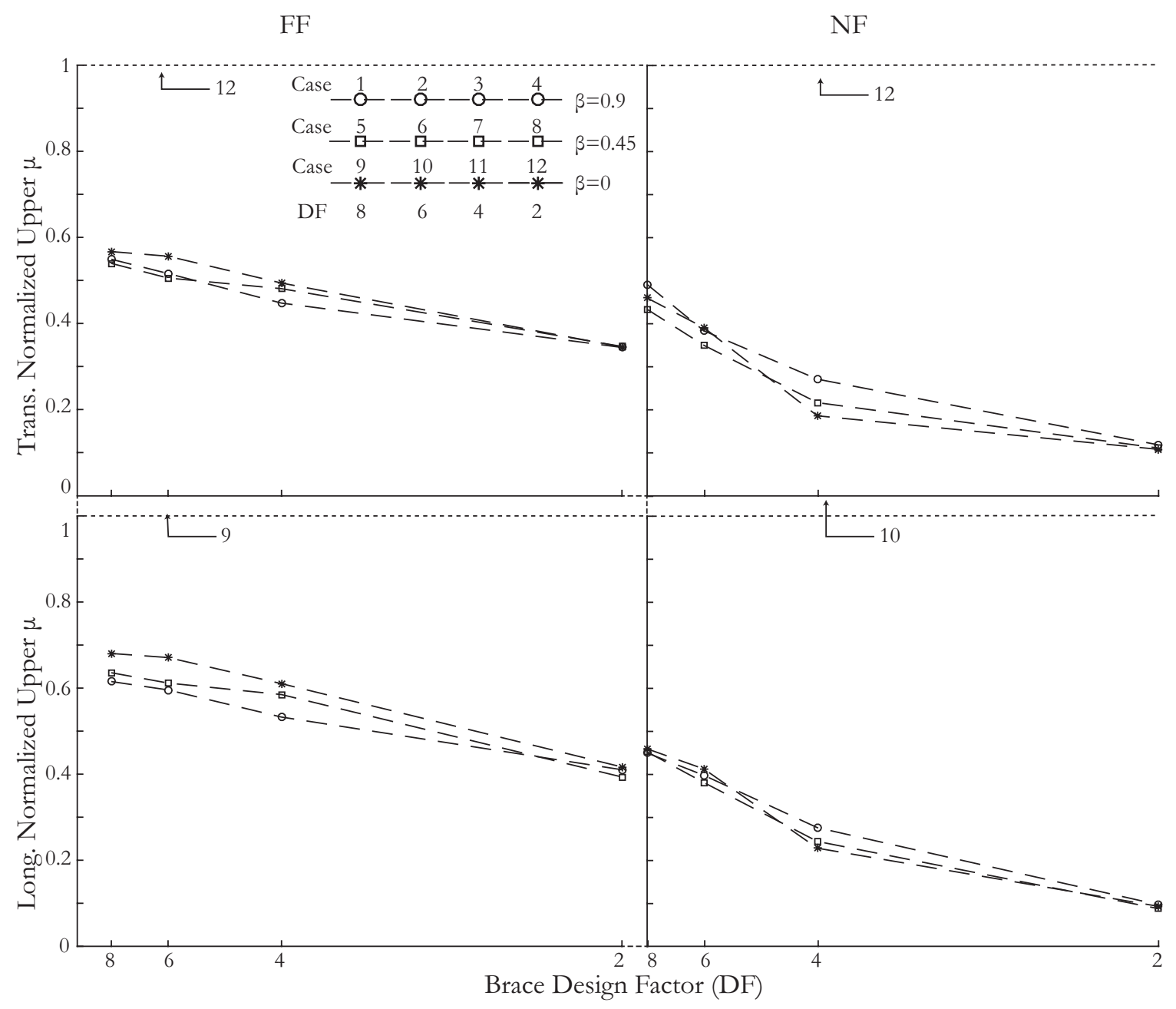

Figure 6.25: Comparison of Upper Ductility for M4 


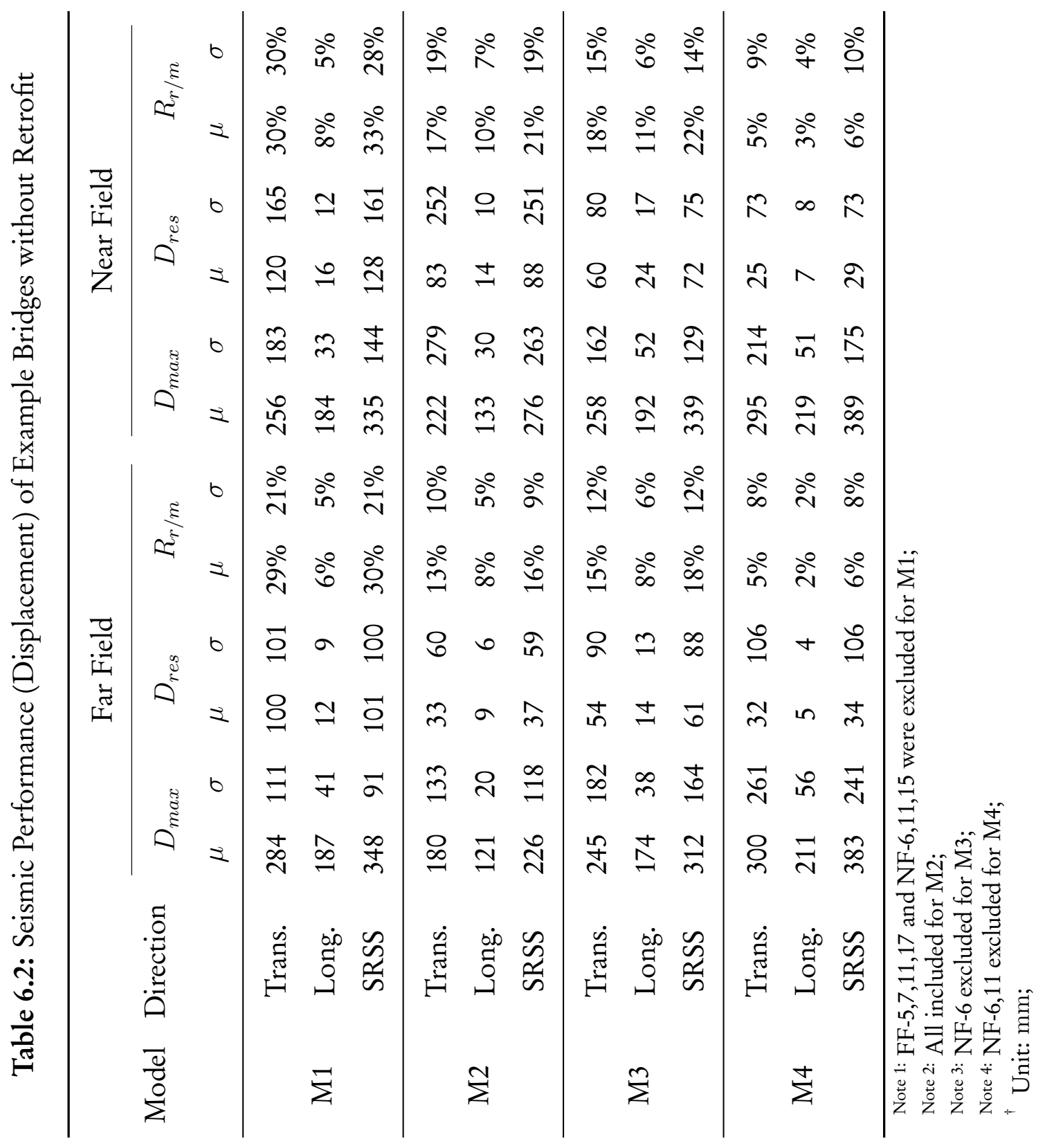


Table 6.3: Seismic Performance of Retrofitted M1

\begin{tabular}{|c|c|c|c|c|c|c|c|c|c|c|c|c|c|c|}
\hline \multirow{3}{*}{ Case } & \multirow{3}{*}{$\beta$} & \multirow{3}{*}{$\mathrm{DF}$} & \multicolumn{4}{|c|}{$D_{\max }$} & \multicolumn{4}{|c|}{$D_{\text {res }}$} & \multicolumn{4}{|c|}{$R_{r / m}$} \\
\hline & & & \multicolumn{2}{|c|}{ Trans. } & \multicolumn{2}{|c|}{ Long. } & \multicolumn{2}{|c|}{ Trans. } & \multicolumn{2}{|c|}{ Long. } & \multicolumn{2}{|c|}{ Trans. } & \multicolumn{2}{|c|}{ Long. } \\
\hline & & & $\mu$ & $\sigma$ & $\mu$ & $\sigma$ & $\mu$ & $\sigma$ & $\mu$ & $\tau$ & $\mu$ & $\sigma$ & $\mu$ & $\sigma$ \\
\hline \multicolumn{15}{|c|}{ Parameteric Study Results of Far-Field (FF) Excitations } \\
\hline 1 & & 8 & 142 & 81 & 118 & 47 & 0 & 0 & 0 & 0 & $0 \%$ & $0 \%$ & $0 \%$ & $0 \%$ \\
\hline 2 & & 6 & 129 & 76 & 116 & 47 & 0 & 0 & 0 & 0 & $0 \%$ & $0 \%$ & $0 \%$ & $0 \%$ \\
\hline 3 & & 4 & 113 & 63 & 111 & 46 & 0 & 0 & 0 & 0 & $0 \%$ & $0 \%$ & $0 \%$ & $0 \%$ \\
\hline 4 & & 2 & 90 & 63 & 89 & 51 & 0 & 0 & 0 & 0 & $0 \%$ & $0 \%$ & $0 \%$ & $0 \%$ \\
\hline 5 & \multirow{4}{*}{0.45} & 8 & 136 & 76 & 121 & 45 & 0 & 0 & 0 & 0 & $0 \%$ & $0 \%$ & $0 \%$ & $0 \%$ \\
\hline 6 & & 6 & 131 & 74 & 121 & 45 & 0 & 0 & 0 & 0 & $0 \%$ & $0 \%$ & $0 \%$ & $0 \%$ \\
\hline 7 & & 4 & 112 & 62 & 113 & 49 & 0 & 0 & 0 & 0 & $0 \%$ & $0 \%$ & $0 \%$ & $0 \%$ \\
\hline 8 & & 2 & 94 & 65 & 92 & 54 & 0 & 0 & 0 & 0 & $0 \%$ & $0 \%$ & $0 \%$ & $0 \%$ \\
\hline 9 & & 8 & 129 & 63 & 125 & 45 & 0 & 0 & 0 & 0 & $0 \%$ & $0 \%$ & $0 \%$ & $0 \%$ \\
\hline 10 & & 6 & 126 & 60 & 121 & 46 & 0 & 0 & 0 & 0 & $0 \%$ & $0 \%$ & $0 \%$ & $0 \%$ \\
\hline 11 & & 4 & 114 & 61 & 117 & 52 & 0 & 0 & 0 & 0 & $0 \%$ & $0 \%$ & $0 \%$ & $0 \%$ \\
\hline 12 & & 2 & 91 & 59 & 92 & 48 & 0 & 0 & 0 & 0 & $0 \%$ & $0 \%$ & $0 \%$ & $0 \%$ \\
\hline
\end{tabular}

Parameteric Study Results of Near-Field (NF) Excitations

\begin{tabular}{lllllllllllllll}
1 & & 8 & 128 & 170 & 85 & 30 & 0 & 0 & 0 & 0 & $0 \%$ & $0 \%$ & $0 \%$ & $0 \%$ \\
2 & 0.9 & 6 & 95 & 118 & 81 & 32 & 0 & 0 & 0 & 0 & $0 \%$ & $0 \%$ & $0 \%$ & $0 \%$ \\
3 & & 4 & 75 & 91 & 70 & 40 & 0 & 0 & 0 & 0 & $0 \%$ & $0 \%$ & $0 \%$ & $0 \%$ \\
4 & & 2 & 44 & 59 & 39 & 38 & 0 & 0 & 0 & 0 & $0 \%$ & $0 \%$ & $0 \%$ & $0 \%$ \\
\hline 5 & & 8 & 102 & 117 & 86 & 36 & 0 & 0 & 0 & 0 & $0 \%$ & $0 \%$ & $0 \%$ & $0 \%$ \\
6 & 0.45 & 6 & 96 & 114 & 83 & 39 & 0 & 0 & 0 & 0 & $0 \%$ & $0 \%$ & $0 \%$ & $0 \%$ \\
7 & & 4 & 66 & 80 & 72 & 44 & 0 & 0 & 0 & 0 & $0 \%$ & $0 \%$ & $0 \%$ & $0 \%$ \\
8 & & 2 & 40 & 50 & 37 & 35 & 0 & 0 & 0 & 0 & $0 \%$ & $0 \%$ & $0 \%$ & $0 \%$ \\
\hline 9 & & 8 & 92 & 93 & 90 & 38 & 0 & 0 & 0 & 0 & $0 \%$ & $0 \%$ & $0 \%$ & $0 \%$ \\
10 & & 6 & 88 & 92 & 82 & 44 & 0 & 0 & 0 & 0 & $0 \%$ & $0 \%$ & $0 \%$ & $0 \%$ \\
11 & 0 & 4 & 67 & 78 & 67 & 43 & 0 & 0 & 0 & 0 & $0 \%$ & $0 \%$ & $0 \%$ & $0 \%$ \\
12 & & 2 & 40 & 45 & 36 & 27 & 0 & 0 & 0 & 0 & $0 \%$ & $0 \%$ & $0 \%$ & $0 \%$ \\
\hline
\end{tabular}


Table 6.4: Seismic Performance of Retrofitted M2

\begin{tabular}{|c|c|c|c|c|c|c|c|c|c|c|c|c|c|c|}
\hline \multirow[b]{2}{*}{ Case } & \multirow[b]{2}{*}{$\beta$} & \multirow[b]{2}{*}{$\mathrm{DF}$} & \multicolumn{4}{|c|}{$D_{\max }$} & \multicolumn{4}{|c|}{$D_{\text {res }}$} & \multicolumn{4}{|c|}{$R_{r / m}$} \\
\hline & & & \multicolumn{2}{|c|}{ Trans. } & \multicolumn{2}{|c|}{ Long. } & Trans. & & \multicolumn{2}{|c|}{ Long. } & $\begin{array}{l}\text { Tra } \\
\mu\end{array}$ & & \multicolumn{2}{|c|}{ Long. } \\
\hline \multicolumn{15}{|c|}{ Parameteric Study Results of Far-Field (FF) Excitations } \\
\hline 1 & \multirow{4}{*}{0.9} & 8 & 98 & 56 & 99 & 31 & 0 & 0 & 1 & 0 & $0 \%$ & $0 \%$ & $0 \%$ & $0 \%$ \\
\hline 2 & & 6 & 92 & 60 & 93 & 29 & 0 & 0 & 0 & 0 & $0 \%$ & $0 \%$ & $0 \%$ & $0 \%$ \\
\hline 3 & & 4 & 75 & 54 & 81 & 34 & 0 & 0 & 0 & 0 & $0 \%$ & $0 \%$ & $0 \%$ & $0 \%$ \\
\hline 4 & & 2 & 46 & 46 & 52 & 39 & 0 & 0 & 0 & 0 & $0 \%$ & $0 \%$ & $0 \%$ & $0 \%$ \\
\hline 5 & \multirow{4}{*}{0.45} & 8 & 102 & 58 & 102 & 32 & 0 & 0 & 0 & 0 & $0 \%$ & $0 \%$ & $0 \%$ & $0 \%$ \\
\hline 6 & & 6 & 94 & 61 & 95 & 32 & 0 & 0 & 0 & 0 & $0 \%$ & $0 \%$ & $0 \%$ & $0 \%$ \\
\hline 7 & & 4 & 72 & 49 & 85 & 37 & 0 & 0 & 0 & 0 & $0 \%$ & $0 \%$ & $0 \%$ & $0 \%$ \\
\hline 8 & & 2 & 44 & 38 & 59 & 49 & 0 & 0 & 0 & 0 & $0 \%$ & $0 \%$ & $0 \%$ & $0 \%$ \\
\hline 9 & & 8 & 109 & 61 & 104 & 35 & 0 & 0 & 0 & 0 & $0 \%$ & $0 \%$ & $0 \%$ & $0 \%$ \\
\hline 10 & & 6 & 102 & 63 & 97 & 32 & 0 & 0 & 0 & 0 & $0 \%$ & $0 \%$ & $0 \%$ & $0 \%$ \\
\hline 11 & & 4 & 77 & 55 & 90 & 35 & 0 & 0 & 0 & 0 & $0 \%$ & $0 \%$ & $0 \%$ & $0 \%$ \\
\hline 12 & & 2 & 39 & 30 & 62 & 47 & 0 & 2 & 2 & 4 & $0 \%$ & $1 \%$ & $2 \%$ & $5 \%$ \\
\hline
\end{tabular}

Parameteric Study Results of Near-Field (NF) Excitations

\begin{tabular}{lllllllllllllll}
1 & & 8 & 68 & 56 & 78 & 29 & 0 & 0 & 0 & 0 & $0 \%$ & $0 \%$ & $0 \%$ & $0 \%$ \\
2 & 0.9 & 6 & 55 & 45 & 66 & 29 & 0 & 0 & 0 & 0 & $0 \%$ & $0 \%$ & $0 \%$ & $0 \%$ \\
3 & & 4 & 38 & 28 & 45 & 27 & 0 & 0 & 0 & 0 & $0 \%$ & $0 \%$ & $0 \%$ & $0 \%$ \\
4 & & 2 & 18 & 12 & 24 & 20 & 0 & 0 & 0 & 0 & $0 \%$ & $0 \%$ & $0 \%$ & $0 \%$ \\
\hline 5 & & 8 & 65 & 51 & 77 & 32 & 0 & 0 & 0 & 0 & $0 \%$ & $0 \%$ & $0 \%$ & $0 \%$ \\
6 & 0.45 & 6 & 52 & 37 & 65 & 29 & 0 & 0 & 0 & 0 & $0 \%$ & $0 \%$ & $0 \%$ & $0 \%$ \\
7 & & 4 & 36 & 22 & 45 & 26 & 0 & 0 & 0 & 0 & $0 \%$ & $0 \%$ & $0 \%$ & $0 \%$ \\
8 & & 2 & 19 & 14 & 28 & 25 & 0 & 0 & 0 & 0 & $0 \%$ & $0 \%$ & $0 \%$ & $0 \%$ \\
\hline 9 & & 8 & 65 & 48 & 76 & 31 & 0 & 0 & 0 & 0 & $0 \%$ & $0 \%$ & $0 \%$ & $0 \%$ \\
10 & & 6 & 57 & 40 & 62 & 27 & 0 & 0 & 0 & 0 & $0 \%$ & $0 \%$ & $0 \%$ & $0 \%$ \\
11 & 0 & 4 & 36 & 20 & 48 & 25 & 0 & 0 & 0 & 0 & $0 \%$ & $0 \%$ & $0 \%$ & $0 \%$ \\
12 & & 2 & 21 & 15 & 33 & 25 & 0 & 0 & 0 & 2 & $0 \%$ & $0 \%$ & $1 \%$ & $2 \%$ \\
\hline
\end{tabular}


Table 6.5: Seismic Performance of Retrofitted M3

\begin{tabular}{|c|c|c|c|c|c|c|c|c|c|c|c|c|c|c|}
\hline \multirow[b]{2}{*}{ Case } & \multirow[b]{2}{*}{$\beta$} & \multirow[b]{2}{*}{$\mathrm{DF}$} & \multicolumn{4}{|c|}{$D_{\max }$} & \multicolumn{4}{|c|}{$D_{\text {res }}$} & \multicolumn{4}{|c|}{$R_{r / m}$} \\
\hline & & & \multicolumn{2}{|c|}{ Trans. } & \multicolumn{2}{|c|}{ Long. } & Trans. & & \multicolumn{2}{|c|}{ Long. } & $\begin{array}{l}\text { Tra } \\
\mu\end{array}$ & & \multicolumn{2}{|c|}{ Long. } \\
\hline \multicolumn{15}{|c|}{ Parameteric Study Results of Far-Field (FF) Excitations } \\
\hline 1 & \multirow{4}{*}{0.9} & 8 & 131 & 78 & 112 & 30 & 0 & 0 & 0 & 1 & $0 \%$ & $0 \%$ & $0 \%$ & $0 \%$ \\
\hline 2 & & 6 & 125 & 75 & 109 & 32 & 0 & 0 & 0 & 0 & $0 \%$ & $0 \%$ & $0 \%$ & $0 \%$ \\
\hline 3 & & 4 & 110 & 73 & 92 & 35 & 0 & 0 & 0 & 0 & $0 \%$ & $0 \%$ & $0 \%$ & $0 \%$ \\
\hline 4 & & 2 & 66 & 54 & 65 & 41 & 0 & 0 & 0 & 1 & $0 \%$ & $0 \%$ & $0 \%$ & $1 \%$ \\
\hline 5 & \multirow{4}{*}{0.45} & 8 & 130 & 73 & 118 & 29 & 0 & 0 & 0 & 0 & $0 \%$ & $0 \%$ & $0 \%$ & $0 \%$ \\
\hline 6 & & 6 & 127 & 72 & 112 & 34 & 0 & 0 & 0 & 0 & $0 \%$ & $0 \%$ & $0 \%$ & $0 \%$ \\
\hline 7 & & 4 & 113 & 72 & 92 & 41 & 0 & 0 & 0 & 1 & $0 \%$ & $0 \%$ & $0 \%$ & $1 \%$ \\
\hline 8 & & 2 & 67 & 54 & 72 & 46 & 0 & 0 & 0 & 0 & $0 \%$ & $0 \%$ & $0 \%$ & $0 \%$ \\
\hline 9 & & 8 & 132 & 72 & 120 & 35 & 0 & 0 & 0 & 0 & $0 \%$ & $0 \%$ & $0 \%$ & $0 \%$ \\
\hline 10 & & 6 & 127 & 73 & 109 & 36 & 0 & 0 & 0 & 0 & $0 \%$ & $0 \%$ & $0 \%$ & $0 \%$ \\
\hline 11 & & 4 & 108 & 71 & 91 & 43 & 0 & 0 & 0 & 0 & $0 \%$ & $0 \%$ & $0 \%$ & $0 \%$ \\
\hline 12 & & 2 & 63 & 48 & 75 & 52 & 0 & 0 & 0 & 0 & $0 \%$ & $0 \%$ & $0 \%$ & $0 \%$ \\
\hline
\end{tabular}

Parameteric Study Results of Near-Field (NF) Excitations

\begin{tabular}{ccccccccccccccc}
1 & & 8 & 105 & 71 & 103 & 34 & 1 & 2 & 0 & 0 & $0 \%$ & $1 \%$ & $0 \%$ & $0 \%$ \\
2 & 0.9 & 6 & 98 & 72 & 94 & 39 & 0 & 1 & 0 & 0 & $0 \%$ & $0 \%$ & $0 \%$ & $0 \%$ \\
3 & & 4 & 72 & 58 & 63 & 38 & 0 & 0 & 0 & 0 & $0 \%$ & $0 \%$ & $0 \%$ & $0 \%$ \\
4 & & 2 & 31 & 32 & 34 & 25 & 0 & 0 & 0 & 0 & $0 \%$ & $0 \%$ & $0 \%$ & $0 \%$ \\
\hline 5 & & 8 & 103 & 73 & 104 & 39 & 0 & 0 & 0 & 0 & $0 \%$ & $0 \%$ & $0 \%$ & $0 \%$ \\
6 & & 6 & 92 & 70 & 90 & 42 & 0 & 0 & 0 & 0 & $0 \%$ & $0 \%$ & $0 \%$ & $0 \%$ \\
7 & 0.45 & 4 & 68 & 54 & 59 & 38 & 0 & 0 & 0 & 0 & $0 \%$ & $0 \%$ & $0 \%$ & $0 \%$ \\
8 & & 2 & 30 & 28 & 34 & 21 & 0 & 0 & 0 & 0 & $0 \%$ & $0 \%$ & $0 \%$ & $0 \%$ \\
\hline 9 & & 8 & 105 & 71 & 101 & 41 & 0 & 0 & 0 & 0 & $0 \%$ & $0 \%$ & $0 \%$ & $0 \%$ \\
10 & 0 & 6 & 85 & 60 & 81 & 42 & 0 & 0 & 0 & 0 & $0 \%$ & $0 \%$ & $0 \%$ & $0 \%$ \\
11 & 0 & 4 & 56 & 47 & 54 & 32 & 0 & 0 & 0 & 0 & $0 \%$ & $0 \%$ & $0 \%$ & $0 \%$ \\
12 & & 2 & 29 & 26 & 35 & 21 & 0 & 0 & 0 & 1 & $0 \%$ & $0 \%$ & $0 \%$ & $1 \%$ \\
\hline
\end{tabular}


Table 6.6: Seismic Performance of Retrofitted M4

\begin{tabular}{|c|c|c|c|c|c|c|c|c|c|c|c|c|c|c|}
\hline \multirow{3}{*}{ Case } & \multirow{3}{*}{$\beta$} & \multirow{3}{*}{$\mathrm{DF}$} & \multicolumn{4}{|c|}{$D_{\max }$} & \multicolumn{4}{|c|}{$D_{\text {res }}$} & \multicolumn{4}{|c|}{$R_{r / m}$} \\
\hline & & & \multicolumn{2}{|c|}{ Trans. } & \multicolumn{2}{|c|}{ Long. } & \multicolumn{2}{|c|}{ Trans. } & \multicolumn{2}{|c|}{ Long. } & \multicolumn{2}{|c|}{ Trans. } & \multicolumn{2}{|c|}{ Long. } \\
\hline & & & $\mu$ & $\sigma$ & $\mu$ & $\sigma$ & $\mu$ & $\sigma$ & $\mu$ & $\sigma$ & $\mu$ & $\sigma$ & $\mu$ & $\sigma$ \\
\hline \multicolumn{15}{|c|}{ Parameteric Study Results of Far-Field (FF) Excitations } \\
\hline 1 & \multirow{4}{*}{0.9} & 8 & 144 & 95 & 129 & 71 & 0 & 0 & 0 & 0 & $0 \%$ & $0 \%$ & $0 \%$ & $0 \%$ \\
\hline 2 & & 6 & 130 & 77 & 124 & 70 & 0 & 0 & 0 & 0 & $0 \%$ & $0 \%$ & $0 \%$ & $0 \%$ \\
\hline 3 & & 4 & 113 & 74 & 110 & 63 & 0 & 0 & 0 & 0 & $0 \%$ & $0 \%$ & $0 \%$ & $0 \%$ \\
\hline 4 & & 2 & 86 & 74 & 83 & 64 & 0 & 0 & 0 & 0 & $0 \%$ & $0 \%$ & $0 \%$ & $0 \%$ \\
\hline 5 & \multirow{4}{*}{0.45} & 8 & 135 & 76 & 128 & 68 & 0 & 0 & 0 & 0 & $0 \%$ & $0 \%$ & $0 \%$ & $0 \%$ \\
\hline 6 & & 6 & 126 & 73 & 123 & 65 & 0 & 0 & 0 & 0 & $0 \%$ & $0 \%$ & $0 \%$ & $0 \%$ \\
\hline 7 & & 4 & 116 & 81 & 114 & 67 & 0 & 0 & 0 & 0 & $0 \%$ & $0 \%$ & $0 \%$ & $0 \%$ \\
\hline 8 & & 2 & 87 & 71 & 81 & 56 & 0 & 0 & 0 & 0 & $0 \%$ & $0 \%$ & $0 \%$ & $0 \%$ \\
\hline 9 & & 8 & 140 & 76 & 136 & 72 & 0 & 0 & 0 & 0 & $0 \%$ & $0 \%$ & $0 \%$ & $0 \%$ \\
\hline 10 & & 6 & 136 & 76 & 133 & 73 & 0 & 0 & 0 & 0 & $0 \%$ & $0 \%$ & $0 \%$ & $0 \%$ \\
\hline 11 & & 4 & 115 & 77 & 118 & 70 & 0 & 0 & 0 & 0 & $0 \%$ & $0 \%$ & $0 \%$ & $0 \%$ \\
\hline 12 & & 2 & 90 & 72 & 88 & 62 & 0 & 0 & 0 & 0 & $0 \%$ & $0 \%$ & $0 \%$ & $0 \%$ \\
\hline
\end{tabular}

Parameteric Study Results of Near-Field (NF) Excitations

\begin{tabular}{lllllllllllllll}
1 & & 8 & 122 & 117 & 95 & 40 & 0 & 0 & 0 & 0 & $0 \%$ & $0 \%$ & $0 \%$ & $0 \%$ \\
2 & 0.9 & 6 & 96 & 92 & 86 & 42 & 0 & 0 & 0 & 0 & $0 \%$ & $0 \%$ & $0 \%$ & $0 \%$ \\
3 & & 4 & 71 & 71 & 64 & 42 & 0 & 1 & 0 & 0 & $0 \%$ & $1 \%$ & $0 \%$ & $0 \%$ \\
4 & & 2 & 38 & 45 & 32 & 28 & 0 & 0 & 0 & 0 & $0 \%$ & $0 \%$ & $0 \%$ & $0 \%$ \\
\hline 5 & & 8 & 103 & 91 & 93 & 45 & 0 & 0 & 1 & 5 & $0 \%$ & $0 \%$ & $1 \%$ & $2 \%$ \\
6 & 0.45 & 6 & 88 & 80 & 82 & 45 & 0 & 0 & 0 & 0 & $0 \%$ & $0 \%$ & $0 \%$ & $0 \%$ \\
7 & & 4 & 60 & 59 & 60 & 44 & 0 & 0 & 0 & 0 & $0 \%$ & $0 \%$ & $0 \%$ & $0 \%$ \\
8 & & 2 & 36 & 38 & 30 & 20 & 0 & 1 & 4 & 8 & $0 \%$ & $1 \%$ & $7 \%$ & $12 \%$ \\
\hline 9 & & 8 & 108 & 91 & 93 & 49 & 0 & 0 & 3 & 13 & $0 \%$ & $0 \%$ & $1 \%$ & $6 \%$ \\
10 & & 6 & 96 & 83 & 85 & 46 & 0 & 0 & 0 & 0 & $0 \%$ & $0 \%$ & $0 \%$ & $0 \%$ \\
11 & 0 & 4 & 52 & 47 & 58 & 38 & 1 & 3 & 1 & 4 & $0 \%$ & $2 \%$ & $1 \%$ & $3 \%$ \\
12 & & 2 & 33 & 32 & 32 & 19 & 0 & 0 & 0 & 0 & $0 \%$ & $0 \%$ & $0 \%$ & $0 \%$ \\
\hline
\end{tabular}




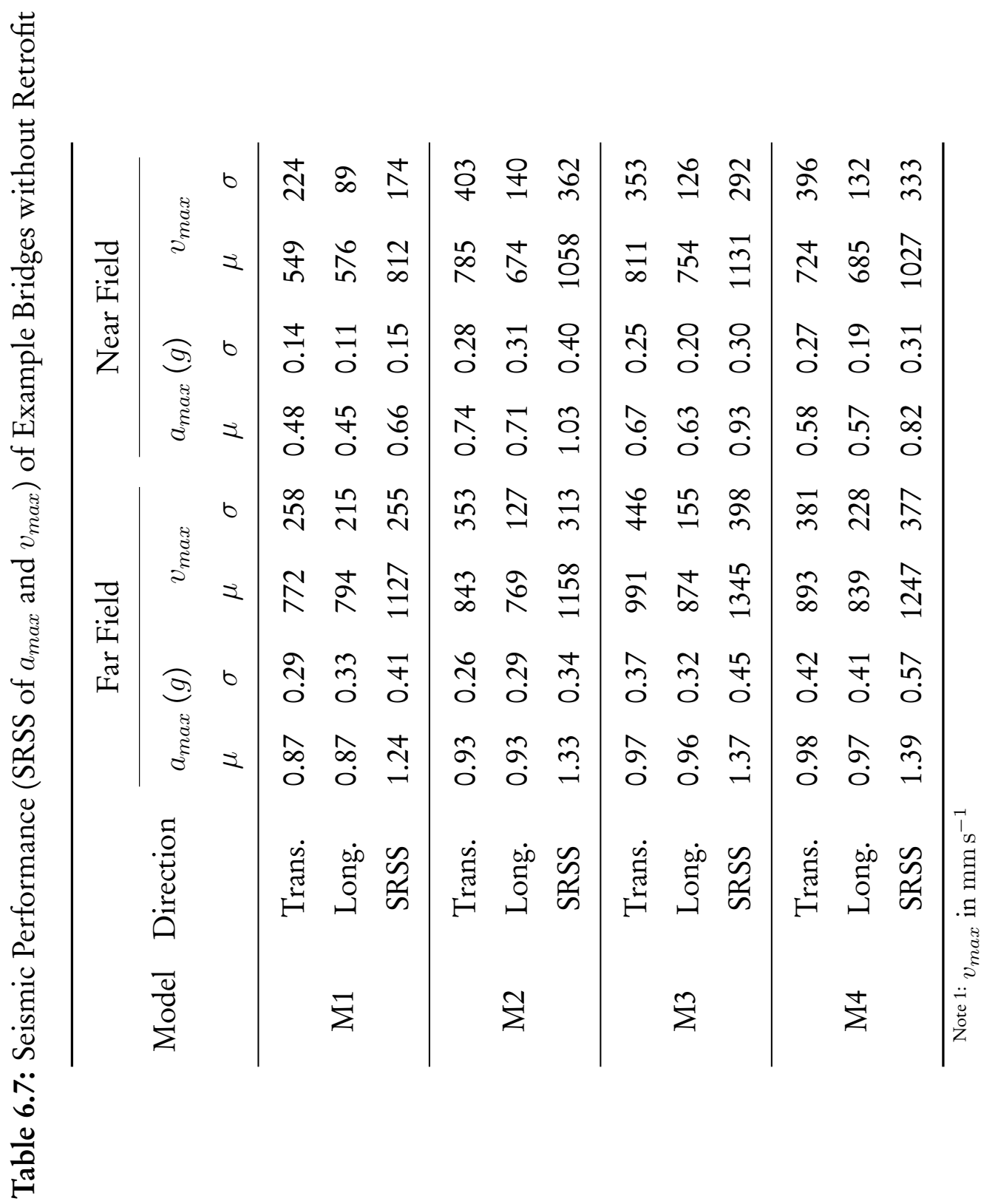




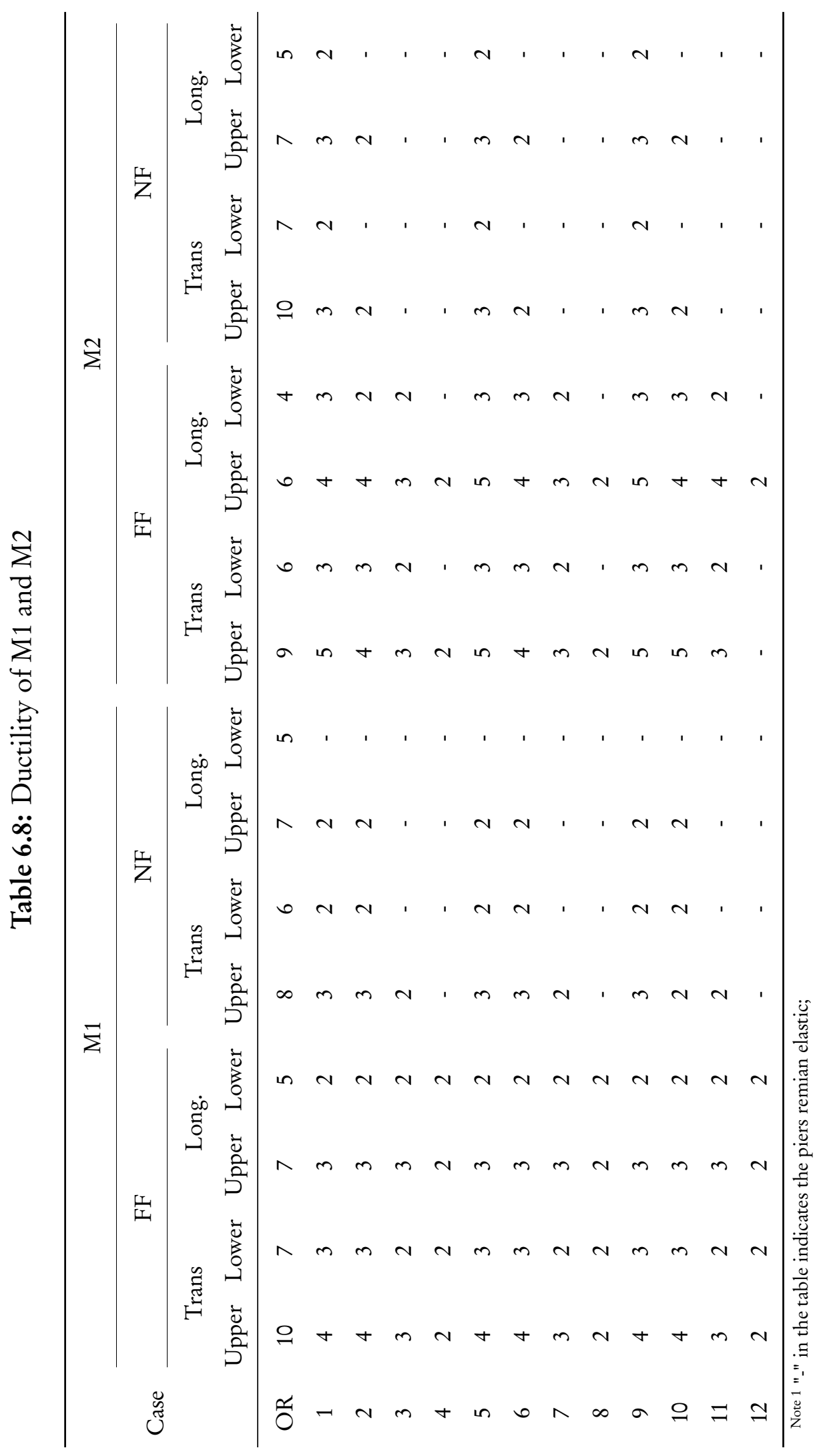

Xi Cheng, Department of Civil and Environmental Engineering, Carleton University 


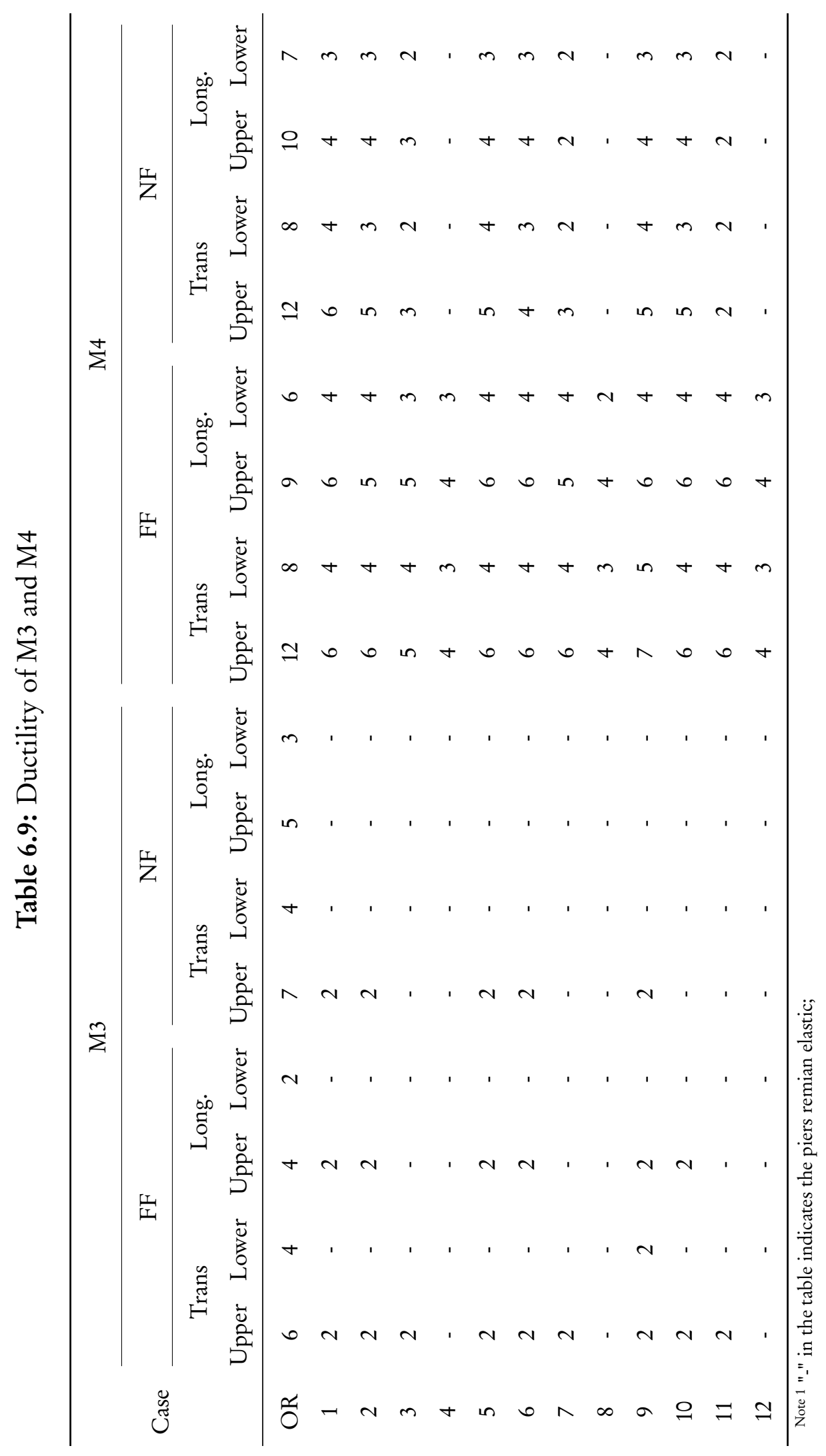

Xi Cheng, Department of Civil and Environmental Engineering, Carleton University 
Table 6.10: Brace Properties in Retrofit Scheme-2 for M4

\begin{tabular}{cccc}
\hline \multirow{2}{*}{ Parameters } & \multicolumn{2}{c}{ Trans } & Long. \\
& Abt. & Mid-bent & \\
\hline Length $(L)$ & 4000 & 8750 & 4000 \\
Activation Force $\left(P_{a}\right)$ & 1950 & 1950 & 4750 \\
Initial Stiffness $\left(k_{1}{ }^{\mathrm{a}}\right)$ & 646 & 296 & 1319 \\
Stiffness Ratio $(\alpha)$ & 0.109 & 0.108 & 0.107 \\
Energy Dissipation $(\beta)$ & & 0.45 & \\
Design Factor $(D F)$ & & 2 & \\
\hline
\end{tabular}

${ }^{a}$ Effective initial stiffness;

The properties are in $\mathrm{mm}, \mathrm{kN} ; \beta$ and $D F$ are unitless.

Table 6.11: Response Comparison in Different Schemes for M4

\begin{tabular}{|c|c|c|c|c|c|c|c|c|c|c|c|c|}
\hline \multirow{2}{*}{ EQ } & \multirow{2}{*}{ Scheme } & \multirow{2}{*}{ Parameter } & \multicolumn{2}{|c|}{$D_{\max }$} & \multicolumn{2}{|c|}{$D_{\text {res }}$} & \multicolumn{2}{|c|}{$R_{r / m}$} & \multicolumn{2}{|c|}{$a_{\max }{ }^{\dagger}$} & \multicolumn{2}{|c|}{$v_{\max }$} \\
\hline & & & Trans. & Long. & Trans. & Long. & Trans. & Long. & Trans. & Long. & Trans. & Long. \\
\hline \multirow{4}{*}{ FF } & \multirow{2}{*}{1} & $\mu$ & 87 & 81 & 0 & 0 & $0 \%$ & $0 \%$ & 1.99 & 1.43 & 1036 & 996 \\
\hline & & $\sigma$ & 71 & 56 & 0 & 0 & $0 \%$ & $0 \%$ & 0.77 & 0.58 & 741 & 578 \\
\hline & \multirow{2}{*}{2} & $\mu$ & 89 & 82 & 0 & 0 & $0 \%$ & $0 \%$ & 1.85 & 1.43 & 1052 & 997 \\
\hline & & $\sigma$ & 71 & 56 & 0 & 0 & $0 \%$ & $0 \%$ & 0.74 & 0.58 & 753 & 578 \\
\hline \multirow{4}{*}{ NF } & \multirow{2}{*}{1} & $\mu$ & 36 & 30 & 0 & 4 & $0 \%$ & $7 \%$ & 1.37 & 0.84 & 476 & 427 \\
\hline & & $\sigma$ & 38 & 20 & 1 & 8 & $1 \%$ & $12 \%$ & 0.73 & 0.56 & 333 & 211 \\
\hline & \multirow{2}{*}{2} & $\mu$ & 38 & 30 & 0 & 0 & $1 \%$ & $0 \%$ & 1.28 & 0.85 & 496 & 454 \\
\hline & & $\sigma$ & 40 & 23 & 0 & 0 & $0 \%$ & $0 \%$ & 0.65 & 0.56 & 362 & 264 \\
\hline
\end{tabular}

Unit: $g=9810 \mathrm{~mm} / \mathrm{s}^{2}$;

Other responses are in $\mathrm{mm}, \mathrm{s}$ and $\mathrm{kN}$; 
Sample Time History Results: Displacement
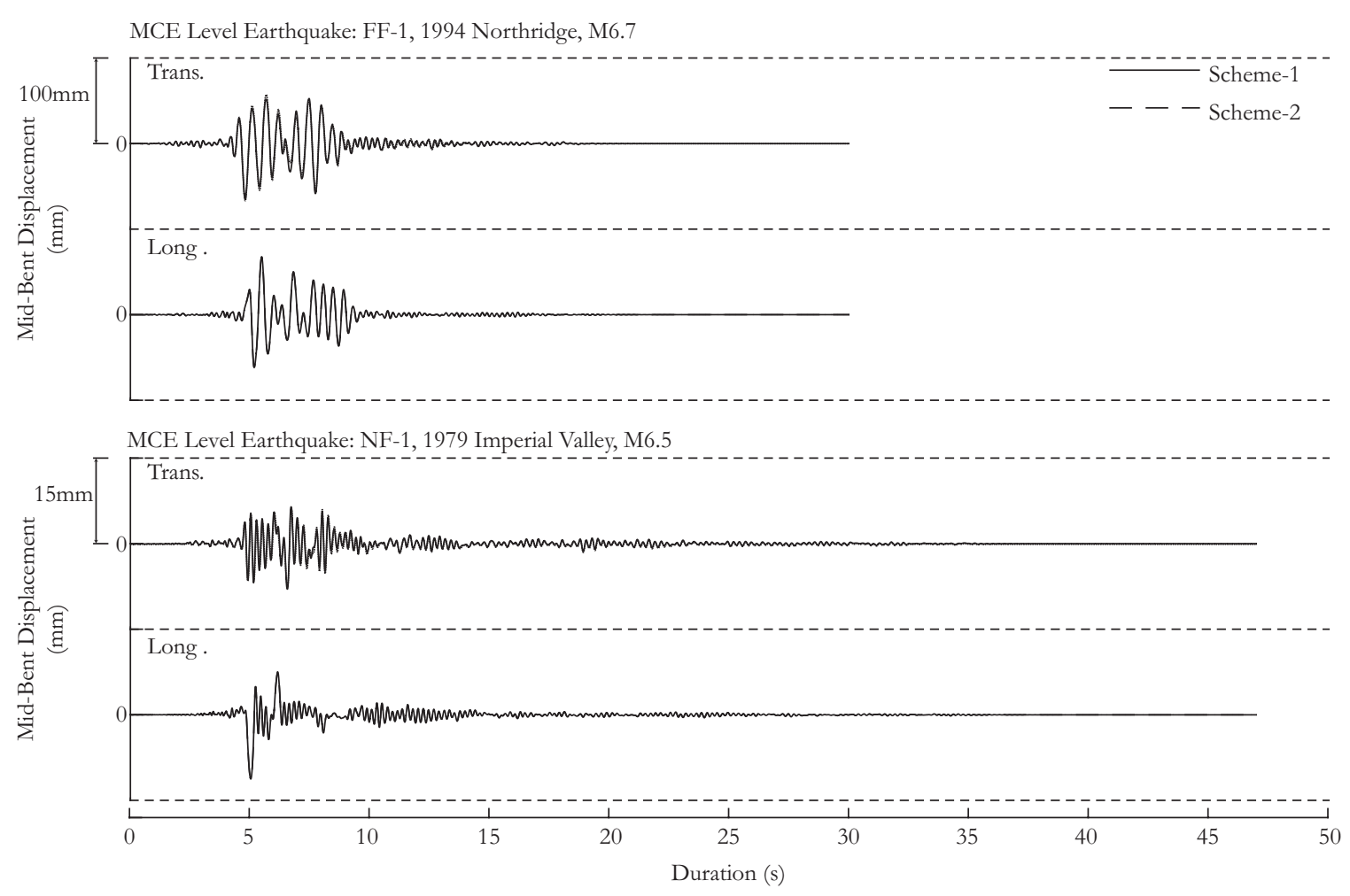

Figure 6.26: Time History Comparison of Mid-Bent Displacement 


\section{Chapter 7: Conclusions}

The goal of this research is to extend the application of the Self-Centering Energy Dissipative (SCED) braces from the retrofit of buildings to the retrofit of bridges. A design procedure, adapted from Erochko et al. [13], for bridge retrofit with SCED braces was proposed. A series of analytical investigations has been conducted to assess the design procedure and the effectiveness of the SCED braces in improving seismic performance.

\subsection{Summary of the Research}

In Chapter 1, the background and motivations for the research were presented. This included the current state of the bridges in Canada, the necessity of retrofitting bridges designed with obsolete codes and overview of various retrofit strategies for bridges. Previous self-centering systems were focused on building design fewer applications to bridges have been previously studied.

In Chapter 2, the basic concepts of the self-centering system were discussed and different types of self-centering systems were presented. The SCED brace is attractive due to its high capacity and feasibility of retrofitting existing bridges. The limitations of other SC systems were also presented. The mechanics and hysteresis of the SCED brace were explained.

In Chapter 3, the example bridges and modeling strategies were presented. The 
limitations of the models were also acknowledged. The skew of the bridge and the interaction between the structure and soil are ignored for simplicity. The piers are assumed to be fixed to the ground in all directions. The nonlinearity of the model concentrates in the piers since the prestressed concrete deck is assumed to be elastic during ground motions. The piers were modeled using force-based fiber elements. The unconfined and confined concrete properties were calculated according to Manders' Model. A parametric study was conducted to determine the proper material types of concrete and steel, cross-section configurations and the distribution of plasticity along the element. The parametric study showed that the distributed plasticity element with Steel02 and Concrete01 fibers on the cross-section was able to produce stable and convergent analyses.

In Chapter 4, the selection and scaling of the ground motion were presented. The far-field and near-field ground motions from FEMA P695 were scaled to the seismic hazard level of $2 \%$ in 50 years for Victoria, BC using modal pushover scaling method. These two horizontal components of these ground motions were applied concurrently in the transverse and longitudinal directions. Each pair of components were switched to avoid direction bias. These ground motions were scaled based on the first mode response in the longitudinal direction.

In Chapter 5, several retrofit strategies used in the previous studies were discussed, and two retrofit schemes for the SCED brace were proposed. A new SCED design procedure was proposed. The vital step in this procedure related the activation force of the SCED brace to the total base shear of the equivalent elastic structure. The ratio of the elastic total base shear to the activation force was defined as the target activation force design factor $D F$. Once the activation force was determined, each component of the SCED brace could be designed iteratively. The controlled criteria in designing each component were as follows: (1) The brace should be able to resist the estimated ultimate load; (2) The steel tubes should be able to contain the tendons and required clearance. 
The parameters investigated in the parametric study are $D F$ and energy dissipation capacity $\beta$. For the braces located along the longitudinal direction, the lock-up device was recommended to work in series with the brace to accommodate the thermal expansion in that direction.

In Chapter6, a parametric study was conducted to assess the effects of different retrofit schemes, ground motion types, brace target activation force design factor and properties of the SCED braces on the retrofit performance. The results of the parametric study showed that the SCED braces were effective for both far field and near field records but were particularly effective for the structures subjected to near-field ground motions. With the braces implemented to the structure, the peak displacement could be limited within $60 \%$ of the original peak displacement. The residual displacement was eliminated or close to zero. The costs of the better performance in the peak and residual displacement are the increased peak acceleration and velocity, and higher design load for the connections and foundations connecting the SCED braces. The desirable design parameter combination is $\beta=0.45$ and $D F=4$ or 6 . The proposed two schemes were adopted in M4 retrofit with the desirable design parameters. The performances of these two schemes are almost identical, showing that for these bridges, it is not necessary to include SCED braces at the mid-span of the bridge.

\subsection{Primary Contribution of the Thesis}

This thesis extended the application of the SCED braces to bridge and proposed a design procedure. The primary contributions of the thesis are summarized below:

1. The SCED braces were extensively studied by previous researchers but had not been adopted in retrofitting bridges. This study implemented the SCED brace to the bridges. This thesis proposed a design procedure for retrofitting bridges with the SCED braces. The desirable combination of the design parameters is also 
recommended.

2. This thesis took advantages of the SCED Mechanics Simulator in the design. This tool provided a good estimate of the hysteretic behavior. However, the theoretical initial stiffness from the rough plot provided by this tool were reduced to accommodate the realistic initial stiffness.

3. Bridges with different geometric properties were selected as examples. The results of the parametric study proved that the SCED braces were effective for bridges with various span lengths, the number of spans and number of piers at each bent. Different retrofit schemes were also compared for one of the example bridge."

\subsection{Suggestion for Future Research}

This thesis provided some valuable recommendation on retrofitting bridges with the SCED braces. However, the following issues are required further study to apply it to the real bridge structures.

1. Some details of the bridges were ignored for simplicity when built the model. For instance, the skew of the bridges, the soil-structure interaction, the movement of the foundations of the piers, etc., do affect the response of the bridge.

2. The classical damping of the structure with perfect fixity on the ground was assumed to be $5 \%$ according to some codes. It is recognized that the damping ratio can be up to $10 \%$ of critical and needs to be justified by the designers.

3. The detailed failure mechanism at the bottom of the pier was not considered. The bar-pullout effect may worsen the retrofit performance. The behavior of the pier in the numerical model may be significantly different from reality. The properties of the pier in the model need to be modified to match the real response. The 
properties of the shear key are estimated based on other research due to the lack of detailed drawings.

4. The SCED brace model uses sharper stiffness transitions than real SCED braces. This would overestimate the acceleration in the parametric study. A more realistic self-centering model with gradual transition could be used to get a better estimate of the acceleration. The external friction fuse was not considered in this research. Thus, the residual deformation may be greater but can be ignored if the brace is well designed.

5. The desirable design case selected from the parametric study is appropriate for the braces with $4 \mathrm{~m}$ length. Together with the reduced response after retrofit, the braces deforming within their deformation capacity is another criterion. To make more design cases where braces deform within their capacity, implementing longer braces or Telescoping (T-SCED) braces is an alternative method. Especially, the TSCED braces have double deformation capacity compared with a SCED brace in the same length. 


\section{List of References}

[1] K. Vishnukanthan, Probabilistic performance-based seismic risk assessment of bridge inventories with loss and impact estimates. Master's thesis, Carleton University, 2013.

[2] M. J. N. Priestley, F. Seible, and G. M. Calvi, Seismic design and retrofit of bridges. John Wiley \& Sons, 1996.

[3] Y. Wang, L. Ibarra, and C. Pantelides, "Seismic Retrofit of a Three-Span RC Bridge with Buckling-Restrained Braces," Journal of Bridge Engineering, vol. 3, no. 14, p. 04016073, 2016.

[4] M. A. ElGawady and A. Sha'lan, "Seismic Behavior of Self-Centering Precast Segmental Bridge Bents," Journal of Bridge Engineering, vol. 16, no. 3, pp. 328-339, 2011.

[5] A. Filiatrault, J. Restrepo, and C. Christopoulos, "Development of self-centering earthquake resisting systems," 13th World Conference on Earthquake Engineering Vancouver, B.C., Canada, 2004.

[6] K. Kawashima, G. a. MacRae, J. I. Hoshikuma, and K. Nagaya, "Residual displacement response spectrum," Journal of Structural Engineering, vol. 124, no. May, pp. 523-530, 1998.

[7] N. A. Miklas, State of Bridge Management in Canada. Master's thesis, North Dakota State University, 2012.

[8] L. Bisby, “An Introduction to Structural Health Monitoring," 2005.

[9] Statistics Canada, "Age of Public Infrastructure: A Provincial Perspective."

[10] D. Mitchell, R. G. Sexsmith, and R. Tinawi, "Seismic retrofitting techniques for bridges-a state-of-the-art report," International Journal of Rock Mechanics and Mining Sciences, vol. 32, no. 4, p. A185, 1995. 
[11] G. Pekan, J. B. Mander, and S. S. Chen, "Seismic Retrofit of Steel Deck-Truss Bridges with Supplemental Tendon Systems," in Advanced Technology in Structural Engineering, pp. 1-8, 2000.

[12] H. I. L. Jeong, Evaluation of self-centering reinforced concerete columns by shaking table tests and numerical simulations.pdf. PhD thesis, UNIVERSITY OF CALIFORNIA, BERKELEY, 2007.

[13] J. Erochko, C. Christopoulos, and R. Tremblay, "Design, testing, and detailed component modeling of a high-capacity self-centering energy-dissipative brace," Journal of Structural Engineering, vol. 141, no. 8, p. 04014193, 2014.

[14] M. J. N. Priestley, S. Sritharan, J. R. Conley, and S. Pampanin, "Preliminary Results and Conclusions From the PRESSS Five-Story Precast Concrete Test Building," PCI Journal, vol. 44, no. 6, pp. 42-67, 1999.

[15] C. Christopoulos, R. Tremblay, H.-J. Kim, and M. Lacerte, "Self-centering energy dissipative bracing system for the seismic resistance of structures: development and validation," Journal of Structural Engineering, vol. 134, no. 1, pp. 96-107, 2008.

[16] I. D. Aiken, D. K. Nims, and Kelly Jam, "Comparative study of four passive energy dissipation systems," Bull. New Zealand Nat. Soc. For Earthquake Engrg, vol. 25, no. 3, pp. 175-192, 1992.

[17] R. DesRoches and B. Smith, "Shape memory alloys in seismic resistant design and retrofit: A critical review of their potential and limitations," Journal of Earthquake Engineering, vol. 7, no. C, pp. 2005-2006, 2003.

[18] G. Guerrini, J. I. Restrepo, A. Vervelidis, and M. Massari, "Self-centering precast concrete dual-steel-shell columns for accelerated bridge construction : seismic performance, analysis , and design,” tech. rep., Pacific Earthquake Engineering Research Center, 2015.

[19] L. Cormack, “The design and construction of the major bridges on the Mangaweka rail deviation," Transactions of the Institution of Professional Engineers New Zealand: Civil Engineering Section, vol. 15, no. 1, p. 17, 1988.

[20] J. B. Mander and C. T. Cheng, "Seismic resistance of bridge piers based on damage avoidance design,” tech. rep., State University of New York, Buffalo, NY, 1997.

[21] J. Guo, K.-G. Xin, M.-H. He, and L. Hu, "Experimental study and analysis on the seismic performance of a self-centering bridge pier," Gongcheng Lixue/Engineering Mechanics, vol. 29, no. SUPPL.1, pp. 29-34+45, 2012. 
[22] S. Mazzoni, F. Mckenna, M. H. Scott, and G. L. Fenves, "OpenSees command language manual,” Pacific Earthquake Engineering Research (PEER) Center, 2006.

[23] C. Christopoulos and A. Filiatrault, Principles of Passive Supplemental Damping and Seismic Isolation, vol. 133. IUSS Press, 2006.

[24] R. Tremblay, . M. Lacerte, and C. Christopoulos, "Seismic Response of Multistory Buildings with Self-Centering Energy Dissipative Steel Braces," Journal of Structural Engineering, vol. 134, no. 1, pp. 108-120, 2008.

[25] N. Chancellor, M. Eatherton, D. Roke, and T. AkbaÅ§, “Self-Centering Seismic Lateral Force Resisting Systems: High Performance Structures for the City of Tomorrow,” Buildings, vol. 4, no. 3, pp. 520-548, 2014.

[26] T. Holden, J. Restrepo, and J. B. Mander, "Seismic Performance of Precast Reinforced and Prestressed Concrete Walls," Journal of Structural Engineering, vol. 129, no. 3, pp. 286-296, 2003.

[27] A. Palermo, S. Pampanin, and D. Marriott, "Design, Modeling, and Experimental Response of Seismic Resistant Bridge Piers with Posttensioned Dissipating Connections," Journal of Structural Engineering, vol. 133, no. 11, pp. 1648-1661, 2007.

[28] C. Christopoulos, A. Filiatrault, C.-M. Uang, and B. Folz, "Posttensioned Energy Dissipating Connections for Moment-Resisting Steel Frames," Journal of Structural Engineering, vol. 128, no. 9, pp. 1111-1120, 2002.

[29] C. C. Chou and Y. J. Lai, "Post-tensioned self-centering moment connections with beam bottom flange energy dissipators," Journal of Constructional Steel Research, vol. 65, no. 10-11, pp. 1931-1941, 2009.

[30] C. Christopoulos, Self-Centering Post-Tensioned Energy Dissipating (PTED) Steel Frames For Seismic Regions. PhD thesis, University of California, San Diego, 1997.

[31] J. M. Ricles, R. Sause, M. M. Garlock, and C. Zhao, "Posttensioned seismicresistant connections for steel frames," Journal of Structural Engineering, vol. 127, no. 2, pp. 113-121, 2001.

[32] J. S. Hwang, C. H. Tsai, S. J. Wang, and Y. N. Huang, "Experimental study of RC building structures with supplemental viscous dampers and lightly reinforced walls," Engineering Structures, vol. 28, no. 13, pp. 1816-1824, 2006. 
[33] L. C. Chang and T. A. Read, "Plastic deformation and diffusionless phase changes in metals-the gold-cadmium beta-phase," Transactions of the American Institute of Mining and Metallurgical Engineers, vol. 191, no. 1, pp. 47-52, 1951.

[34] M. Dolce, D. Cardone, and R. Marnetto, "Implementation and testing of passive control devices based on shape memory alloys," Earthquake Engineering E Structural Dynamics, vol. 29, no. v, pp. 945-968, 2000.

[35] P. Clark, I. Aiken, and J. Kelly, "Experimental and analytical studies of shapememory alloy dampers for structural control," in SPIE 2445 Smart Structures and Materials, vol. 2445, pp. 241-251, 1995.

[36] A. Whittaker, R. Krumme, S. C. Sweeney, and J. R. Hayes, "Structural control of building response using shape memory alloy," tech. rep., US Army Corps of Engineers, 1995.

[37] M. Higashino, S. Aizawa, P. W. Clark, A. S. Whittaker, I. D. Aiken, and J. M. Kelly, "Experimental and analytical studies of structural control system using shape memory alloy," in Second International Workshop on Structural Control, December, pp. 18-21, 1996.

[38] I. D. Aiken and J. M. Kelly, Earthquake simulator testing and analytical studies of two energy-absorbing systems for multistory structures. PhD thesis, University of California, 1990.

[39] S. C. Sweeney and J. Hayes, "Shape memory alloy dampers for seismic rehabilitation of existing buildings," in Proceedings of 27th Joint Meeting on Wind and Seismic Effects, pp. 317-332, 1995.

[40] J. Ocel, M. Asce, R. Desroches, R. T. Leon, . W. G. Hess, R. Krumme, J. R. Hayes, and S. Sweeney, "Steel Beam-Column Connections Using Shape Memory Alloys," Journal of Structural Engineering negineering, vol. 130, no. 5, pp. 732-740, 2004.

[41] M. Indirli, M. G. Castellano, P. Clemente, and A. Martelli, "Demo-Application of Shape Memory Alloy Devices: the Rehabilitation of the S. Giorgio Church Bell Tower," SPIE's 8th Annual International Symposium on Smart Structures and Materials, pp. 262-272, 2001.

[42] G. Croci, "The basilica of St. Francis of Assisi after the September 1997 earthquake," Structural engineering international, vol. 8, no. 1, pp. 56-58, 1998. 
[43] K. Wilde, P. Gardoni, and Y. Fujino, "Base isolation system with shape memory alloy device for elevated highway bridges," Engineering Structures, vol. 22, no. 3, pp. 222-229, 2000.

[44] R. DesRoches and M. Delemont, "Seismic retrofit of simply supported bridges using shape memory alloys,” Engineering Structures, vol. 24, no. 3, pp. 325-332, 2002.

[45] D. K. Nims, P. J. Richter, and R. E. Bachman, “The use of the energy dissipating restraint for seismic hazard mitigation," Earthquake Spectra, vol. 9, no. 3, pp. 467489, 1993.

[46] R. Kar, J. H. Rainer, and A. C. Lefrançois, "Dynamic properties of a circuit breaker with friction-based seismic dampers," Earthquake spectra, vol. 12, no. 2, pp. 297314, 1996.

[47] A. Filiatrault, R. Tremblay, and R. Kar, "Performance evaluation of friction spring seismic damper," Journal of Structural Engineering, vol. 126, no. 4, pp. 491-499, 2000.

[48] S. Zhu and Y. Zhang, "Seismic Analysis of Concentrically Braced Frame Systems with Self-Centering Friction Damping Braces," Journal of Structural Engineering, vol. 134, no. January, pp. 121-131, 2008.

[49] Y.-C. Ou, M. Chiewanichakorn, I.-S. Ahn, A. Aref, S. Chen, A. Filiatrault, and G. Lee, "Cyclic Performance of Precast Concrete Segmental Bridge Columns: Simplified Analytical and Finite Element Studies," Transportation Research Record, vol. 1976, no. 1, pp. 66-74, 2006.

[50] J. T. Hewes and M. J. N. Priestley, "Seismic design and performance of precast concrete segmental bridge columns,” Tech. Rep. UCSD / SSRP-2001/25, 2002.

[51] D. Marriott, S. Pampanin, and A. Palermo, "Quasi static and pseudo dynamic testing of unbonded posttensioned rocking bridge piers with external replaceable dissipaters," Earthquake Engineering E Structural Dynamics, vol. 38, no. 3, pp. 331-354, 2009.

[52] C. C. Chou and Y. C. Chen, "Cyclic tests of post-tensioned precast CFT segmental bridge columns with unbonded strands," Earthquake Engineering and Structural Dynamics, vol. 35, no. 2, pp. 159-175, 2006.

[53] H. J. Kim, Self-centering steel moment-resisting frames with energy dissipating systems. Doctoral thesis, University of Toronto, 2007. 
[54] H. Choi, J. Erochko, C. Christopoulos, and R. Tremblay, "Comparison of the seismic response of steel buildings incorporating self-Centering energy dissipative braces , buckling restrained braced and moment resisting frames," The 14-th World Conference on Earthquake Engineering, 2008.

[55] J. Erochko, C. Christopoulos, and R. Tremblay, "Design and Testing of an Enhanced-Elongation Telescoping Self-Centering Energy-Dissipative Brace," Journal of Structural Engineering, vol. 141, no. 6, pp. 1-11, 2015.

[56] S. El-Bahey and M. Bruneau, "Buckling restrained braces as structural fuses for the seismic retrofit of reinforced concrete bridge bents," Engineering Structures, vol. 33, no. 3, pp. 1052-1061, 2011.

[57] O. C. Celik and M. Bruneau, "Seismic behavior of bidirectional-resistant ductile end diaphragms with buckling restrained braces in straight steel bridges," Engineering Structures, vol. 31, no. 2, pp. 380-393, 2009.

[58] C. Field and K. West, "Lessons learned from design \& engineering of naval facilities," no. October, 1985.

[59] M. Marsh, I. G. Buckle, and E. Kavazanjian, "LRFD Seismic Analysis and Design of Bridges Reference Manual,” Tech. Rep. 130093, U.S. Department of Transportation Federal Highway Administration, 2014.

[60] A. Aviram, K. Mackie, and B. Stojadinovic, Guidelines of Nonlinear Analysis of Bridge Structures in California. No. August, Pacific Earthquake Engineering Research Center, 2008.

[61] C. Wai-Fah and D. Lian, "Bridge engineering handbook," New York: CRC Press.[2] Miles, JC, E Moore, CJ (1991). An expert system for the conceptual design of bridges. Computers and Structures, vol. 40, no. 1, p. 101105, 2000.

[62] A. Krimotat and L.-H. Sheng, Structural Modeling. Boca Raton, FL: CRC Press, 2000.

[63] CalTrans, "Seismic Design Criteria Version 1.7,” 2013.

[64] J. B. Mander, M. J. Priestley, and R. Park, “Theoretical Stress-strain Model for Confined Concrete," Journal of structural engineering, vol. 114, no. 8, pp. 1804$1826,1988$.

[65] S. Bae and O. Bayrak, "Plastic Hinge Length of Reinforced Concrete Columns," ACI Structural Journal, vol. 105, no. 3, pp. 290-300, 3. 
[66] M. S. Zadeh and M. S. Saiidi, "Pre-test Analytical Studies of NEESR-SG 4-Span Bridge Model Using OpenSees," Tech. Rep. February, Civil Engineering Department, University of Nevada, Reno, 2007.

[67] P. Kaviani, F. Zareian, and E. Taciroglu, "Seismic behavior of reinforced concrete bridges with skew-angled seat-type abutments," Engineering Structures, vol. 45, pp. 137-150, 2012.

[68] S. H. Megally, P. F. Silva, and F. Seible, "SEISMIC RESPONSE OF SACRIFICIAL SHEAR KEYS IN BRIDGE ABUTMENTS," tech. rep., Department of Structural Engineering University of California, San Diego, 2002.

[69] J. J. Bommer and A. B. Acevedo, "The Use Of Real Earthquake Accelerograms As Input To Dynamic Analysis,” Earthquake, vol. 8, no. 1, pp. 43-91, 2004.

[70] D. A. Gasparini and E. Vanmarcke, SIMQKE: A Program for Artificial Motion Generation: User's Manual and Documentation. MIT Department of Civil Engineering, 1976.

[71] P. Dunbar and L. W. Row III, "An Earthquake Strong-Motion Data Catalog for Personal Computers," National Geophysical Data Center, NOAA, 1996.

[72] N. N. Ambraseys, P. M. Smith, D. Berardi, F. Cotton, and C. Berge, "Dissemination of European Strong-motion Data," tech. rep., 2000.

[73] N. N. Ambraseys and J. J. Bommer, "Database of European Strong-motion Records," Eur. Earthq. Engrg, vol. 5, no. 2, pp. 18-37, 1991.

[74] Federal Emergency Management Agency (FEMA), "Quantification of building seismic performance factors,” Tech. Rep. April, 2009.

[75] E. Kalkan and A. K. Chopra, "Practical guidelines to select and scale earthquake records for nonlinear response history analysis of structures," US Geological Survey Open-File Report, pp. 1-113, 2010.

[76] A. Arias, "MEASURE OF EARTHQUAKE INTENSITY.," tech. rep., Massachusetts Inst. of Tech., Cambridge. Univ. of Chile, Santiago de Chile, 1970.

[77] N. Luco and C. A. Cornell, "Structure-specific scalar intensity measures for nearsource and ordinary earthquake ground motions," Earthquake Spectra, vol. 23, no. 2, pp. 357-392, 2007. 
[78] P. Bazzurro and N. Luco, "Parameterization of non-stationary acceleration time histories," Lifelines Program Project 1 G00 Addenda, 2004.

[79] National Research Council of Canada [NRC], National Building Code of Canada. Ottawa, Canada: National Research Council of Canada, 2015.

[80] A. K. Chopra and C. Chintanapakdee, "Inelastic deformation ratios for design and evaluation of structures: Single-degree-of-freedom bilinear systems," Journal of Structural Engineering, vol. 130, no. 9, pp. 1309-1319, 2004.

[81] D. Taylor, "Fluid lock-up devices-a Robust Means to Control Multiple Mass Structural Systems Subjected to Seismic or Wind Inputs," in Proceedings, 71st SAVIAC Shock and Vibration Symposium, Arlington, VA, 2000. 


\section{Appendix A: Drawings of the Exam- ple Bridges}

The drawing of the example bridges are included. When modeling the bridges, some modification are made. 


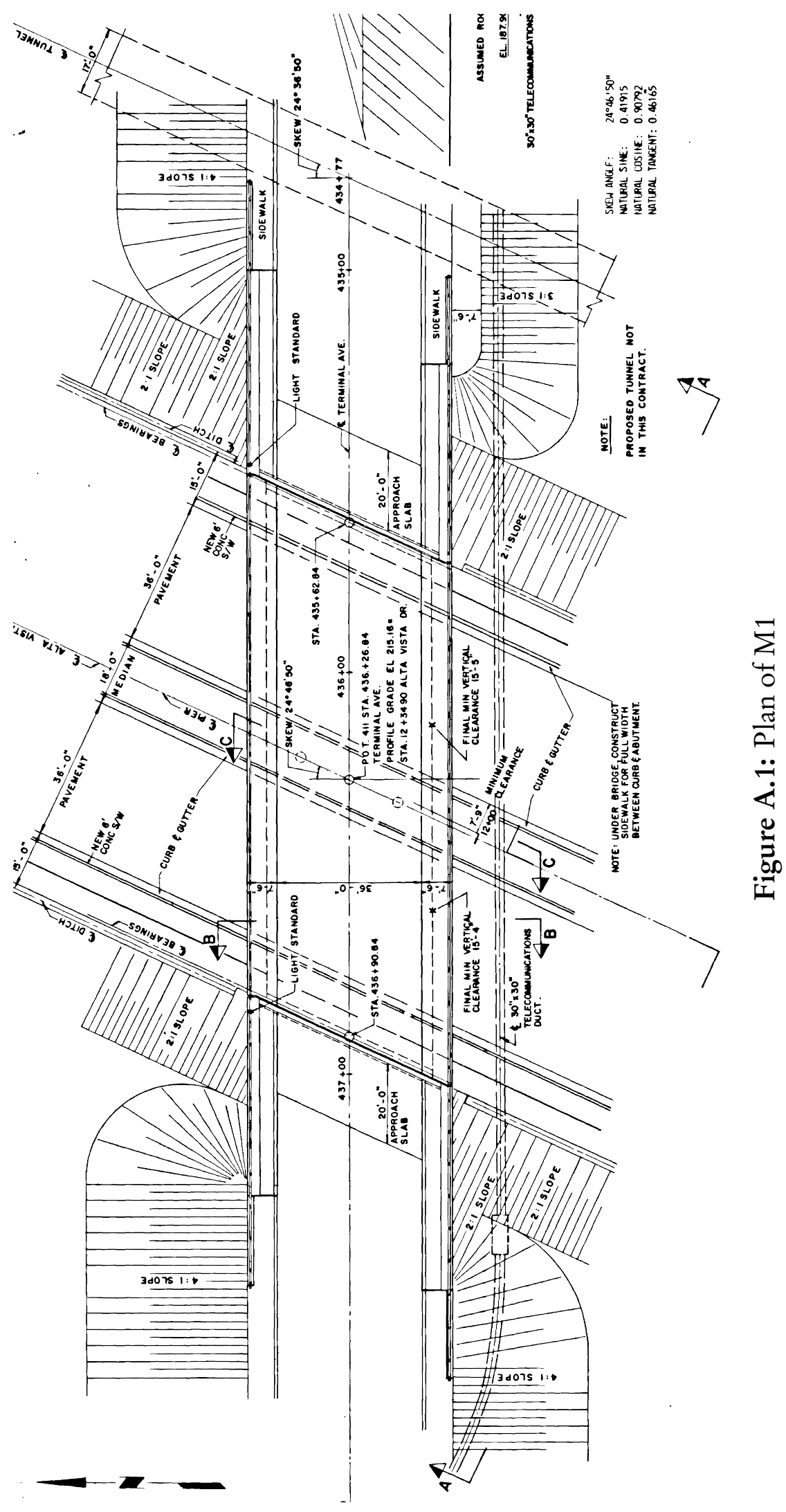




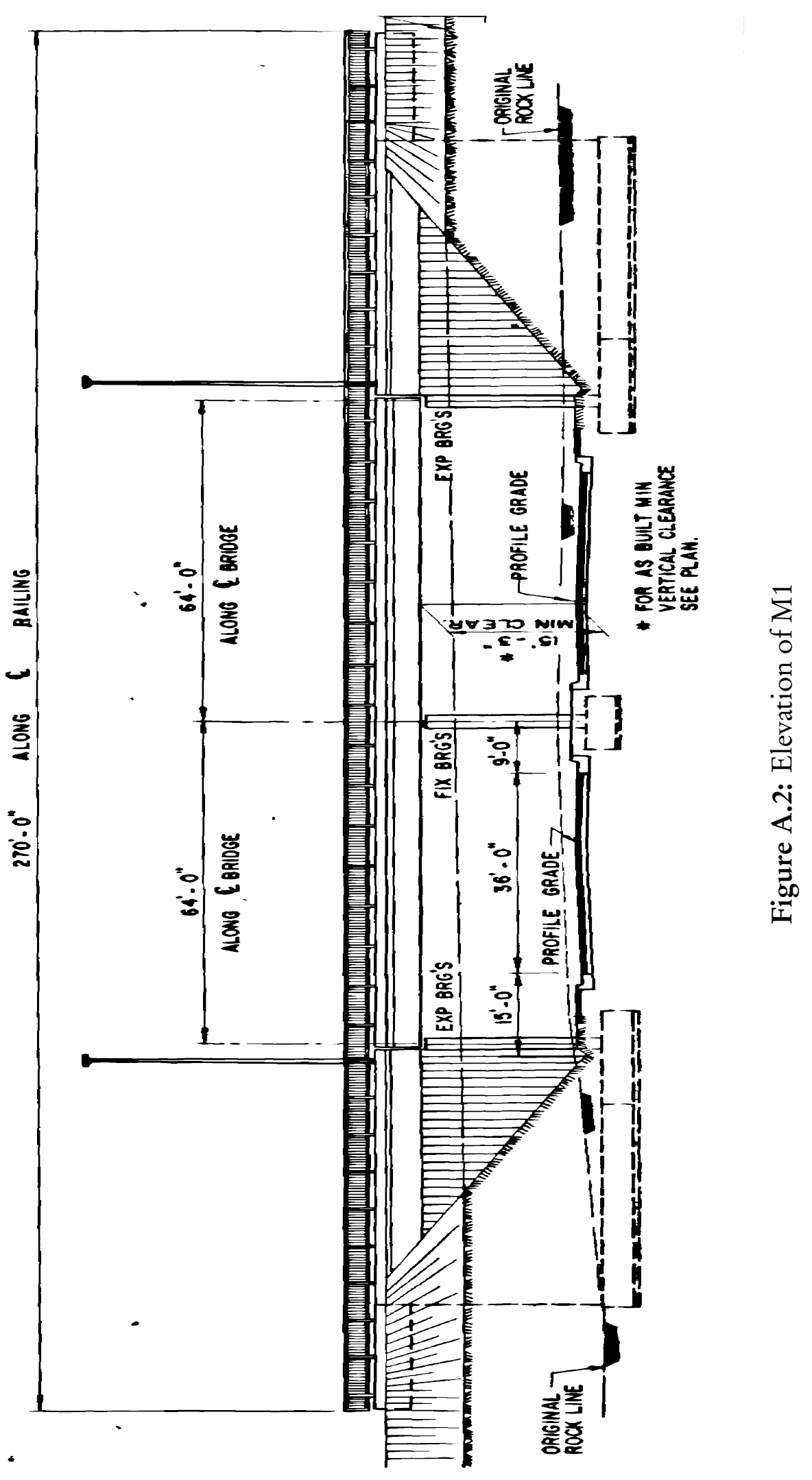

Xi Cheng, Department of Civil and Environmental Engineering, Carleton University 


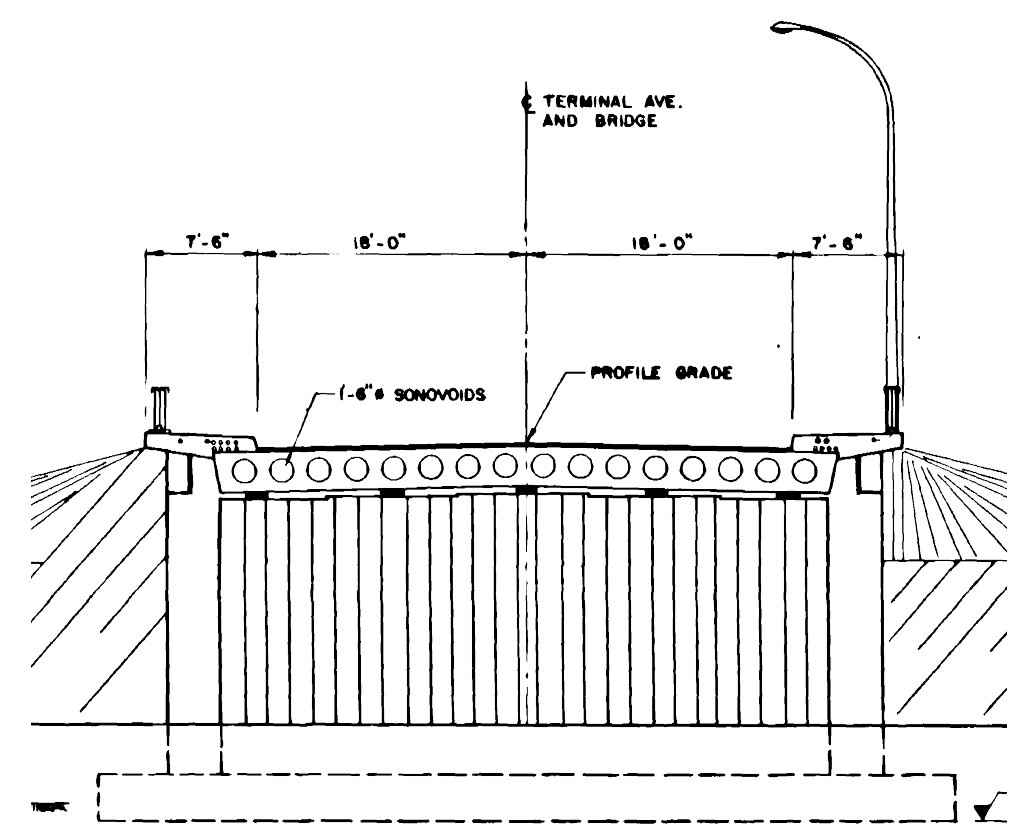

Figure A.3: Cross Section of M1

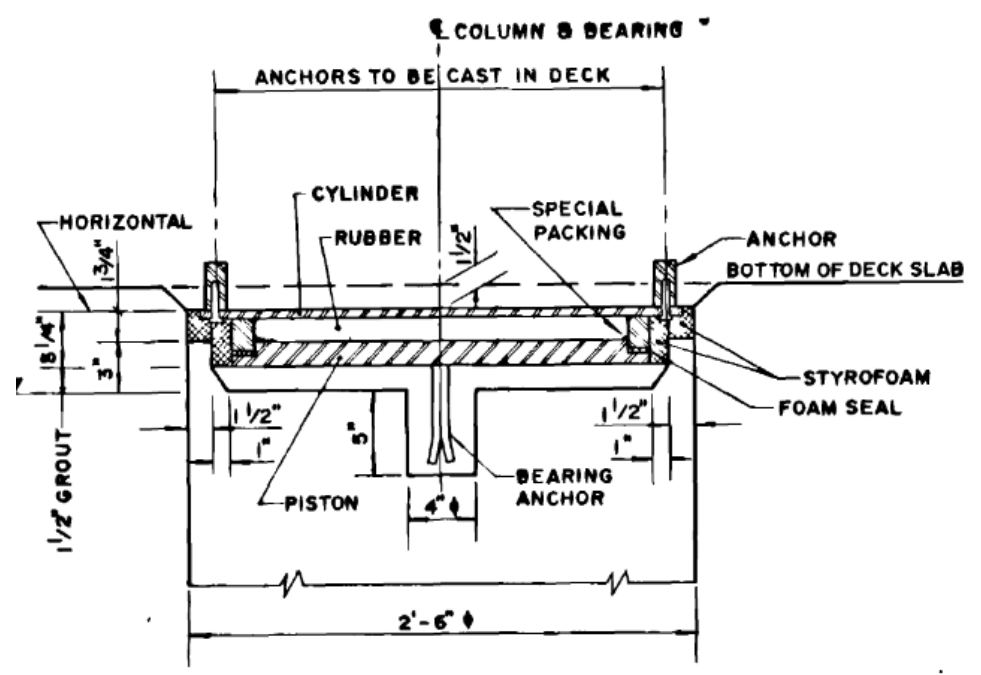

Figure A.4: Bearing of M1 


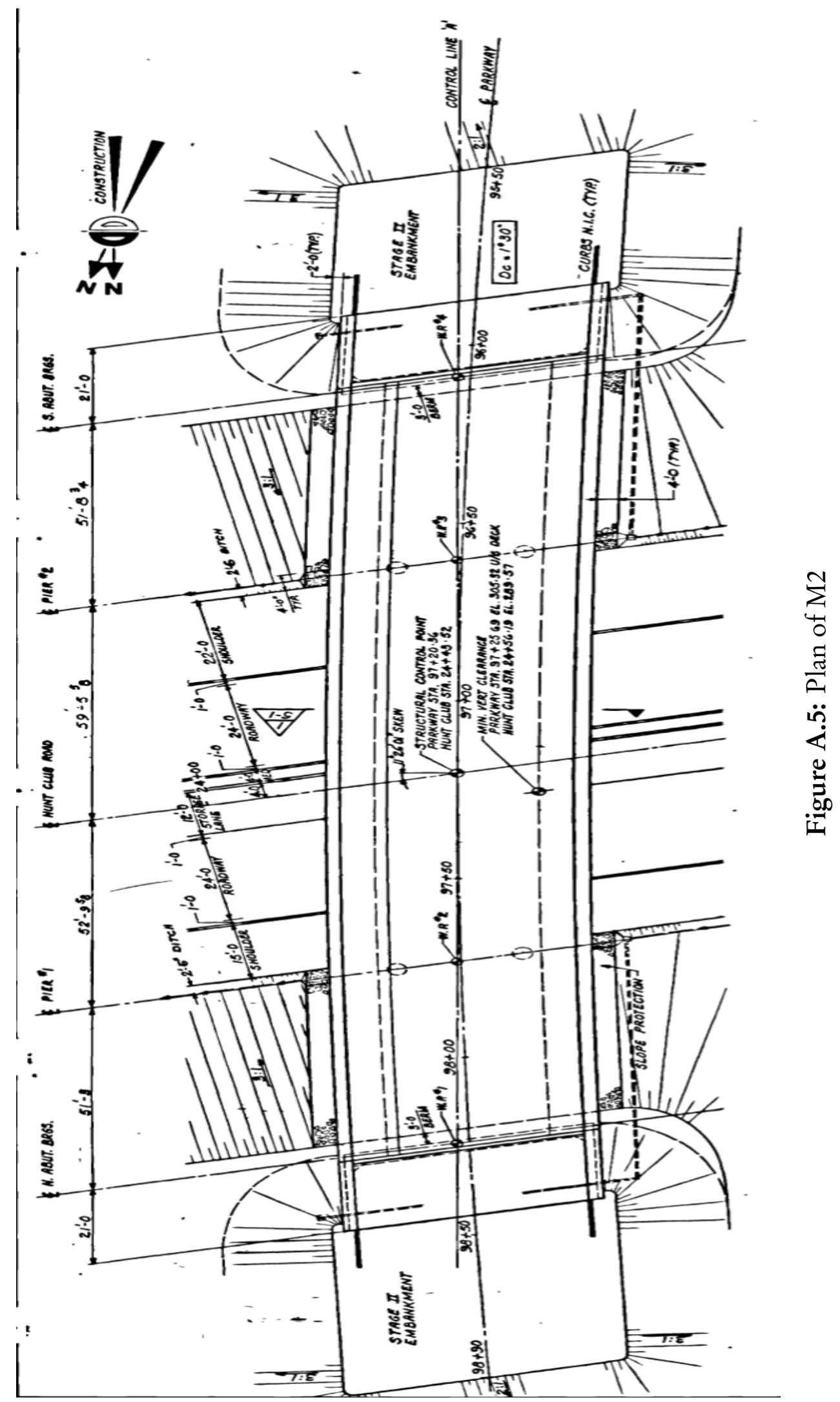

Xi Cheng, Department of Civil and Environmental Engineering, Carleton University 


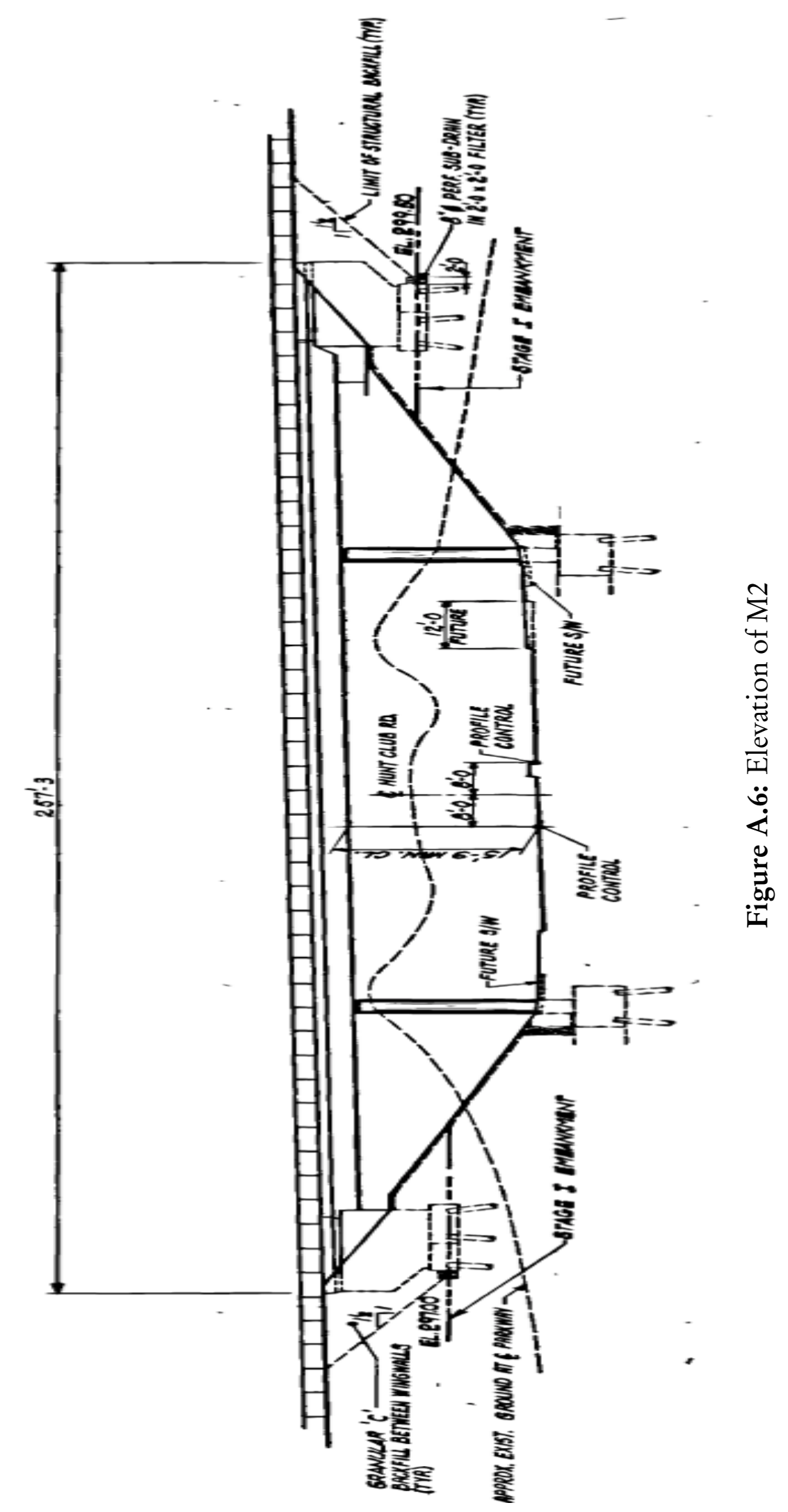




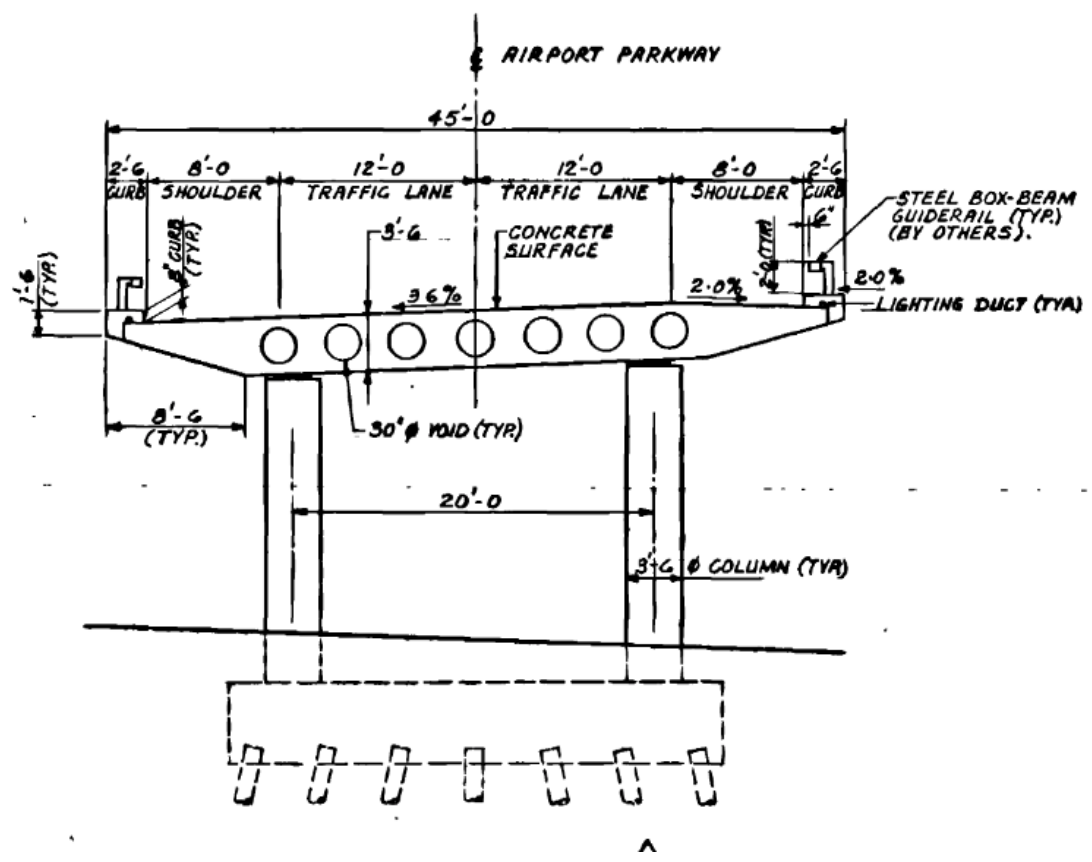

Figure A.7: Cross Section of M2

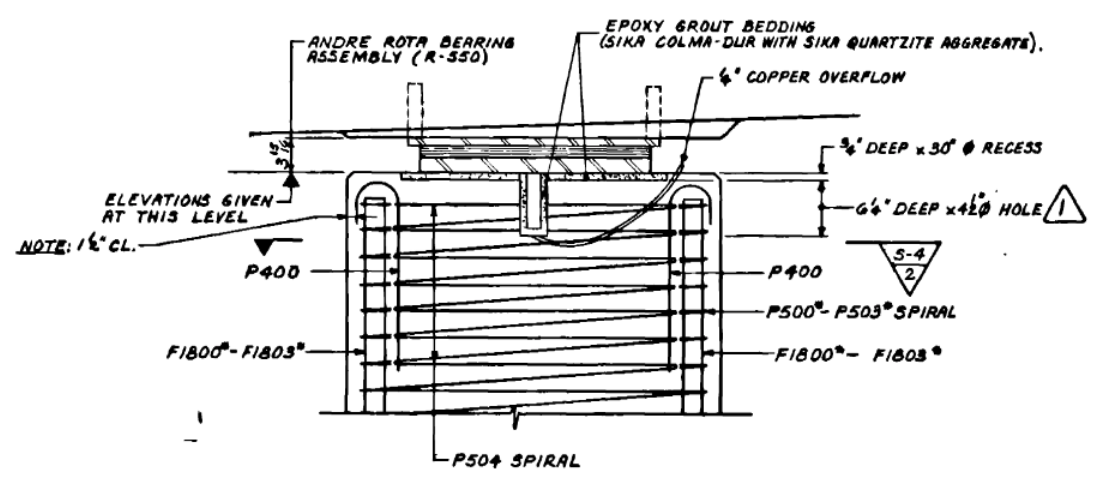

Figure A.8: Bearing of M2 


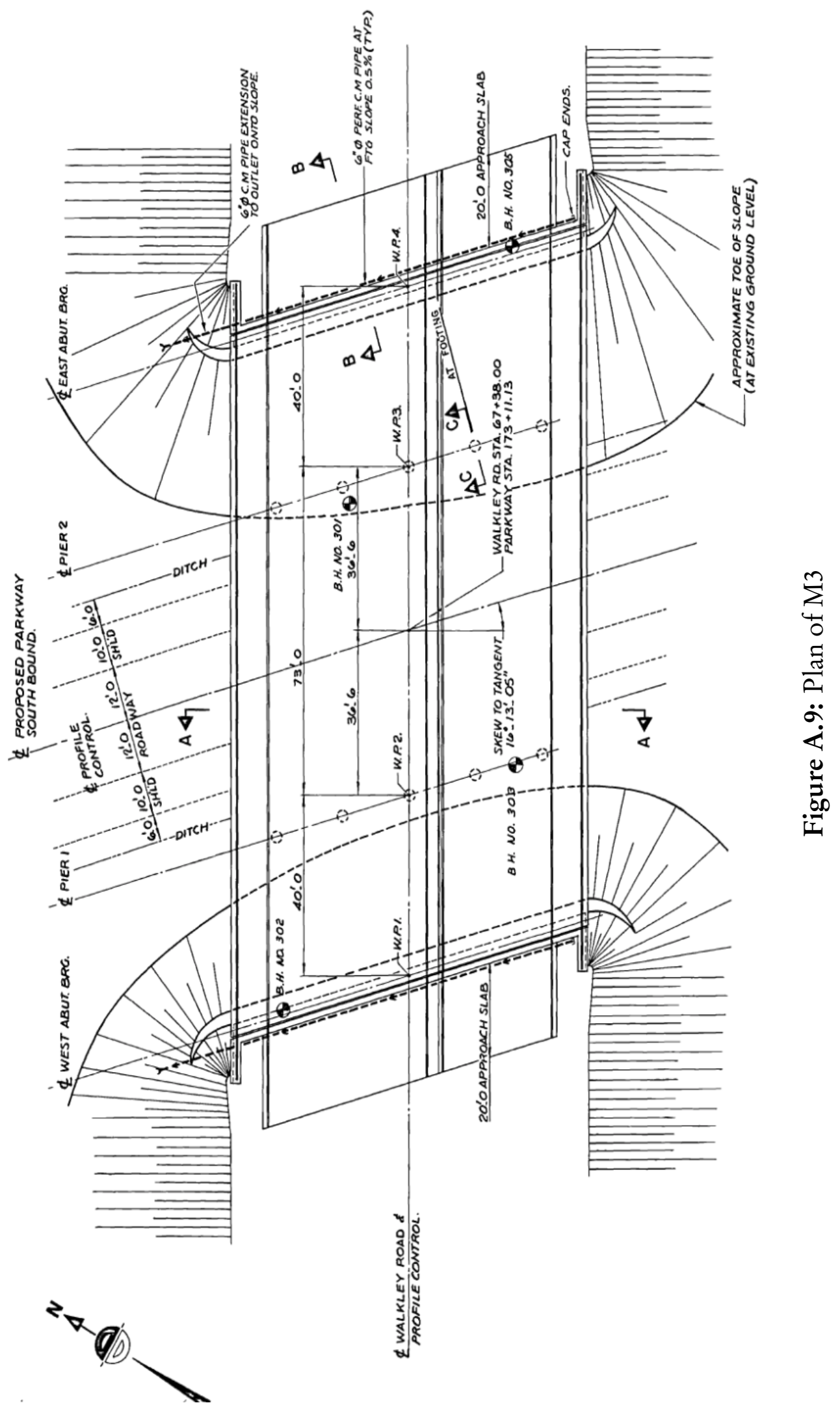




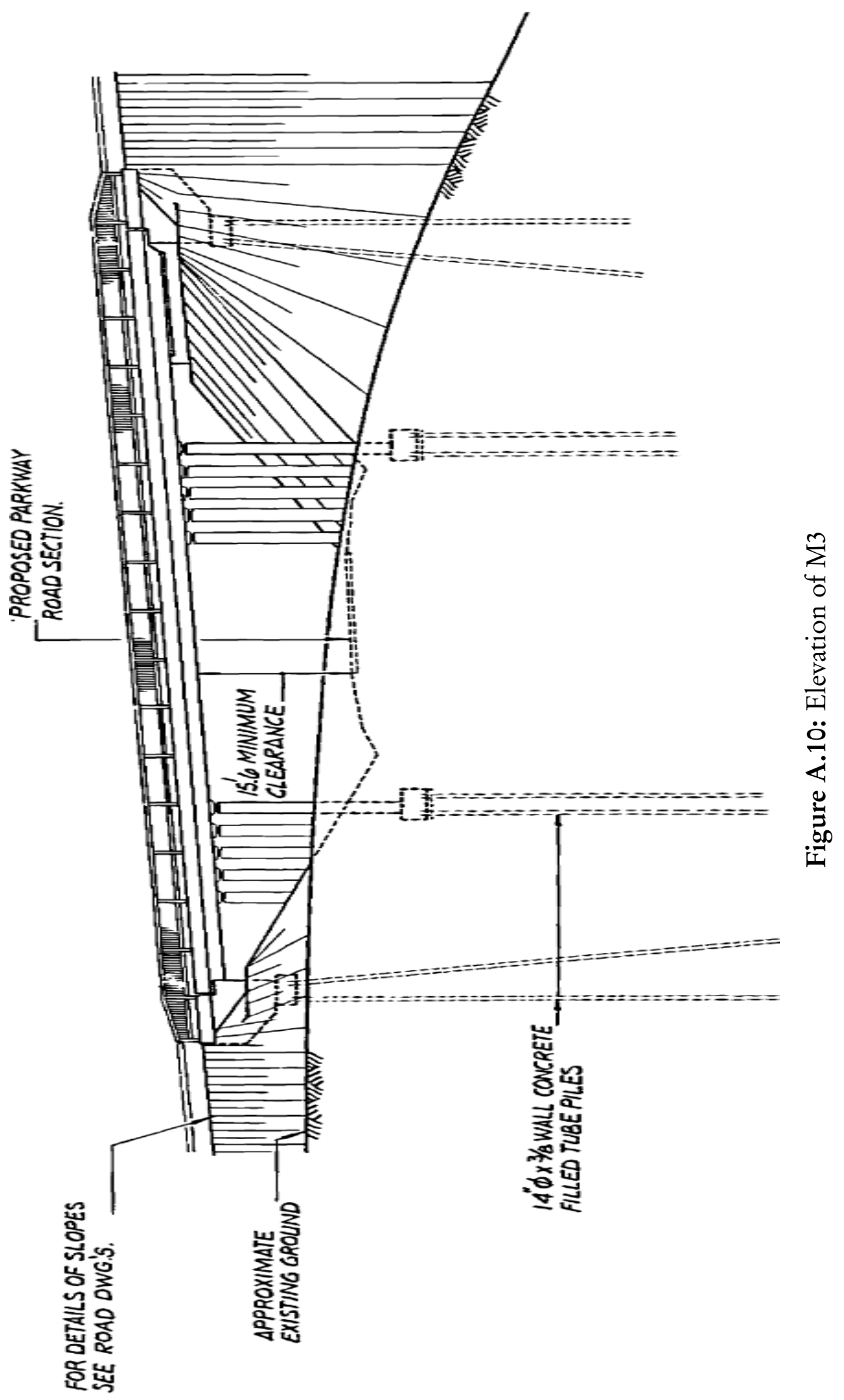




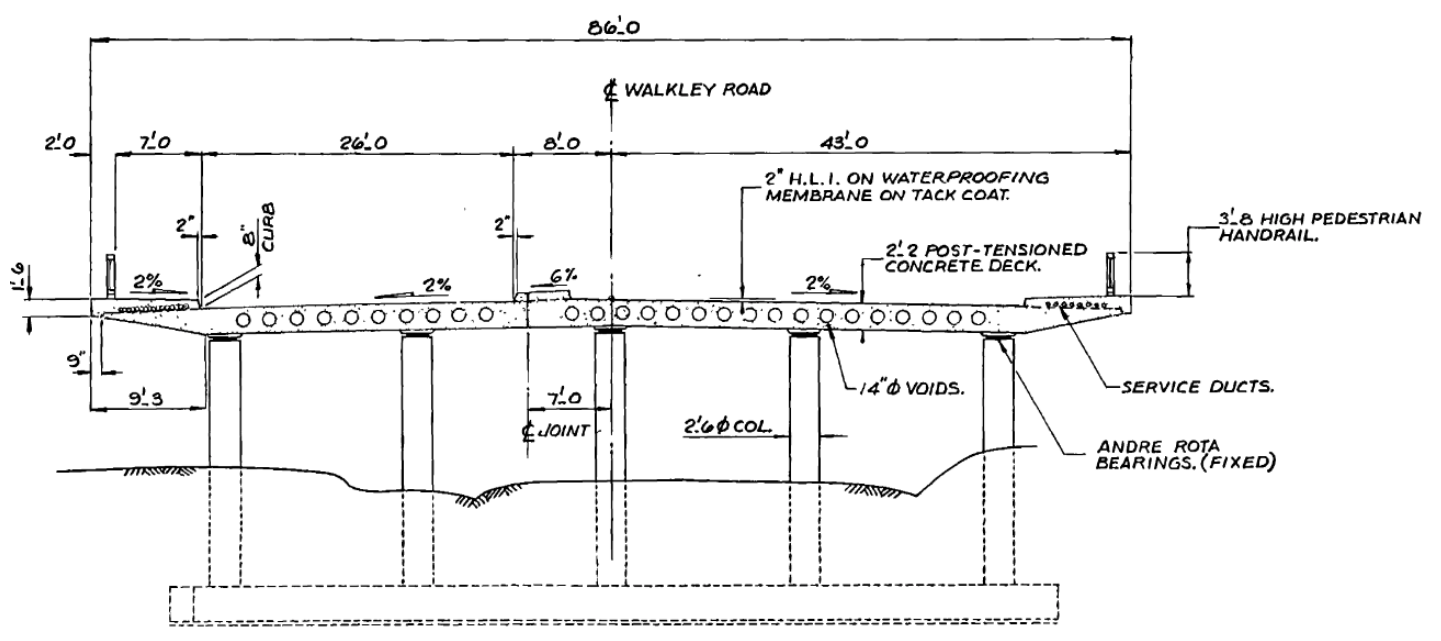

Figure A.11: Cross Section of M3
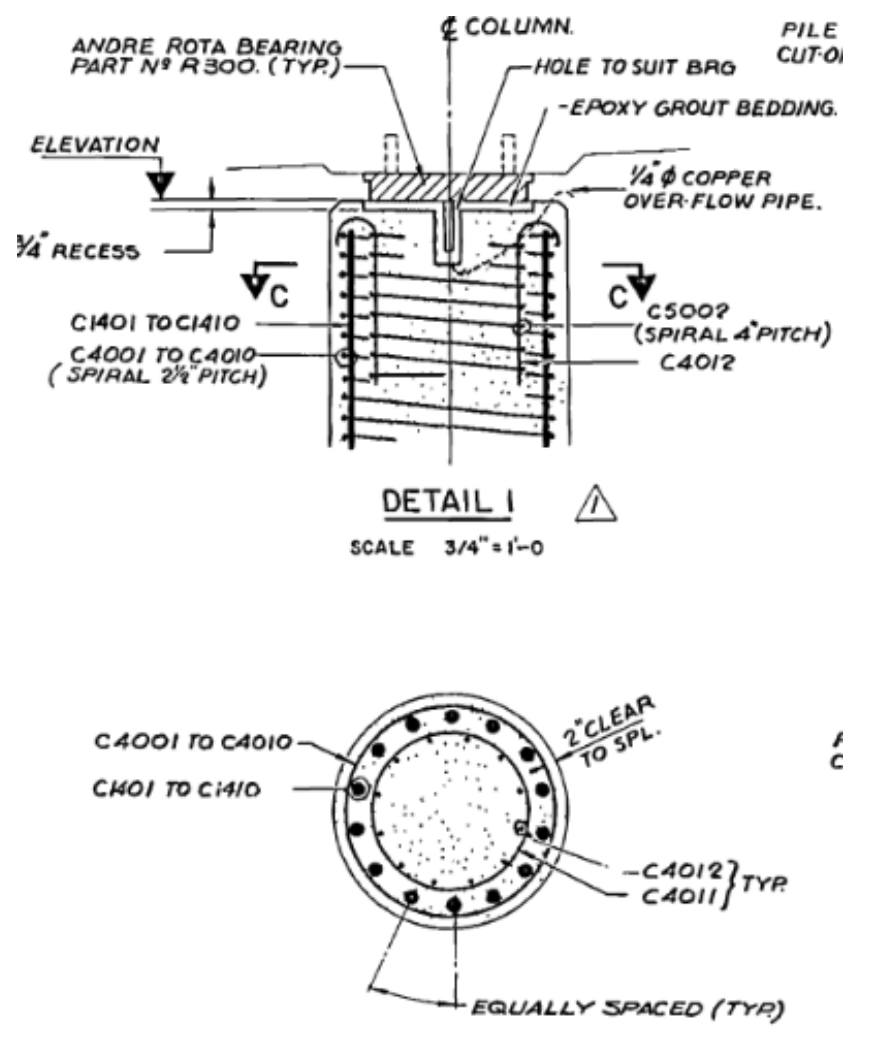

Figure A.12: Pier Cross-section and Bearing of M3 


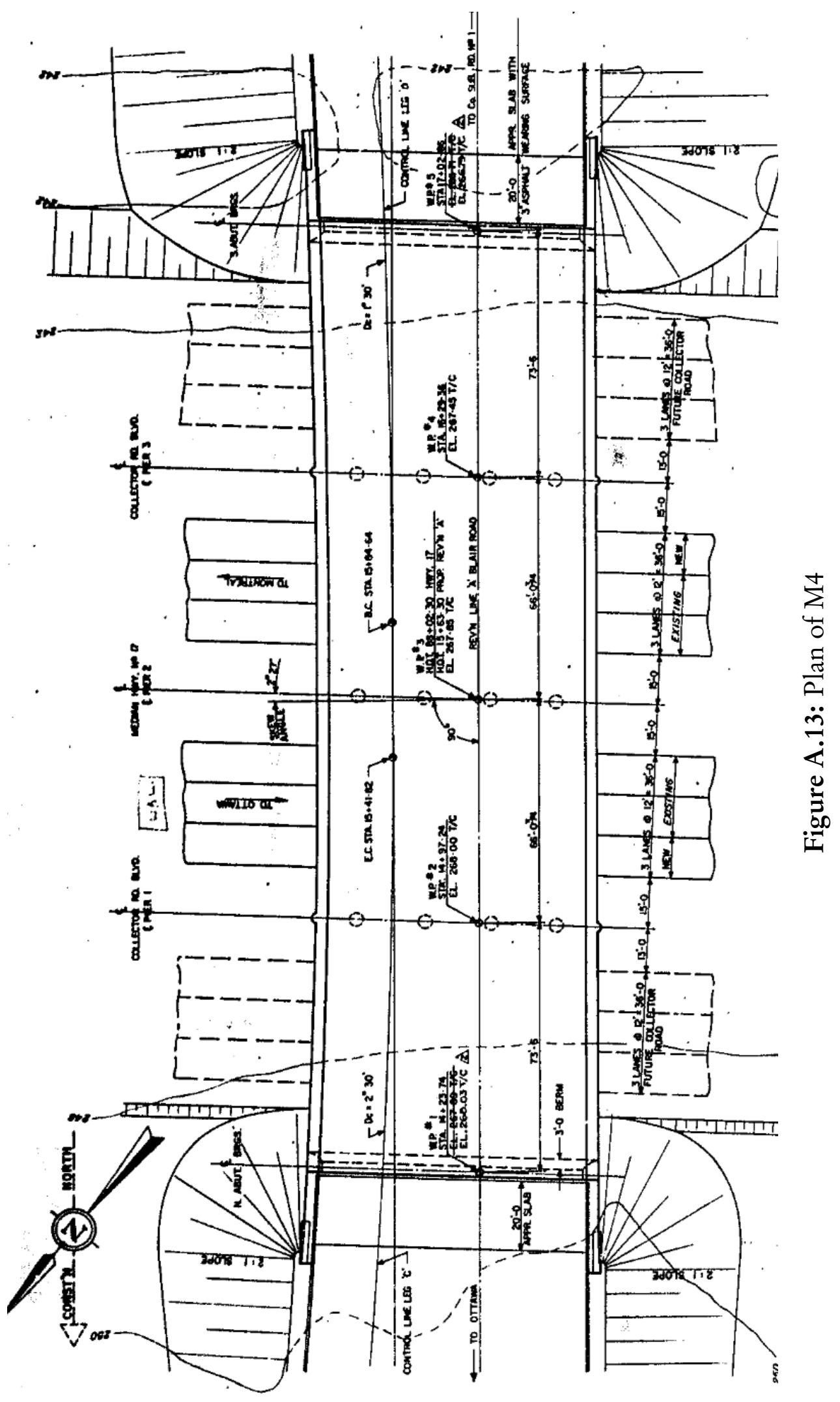

Xi Cheng, Department of Civil and Environmental Engineering, Carleton University 


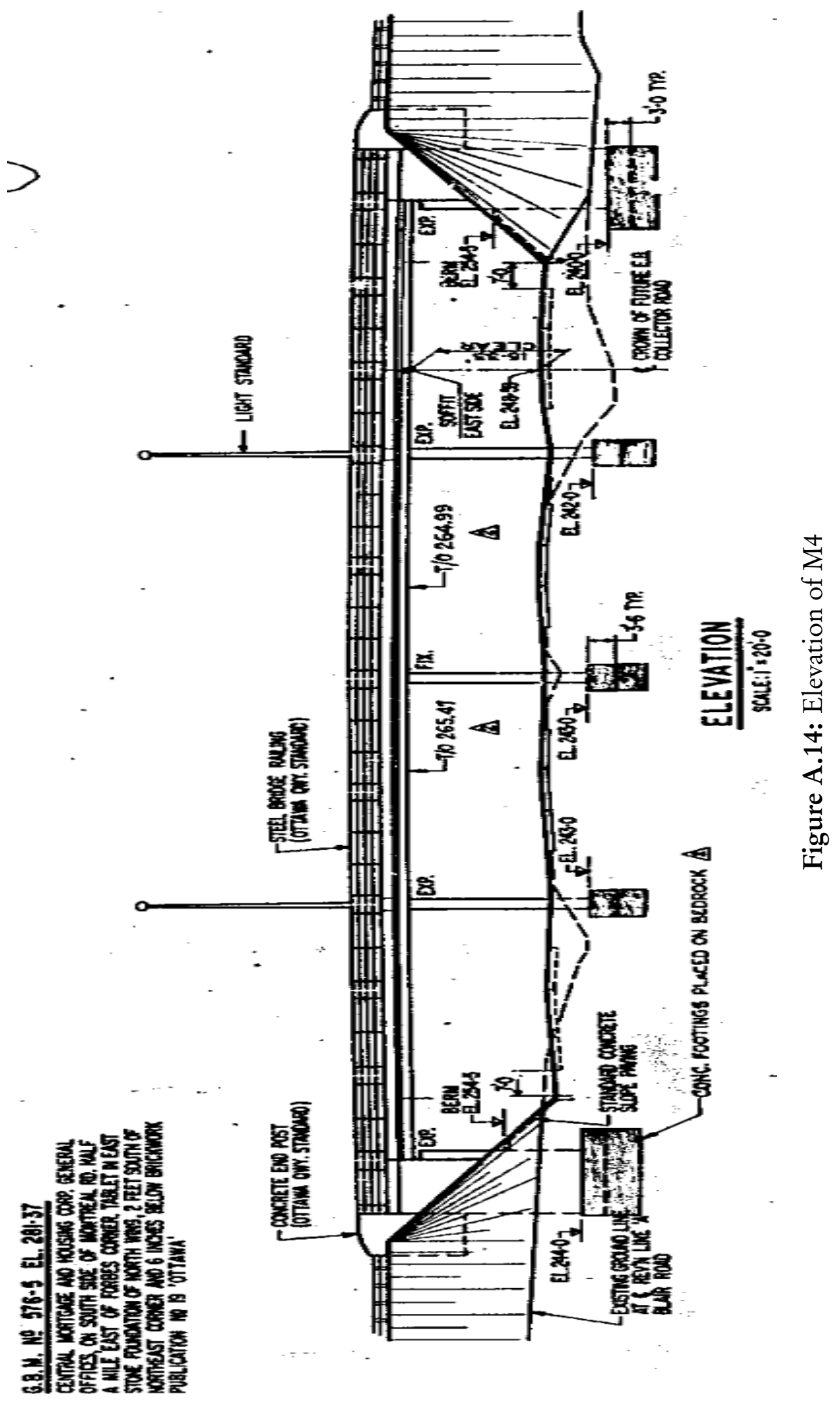

Xi Cheng, Department of Civil and Environmental Engineering, Carleton University 


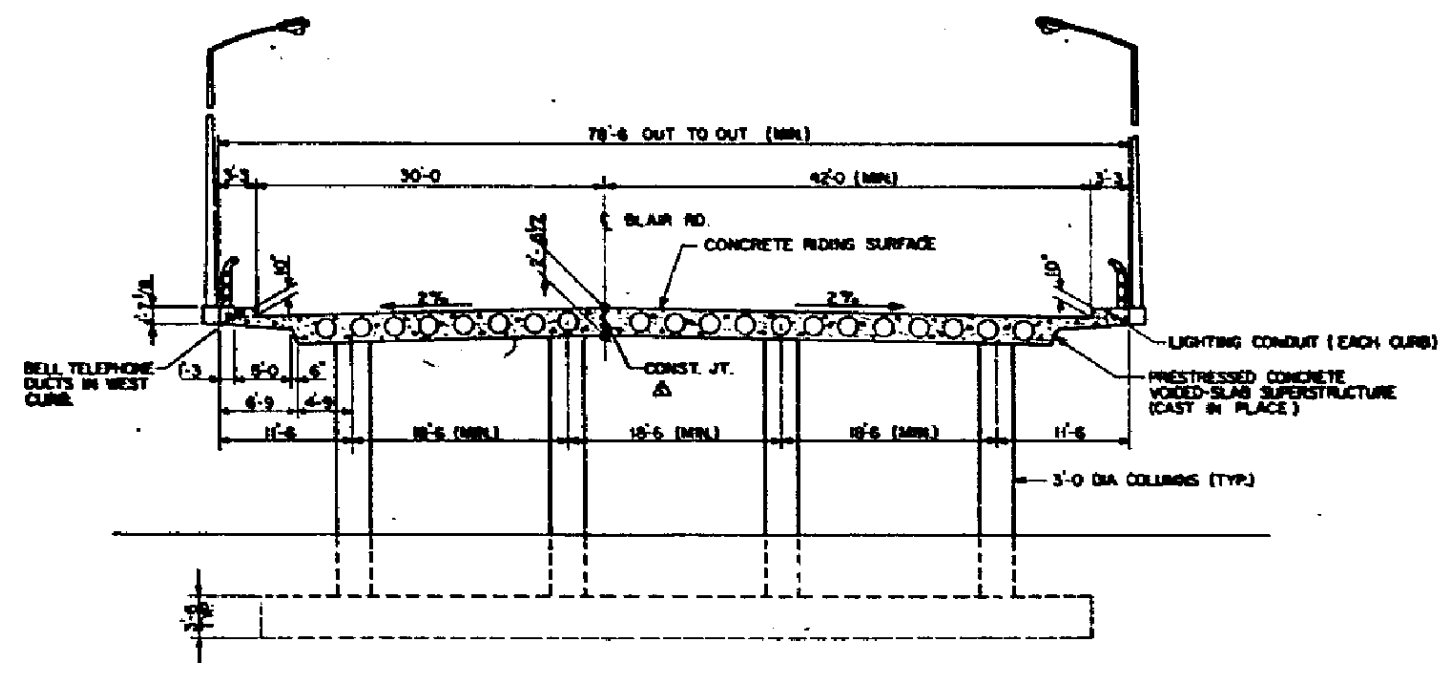

Figure A.15: Cross Section of M4 
magnitude that would be required for a full-scale building or bridge application.

The energy dissipating restraint (EDR) is a self-centering bracing element originally developed for supporting pipe systems in nuclear plants [23]. As shown in Figure 2.2, this passive friction device consists of internal springs, compression wedges, stops and a cylinder. When the brace is compressed and the external force exceeds the slip force of the friction wedges, the device is activated. With increasing compressive load, the rod and the friction wedges move together toward the left stops. After the rod strikes the stop, the external force rises due to the compression in the spring. When in tension, the rod and the wedges move toward the right end of the cylinder. The mechanics of the EDR is explained by Nims et al. [45].

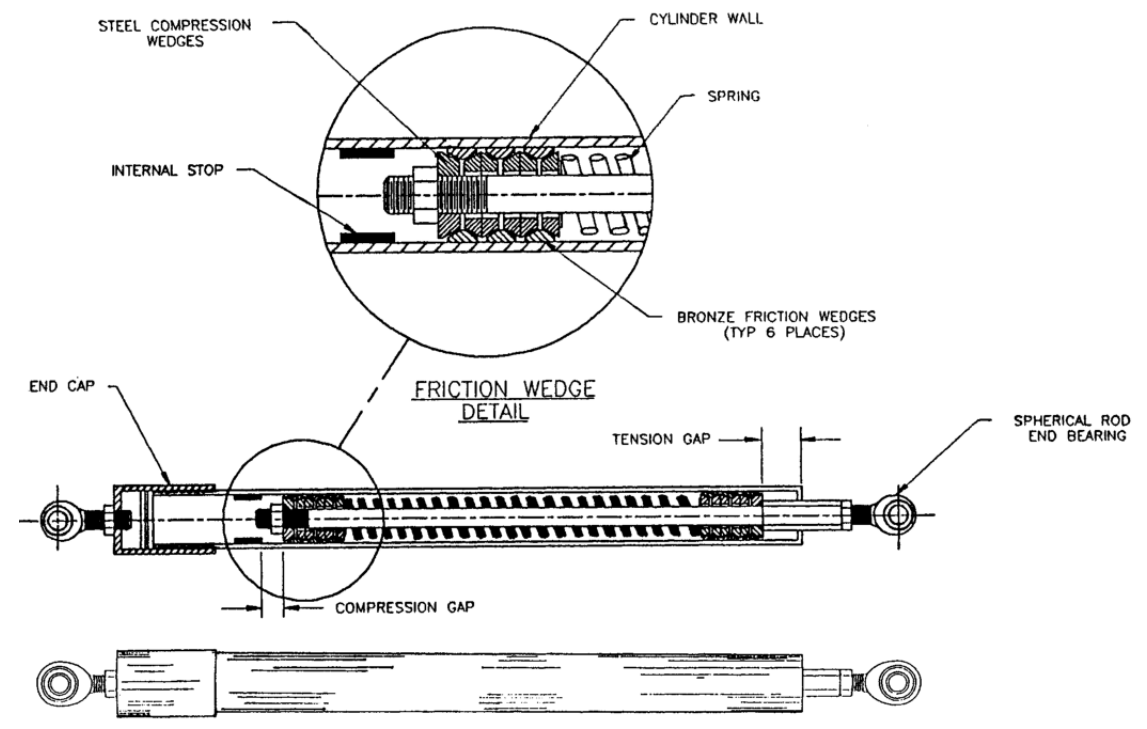

Figure 2.2: The Energy Dissipating Restraint (EDR) (from [45])

Similarly, the SHAPIA damper using a ring spring, also known as friction spring, has been developed by Spectrum Engineering in Canada [46]. As shwon in Figure 2.3, the main components of the ring spring are the inner and outer rings. When the brace is under compressive load, the axial displacement is accompanied by the sliding of rings on the conical friction surfaces [47]. Filiatrault et al. [47] has conducted performance evaluation tests of the ring spring damping system. The flag-shaped hysteresis loops 
of such damper are found to be stable, repeatable and identical in both tension and compression. It is also found that the amount of energy dissipated by the friction ring damper is in the range that would be sufficient to protect structure from severe inelastic deformation.
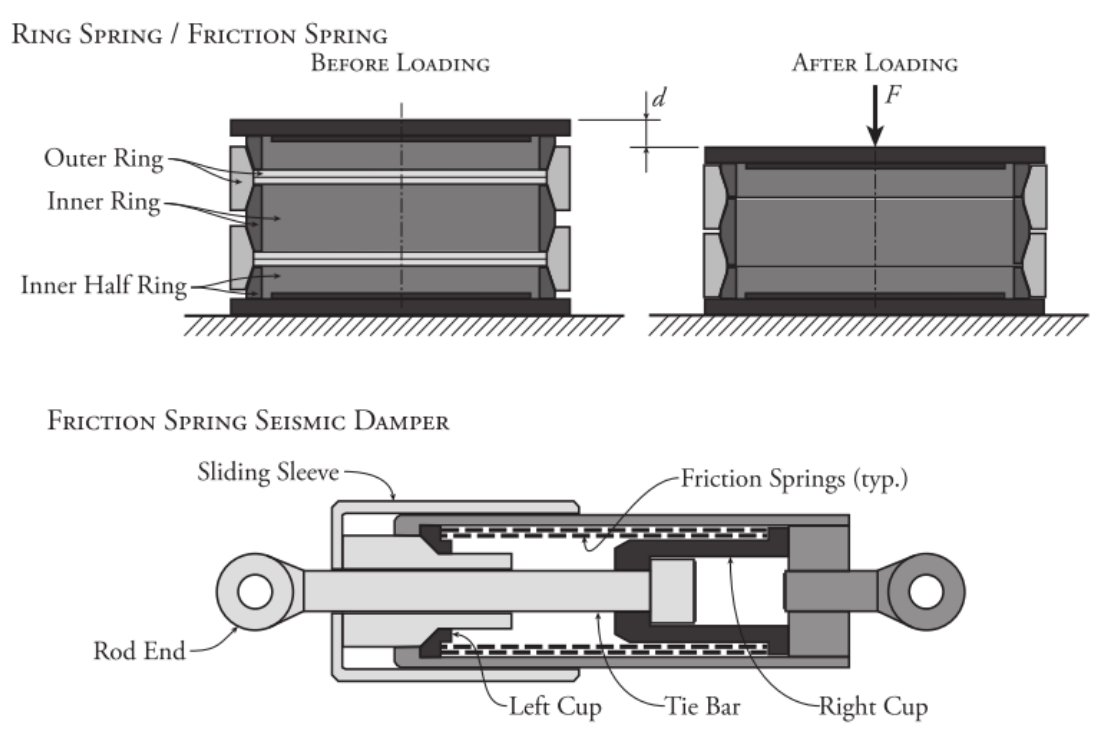

Figure 2.3: Ring Spring (from [13])

The third notable self-centering bracing system termed friction damping brace is developed and tested by Zhu et al. [48]. As illustrated in Figure 2.4, the brace mainly consists of two steel parts (Block A and Block B) and Nitinol wire strands. The steel parts are connected together by the strands and the bolts. The strands are made of SMA and inherently possess self-centering behavior. The bolts aim to provide different amount of normal force on the friction interface such that the energy dissipation capacity can be adjusted. Once the steel parts move relatively to each other, the strands will elongate and the friction interface will dissipate energy. 

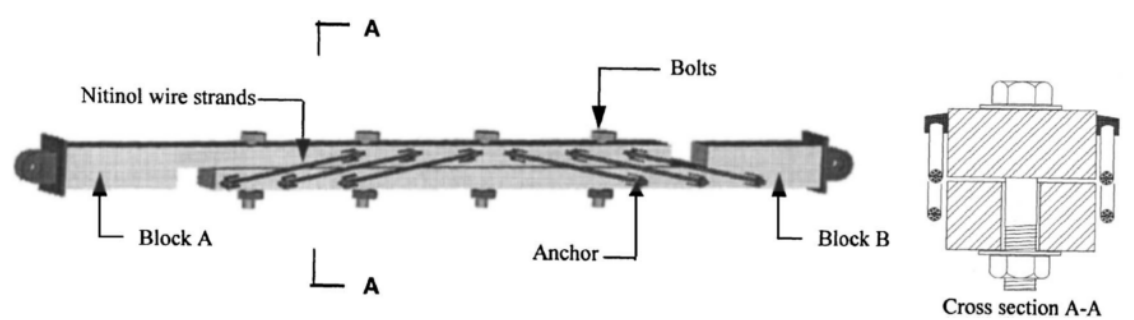

Figure 2.4: Friction Damping Brace (from [48])

\subsubsection{Rocking Systems}

As inspired by the PRESSS (Precast Seismic Structural Systems program), the precast concrete elements are assembled through post tensioned techniques at the interface [27]. This rocking mechanism prevents or minimizes damage in the structural system. As previously mentioned, the rocking systems develop gaps between individual elements when they have relative movements. Typical examples of such system are rocking walls and rocking moment frames as shown in Figure 2.5. 


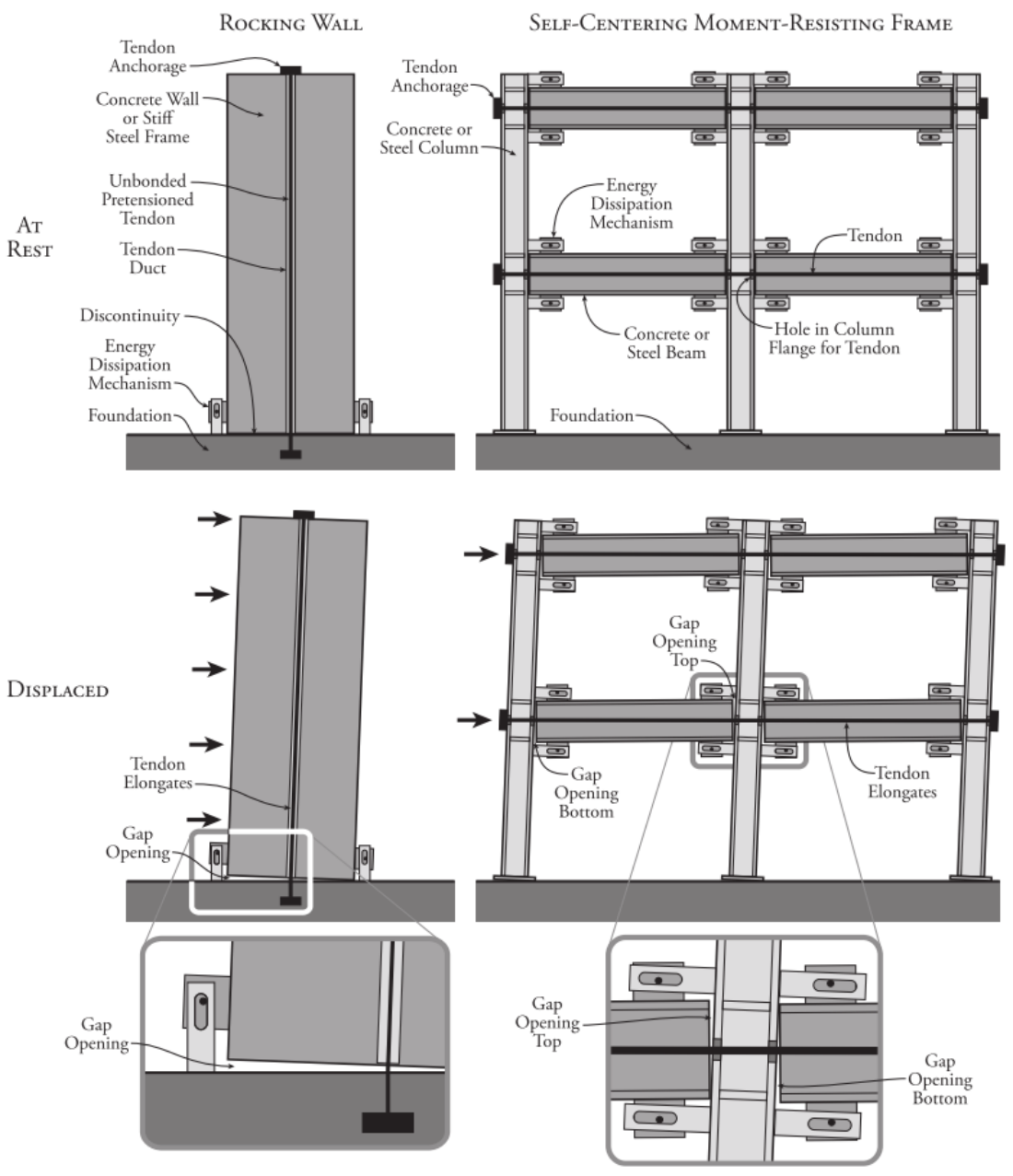

Figure 2.5: Rocking Systems (from [13])

Precast rocking systems based on similar principles have been previously adapted for application to bridge piers. These systems have attracted increasing interest for new construction of bridges due to their advantages of less traffic disruption, faster construction speed, reduced lifetime cost and reduced environmental impact [49]. Researchers (e.g., $[49,50])$ have found that segmental precast unbonded post-tensioned piers can effectively resist lateral cyclic forces, but experience large displacements without significant or sudden loss of strength [4]. Cyclic load test results show that segmental rocking bridge 


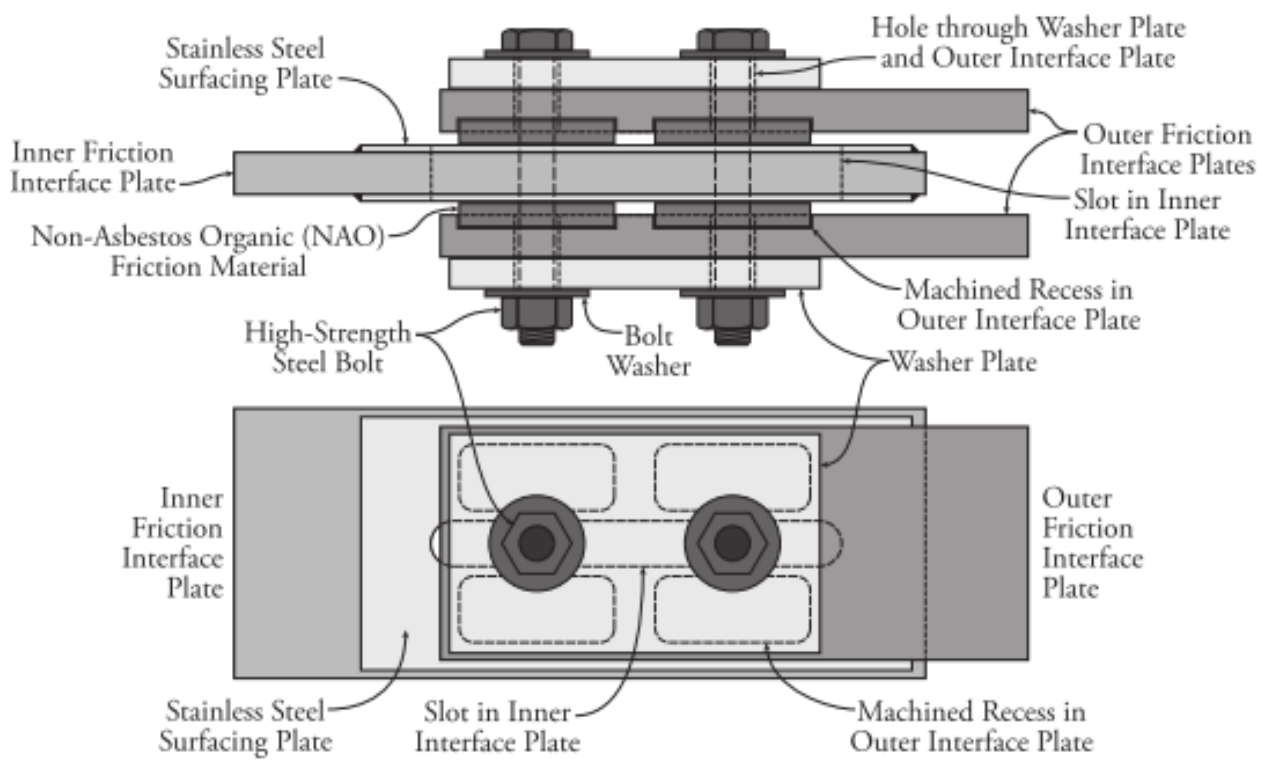

Figure 2.7: Internal Frction Damper (from [53])

As shown in Figure 2.6, the brace mechanism of a SCED system has four main components: (1) an inner steel member, (2) an outer steel member, (3) energy dissipating device and (4) a tensioning system. The inner steel member can be an I-section beam or a steel tube. The tensioning system usually consists of pretensioned tendons which are installed between the end plates. Once the relative movement between the inner and outer members is induced, the energy dissipating device is activated, accompanied by stiffness change. Energy dissipaters which may potentially be used with SCED braces include hysteretic yielding devices, friction slip devices, viscous dampers, or shape memory alloys. In this research, seismic energy is assumed to be dissipated by a friction slip device. The friction damper as shown in Figure 2.7 is developed by Kim [53]. It consists of inner and outer interface plates, friction material pads, stainless steel surfacing plates welded to inner interface plate, high strength steel bots and washer plates. The inner plate has a slot to allow the bolt movement. The bolts connect friction damper through the holes in the outer plates and the slots in the inner plate. The coulomb friction behavior is assumed in the interfaces and the slip force $F$ of the internal friction damper is 
brace numerical model exaggerates this effects

Another SCED frame study is conducted by Choi et al. [54]. Besides comparing SCED and BRB braced frames, special moment-resisting frames are investigated as well. Although it is found SCED braced frames experience similar peak story drifts, the much smaller residual drift response is found to be a desirable advantage. Similarly, this study shows higher floor acceleration in SCED braced frame compared with the other two systems.

A full-scale SCED brace and telescoping (T-SCED) brace have been tested by Erochko $[13,55]$ in a full-scale steel test frame. The results show that the SCED brace achieves full self-centering capability while accommodating a 3.8\% drift in the test frame. Shake table tests of a one-third scaled SCED braced frame are also carried out in the research conducted by Erochko et al. $[13,55]$. The companion OpenSees model and SAP2000 model of the test frames are able to predict the results of the tests. A six-story frame braced with SCED braces is modeled to compare the effects of theoretical initial stiffness and lower effective stiffness of the braces on the frame response. The case study shows that a lower effective initial stiffness does not significantly affect the dynamic response of the frame even though it modifies the building fundamental period.

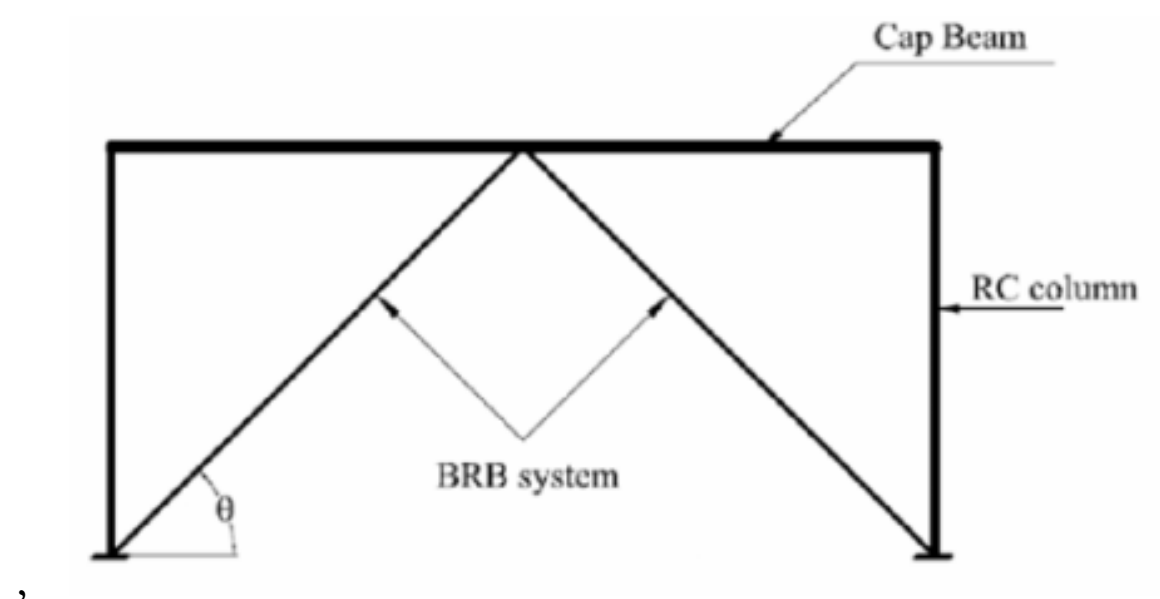

Figure 2.9: Retrofit Bridge Bent with BRB (from [56]) 
comparison information on the difference between the actual strengths and the design values. The shear key's dimensions and force-displacement relationship from the test are shown in Figure 3.13. This shear key performs as a structural fuse and prevent further damage in the abutment during the tests. The failure mechanism follows the strut-andtie analogous model where the lateral load is transferred to the footing by a diagonal compressive strut [68]. Due to lack of details available of the example bridges, the shear keys capacity and corresponding deformation are assumed according to the experiment data presented by Megally et al. [68] considering their similar dimensions. The constitutive behavior of the exterior shear key is represented by the no tensile strength concrete (Concrete01) model, as shown in Figure 3.12(b), considering it can only take compressive load.

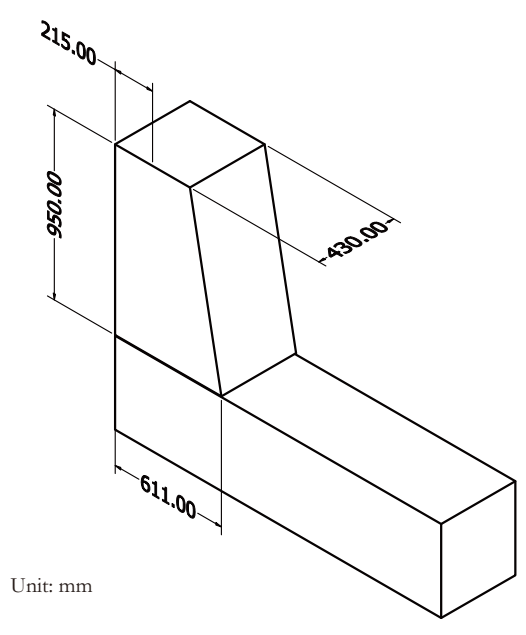

(a) Schematic Drawing of Shear Key

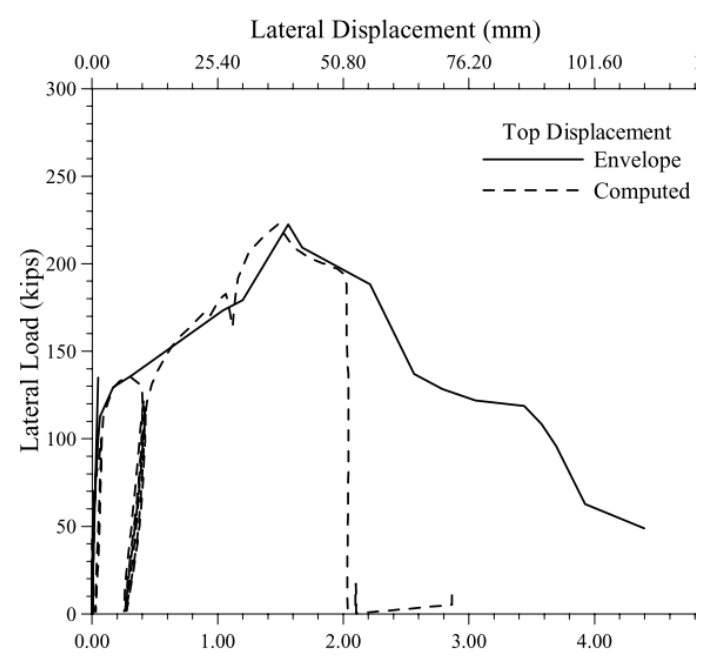

(b) Load-Deformation Response of Shear Key

Figure 3.13: Shear Key Properties [from [68]]

\subsubsection{Modeling of Self-centering Braces}

Erochko et al. [13] has developed a self-centering hysteresis model as a uniaxial material for OpenSEES [22]. This material is capable of modeling the external fuse and 
the bearing effect due to the limited deformation capacity. The constitutive behavior of the self-centering material model is shown in Figure 3.14. Its behavior is characterized by the following parameters:

- Activation force, $P_{a}$;

- Energy dissipation capacity parameter, $\beta$;

- Initial stiffness, $k_{1}$ and post-activation stiffness $k_{2}$;

- Slip deformation, $\varepsilon_{s l i p}$

- Total deformation that cause the external fuse to bear;

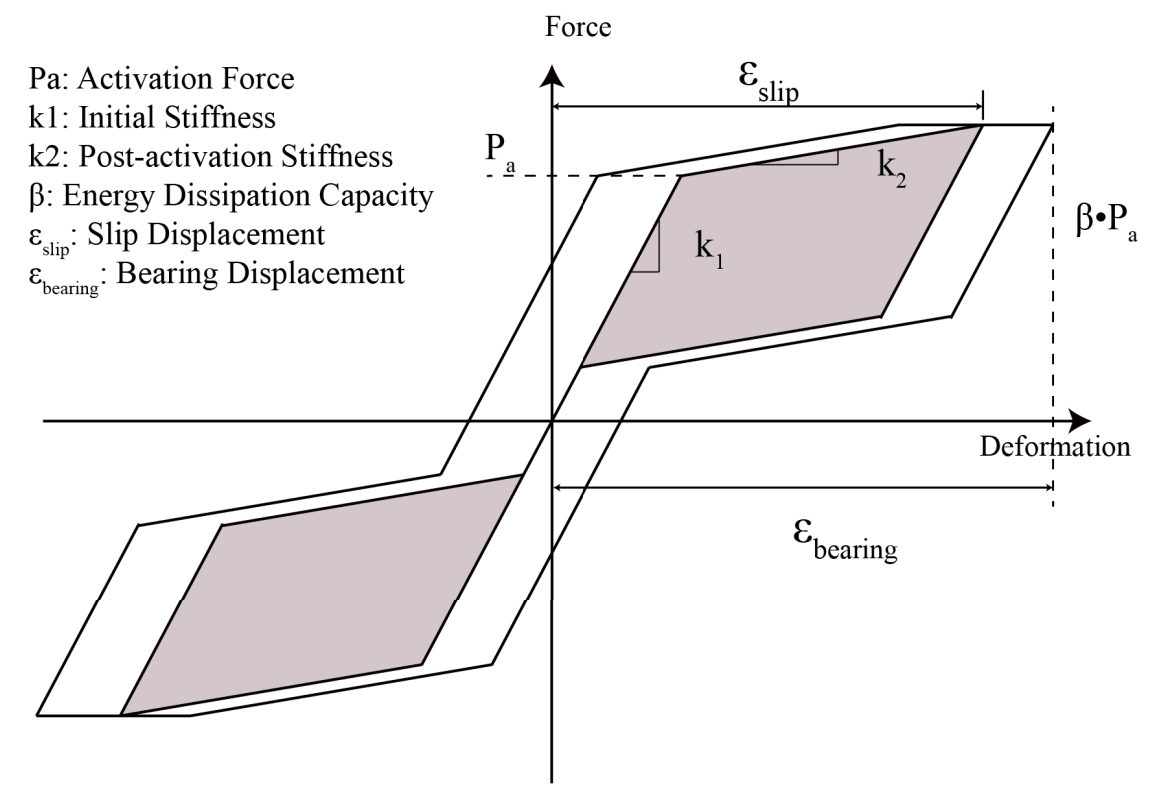

Figure 3.14: SCED Brace Hysteresis

In this research, no external fuse is considered for simplicity, therefore, the hysteretic response of the SCED brace is only affected by the parameters $k_{1}, k_{2}, P_{a}$ and $\beta$. The initial stiffness is controlled by the steel members and the tendons. As previously discussed, several different devices can be implemented in a SCED to dissipate energy. 
The friction mechanism is attractive given that it is easy to control the slip force and remains undamaged under cyclic loads. The parameter $\beta$ indicates the internal friction force magnitude, which is controlled by the friction pad and high strength steel bolts providing normal force.

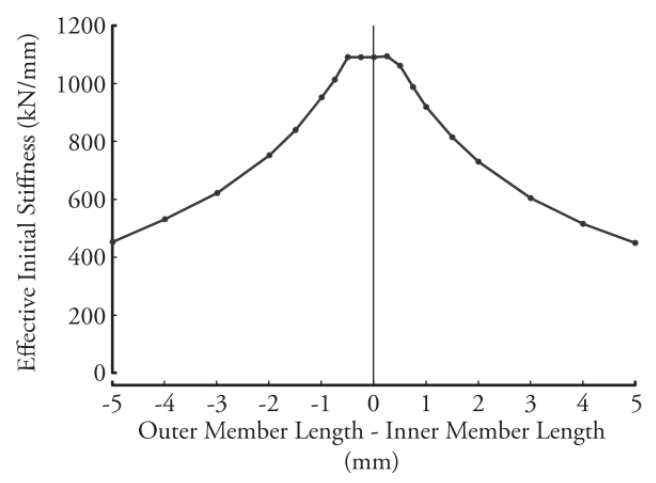

(a) Effect of Member Length Difference on Effective Initial Stiffness (from [13])

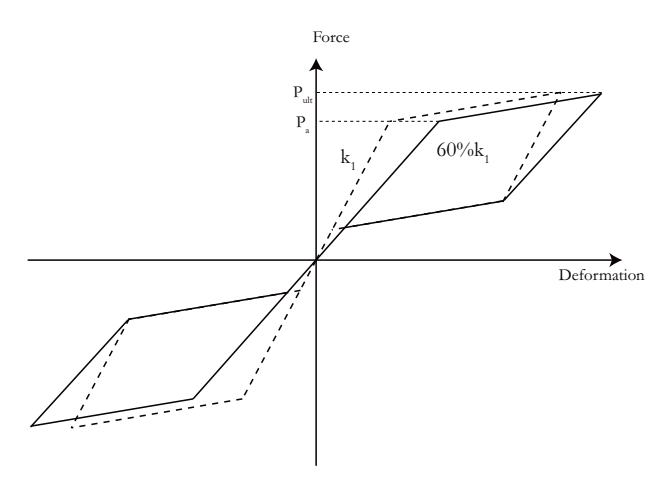

(b) Initial Stiffness Reduction

Figure 3.15: Effective Initial Stiffness of SCED Brace

As noted by Erochko et al. [13], the realistic $k_{1}$ is lower than the theoretical calculated value by Equation 2.2 even with identical length members and perfect fabrication. For a force-based design which relies on the structure period estimation, it is important the designer uses a realistic value of the initial stiffness instead of the value obtained using theoretical model [13]. As such, effective initial stiffness should be used in modeling of the SCED brace. The reduction of the initial stiffness should consider the effects of length differences and fabrication conditions. The increasing axial member difference reduces the effective initial stiffness rapidly as it is shown in Figure 3.15(a). For instance, a $5 \mathrm{~mm}$ difference in length decreases the initial stiffness by approximate $60 \%$ from the highest possible value. Figure 3.15(a) reveals that the length difference less than $0.5 \mathrm{~mm}$ does not decrease initial stiffness. The effective initial stiffness of the SCED brace is suggested to be reduced by $40 \%$ from the theoretical value while $P_{a}, k_{2}$ and $\beta$ remain the 
accommodate the tendons with sufficient clearance space. This requirement is satisfied by trial and error in an iterative design process by selecting different crosssection arrangements depending on the designer experience.

8. Use the SCED Mechanics Simulator [13] to predict the hysteresis of the SCED brace. The hysteresis of the SCED brace is characterized by $k_{i}, \alpha$ and $\beta$. As mentioned in Section3.2.6, $k_{i}$ is the effective initial stiffness. These parameters are used to model the SCED braces.

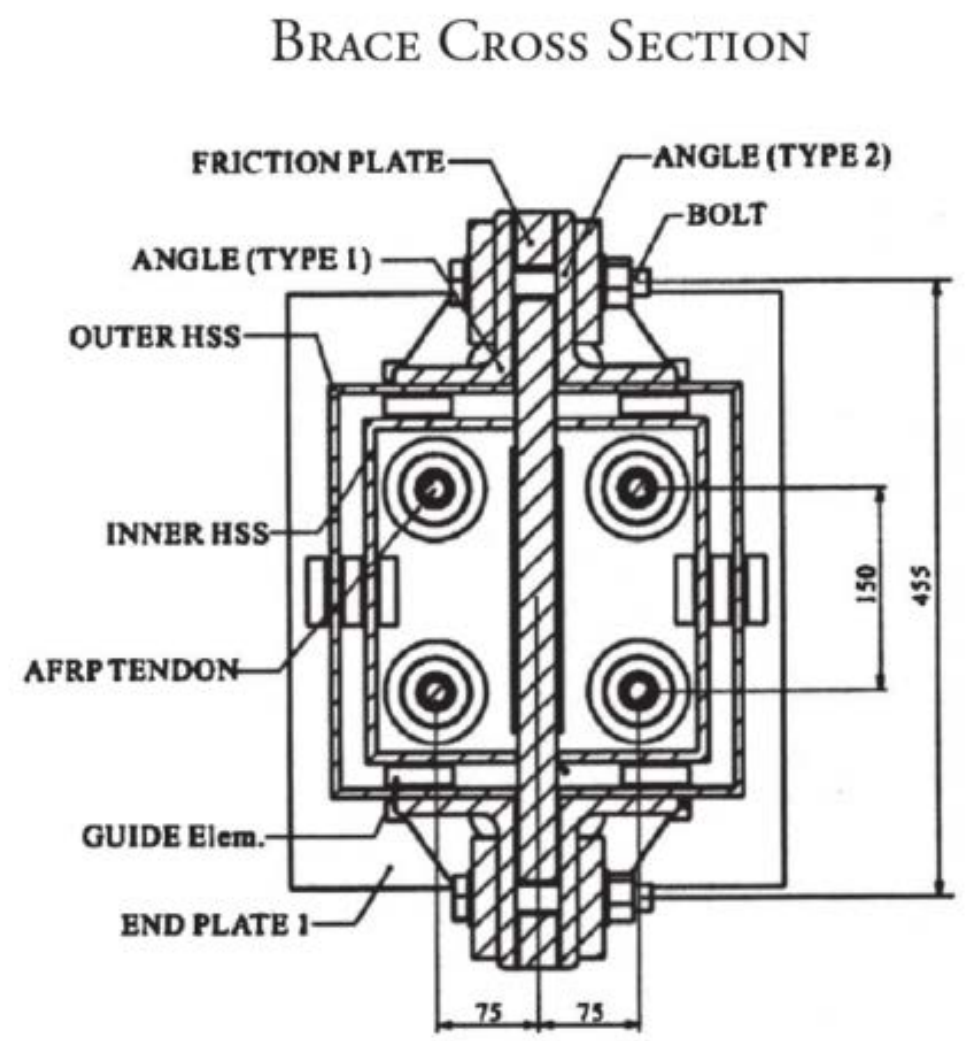

Figure 5.2: SCED Brace Cross-Section (from [15]) 


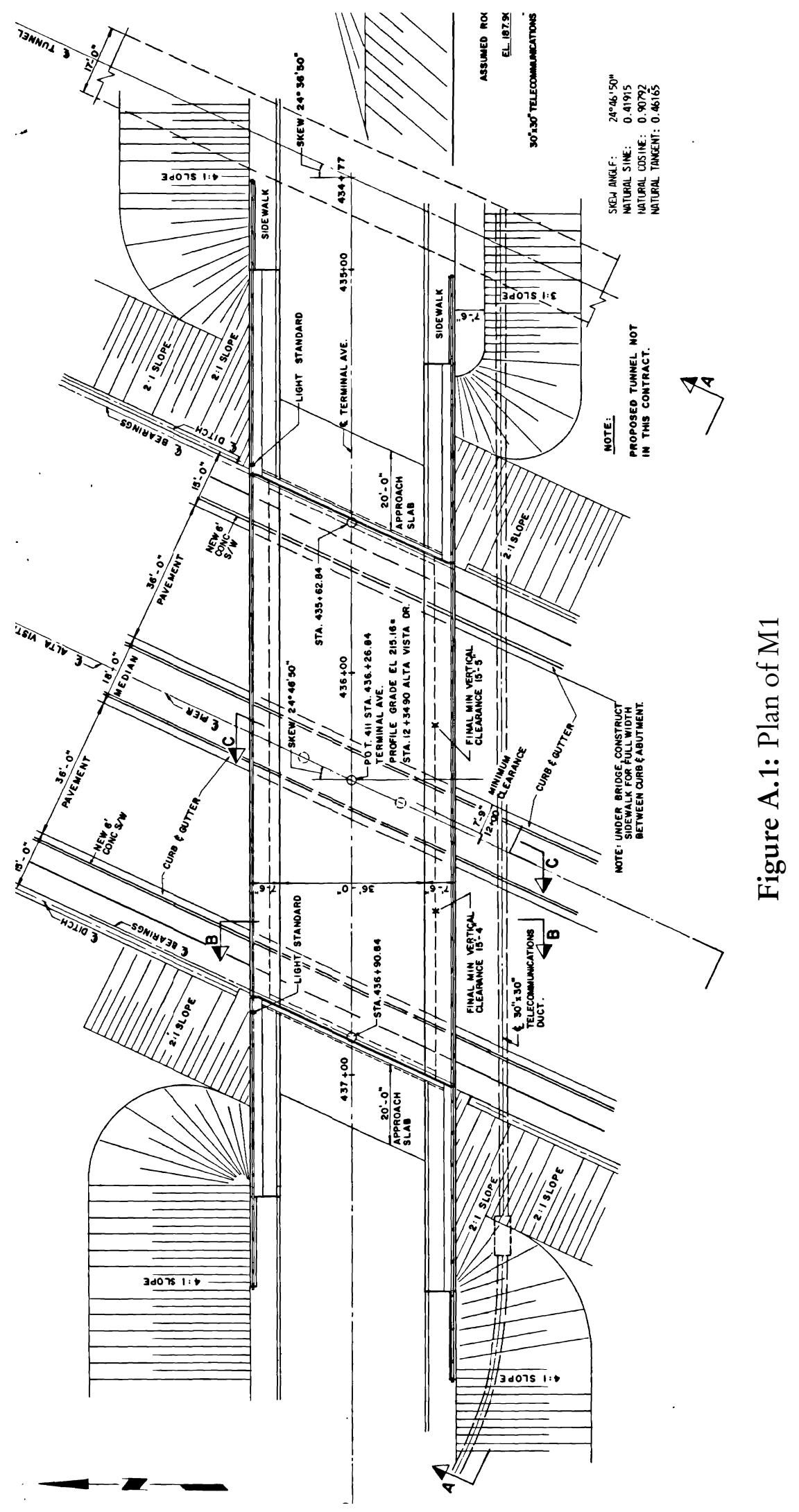

Xi Cheng, Department of Civil and Environmental Engineering, Carleton University 


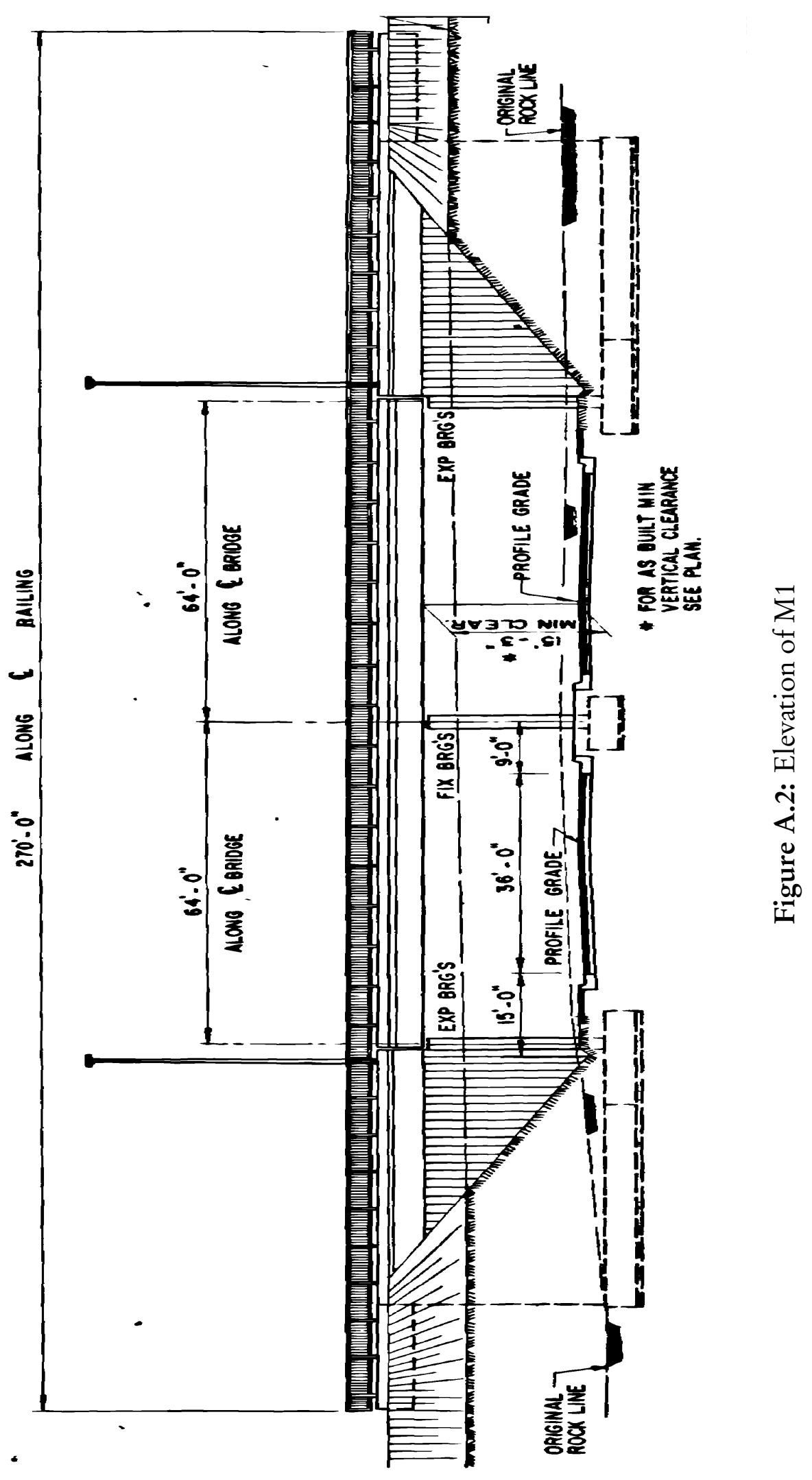

Xi Cheng, Department of Civil and Environmental Engineering, Carleton University 


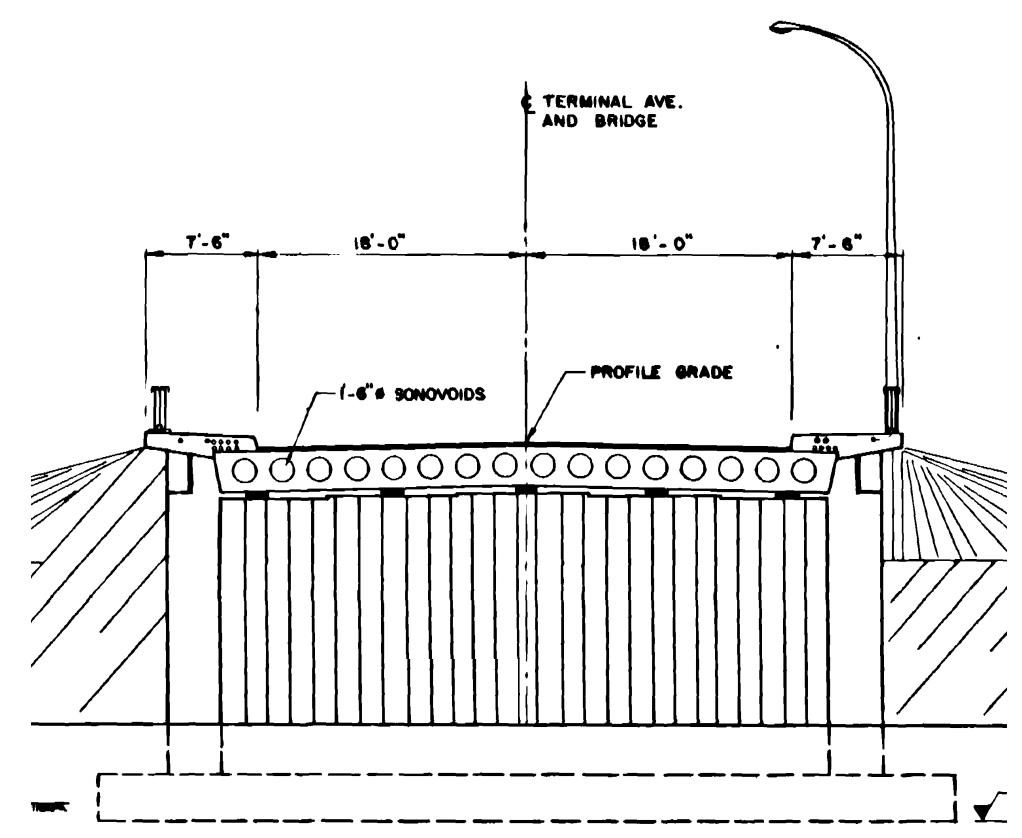

Figure A.3: Cross Section of M1

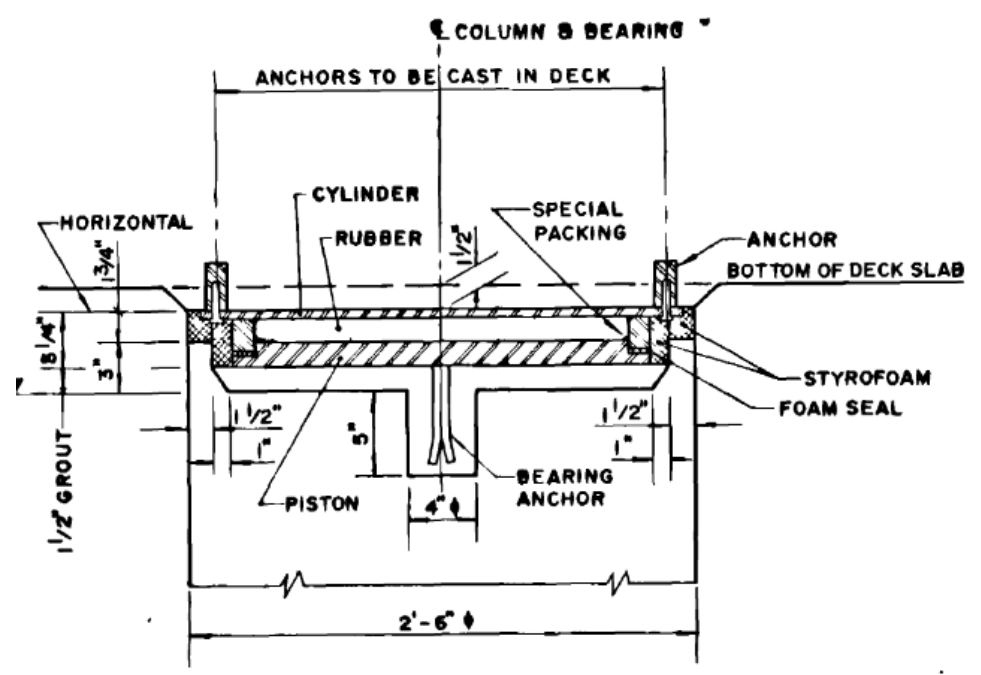

Figure A.4: Bearing of M1 


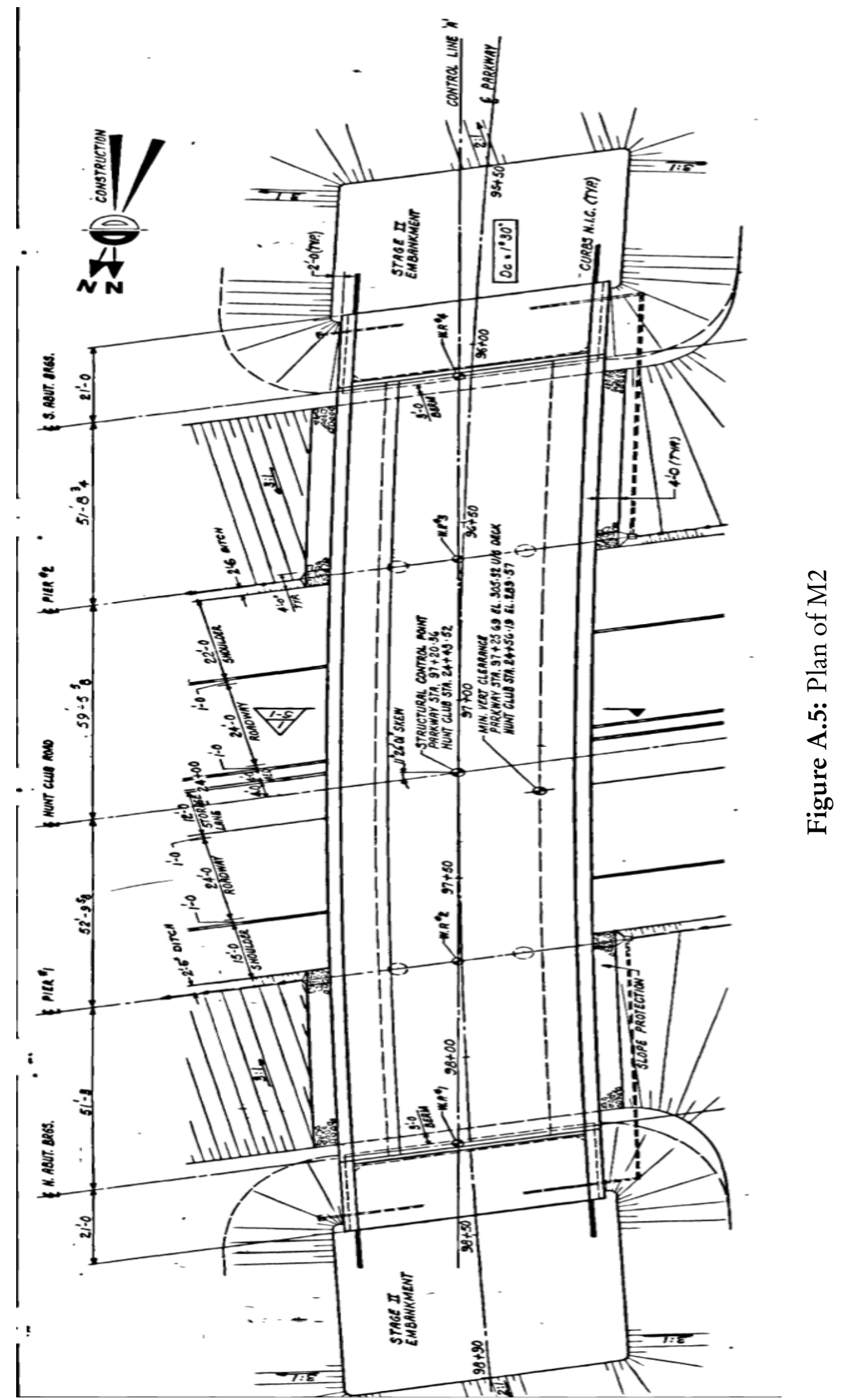

Xi Cheng, Department of Civil and Environmental Engineering, Carleton University 


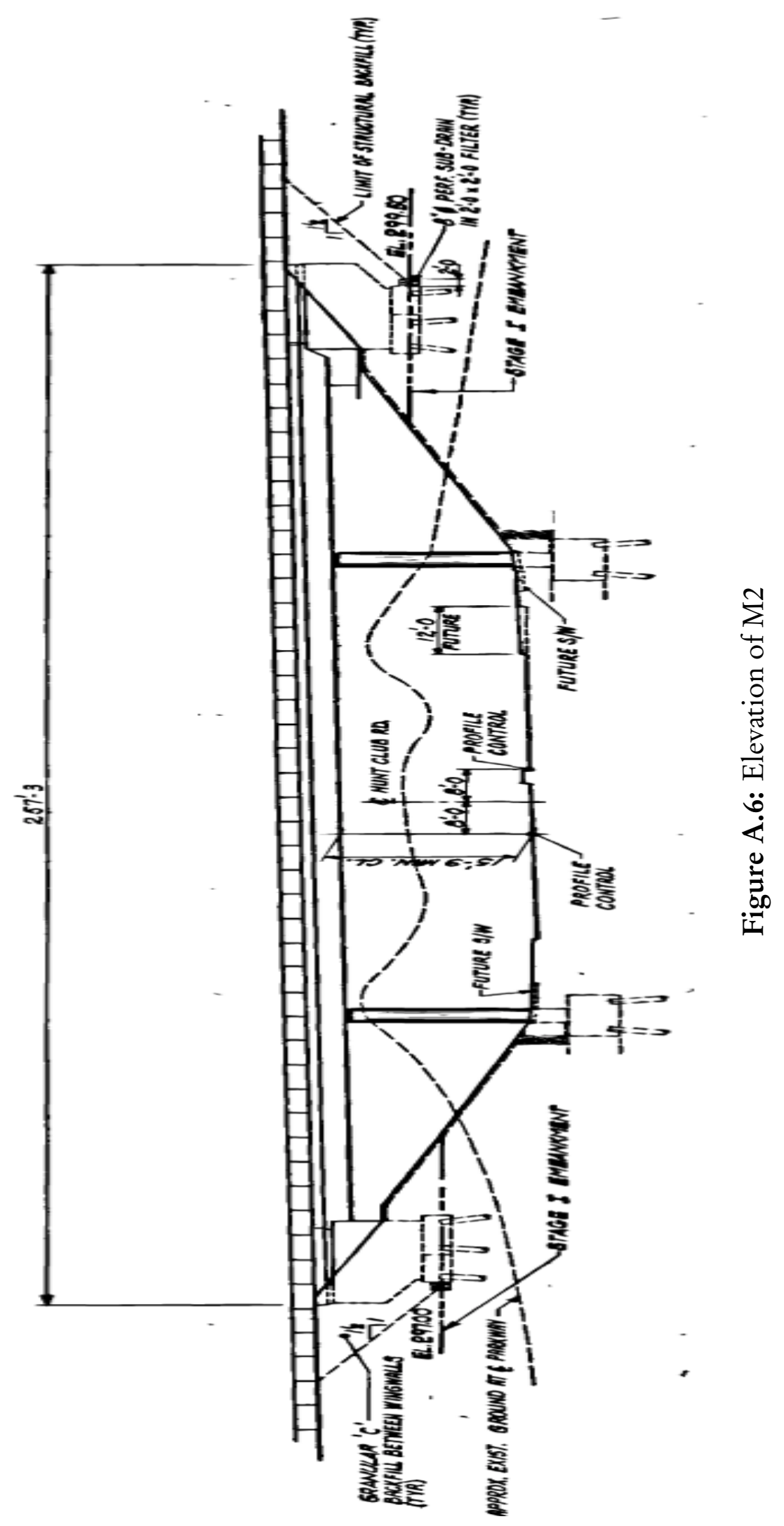




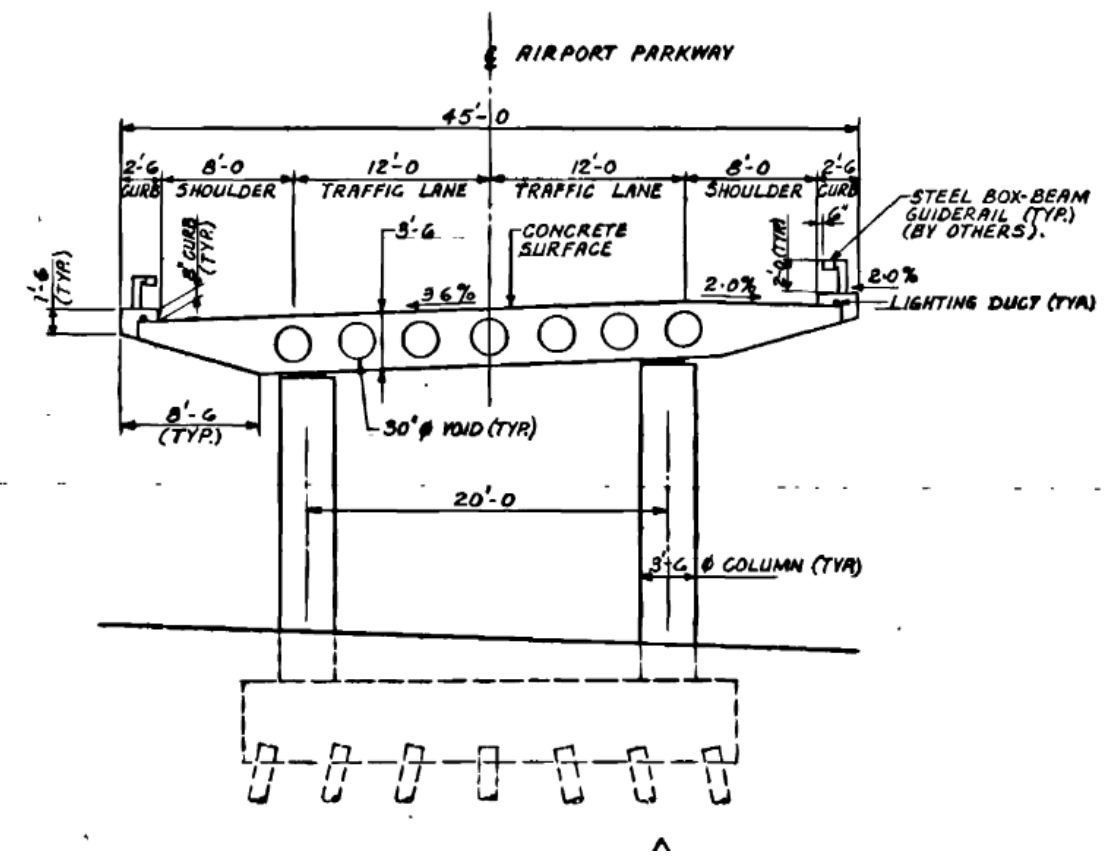

Figure A.7: Cross Section of M2

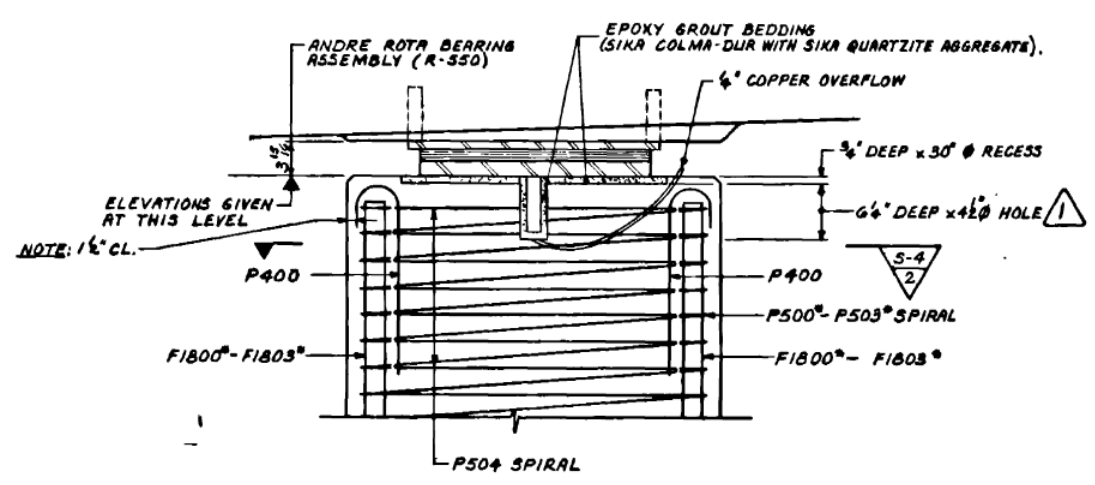

Figure A.8: Bearing of M2 


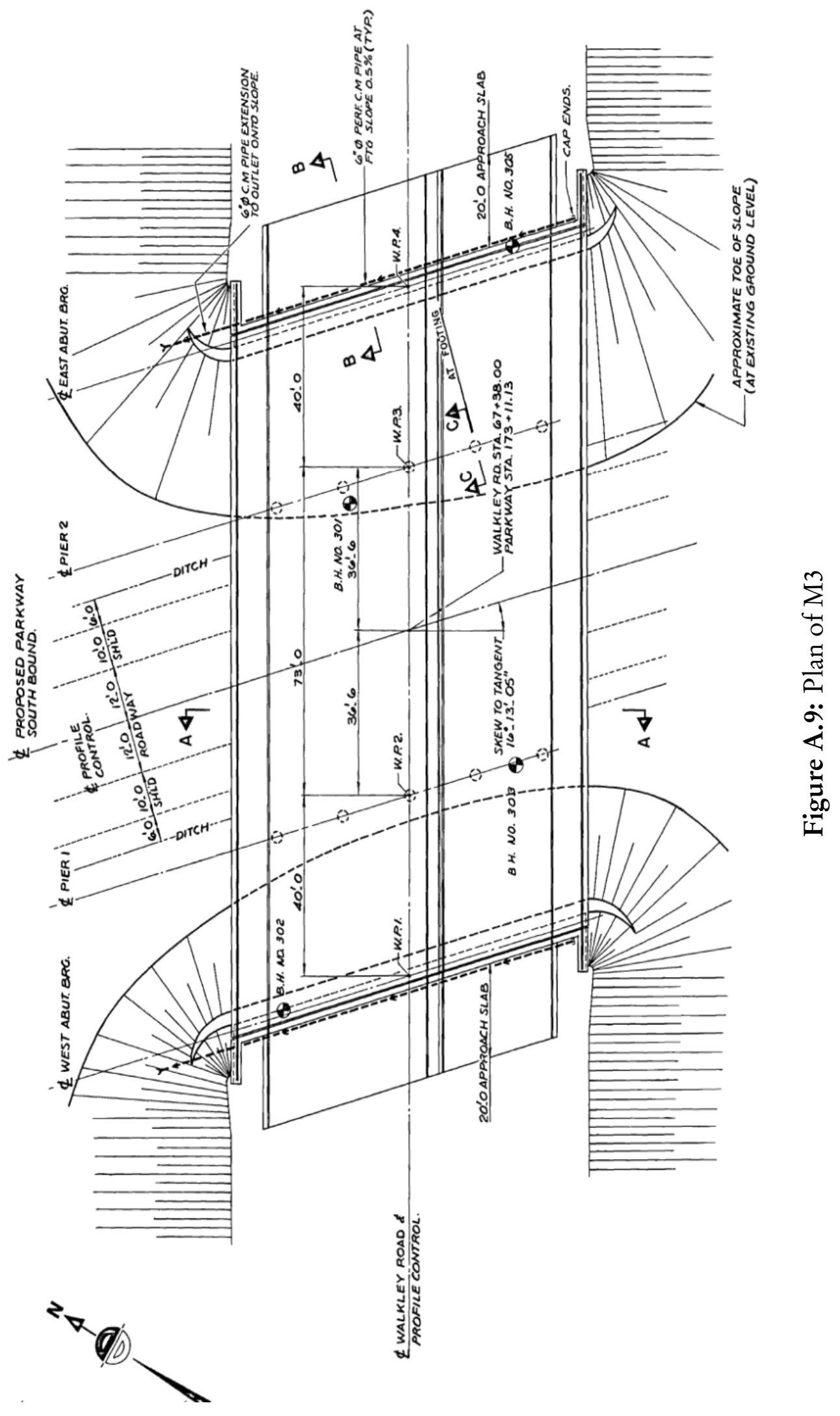




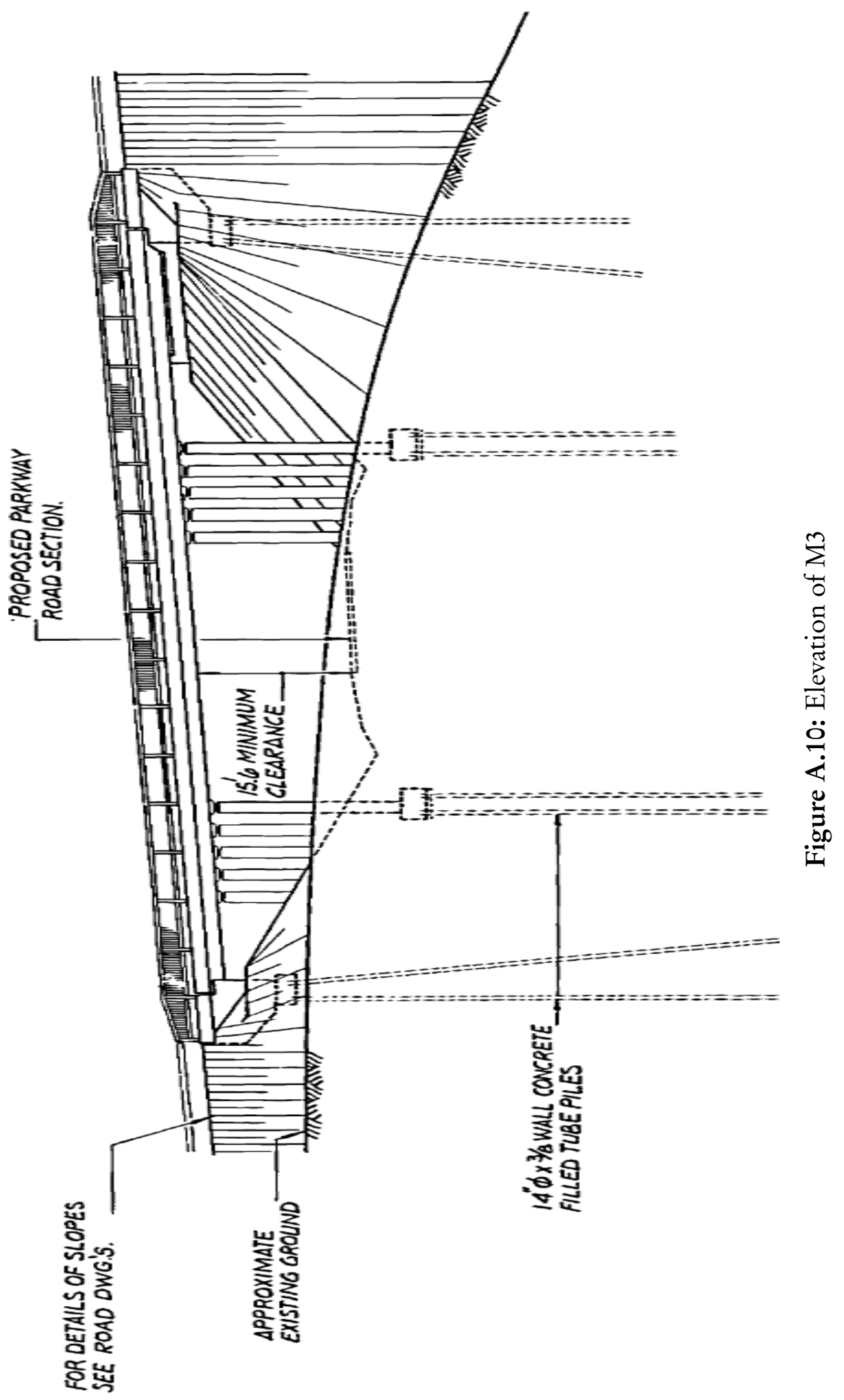




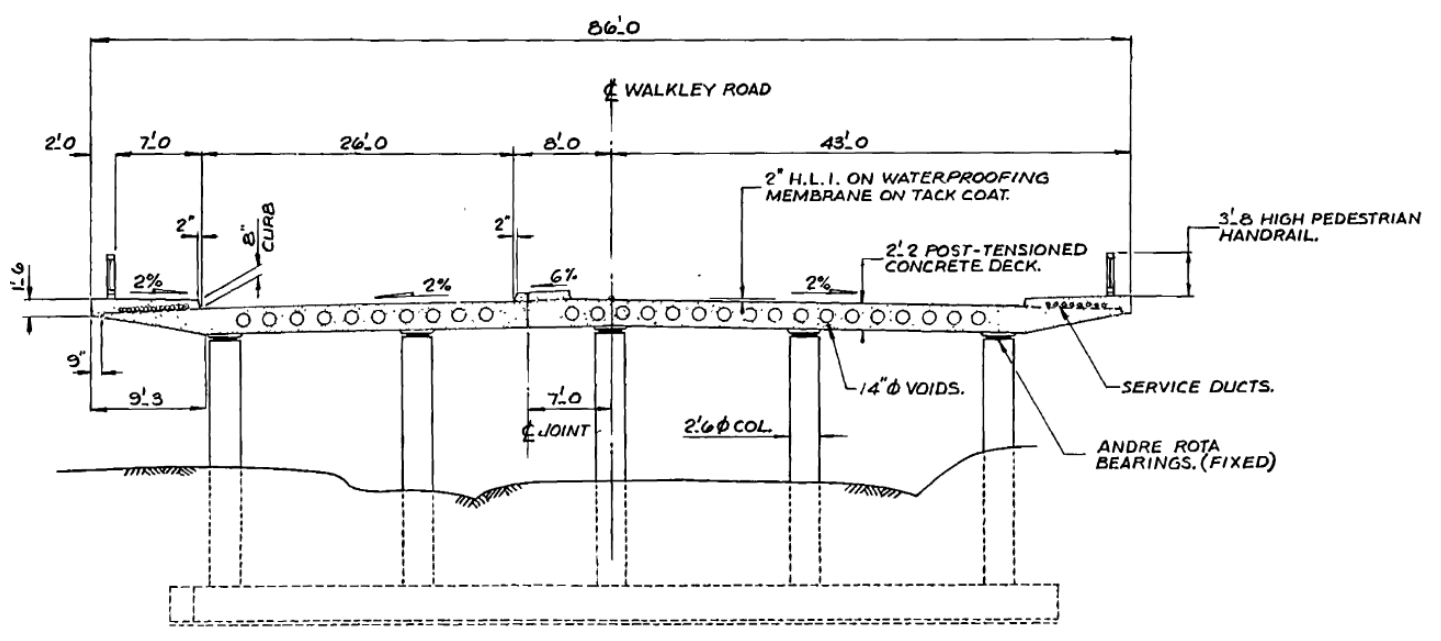

Figure A.11: Cross Section of M3
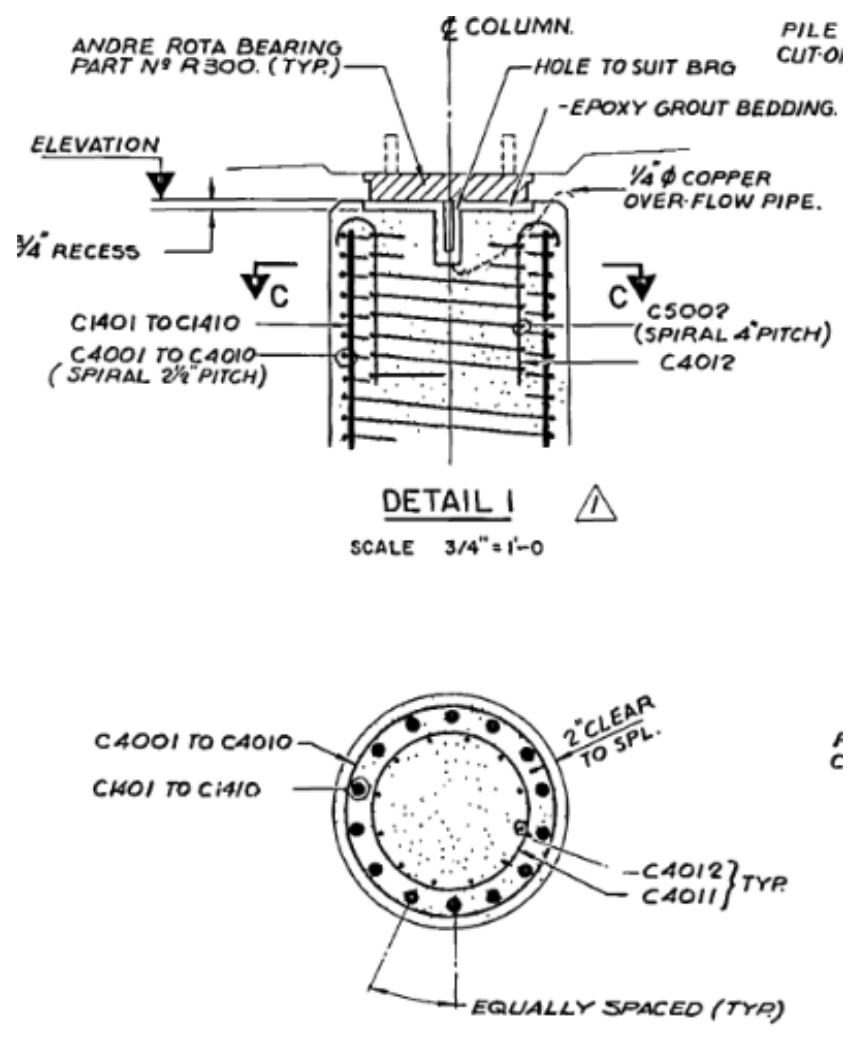

Figure A.12: Pier Cross-section and Bearing of M3 


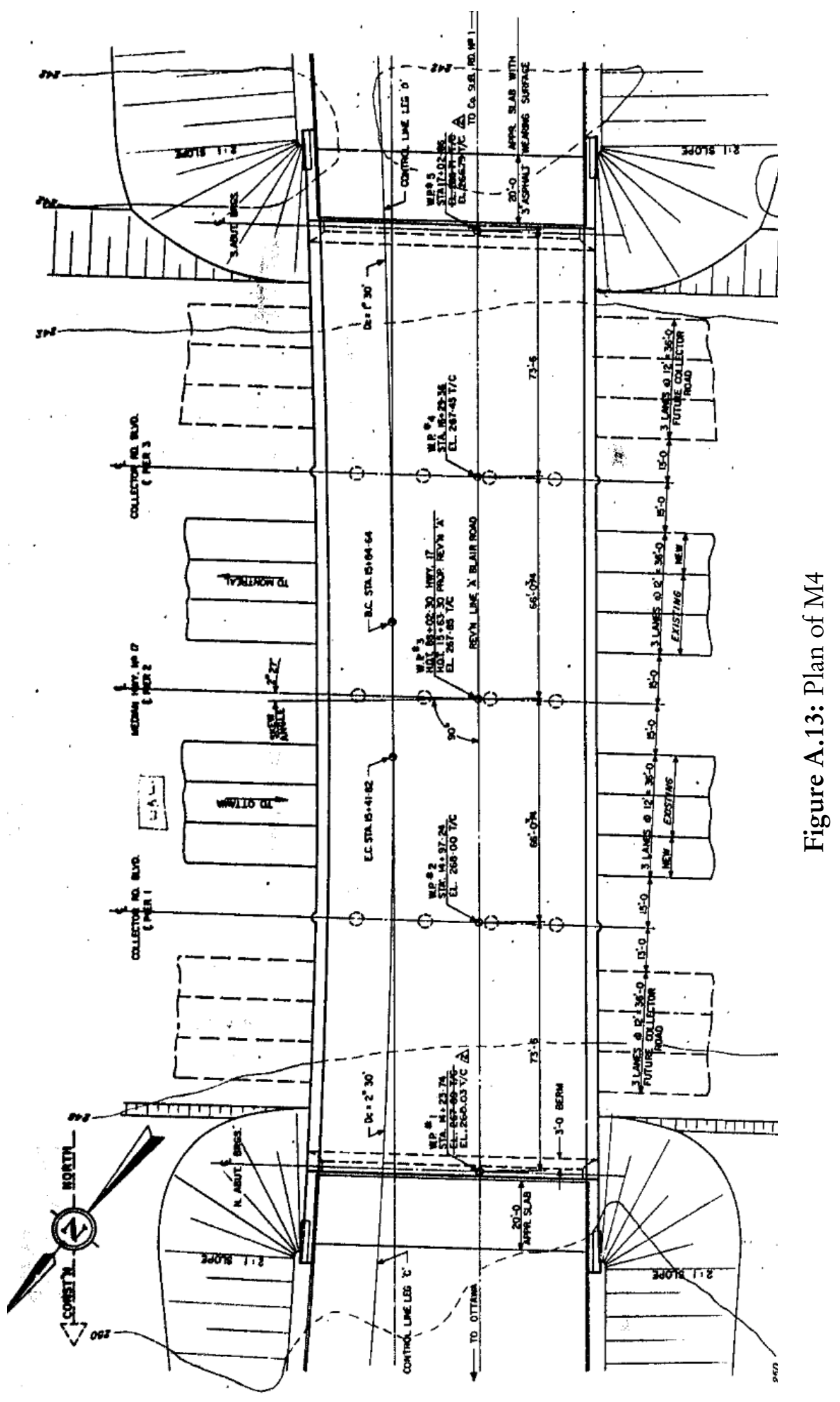

Xi Cheng, Department of Civil and Environmental Engineering, Carleton University 


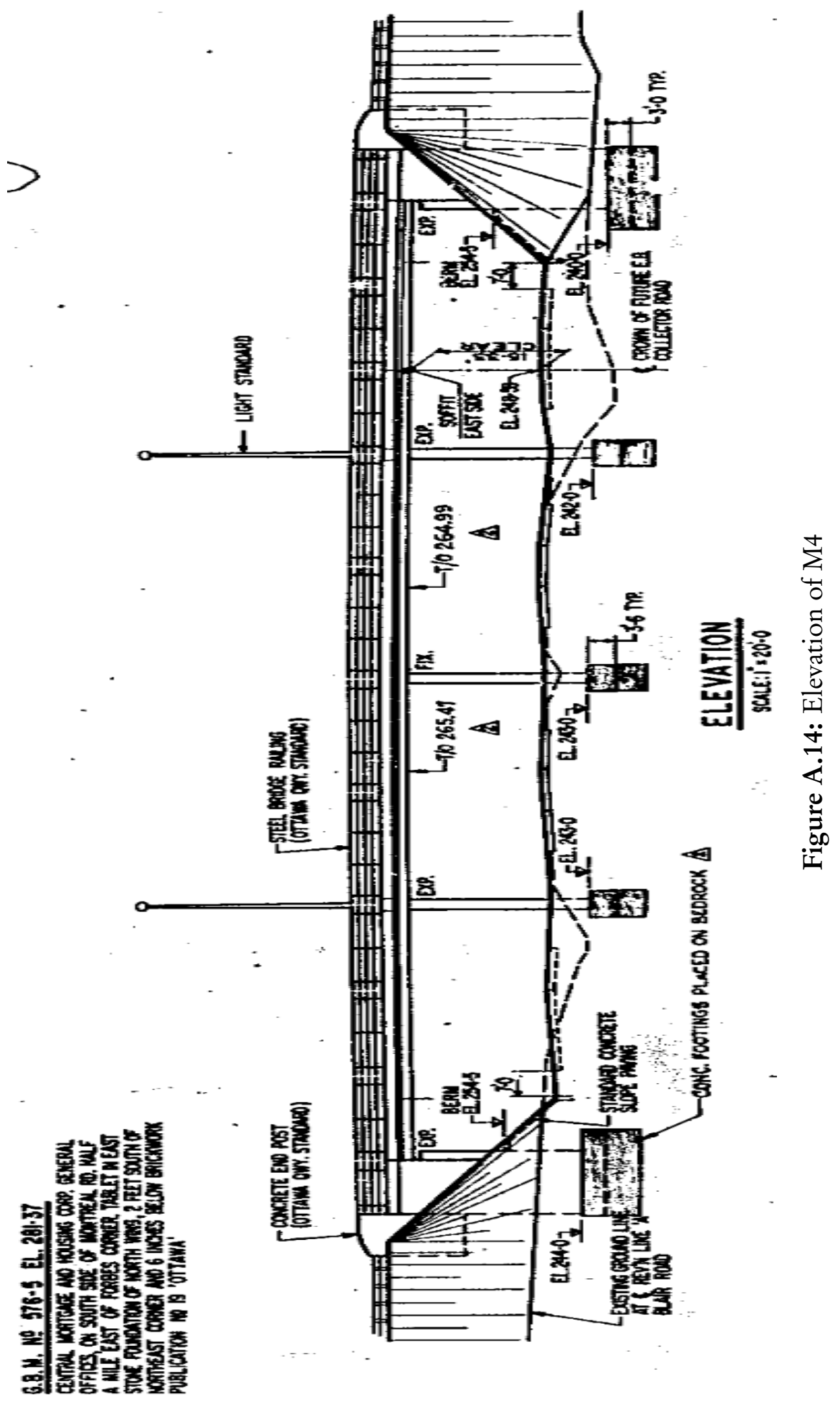

Xi Cheng, Department of Civil and Environmental Engineering, Carleton University 


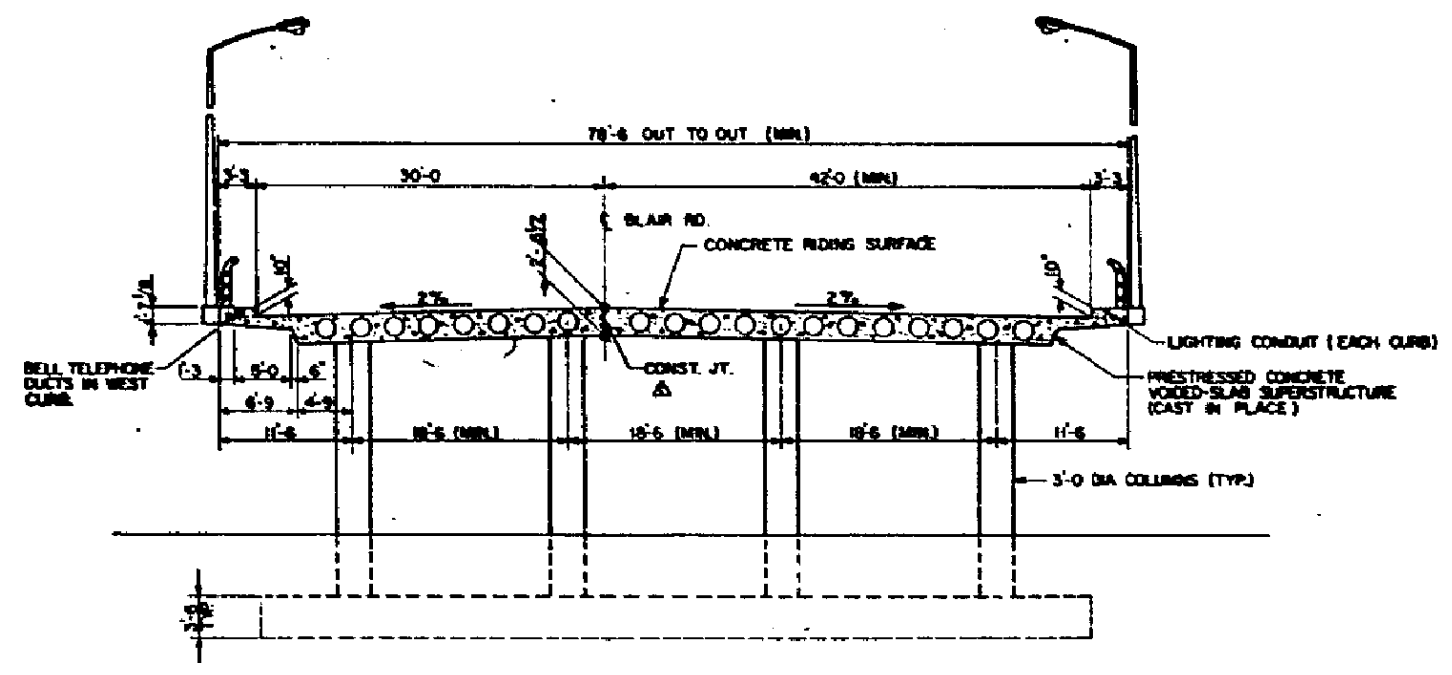

Figure A.15: Cross Section of M4 